University of Louisville

ThinkIR: The University of Louisville's Institutional Repository

Electronic Theses and Dissertations

8-2018

\title{
Microstructure and mechanical properties of selective laser melted superalloy inconel 625.
}

Md Ashabul Anam

University of Louisville

Follow this and additional works at: https://ir.library.louisville.edu/etd

Part of the Computer-Aided Engineering and Design Commons, Manufacturing Commons, and the Metallurgy Commons

\section{Recommended Citation}

Anam, Md Ashabul, "Microstructure and mechanical properties of selective laser melted superalloy inconel 625." (2018). Electronic Theses and Dissertations. Paper 3029.

https://doi.org/10.18297/etd/3029

This Doctoral Dissertation is brought to you for free and open access by ThinkIR: The University of Louisville's Institutional Repository. It has been accepted for inclusion in Electronic Theses and Dissertations by an authorized administrator of ThinkIR: The University of Louisville's Institutional Repository. This title appears here courtesy of the author, who has retained all other copyrights. For more information, please contact thinkir@louisville.edu. 


\title{
MICROSTRUCTURE AND MECHANICAL PROPERTIES OF SELECTIVE LASER MELTED SUPERALLOY INCONEL 625
}

\author{
By
}

Md Ashabul Anam

\begin{abstract}
A Dissertation
Submitted to the Faculty of the

J.B. Speed School of Engineering of the University of Louisville in Partial Fulfillment of the Requirements

for the Degree of

Doctor of Philosophy

in Industrial Engineering

Department of Industrial Engineering

Louisville, Kentucky
\end{abstract}

August 2018 
Copyright 2018 by Md Ashabul Anam

All rights reserve 



\title{
MICROSTRUCTURE AND MECHANICAL PROPERTIES OF SELECTIVE LASER MELTED SUPERALLOY INCONEL 625
}

\author{
By \\ Md Ashabul Anam \\ A Dissertation Approved on \\ July 10, 2018 \\ by the following Dissertation Committee: \\ Dissertation Director: Dr. Li Yang \\ Dr. Thomas L. Starr \\ Dr. Kevin Chou \\ Dr. Gail W. DePuy
}




\section{ACKNOWLEDGEMENTS}

I am grateful to my advisor, Dr. Li Yang, for his guidance and support during the last two years of my study. I am grateful to Dr. Brent Stucker who guided and supported me during the first three years of my PhD works. Special thanks goes to other committee members, Dr. Thomas Starr, Dr. Gail Depuy, and Dr. Kevin Chou for their advice.

I would like to express my gratitude to all the fellows in my research group, especially Dr. Samuel Dilip from whom I learned a great deal about metallography. I am thankful to the stuff of the Rapid Prototyping Center at the University of Louisville for their technical support to my experiments.

The research project was financially supported by National Institute of Standards and Technology (NIST) through a collaboration grant 70NANB12H262.

Last but not the least, I would like to acknowledge my families for their endless support, encouragement, patience and understanding.

Md Ashabul Anam 


\title{
ABSTRACT
}

\section{MICROSTRUCTURE AND MECHANICAL PROPERTIES OF SELECTIVE LASER MELTED SUPERALLOY INCONEL 625}

\author{
Md Ashabul Anam
}

July 10, 2018

Selective Laser Melting (SLM), a powder based Additive Manufacturing (AM) process, has gained considerable attention in the aerospace, biomedical and automotive industries due to its many potential benefits, such as, capability of fabricating complex three-dimensional components, shortened design to product time, reduction in process steps, component mass reduction and material flexibility. This process uses metallic powder and is capable of fabricating complex structures with excellent microstructure which make SLM not only an improvement over other manufacturing processes but also innovative material processing technology. Inconel 625, a nickel-based super alloy is widely popular in aerospace, chemical and nuclear industries. This alloy is characterized by having high tensile, creep and rupture strength and is widely used because of its excellent fatigue and good oxidation resistance properties. However, excessive tool wear and low material removal rate make it difficult to manufacture by conventional machining methods at room temperature. Selective laser melting, therefore, becomes a 
good solution for complex Inconel 625 parts. The formation of constituent phases of this alloy is a function of process parameters such as local temperature, hold time at temperature, local cooling rate and local compositions in the melt-pool. The effect of each process parameter on the resulting microstructure and mechanical properties must be understood in order to properly control the machines and predict the properties of the parts being fabricated. Therefore, the aim of the research work is to investigate the effect of key process variables of SLM systems (the EOS M270 Powder-bed system at The University of Louisville) on the melting response and solidification microstructure of Nickel based super-alloy Inconel 625.

The effect of processing parameters on Inconel 625 was investigated on single track deposits and bulk deposits. Multiple combinations of laser power and scan speed were used to fabricate the deposits by selective laser melting (SLM). Surface morphology and dimensions of the single track deposits were characterized using optical and SEM microscopy. To evaluate the geometrical feature of the melt pool, the cross-section of the single track deposits was studied. The result was then utilized to develop a process parameter map which is insightful to identify the optimum parameters that produce highdensity parts. Beside laser power and scan speed, scan pattern plays an important role in controlling microstructural features. Therefore, a careful study of scan pattern is important to understand microstructural evolution during SLM. In this study, two types of scanning pattern (Alternating and Rotating) were used to build samples of Inconel 625. Microstructure differences due to different scan patterns in as-built Inconel 625 samples were then studied in detail. In both cases, the grains were observed to grow preferentially in the build direction, but there were also clear effects of grain orientation differences due 
to scan direction effects. The tensile properties were compared with respect to laser scanning pattern, build orientation and post-processing heat treatment. Results show that although different scanning pattern produces distinctively different microstructures, its effect on the tensile property was not significant. However, tensile property anisotropy was observed with respect to the build orientation. The horizontally built samples showed relatively higher tensile strength as compared to the vertically built samples. Although the tensile strength decreased after heat-treatment, it was still comparable to the standard wrought processed ones. Fractography on the tensile tested samples showed ductile fracture characteristics. Investigation on fatigue behavior of Inconel 625 by SLM process was performed with respect to build orientation and post-manufacturing heat treatment. The study revealed the anisotropic behavior of Inconel 625 where horizontally built samples showed superior fatigue property than vertically built samples. The lower fatigue lives of vertical samples are primarily because of the presence of voids and un-melted particles located near the surface of the samples. In general, fatigue life of Inconel 625 by SLM improved after heat treatment. The improvement is attributed to the formation of coarser grains after heat treatment. The study provides a comprehensive understanding of the microstructure and mechanical properties of Inconel 625 manufactured by SLM process which fills an immediate need of the metal AM community. 


\section{TABLE OF CONTENTS}

Acknowledgements...........................................................

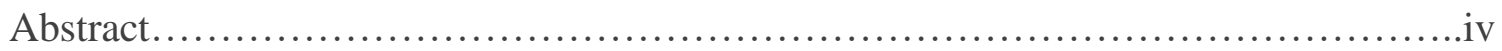

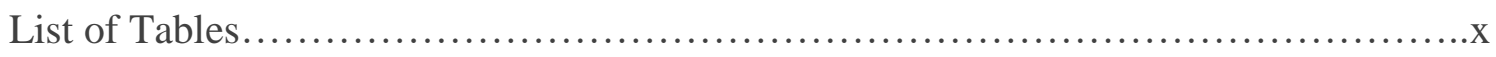

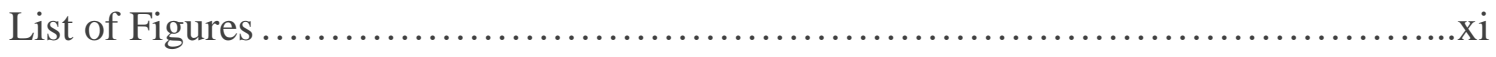

Chapter 1: Research Motivation and Problem Statement.............................1

Chapter 2: Literature Review............................................. 3

2.1 Superalloys........................................................

2.1.1 Alloy systems.....................................................

2.1.2 Physical metallurgy................................................6

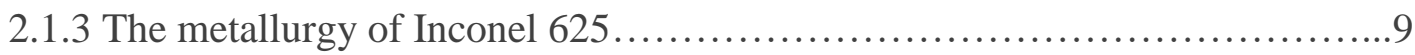

2.2 Fundamentals of solidification.......................................... 14

2.2.1 Dendrites..................................................... 15

2.2.2 Solidification during laser processing and welding $\ldots \ldots \ldots \ldots \ldots \ldots \ldots \ldots \ldots \ldots$

2.2.3 Solidification of Inconel 625 laser coatings............................ 19

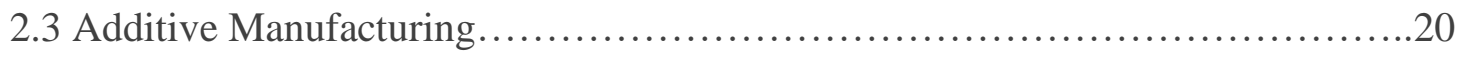

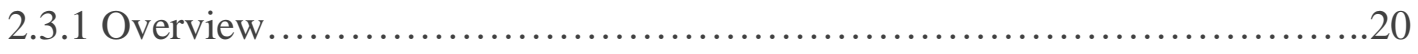

2.3.2 Classification..................................................... 21

2.3.3 Metal-based AM................................................22

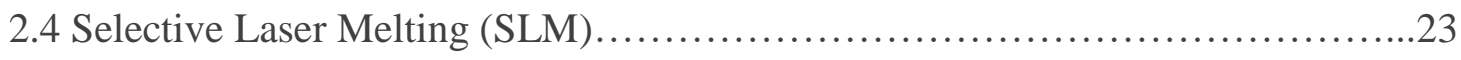

2.4.1 Process parameters.................................................. 25

2.4.2 Build quality.................................................. 27

2.4.3 Microstructure of laser deposited Inconel 625 alloy....................29 
2.4.4 Mechanical properties.....................................................

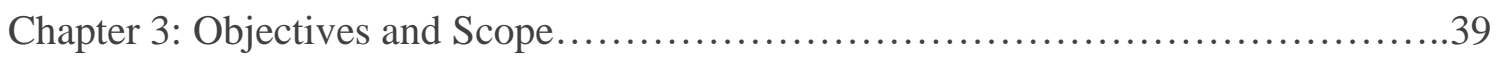

Chapter 4: The effect of processing parameters on microstructures and physical properties of selective laser melted superalloy Inconel $625 \ldots \ldots \ldots \ldots \ldots \ldots \ldots \ldots \ldots . \ldots 41$

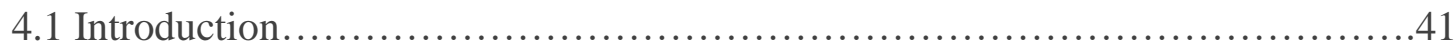

4.2 Experimental Procedure ....................................................... 43

4.2.1 Material specifications.................................................. 43

4.2.2 Processing parameters...................................................... 44

4.2.3 Process of building single track on rectangular pad........................47

4.2.4 Microstructural characterization and porosity measurements.................49

4.2.5 Hardness measurement..................................................... 49

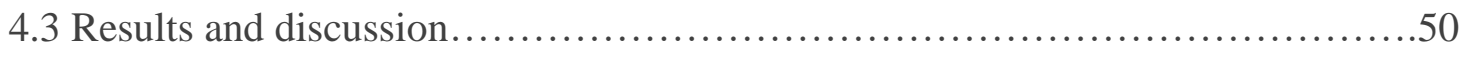

4.3.1 Surface morphology of single track..................................50

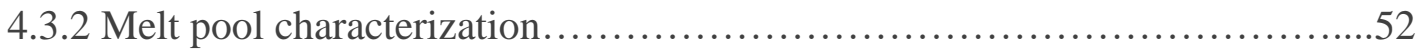

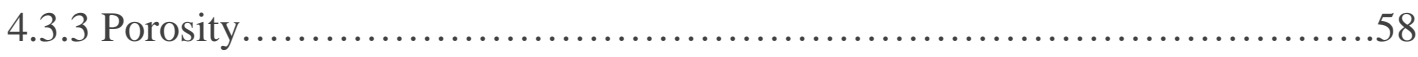

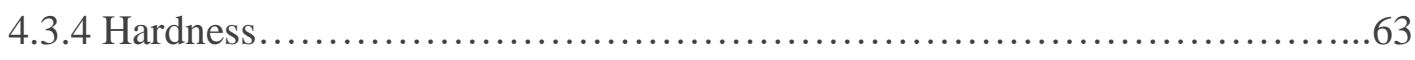

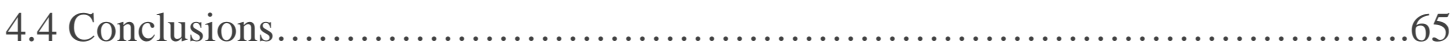

Chapter 5: Effect of Scan Pattern on the Microstructural Evolution of Inconel 625 during

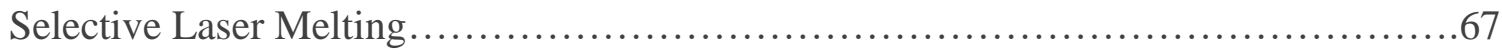

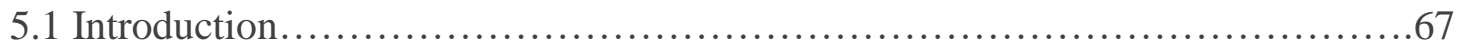

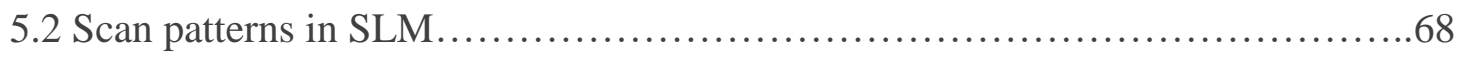

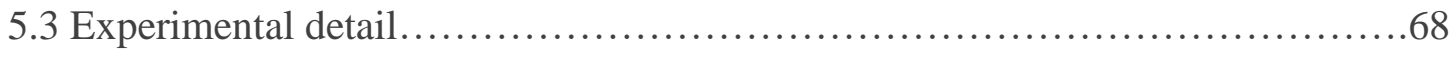

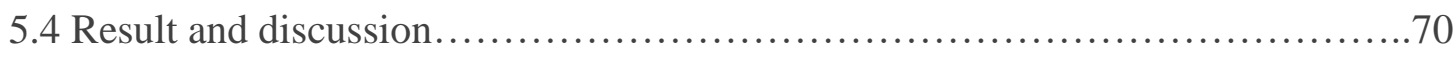

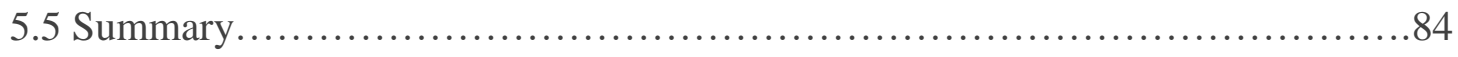

Chapter 6: Tensile properties of Inconel 625 Manufactured by Selective Laser

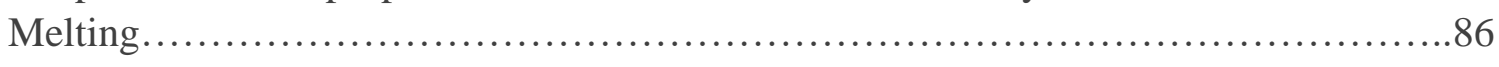

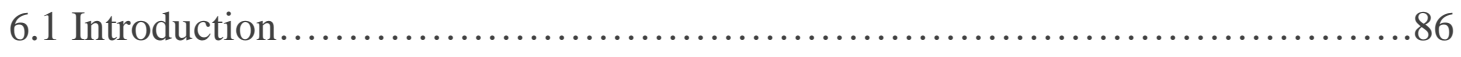

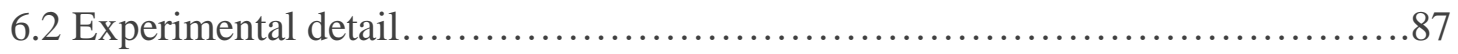

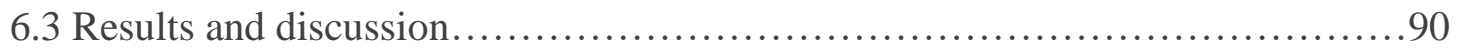




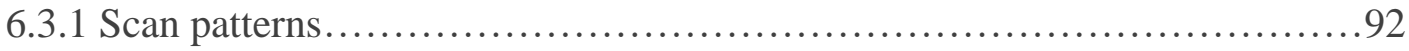

6.3.2 Build orientation and post-processing................................ 95

6.3.3 Fractography..................................................... 101

6.4 Conclusion..................................................... 108

Chapter 7: Fatigue Behavior of Inconel 625 Manufactured by Selective Laser Melting............................................................... 110

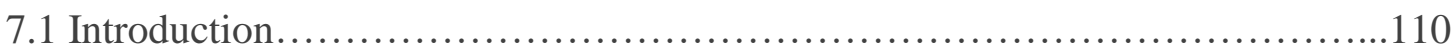

7.2 Material and experimental detail......................................... 112

7.2.1 Material specifications............................................. 112

7.2.2 Methods.......................................................... 113

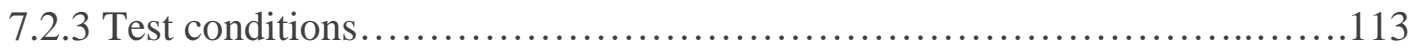

7.3 Results and discussion.....................................................

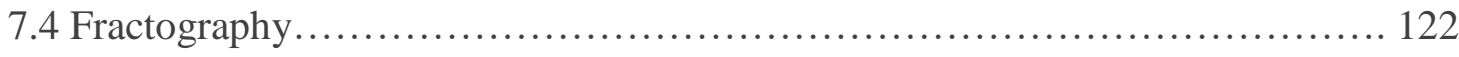

7.5 Conclusion............................................................ 130

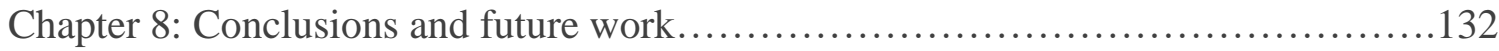

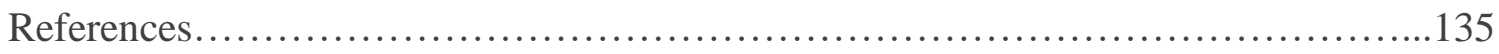

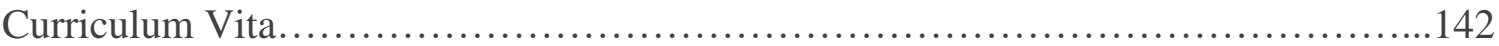




\section{LIST OF TABLES}

Table 2. 1: Chemical compositions of Inconel 625 (wt.\%) [9]..................................... 9

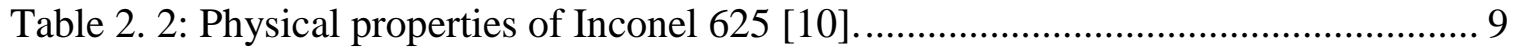

Table 2. 3: Chemical compositions of Laves phase particles (at. \%) from different Alloy

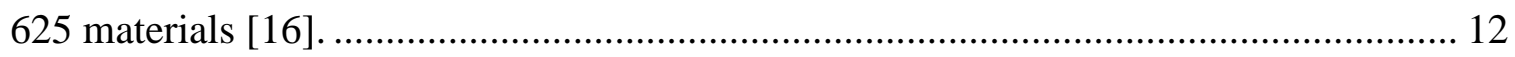

Table 2. 4: Composition of NbC phase (wt. \%) in different Alloy 625 materials [16]... 12

Table 2. 5: The Seven AM Process Categories by ASTM F42 [30]............................. 21

Table 2. 6: Mechanical property data from literature. ............................................. 36

Table 4. 1: Elemental composition analysis of the Inconel 625 as-built deposit carried out

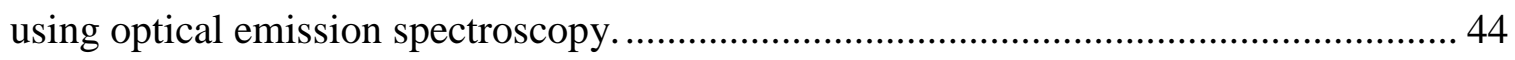

Table 4. 2: Factors and levels of experimental design for single beads. ....................... 45

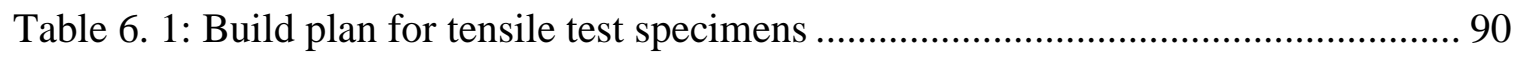

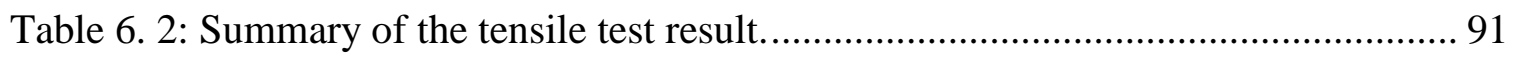

Table 7. 1: Elemental composition analysis of the Inconel 625 as-built deposit carried out

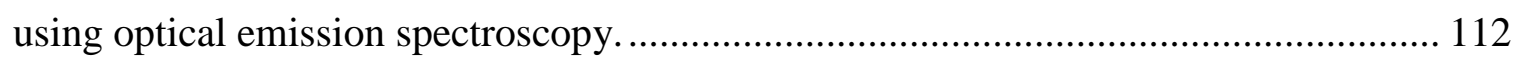

Table 7. 2: Build plan for fatigue test specimens.................................................... 114 


\section{LIST OF FIGURES}

Figure 2. 1 (a) Elements' melting temperature as a function of atomic number, (b) section of the periodic table showing crystal structures of transition metals from bcc to hcp to fcc [6].

Figure 2. 2 Section of the periodic table of elements showing common metals used in superalloys and their partitioning characteristics [6] ............................................. 7

Figure 2. 3 Unit cells for various common phases on superalloys [8] ............................ 9

Figure 2. 4: An extract from the pseudo-equilibrium diagram for Alloy 718 showing the

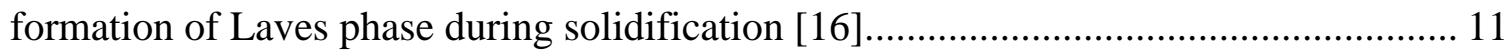

Figure 2. 5: An approximate time-temperature-transformation diagram for phases forming at higher temperatures in Alloy $625[16]$..................................................... 13

Figure 2. 6: (a) columnar and (b) equiaxed dendrites, arrows show the $x-y<100>$ direction, the $\mathrm{z}$ axis is perpendicular to the page. After Wang et al. [21]. The four vertical trunks in (a) are primary dendrite arms and similarly in (b) the larger trunks forming an 'x'.

Figure 2. 7: Schematic illustration showing the change in growth morphology with increasing isotherm velocity (a) planar, (b) and (c) Cells, (d) and (e) dendrites [24]..... 16 Figure 2. 8: Schematic diagram showing change in morphology along the fusion zone during welding-type processes $\left(\mathrm{R}_{\mathrm{S}}=\right.$ grain growth rate, $\mathrm{G}_{\mathrm{L}}=$ thermal gradient in the liquid) [23]. 18

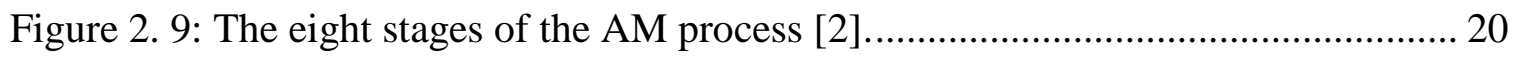

Figure 2. 10: Schematic diagram of typical powder bed SLM system [32, 33] ............. 24 Figure 2. 11: Graphs showing the effect of beam velocity, V, laser power, P, beam diameter, D, and powder feed rate, Q, on deposition track height, (a) and (b), and width, (c) (d). [46]. 27 
Figure 2. 12: Laser deposited Ti-6-4 (a) lack-of-fusion porosity (b) entrapped gas porosity indicated by arrow. [48].

Figure 2. 13: Transverse-section microstructures at different locations of an Inconel 625

powder thin wall sample built using direct laser metal deposition technique [11].......... 30

Figure 2. 14: The microstructure of the horizontal section of an Inconel 625 thin wall sample built using direct laser metal deposition technique [11] ................................. 30

Figure 2. 15: Cross-sections (a) perpendicular and (b) parallel to the build direction in the middle of Inconel 625 sample fabricated by laser metal deposition [27]. 31 Figure 2. 16: Yield strength $(0.2 \%)$ in as fabricated (AF) and heat treated (HT) condition.

Figure 2. 17: Ultimate tensile strength (UTS) in as fabricated (AF) and heat treated (HT) condition 37

Figure 2. 18: Elongation in as fabricated (AF) and heat treated (HT) condition. 38

Figure 4. 1: (a) Scanning electron micrograph of Inconel 625 powders (b) High magnification image showing dendritic features

Figure 4. 2: Schematic showing pad layout with horizontal single bead lines and crosssection of laser melted track. 46

Figure 4. 3: Photograph of the single track deposits made on pad substrate. Arrows indicate single track deposits. 46

Figure 4. 4: (a) Top surface of the pad with solid support. (b) Bottom surface of the pad showing solid support of thickness $1.5 \mathrm{~mm}$.

Figure 4. 5: (a) Sacrificial thin walls were placed on top of the pad. (b) A single line support beneath the sacrificial thin walled part. (c) An array of line support beneath the sacrificial part. (d) Conventional block support supports the overhanging region.

Figure 4. 6: SEM micrographs of the top surface of the single track deposits produced using various process parameters (laser power, scan speed).

Figure 4. 7: Optical micrographs of the cross-section of the single track deposits produced using various process parameters (laser power, scan speed). 
Figure 4. 8: Metallographic cross section of single track deposit showing keyhole melting (a) $150 \mathrm{~W}$ laser power, $200 \mathrm{~mm} / \mathrm{s}$ scan speed, (b) $195 \mathrm{~W}$ laser power, $200 \mathrm{~mm} / \mathrm{s}$ scan speed.

Figure 4. 9: Width and penetration depth of the single beads versus scan speed of laser beam for different power levels. 56

Figure 4. 10: Depth to width ratio as a function of processing parameters (laser power and scan speed).

Figure 4. 11: Optical micrographs of the polished cross-section of the cubes produced using various process parameters (laser power, scan speed). The input energy density values are mentioned on top of each micrograph. 59

Figure 4. 12: Porosity versus input energy density 60

Figure 4. 13: Porosity for various processing parameters (Laser power, scan speed)..... 60 Figure 4. 14: Micrograph showing porosity. Parameter: 50W-800mm/s, E. 31J/mm³ (a) OM of as polished un-etched cross-section, (b) polished and etched cross-section, (c) SEM of top surface

Figure 4. 15: Optical micrographs for porosity; (a \& b) 195W-800mm/s, E. $122 \mathrm{~J} / \mathrm{mm}^{3}$ (a) as polished cross-section, (b) polished and etched cross-section. (c \& d) $175 \mathrm{~W}-200 \mathrm{~mm} / \mathrm{s}$, E. $438 \mathrm{~J} / \mathrm{mm}^{3}$ (c) as polished un-etched cross-section, (d) polished and etched crosssection.

Figure 4. 16: Hardness (HV) vs input energy density $\left(\mathrm{J} / \mathrm{mm}^{3}\right)$.

Figure 4. 17: Change in hardness value due to the indenter's interference with porosity (parameter: $195 \mathrm{~W}-1200 \mathrm{~mm} / \mathrm{s}$ ); (a) before indentation, surface with pore, (b) after indentation, less hardness value due to pore $(285 \mathrm{HV})$.

Figure 5. 1: Schematic of a rotating scan pattern (left) and alternating scan pattern (right).

Figure 5. 2: (a) Microstructural evidence of the rotating pattern from a horizontal (XY plane) cross-section. (b) Melt-pool arrangement as seen from a vertical cross-section (YZ plane) for a rotating pattern. 
Figure 5. 3: (a) Horizontal cross-section showing laser tracks for the alternating scan pattern. (b) Melt-pool arrangement in a vertical cross-section using the alternating scan strategy

Figure 5. 4: (a) SEM image of a horizontal (XY) section showing cellular/dendritic growth (red arrows) towards the center of the scan track (white arrow), (b) vertical (YZ) section showing radial growth of cellular dendrites. Clear melt-pool boundaries are observed which has an effect on grain size and orientation. 72 Figure 5. 5: Orientation of elongated grains scanned with: (a) unidirectional scan vectors, and (b) alternating hatch scan vectors. View plane: Side view (YZ plane), Material: Ti$6 \mathrm{Al}-4 \mathrm{~V}[34]$. 73

Figure 5. 6: Orientation of elongated equiaxed grains (dark and white regions) formed due to the rotating pattern, which grow preferentially in the build direction (z) indicated by arrows across multiple layers.

Figure 5. 7: (a) Optical microscopy showing a vertical section of Inconel 625 where melt pools are distinguishable due to the appearance of dark bands. (b) Horizontal section showing dark band region. (c) SEM image showing the same section as 'a' but magnified to illustrate that SEM white regions represent optical microscopy dark bands. (d) High magnification SEM image of a horizontal section showing the cross-section of a single dendrite where the white region is formed due to segregation of $\mathrm{Nb}$ and Mo. 74 Figure 5. 8: SEM image showing vertical cross-section (YZ plane) of Inconel 625 sample built using (a) Rotating pattern and (b) Alternating pattern. Arrows in the right section in ' $b$ ' show alternating scan directions.

Figure 5. 9: SEM image showing intercellular spacing less than $1 \mu \mathrm{m}$ for a rotated stripe scan pattern in (a) vertical and (b) horizontal sections, which provide excellent strength and hardness.

Figure 5. 10: IPF maps of the vertical cross-section of samples built using (a) alternating and (b) rotating scan pattern 77

Figure 5. 11: EBSD results on the alternating scan pattern horizontal cross section of the

Figure 5. 12: EBSD results on the rotating scan pattern horizontal cross section of the SLM processed Inconel 625 sample in an as-fabricated condition... 
Figure 5. 13: TEM micrograph showing coarse carbide particles precipitated in the interdendritic regions of the SLM built sample.

Figure 5. 14: TEM micrograph showing dislocation network in the matrix along with fine carbides. 82

Figure 5. 15: TEM micrograph showing connected network of carbide particles. Corresponding SAD pattern showing diffraction spots from the carbide particles. 82 Figure 5. 16: STEM image of the matrix region with carbide particles and corresponding EDS analysis of a typical carbide particle. 83 Figure 5. 17: BSE image of a vertical (YZ) cross-section at two different magnifications.

Figure 6. 1: SEM micrographs of Inconel 625 powder particles. 88

Figure 6. 2: CAD model and samples built for tensile testing in three different orientations. 89

Figure 6. 3: Stress-strain curve showing build orientation effect (left) and post-processing effect (right).

Figure 6. 4: Micrographs showing laser tracks for rotating pattern (left) and alternating pattern (right). 92

Figure 6. 5: SEM image showing vertical cross-section (YZ plane) of Inconel 625 sample built using (a) rotated stripe pattern and (b) alternating block pattern. Arrows in the right section in ' $b$ ' show alternating scan directions. 93 Figure 6. 6: Comparison of the tensile strength of samples fabricated with rotating and alternating scan pattern in different build orientations. The left figure shows results for as-built condition and the right figure for heat treated condition. Figure 6. 7: Comparison of elongation of samples fabricated with rotating and alternating scan pattern. .95

Figure 6. 8: Tensile property of Inconel 625 processed by SLM at different build orientation. 96

Figure 6. 9: Color grain map of a vertical cross-section of Inconel 625 sample fabricated by SLM process. Arrow indicates the build direction. 99 
Figure 6. 10: Schematic showing the direction of the tensile load relative to the grain orientation for samples built in three different orientations.

Figure 6. 11: Vertical cross-section of Inconel 625 samples, (a) microstructure in as-built condition, (b) microstructure after heat treatment. The arrow shows the build direction.

Figure 6. 12: Tensile fracture surface of horizontally $\left(0^{\circ}\right)$ built Inconel 625 sample tested in as-built condition, (a) overall view showing a smooth flat surface, (b) cleavage fracture with a ductile dimple structure, (c) magnified view showing microvoid, (d) fine and shallow dimple structure. 103

Figure 6. 13: Tensile fracture surface of vertically $\left(90^{\circ}\right)$ built Inconel 625 sample tested in as-built condition, (a) overall view showing a rough surface, (b) a ductile dimple structure with microvoids and grain boundary cracks, (c) magnified view showing microvoid, (d) fine dimple structure with microcracks. 104 Figure 6. 14: Tensile fracture surface of horizontally $\left(0^{\circ}\right)$ built Inconel 625 sample tested in heat treated condition, (a) overall view showing a smooth flat surface, (b) small number of microvoids can be seen, (c) magnified view showing grain boundary crack, (d) fine and shallow dimple structure. 105 Figure 6. 15: Tensile fracture surface of vertically $\left(90^{\circ}\right)$ built Inconel 625 sample tested in heat treated condition, (a) overall view showing a rough surface, (b) a ductile dimple structure with microvoids, (c) magnified view showing microcracks, (d) fine dimple structure

Figure 6. 16:Tensile fracture surface Inconel 625 sample built in inclined $\left(45^{\circ}\right)$

orientation. (a), (b), and (c) are from a sample tested in as-built condition while (d), (e) and (f) are from a heat-treated sample. 107

Figure 6. 17: Elongated shear dimples were found in the share lips of as-built inclined tensile sample. 108

Figure 7. 1: (a) Scanning electron micrograph of Inconel 625 powders (b) High magnification image showing dendritic features. 112

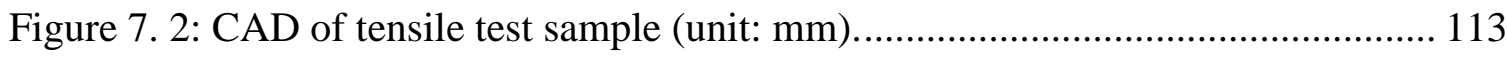

Figure 7. 3: CAD of fatigue test sample (unit: $\mathrm{mm}$ ) 114 
Figure 7. 4: Stress-strain curve of Inconel 625 samples with different orientations and post-processing

Figure 7. 5: Plot of maximum stress versus cycles to failure for samples with different build orientations and post-processing.

Figure 7. 6. Schematics representing the orientation of an un-melted region formed during fabrication of vertical and horizontal specimens with respect to the loading direction and the resultant stress concentrations [111]. 118

Figure 7. 7: (b) SEM micrograph of a vertically built sample showing sharp angle porosity. (b) Interlayer sharp angle pore in fracture surface. 118

Figure 7. 8: IPF map showing elongated columnar grains. 119

Figure 7. 9: Schematic showing expected crack propagation in vertical and horizontal sample. 120

Figure 7. 10: Vertical cross-section of Inconel 625 samples, (a) microstructure in as-built condition, (b) microstructure after heat treatment. The arrow shows the build direction.

Figure 7. 11: SEM micrographs of as-built sample: (a) vertical cross-section showing fine dendritic structure which provides excellent tensile and fatigue strength. (b) Horizontal cross-section showing dendritic structure and intercellular precipitates. 122 Figure 7. 12: Various areas of Inconel 625 fatigue fracture fabricated by SLM process. As-built XY, max stress $500 \mathrm{MPa}$ failed at $1.98 * 10^{6}$ cycles. 123 Figure 7. 13: Crack initiation in as-built vertically oriented sample: (a) Low fatigue life due to inclusion and un-melted particles (marked by dashed line), (As-built Z, failed at $4.58 * 10^{5}$ cycles); (b) Low fatigue life due to pore/groove (marked by dashed line),(Asbuilt $\mathrm{Z}$, failed at $6.58 * 10^{4}$ cycles). 124

Figure 7. 14: (a) TEM of as-built Inconel 625 showing dislocations. (b) A schematics showing possible micro-crack initiation sites due to PSBs [119]... 125 Figure 7. 15: Crack initiation in the as-built horizontal sample (a) Narrow initiation zone (marked by dashed line) (As-built XY, failed at 2.40*105 cycles); (b) Wide initiation zone (marked by dashed line) (As-built XY, failed at $1.42 * 10^{6}$ cycles). 125 Figure 7. 16: (a) Cleavage-like fracture was observed in Area II at the early stage of crack propagation. (b) Striation pattern for Hi-cycle failure where fatigue failure propagated in 
a transcrystalline fashion with distinctive striations ( Propagation Stage). As-built XY,

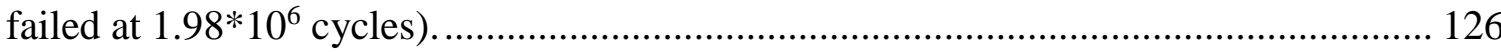
Figure 7. 17: (a) The final stage of fracture showing micro-void coalescence (arrow) and cleavage areas. (b) Higher magnified image shows dimple ductile fracture of the final

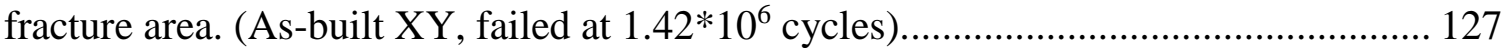
Figure 7. 18: comparison as-built $\mathrm{XY}$ vs as-built $\mathrm{Z}$ (propagation areas are marked by dotted line, crack initiation marked by arrow). (a \& b) As-built XY, failed at $5.17 * 10^{5}$ cycles. (c \& d) As-built Z, failed at $9.22 * 10^{4}$ cycles. Maximum stress $550 \mathrm{MPa}$ in both cases.

Figure 7. 19: A comparison of fracture surface from as-built and heat treated samples in propagation stage. (a) Transgranular cleavage fracture in as-built sample. (b) Mixed mode of failure in heat treated sample.

Figure 7. 20: A comparison of fracture surface from as-built and heat treated samples in final failure stage, (a) as-built sample, (b) heat treated sample. 129 


\section{CHAPTER 1}

\section{RESEARCH MOTIVATION AND PROBLEM STATEMENT}

Over the past decade, Additive Manufacturing (AM) has been developed from Rapid Prototyping industry and is becoming accepted as a manufacturing option for a wide range of products. AM has gained considerable attention in the aerospace, biomedical and automotive industries due to its many potential benefits, such as, more geometric freedom, shortened design to product time, reduction in process steps, component mass reduction and material flexibility. More and more companies are showing their interest as the benefits of AM are hoped to be exploited. For this to happen there must be considerable research into microstructure and mechanical properties of engineering alloys from part production through to post-process treatment such as finishing procedure and heat treatment.

When using metallic powder, Selective Laser Melting (SLM), an additive manufacturing process, is capable of fabricating complex structures with excellent microstructures which make SLM not only an improvement over other manufacturing processes, but also innovative material processing technology [1]. The process of SLM is similar to the Selective Laser Sintering (SLS) process developed in the 1980's; but metallic powder is utilized instead of polymers. However, the high thermal conductivity, propensity to oxidize, high surface tension, and low absorptivity of metal powders make them significantly more difficult to process than polymers [2]. 
Inconel 625 , a nickel based super alloy is widely popular in aerospace, chemical and nuclear industries. This alloy is characterized by having high tensile, creep and rupture strength and is widely used because of its excellent fatigue and good oxidation resistance properties. However, excessive tool wear and low material removal rate make it difficult to manufacture by conventional machining methods at room temperature. Selective laser melting (SLM) therefore becomes a good solution for complex Inconel 625 parts. SLM involves directional solidification concepts as well as novel prospects for microstructure control through the development of scanning strategies or related process variables such as local temperature, hold time at temperature, local cooling rate and local compositions in the melt-pool. These features produce solidification cooling rate and thermal gradient phenomena which contribute to microstructure and microstructural architecture development and resulting mechanical properties [3, 4].The effect of each process parameter on the resulting microstructure and mechanical properties must be understood in order to properly control the machines and predict the properties of the parts being fabricated.

Therefore, the aim of the research work is to investigate the effect of key process variables and to establish an optimum processing condition of SLM systems (the EOS M270 Powder-bed system at The University of Louisville) for Nickel based super-alloy Inconel 625. The correlation between various process parameters and mechanical properties of Inconel 625 has not been studied clearly. Therefore, the aim is also to investigate the mechanical properties of Inconel 625 and to establish a processmicrostructure-property relationship. The study will fill an immediate need of the metal AM community by providing a better understanding on SLM processed Inconel 625 . 


\section{CHAPTER 2}

\section{LITERATURE REVIEW}

This chapter provides an introduction of superalloys and a description of Additive Manufacturing (AM). In particular the laser processing of Inconel 625 and Selective Laser melting (SLM) process are discussed. The underlying physical processes of solidification during laser melting are explored. Microstructure evolution during SLM processing of Inconel 625 and resulting mechanical properties are discussed from the published literature.

\subsection{Superalloys}

\subsubsection{Alloy systems}

The superalloys are a class of high-temperature materials that can maintain its structural integrity at elevated temperatures and are used in high temperature applications and in corrosive and harsh environments such as gas turbine engine [5]. The development of superalloys started in 1940s from the frequent failure of materials in gas turbine engine $[6,7]$. The performance of gas turbine engine increases with the increase of Turbine Entry Temperature (TET). This required the development of special materials that can retain their mechanical strength at the elevated temperature.

There are three categories of superalloys: Iron-bases, Cobalt-based and Nickel-based superallys. Iron-based superalloys were developed from advances in stainless steels, followed by high temperature Cobalt and Nickel based alloys. All of the superalloys have 
a special feature that is they have a common face centered cubic (fcc) crystal structure [8]. Superalloys do not undergo phase transformations with changing temperature and so any limits to their high temperature properties can be attributed to incipient melting of secondary phases and the dissolution of strengthening phases such as precipitates. Superalloys are strengthened by at least one of the following strengthening mechanisms.

- Solid solution strengthening

- Precipitation hardening

- Carbides precipitates

Superalloys are the materials those have the ability to maintain their properties consistently with increasing temperature and are used in many engineering application where the temperature is in excess of $700^{\circ} \mathrm{C}$. Three attributes are often used to define high temperature materials [5].

1. The material must withstand significant load at homologous temperatures of 0.6 $(0.6 \mathrm{Tm})$ and even approaching its melting temperature.

2. The material must resist mechanical degradation over time at elevated temperatures, i.e. thermally activated, inelastic creep.

3. The material must tolerate severe environments such as hot gases, high sulfur levels (i.e. highly corrosive) and the intake of seawater which promotes oxidation at high temperatures.

For moderate temperatures (up to approximately $700^{\circ} \mathrm{C}$ ) application, $\mathrm{Fe}-\mathrm{Ni}$ - based alloys are utilized because of their lower cost, for higher temperature application above $700^{\circ} \mathrm{C}$ Ni-based alloys are more suitable. The preference of Nickel over other metals is due to its atomic/electronic structure. For the transition metals, the melting temperature is 
a function of atomic number where the peak in melting temperature is in the middle of each row of transition metal elements (V, Mo and $\mathrm{W})$ and increases moving down the rows from the $3 \mathrm{~d}$ to the $5 \mathrm{~d}$ elements. This is shown in Figure 2.1(a). Moving from left to right in the transition metals on the periodic table also reveals a change in crystal structure, from body centered cubic (bcc) to hexagonal close packed (hcp) to face centered cubic (fcc) (Figure 2.1(b)).

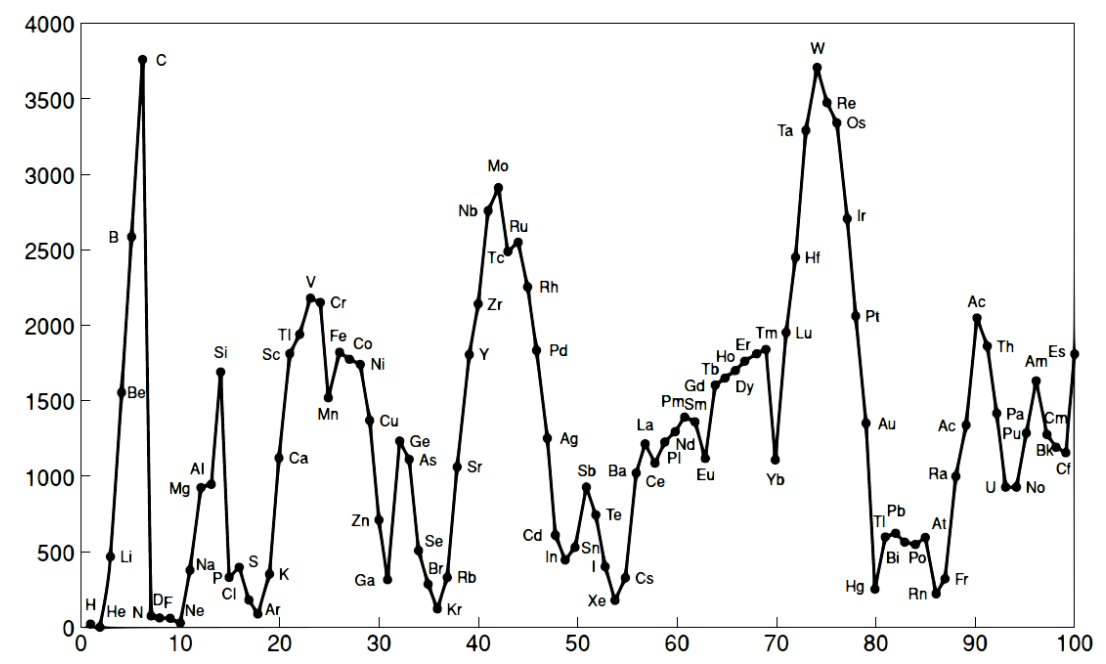

(a)

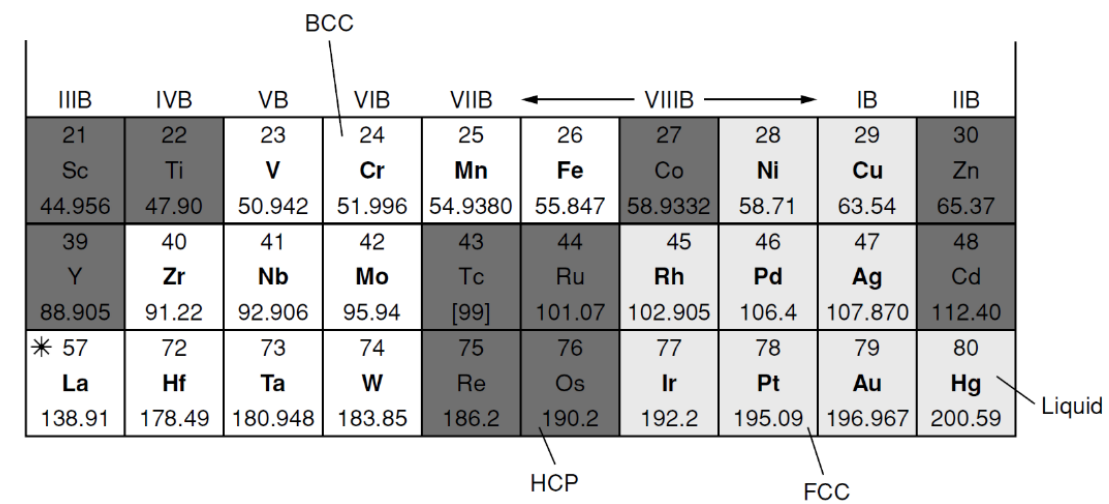

(b)

Figure 2. 1 (a) Elements' melting temperature as a function of atomic number, (b) section of the periodic table showing crystal structures of transition metals from bcc to hep to fcc 
An fcc structure is desirable when a more ductile and tough material is required; this limits the number of suitable metals. The metals with fcc structure is also preferable as they have the property to retain mechanical property at elevated temperature. Nickel meets both of these criteria by having an fcc crystal structure and stable phase. The other crustal structures and metals such as hcp Co, Re, Ru etc. are available but very expensive than Ni therefore are discounted. Tc is radioactive and Os oxide is poisonous so they are discounted as well.

\subsubsection{Physical metallurgy}

Superalloys has a very complex alloy system often containing more than ten alloying additions. Superalloys, however, have been studied in great detail and the effect of these various alloying elements has become much known. Most of the superalloys contain $\mathrm{Cr}, \mathrm{Co}, \mathrm{Al}$ and $\mathrm{Ti}$, with small addition of $\mathrm{Zr}, \mathrm{S}$ and $\mathrm{C}$. Figure 2.2 shows a periodic table containing the common alloying elements and their role in superalloys. For example, $\mathrm{Zr}, \mathrm{B}$ and $\mathrm{C}$ generally partition to grain boundary where $\mathrm{Al}$, $\mathrm{Ti}$ and $\mathrm{Nb}$ partition to secondary phases and form precipitates. 


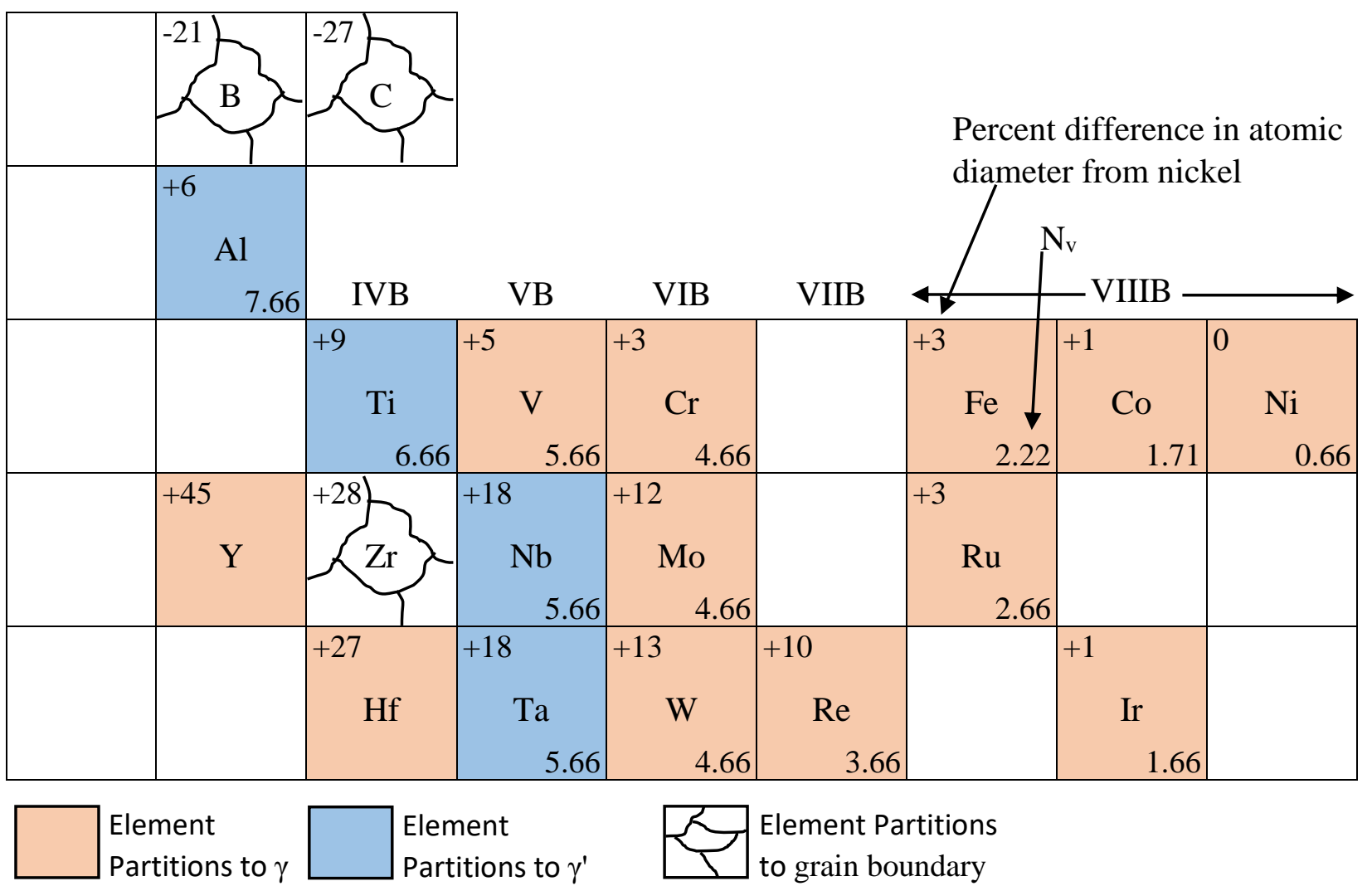

Figure 2. 2 Section of the periodic table of elements showing common metals used in superalloys and their partitioning characteristics [6].

Typical Superalloys are made up of an austenitic Ni matrix $(\gamma)$ with the following additions:

1. Co, Fe, $\mathrm{Cr}, \mathrm{Re}$ and $\mathrm{W}$ have similar atomic radii to $\mathrm{Ni}$ and partition to the $\gamma$ phase and have stabilizing effect.

2. $\mathrm{Al}, \mathrm{Ti}, \mathrm{Nb}$, and $\mathrm{Ta}$ have larger atomic radii and so promote the formation of ordered second phases such as $\gamma^{\prime}, \mathrm{Ni}_{3}(\mathrm{Al}, \mathrm{Ti}, \mathrm{Ta})$ and $\gamma^{\prime \prime}, \mathrm{Ni}_{3} \mathrm{Nb}$.

3. $\mathrm{B}, \mathrm{C}$ and $\mathrm{Zr}$ have different atomic radii compared to $\mathrm{Ni}$ and segregate to the grain boundaries of the $\gamma$ matrix. 
4. Cr, Mo, W, Nb, Ta and Ti also form carbides when present in the right concentrations and after appropriate processing.

5. $\mathrm{Cr}$ and Mo also form Borides

6. Co, Cr, Mo, Ru and Re provide solid solution strengthening of the matrix

The typical microstructure of Superalloys contains a combination of phases, including the following;

1. A continuous, solid solution, fec matrix $(\gamma)$.

2. A coherent, fcc, $\mathrm{L1}_{2}$ precipitate $\left(\gamma^{\prime}\right)$ which acts as a strengthening phase.

3. In Fe-Ni alloys, and those rich in $\mathrm{Nb}$, a body-centred tetragonal (bct), $\mathrm{DO}_{22}$ ordered precipitate is the strengthening phase $\left(\gamma^{\prime \prime}\right)$.

4. Grain boundary carbides and borides; at carbon levels of 0.2wt\% MC-type carbides $\left(\mathrm{M}=\mathrm{Ti}\right.$, Ta, Hi) are formed which can decompose in service to $\mathrm{M}_{23} \mathrm{C}_{6}$ and $\mathrm{M}_{6} \mathrm{C}(\mathrm{M}=\mathrm{Cr}, \mathrm{Mo}, \mathrm{W})$.

5. Topologically Closed Packed (TCP) phases such as $\mu$ (bct $\mathrm{Ni}_{2} \mathrm{Ta}$ ), $\sigma$ (btc $\mathrm{CrMo}_{x} \mathrm{NiCo}_{\mathrm{y}}$ ) and Laves phases (hep $\mathrm{Fe}_{2} \mathrm{Ti}, \mathrm{Mo} \mathrm{Ni} 2 \mathrm{Nb}$ and fcc $\mathrm{Co}_{2} \mathrm{Ta}$ ). These often form in the service-aged condition and are generally considered detrimental to mechanical properties, an alloy's composition is chosen to minimize the chance of forming these phases. 

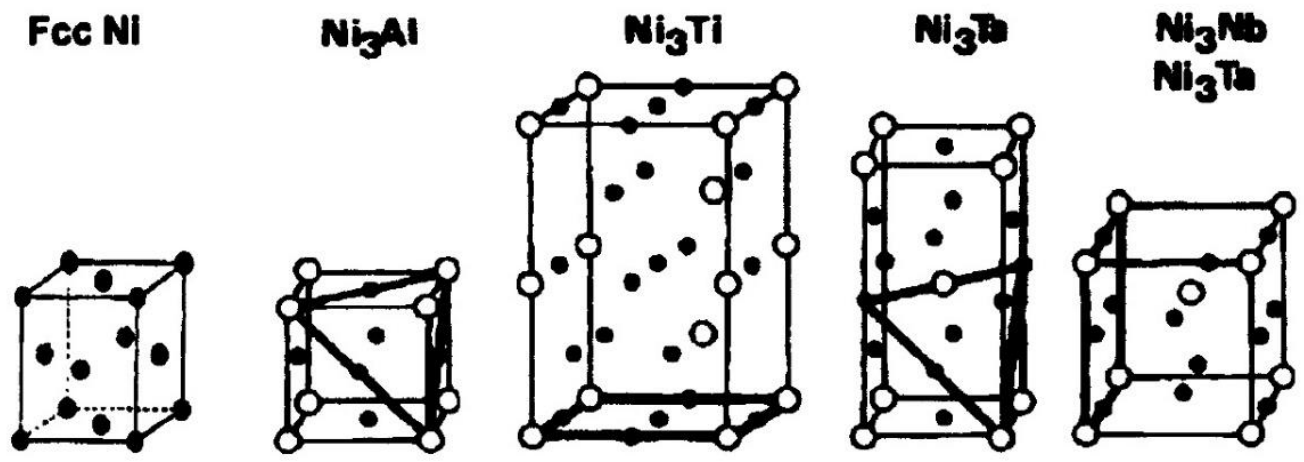

Figure 2. 3 Unit cells for various common phases on superalloys [8].

\subsubsection{The metallurgy of Inconel 625}

\subsubsection{Physical property}

The chemical composition and the properties of the alloy 625 are presented in

Table 2.1 and Table 2.2 respectively.

Table 2. 1: Chemical compositions of Inconel 625 (wt.\%) [9].

\begin{tabular}{|c|c|c|c|c|c|c|c|c|c|c|c|c|}
\hline $\mathbf{N i}$ & $\mathbf{C r}$ & $\mathbf{M o}$ & $\mathbf{N b}$ & $\mathbf{F e}$ & $\mathbf{C}$ & $\mathbf{M n}$ & $\mathbf{S i}$ & $\mathbf{P}$ & $\mathbf{S}$ & $\mathbf{A l}$ & $\mathbf{T i}$ & $\mathbf{C o}$ \\
\hline $\begin{array}{c}58.0 \\
\min \end{array}$ & $20.0-$ & $8.0-$ & $3.15-$ & 5.0 & 0.1 & 0.5 & 0.5 & 0.015 & 0.015 & 0.4 & 0.4 & 1.0 \\
& 23.0 & 10.0 & 4.15 & $\max$ & $\max$ & $\max$ & $\max$ & $\max$ & $\max$ & $\max$ & $\max$ & $\max$ \\
\hline
\end{tabular}

Table 2. 2: Physical properties of Inconel 625 [10].

\begin{tabular}{|c|c|}
\hline Property & Value \\
\hline Density & $8.44 \mathrm{~g} / \mathrm{cm}^{3}$ \\
\hline Melting Point & $1350^{\circ} \mathrm{C}$ \\
\hline Coefficient of expansion & $12.8 \mu \mathrm{m} / \mathrm{m} .{ }^{\circ} \mathrm{C}\left(20-100^{\circ} \mathrm{C}\right)$ \\
\hline Modulus of rigidity & $79 \mathrm{KN} / \mathrm{mm}^{2}$ \\
\hline Modulus of elasticity & $205.8 \mathrm{KN} / \mathrm{mm}^{2}$ \\
\hline
\end{tabular}


Inconel 625 is a non-magnetic nickel-based superalloy strengthened primarily by solid solution hardening of refractory metals such as $\mathrm{Mo}, \mathrm{Nb}$ in the austenitic FCC $\gamma$ matrix. It is also possible for this alloy to be hardened by the precipitation of metastable $\gamma^{\prime \prime}\left(\mathrm{Ni}_{3} \mathrm{Nb}\right)$ phase when annealed in the temperature range of $550-580^{\circ} \mathrm{C}$ for a long period of time [11, 12]. This alloy has excellent corrosion resistant property and can retain its mechanical strength at an elevated temperature [13]. Chromium and Nickel provides resistance against oxidizing environment while Molybdenum and Nickel provides resistance in non-oxidizing environment $[11,12]$. Chromium forms $\mathrm{Cr}_{2} \mathrm{O}_{3}$ and passivates the external surface which is the main reason for resistance to corrosion. The high ductility of Inconel 625 is responsible for its ability to withstand solidification and contraction after welding thereby reducing the possibility of cracking [14]. Because of its high temperature and corrosion resistance properties Inconel 625 is a material of choice for aerospace, chemical petrochemical and seawater applications. Some specific applications are of making gas turbine ducting, furnace hardware, combustion lines, spray bars etc. [12].

\subsubsection{Dendritic $\gamma$ phase}

The solidification reaction in Inconel 625 begins with the formation of austenitic FCC $\gamma$ phase in dendritic form. The $\gamma$ matrix is enriched with $\mathrm{Ni}, \mathrm{Cr}$ and $\mathrm{Fe}$. As the matrix forms elements with higher atomic mass such as $\mathrm{Nb}$ and $\mathrm{M}$ segregates in the interdendritic region. Due to the enrichment of $\mathrm{Nb}$ in the interdendritic liquid, $\mathrm{Nb}$ rich Laves phase and $\mathrm{NbC}$ are formed during the final phase of the solidification $[15,16]$. 


\subsubsection{Laves and $\mathrm{NbC}$ carbide formation}

The formation of $\mathrm{Nb}$ rich Laves phase and $\mathrm{NbC}$ in Inconel 625 is largely dependent on the alloy composition. The solidification path and the resultant microstructures of this alloy can be described using a pseudo ternary equilibrium diagram shown in figure 2.4. The phase transformation in Inconel 625 can occur in three different paths. For path 1 when $\mathrm{C} / \mathrm{Nb}$ ratio is high, $\gamma+\mathrm{NbC}$ forms. Path 2 represents a moderate $\mathrm{C} / \mathrm{Nb}$ ratio which leads to the formation of $\gamma+\mathrm{NbC}$ at first. Later at the end of the solidification this transforms into Laves phase. At a very low $\mathrm{C} / \mathrm{Nb}$ ratios, solidification follows path 3 where Laves phase forms directly with no NbC. The formation of Laves phase without $\mathrm{NbC}$ is very uncommon and happens when the $\mathrm{C}$ content In Inconel 625 is less than $0.01 \%$ [16].

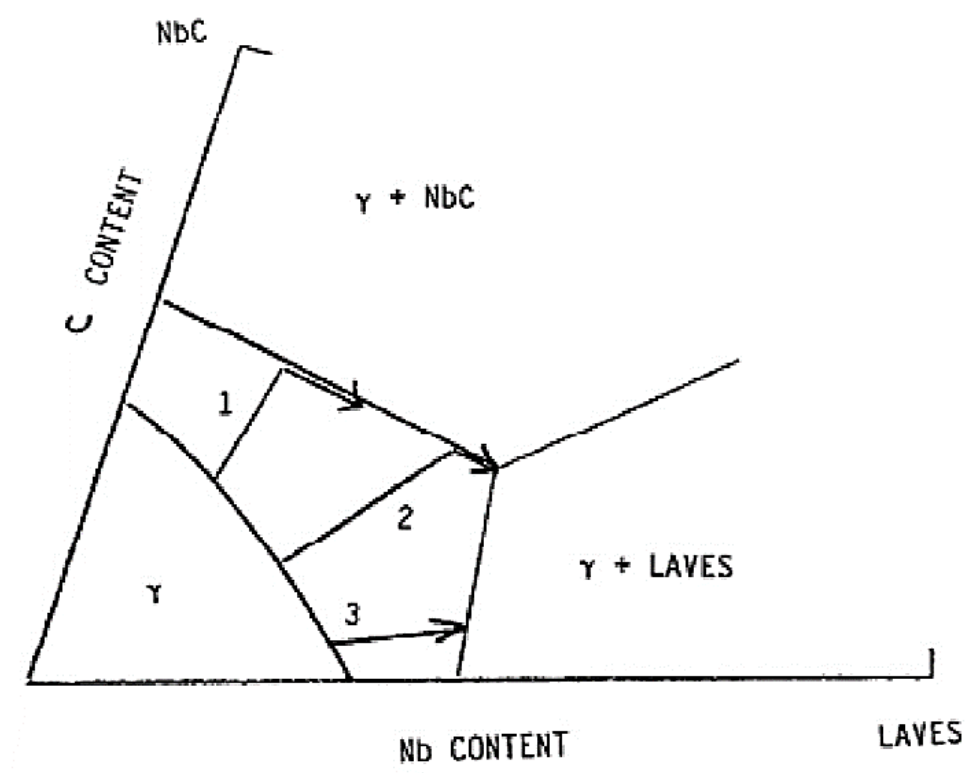

Figure 2. 4: An extract from the pseudo-equilibrium diagram for Alloy 718 showing the formation of Laves phase during solidification [16]. 
The crystal structure of Laves phase is HCP and is irregular in shapes. This phase contains significant amount of other alloying elements and impurities such as $\mathrm{Ni}, \mathrm{Cr}, \mathrm{Mo}$, $\mathrm{Nb}, \mathrm{Fe}, \mathrm{Si}$ etc [17]. Table 2.3 gives a chemical composition of Laves phase in three different product forms of Inconel 625.

Table 2. 3: Chemical compositions of Laves phase particles (at. \%) from different Alloy 625 materials [16].

\begin{tabular}{|c|c|c|c|}
\hline Element & Banded plate stock & $\begin{array}{c}\text { Base plate heat } \\
\text { treated 48hs at } \\
1600^{\circ} \mathrm{F}\end{array}$ & $\begin{array}{c}\text { 6 inch GTA } \\
\text { weldment }\end{array}$ \\
\hline $\mathrm{Ni}$ & 38 & 41 & 48 \\
\hline $\mathrm{Cr}$ & 17 & 20 & 22 \\
\hline $\mathrm{Mo}$ & 23 & 21 & 12 \\
\hline $\mathrm{Nb}$ & 19 & 6 & 11 \\
\hline $\mathrm{Fe}$ & 3 & 5 & 3 \\
\hline $\mathrm{Si}$ & 6 & 6 & 4 \\
\hline
\end{tabular}

The carbides form in the grain boundaries are also irregular in shape but mostly blocky and dendritic Chinese script morphology. Table 2.4 shows the chemical composition of Carbides presents in different types of Inconel 625 products.

Table 2. 4: Composition of NbC phase (wt. \%) in different Alloy 625 materials [16].

\begin{tabular}{|c|c|c|c|c|c|}
\hline \multirow[b]{2}{*}{ Element } & \multicolumn{2}{|c|}{ GTA welds } & \multirow[b]{2}{*}{625 bar } & \multirow{2}{*}{$\begin{array}{c}\text { Wrought } \\
625900^{\circ} \mathrm{C} / \\
1 \mathrm{hr}\end{array}$} & \multirow{2}{*}{$\begin{array}{c}\text { Wrought } \\
625900^{\circ} \mathrm{C} / \\
100 \mathrm{hr}\end{array}$} \\
\hline & $\begin{array}{c}\text { Blocky } \\
\text { NbC }\end{array}$ & $\begin{array}{c}\text { Dendritic } \\
\text { NbC }\end{array}$ & & & \\
\hline $\mathrm{Ni}$ & $0.1-4.1$ & $2.1-4.5$ & 2.6 & - & 6.7 \\
\hline $\mathrm{Cr}$ & $1.3-7.4$ & $4.1-8.6$ & 1.2 & 3.6 & 3.6 \\
\hline Mo & 4.4-13.2 & $6.5-17.6$ & 2.8 & 20.1 & 4.4 \\
\hline $\mathrm{Nb}$ & $65.0-82.6$ & $60.0-73.4$ & 89.3 & 79.7 & 79.7 \\
\hline $\mathrm{Fe}$ & $0-0.4$ & $0.1-0.3$ & - & - & - \\
\hline $\mathrm{Ti}$ & - & - & 4.0 & - & - \\
\hline
\end{tabular}


Beside Niobium and Carbon, other compositions have also some effect on the microstructure of Inconel 625, for example, the formation of Laves phase has been observed to increase with the increase of $\mathrm{Fe}$ and $\mathrm{Si}$, and therefore, lowering this two elements in Inconel 625 alloy can lower the amount of Laves phase which benefits in increasing the ductility of the alloy [18]. There is no benefits of Laves phase in the alloy. Carbides, provides limited strengthening by stabilizing the grain boundaries against shear [19]. Although it is beneficial to have carbide precipitates the concentration should be control to avid forming excessive amount of localized concentration and to improve ductility and chemical stability.

\subsubsection{Other precipitate phases during thermal exposures}

Various precipitates which form in Inconel 625 alloy at different temperatures and compositions can be described by the time-temperature-transformation (T-T-T) diagram (figure 2.5).

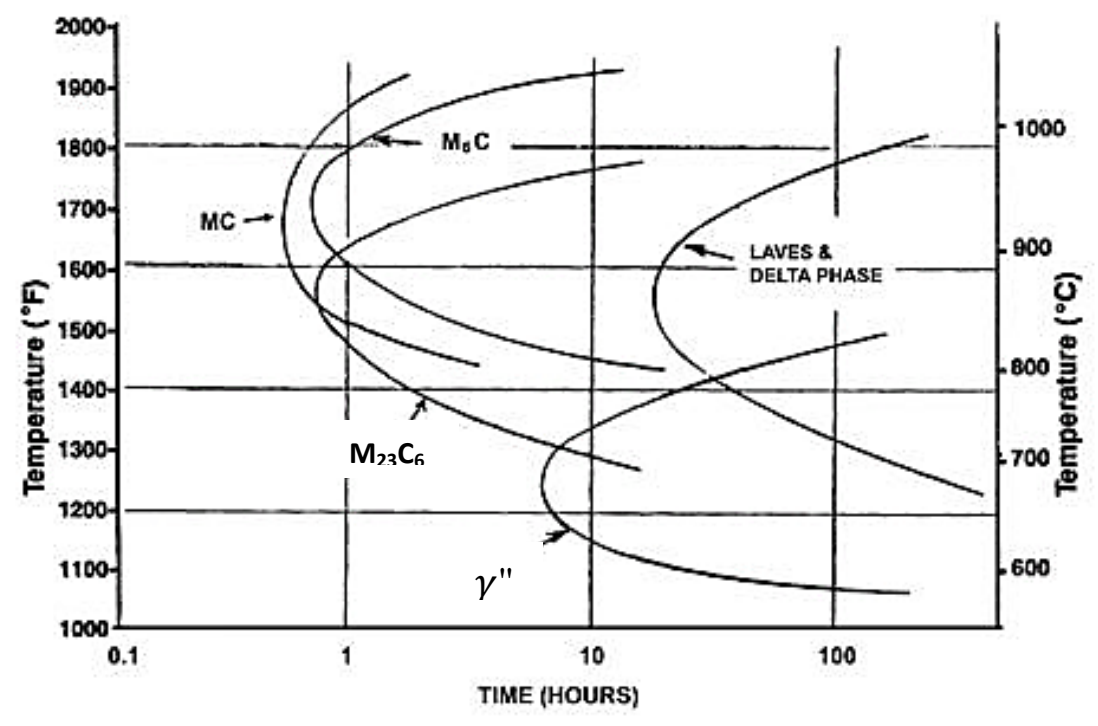

Figure 2. 5: An approximate time-temperature-transformation diagram for phases forming at higher temperatures in Alloy 625 [16]. 
The precipitation of various carbides in the grain boundary is dependent on temperature. At higher temperature in the range of $1600-1900^{\circ} \mathrm{F}$, precipitates are mainly $\mathrm{MC}$ and $\mathrm{M}_{6} \mathrm{C}$. $\mathrm{M}$ in this case is $\mathrm{Ni}, \mathrm{C}$ and Mo. Between $1300-1600^{\circ} \mathrm{F}_{23} \mathrm{C}_{6}$ forms in the grain boundary where $\mathrm{M}$ is mainly $\mathrm{Cr}$. The shape of $\mathrm{M}_{6} \mathrm{C}$ and $\mathrm{M}_{23} \mathrm{C}_{6}$ carbides are blocky, irregular shape and precipitates in the grain boundary as separate, discrete particles [16]. Prolonged thermal exposure beyond 48 hours can cause the formation of Laves and delta particles in the temperature range of $1300-1800^{\circ} \mathrm{F}$. These particles starts to form in the grain boundaries which already contains carbide particles. Laves has similar morphology to $\mathrm{M}_{6} \mathrm{C}$ and $\mathrm{M}_{23} \mathrm{C}_{6}$ and is difficult to distinguish. However, delta particle can be easily identified by its acicular morphology. Both laves and delta particles reduce ductility this are detrimental to mechanical properties of Inconel 625 . The precipitation of $\gamma^{\prime \prime}\left[\mathrm{Ni}_{3}(\mathrm{Nb}\right.$ $>0.05, \mathrm{Ti}>0.5, \mathrm{Al}<0.5)$ ], although rear can still happen in the temperature range of $1100-1400^{\circ} \mathrm{F}$ with prolong thermal exposure beyond $10 \mathrm{hrs}$. Unlike Inconel 718 , this alloy is not designed as a precipitation hardened alloy therefore the formation of $\gamma^{\prime \prime}$ is highly unexpected. The precipitation can still happen with sufficient $\mathrm{Nb}+\mathrm{Ti}+\mathrm{Al}$ in its composition. $\gamma^{\prime \prime}$ is an ordered tetragonal structure typically having plate or disk shaped particles [17].

\subsection{Fundamentals of solidification}

The solidification microstructure of alloys is controlled by cooling conditions i.e. local solidification conditions (cooling rate, temperature gradient and crystal growth velocity) and by alloy composition. The resulting microstructures can be one of two basic types; dendritic (single phase) and eutectic (polyphase). The most relevant to this study is dendritic growth. 


\subsubsection{Dendrites}

The solidification of metals and alloys can occur as a planar front or cells, however, when a stable front breaks down dendrites are formed [20]. Cells and planar fronts grow anti-parallel to the heat flux in the system, whereas dendrites grow preferentially along specific crystallographic directions due to anisotropy in surface tension and attachment kinetics, for example, in cubic materials such as $\mathrm{Ni}$ based superalloys, the preferred direction is along one of the six $<001>$ directions. Figure 2.6 shows examples of columnar and equiaxed dendrites.

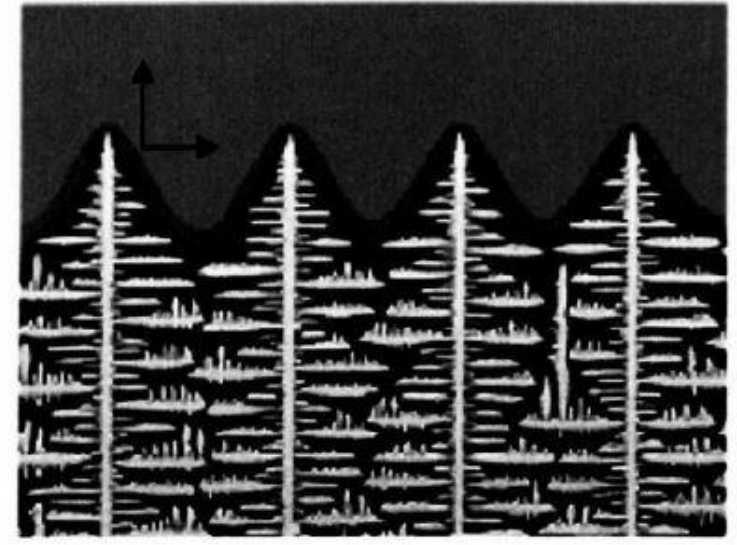

(a)

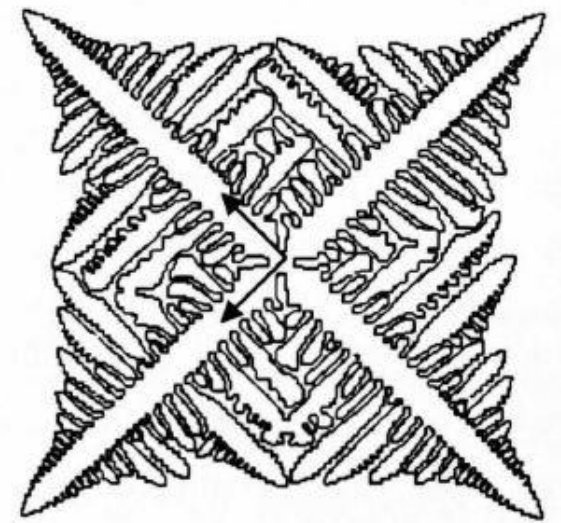

(b)

Figure 2. 6: (a) columnar and (b) equiaxed dendrites, arrows show the $x-y<100>$ direction, the $\mathrm{z}$ axis is perpendicular to the page. After Wang et al. [21]. The four vertical trunks in (a) are primary dendrite arms and similarly in (b) the larger trunks forming an

$$
\text { 'X'. }
$$

At low solidification velocities a planar solidification front is possible, i.e. a flat interface with uniform temperature [22]. As the solidification velocity increases the diffusion of solute atoms at the interface becomes localized, this causes a composition 
gradient ahead of the advancing front and leads to the temperature of the liquid in this region falling below the liquidus temperature. This means that the liquid is constitutionally undercooled; in this region the planar front becomes unstable and perturbations develop and the advancing front becomes cellular, as the velocity further increases the cells become unstable and dendrites are formed. This is shown schematically in Figure 2.7.

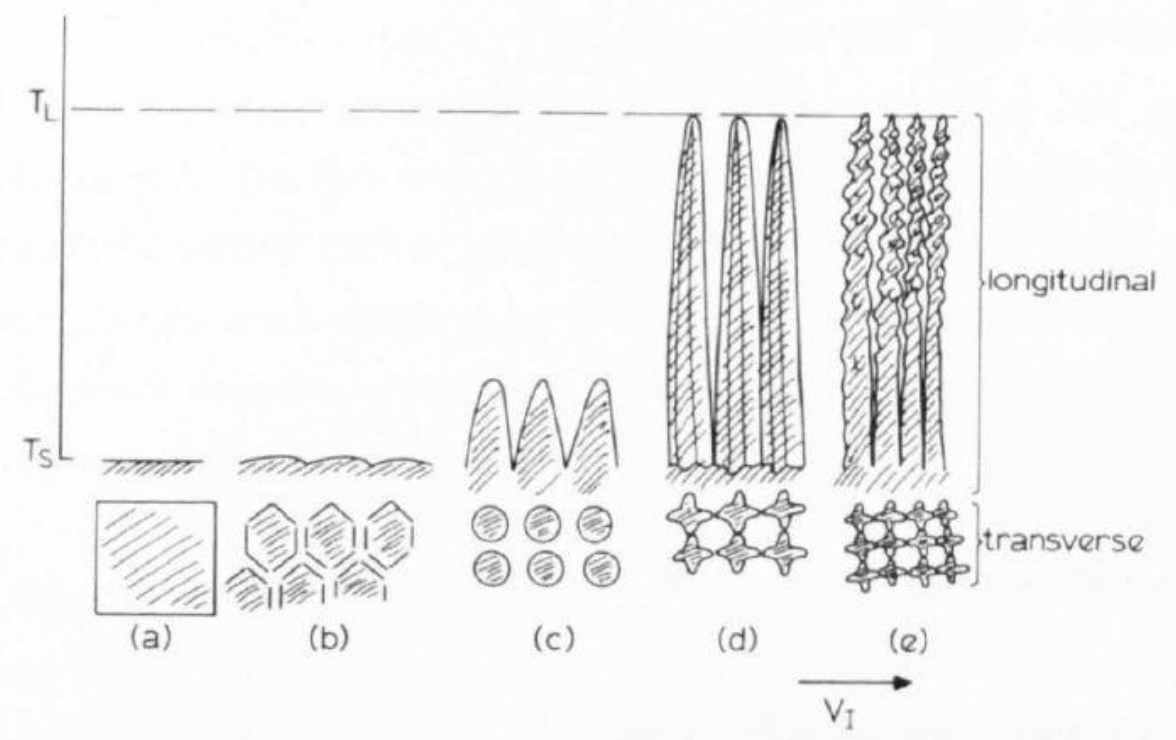

Figure 2. 7: Schematic illustration showing the change in growth morphology with increasing isotherm velocity (a) planar, (b) and (c) Cells, (d) and (e) dendrites [24].

Columnar dendrites are a result of 'constrained' growth, as is the case in directional solidification where a heat sink is present, this means that the rate of advance of isotherms constrains the growing dendrites to grow at a specific velocity and forces them to adopt the corresponding tip undercooling. In directional growth, dendrites are typically arranged with primary trunks parallel to each other. The space between these is known as the Primary Dendrite Arm Spacing $\left(\lambda_{1}\right)$ and is a function of the local 
solidification conditions. Grain boundaries are parallel to primary dendrites with low angle grain boundaries present at dendrite interfaces.

Initially, growth of a primary arm occurs followed by branching of secondary arms which are perpendicular along the other $<001>$ directions and have a spacing, $\lambda_{2}$ (Secondary Dendrite Arm Spacing). Ternary branching perpendicular to the secondary arms also occurs close to the solidification front, but these are mostly consumed during the growth/coarsening of secondary arms.

During directional solidification, isotherms move due to an imposed heat flux. Under these conditions, thin needle-like crystals are more likely to arise than a flat planar front as solute redistribution is more efficient, i.e. as solute is rejected from the solid there is a larger volume of liquid for it to diffuse into which leads to a smaller diffusion boundary layer compared to that of a planar interface.

\subsubsection{Solidification during laser processing and welding}

The melt pool geometry plays an important role in the development of micro- and macro structures in welding and melting processes as this influences the direction of heat flux. Fluid flow in the pool affects weld penetration and also influences the solidification conditions; this in turn influences microstructures, segregation and porosity [23]. The microstructures produced by processes such as welding are complicated and difficult to interpret and have a profound effect on mechanical properties. Important parameters in the development of such microstructures are similar to casting; temperature gradient, G, growth velocity, $V$, degree of undercooling and alloy composition. $\mathrm{G}$ and $V$ are vital in the control of grain morphology and scale of the microstructure. In the solidification region or fusion zone (FZ) the temperature gradient and growth velocity vary along the 
solidification front towards the rear of the pool [24] and influences the grain morphology as depicted in figure 2.8 .

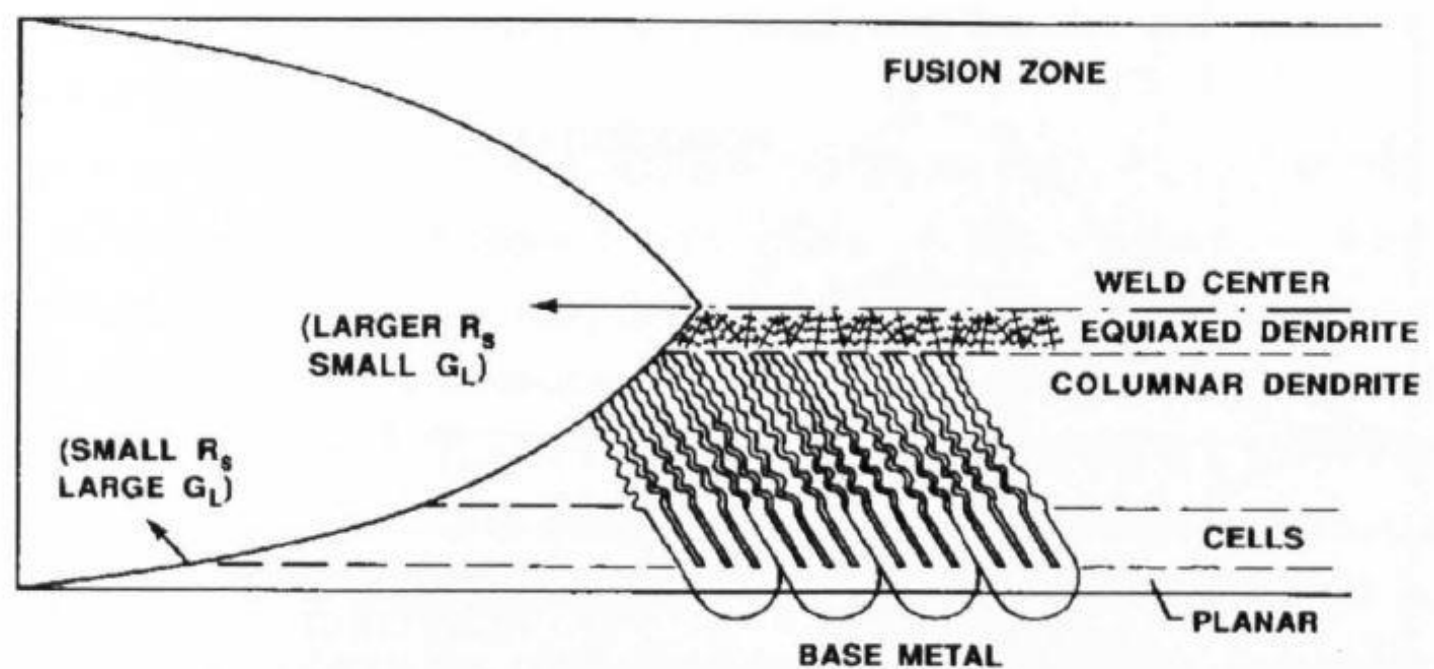

Figure 2. 8: Schematic diagram showing change in morphology along the fusion zone during welding-type processes $\left(\mathrm{R}_{\mathrm{S}}=\right.$ grain growth rate, $\mathrm{G}_{\mathrm{L}}=$ thermal gradient in the liquid) [23].

Microstructures are commonly interpreted by classic nucleation and growth theory. In welding-type solidification, the formation of the solid phase in the melt pool by homogeneous nucleation can be ignored as epitaxy dominates [25]. During autogenous welding (that is welding which does not use a filler material such as laser and electron beam welding) the special case of heterogeneous nucleation known as epitaxy occurs with virtually no barrier to nucleation. During epitaxial solidification, growth occurs by addition of atoms from the liquid to the adjacent solid. The ease at which epitaxy occurs (i.e. the kinetics of the growth process) is controlled by the solid/liquid interface structure on the atomic scale. 
Additive manufacturing processes, like welding and cladding, experience directional solidification as the substrate acts as a heat-sink; this makes directional growth of the microstructure favorable and leads to columnar and even the possibility of single crystal deposits.

\subsubsection{Solidification of Inconel 625 laser coatings}

Microstructure forming during SLM processing of Inconel 625 is very similar to laser coating. During the solidification of Inconel 625 laser coating, elongated $\gamma$ dendrite forms. Mo and $\mathrm{Nb}$ deplete from the core of the $\gamma$ dendrite and segregate in the interdendritic region. Due to this segregation the molten Inconel 625 alloy usually ends up with $\gamma$ dendrite core and Laves particles in the interdendritic regions (equation 2.2.3.1) $[15,18]$. $\mathrm{NbC}(\mathrm{MC})$ is also a common precipitated found in the interdendritic regions of laser coated Inconel $625[26,27]$. The formation of MC carbide is due to the high temperature exposure during laser scanning. This generally occur at around $1250^{\circ} \mathrm{C}$ (equation 2.2.3.2) and the $\mathrm{NbC}$ is produced at a smaller amount.

$$
\begin{aligned}
& \mathrm{L}=\gamma+\text { Laves } \\
& \mathrm{L}=\gamma+\mathrm{NbC}
\end{aligned}
$$

The amount of Laves and $\mathrm{NbC}$ phases are dependent on the $\mathrm{C}, \mathrm{Si}$ and $\mathrm{Fe}$ contents. $\mathrm{NbC}$ is generally favored by $\mathrm{C}$ whereas the presence of Laves is promoted by the $\mathrm{Si}$ and Fe additions [18]. 


\subsection{Additive Manufacturing}

\subsubsection{Overview}

Additive Manufacturing (AM) refers to a "process of joining materials to make objects from 3D model data, usually layer upon layer, as opposed to subtractive manufacturing methodologies." This technology has distinct advantages over traditional manufacturing in its capability to manufacture freeform shapes without any use of molds. Its synonyms include: additive fabrication, additive processes, additive techniques, additive layer manufacturing, layer manufacturing, and freeform fabrication (ASTM F2792-12). The main driving force behind the growth of additive manufacturing in recent years is the transformation of these techniques from fabrication of prototypes to rapid tooling (RT) and rapid manufacturing (RM) of end-use components [28].

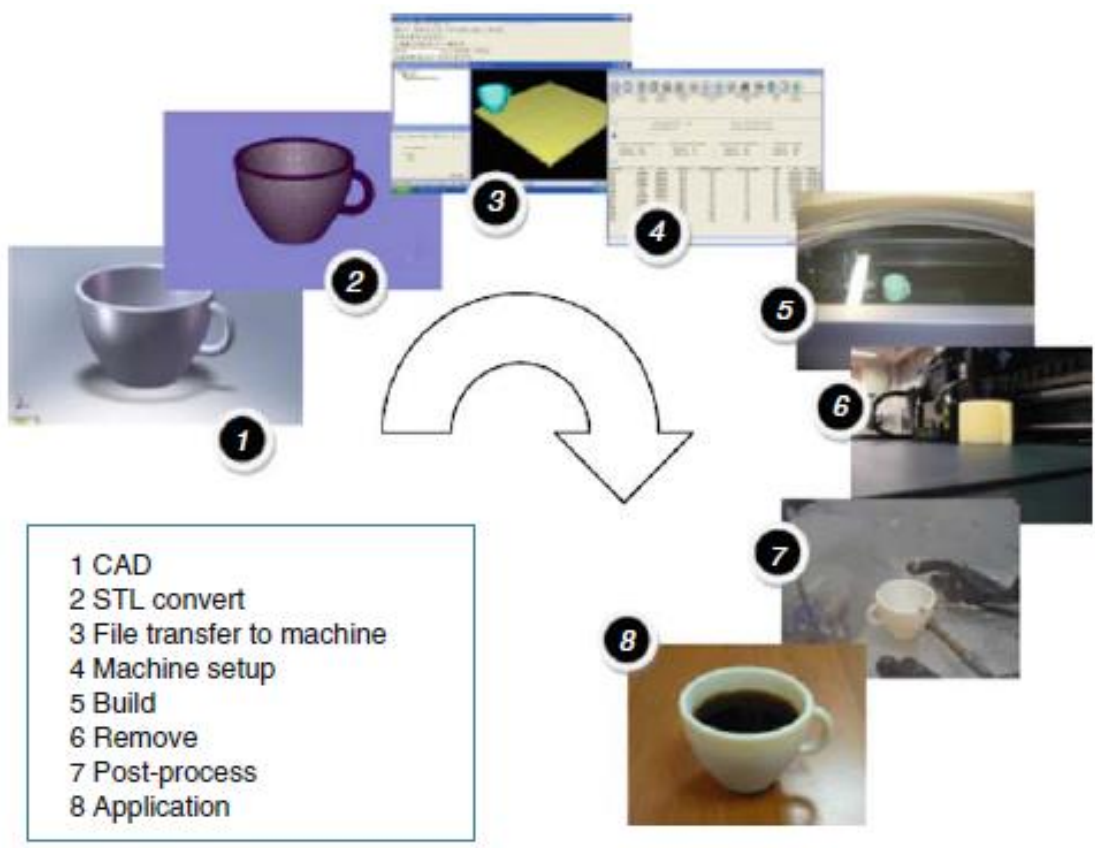

Figure 2. 9: The eight stages of the AM process [2]. 


\subsubsection{Classification}

Additive Manufacturing (AM) technologies have been improved, re-innovated and extended tremendously since the idea of layer-by-layer fabrication from a CAD model was first developed in the 1970s [2, 29]. There are seven major categories of AM technologies according to the ASTM classification as shown in table 2.5. The table also summarizes the materials that different $\mathrm{AM}$ technologies are able to process and examples of companies that produce AM machines worldwide. AM technologies are categorized mainly by the mechanism of processes and each classification has been divided into several other processes according to the materials and/or energy source. Metal and polymers (including photopolymers) are widely used materials in AM. As shown in table 2.5, AM is being utilized all over the world, with the United States and Europe as the main pioneers.

Table 2. 5: The Seven AM Process Categories by ASTM F42 [30].

\begin{tabular}{|c|c|c|c|c|}
\hline Process Type & Materials & Brief Description & $\begin{array}{l}\text { Related } \\
\text { Technologies }\end{array}$ & Companies \\
\hline $\begin{array}{l}\text { Powder Bed } \\
\text { Fusion }\end{array}$ & $\begin{array}{l}\text { Metals, } \\
\text { Polymers }\end{array}$ & $\begin{array}{l}\text { Thermal energy } \\
\text { selectively fuses regions } \\
\text { of a powder bed }\end{array}$ & $\begin{array}{l}\text { Electron beam } \\
\text { melting (EBM), } \\
\text { selective laser } \\
\text { sintering (SLS), } \\
\text { selective heat } \\
\text { sintering (SHS), } \\
\text { and direct metal } \\
\text { laser sintering } \\
\text { (DMLS) }\end{array}$ & $\begin{array}{l}\text { EOS } \\
\text { (Germany), } \\
\text { 3D Systems } \\
\text { (US), } \\
\text { Arcam } \\
\text { (Sweden) }\end{array}$ \\
\hline $\begin{array}{l}\text { Directed } \\
\text { Energy } \\
\text { Deposition }\end{array}$ & $\begin{array}{l}\text { Metals } \\
\text { (Powder/ } \\
\text { Wire) }\end{array}$ & $\begin{array}{l}\text { Focused thermal energy } \\
\text { is used to fuse materials } \\
\text { by melting as the } \\
\text { material is being } \\
\text { deposited }\end{array}$ & $\begin{array}{l}\text { Laser metal } \\
\text { deposition (LMD) }\end{array}$ & $\begin{array}{l}\text { Optomec } \\
\text { (US), POM } \\
\text { (US) }\end{array}$ \\
\hline
\end{tabular}




\begin{tabular}{|l|l|l|l|l|}
\hline $\begin{array}{l}\text { Material } \\
\text { Extrusion }\end{array}$ & Polymers & $\begin{array}{l}\text { Material is selectively } \\
\text { dispensed through a } \\
\text { nozzle or orifice }\end{array}$ & $\begin{array}{l}\text { Fused deposition } \\
\text { modeling (FDM) }\end{array}$ & $\begin{array}{l}\text { Stratasys } \\
\text { (Israel), Bits } \\
\text { from Bytes } \\
\text { (UK) }\end{array}$ \\
\hline $\begin{array}{l}\text { Vat Photo- } \\
\text { polymerization }\end{array}$ & $\begin{array}{l}\text { Photopoly } \\
\text { mers }\end{array}$ & $\begin{array}{l}\text { Liquid photopolymer in a } \\
\text { vat is selectively cured } \\
\text { by light-activated } \\
\text { polymerization }\end{array}$ & $\begin{array}{l}\text { Stereolithography } \\
\text { (SLA), digital light } \\
\text { processing (DLP) }\end{array}$ & $\begin{array}{l}\text { 3D Systems } \\
\text { (US), } \\
\text { Envisiontec } \\
\text { (Germany) }\end{array}$ \\
\hline Binder Jetting & $\begin{array}{l}\text { Foundry } \\
\text { Sand, } \\
\text { Metals }\end{array}$ & $\begin{array}{l}\text { A liquid bonding agent is } \\
\text { selectively deposited to } \\
\text { join powder materials }\end{array}$ & $\begin{array}{l}\text { Powder bed and } \\
\text { inkjet head (PBIH), } \\
\text { plaster-based 3D } \\
\text { printing (PP) }\end{array}$ & $\begin{array}{l}\text { 3D Systems } \\
\text { (US), } \\
\text { ExOne (US) }\end{array}$ \\
\hline $\begin{array}{l}\text { Material } \\
\text { Jetting }\end{array}$ & $\begin{array}{l}\text { Polymers, } \\
\text { Waxes }\end{array}$ & $\begin{array}{l}\text { Droplets of build } \\
\text { material are selectively } \\
\text { deposited }\end{array}$ & $\begin{array}{l}\text { Multi-jet modeling } \\
\text { (MJM) }\end{array}$ & $\begin{array}{l}\text { Objet } \\
\text { (Israel), 3D } \\
\text { Systems } \\
\text { (US) }\end{array}$ \\
\hline $\begin{array}{l}\text { Sheet } \\
\text { Lamination }\end{array}$ & $\begin{array}{l}\text { Paper, } \\
\text { Metals }\end{array}$ & $\begin{array}{l}\text { Sheets of material are } \\
\text { bonded to form an object }\end{array}$ & $\begin{array}{l}\text { Laminated object } \\
\text { manufacturing } \\
\text { (LOM), ultrasonic } \\
\text { consolidation (UC) }\end{array}$ & $\begin{array}{l}\text { Fabrisonic } \\
\text { (US), Mcor } \\
\text { (Ireland) }\end{array}$ \\
\hline
\end{tabular}

\subsubsection{Metal-based AM}

Metal-based AM system can be broadly categorized in terms of the material feed stock: (i) powder bed systems, (ii) powder feed systems, and (iii) wire feed systems. Process description of each category can be found in table 2.5. The powder bed AM method is expensive but allows dimensionally more precise components to be produced. Laser beam powder bed AM is used for small parts with high precision, whereas the electron beam-powder bed AM is used for bigger and parts with rougher surface. However, Arc plus wire AM is an alternative cheaper technique that gives higher deposition rates. This technique is restricted to wider wall thicknesses and is more suitable for larger scale products which can be built out of chamber [31]. 
Selective laser melting (SLM) a powder bed AM process, is the most relevant to this research thus requires detail analysis.

\subsection{Selective Laser Melting (SLM)}

As seen from table 2.5, Selective Laser Melting (SLM) is one of the processes under Powder Bed Fusion (PBF) and is the main interest of this research. SLM is a metal based PBF process and is similar to Selective Laser Sintering (SLS). A wide range of metals have been used in SLM, such as stainless steel alloy (e.g. PH 17-4), Titanium alloy (e.g. Ti-6Al-4V), Nickle based superalloy (e.g. Inconel 625, Inconel 718 etc.) etc.

In SLM, a CAD volume model is sliced into layers of equal thickness. The SLM machine writes each layer onto a powder bed, where powder layers of equal thickness are spread by powder handling system. The laser beam gun melts specific areas that are equal to the cross section of the components in each section slice. Figure 2.10 shows a schematic representation of key components of the selective laser melting (SLM), or direct metal laser sintering (DMLS), process. As shown in Figure 2.10, the machine comprises a process chamber, an optical system with a Nd:YAG laser, and a process computer. The powder is spread on the retractable platform and then levelled using a powder wiper system. The optical system creates and positions the laser beam guided by an expanded fibre laser, scanner mirrors, and a focusing objective to fuse the metal powder by melting it locally. In such highly complex geometries can be created directly from 3D CAD data, fully automatically [32-35]. 


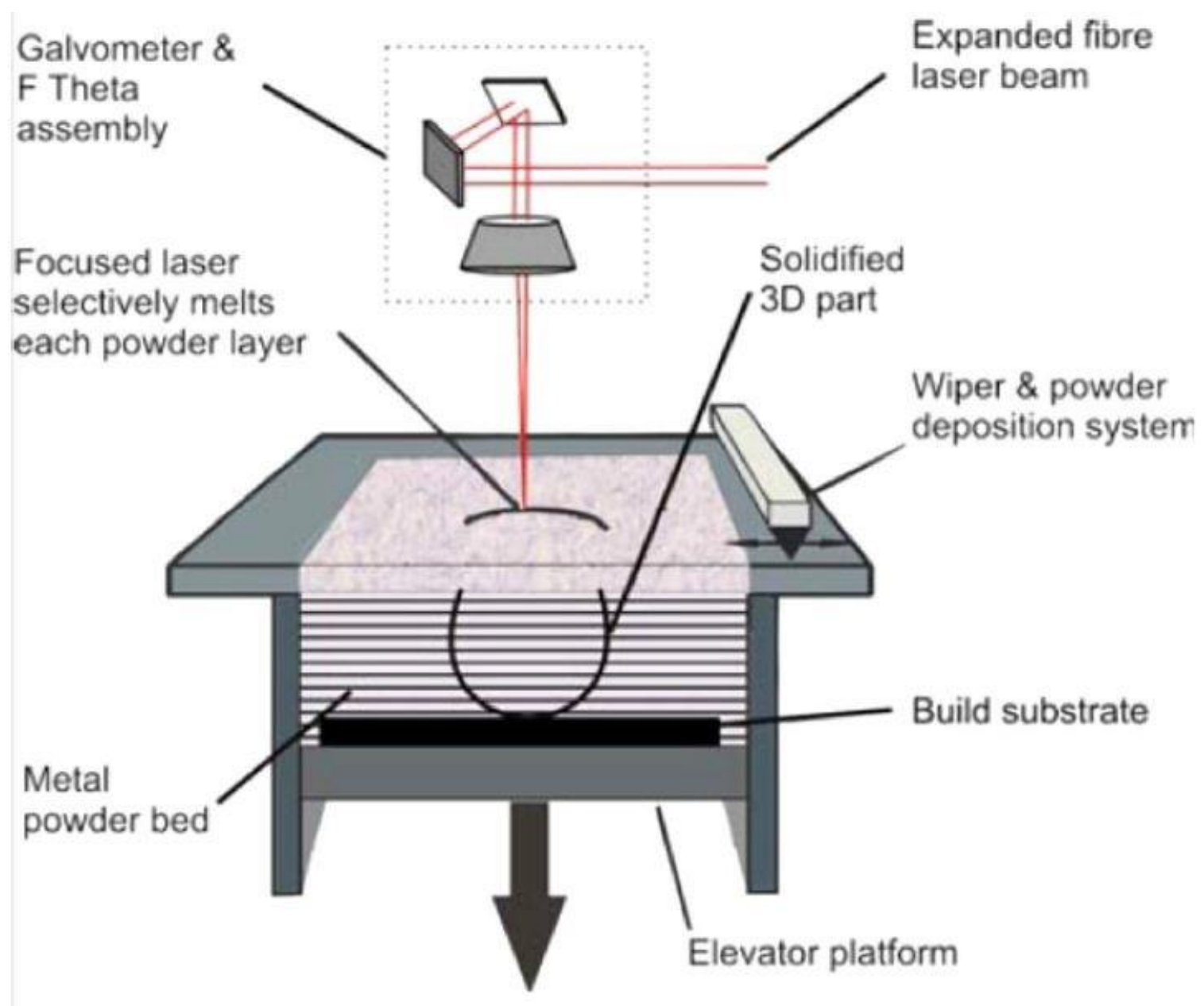

Figure 2. 10: Schematic diagram of typical powder bed SLM system [32, 33].

If the sufficient power is applied, the powder melts and forms a liquid melt pool, which solidifies to room temperature rapidly and forms the final densified product. After the cross-section of each layer is fused by scanning, the build platform is lowered by an amount equal to the layer thickness of about 20 to $30 \mu \mathrm{m}$, and a new layer of powder is spread across the cross-section. This process is repeated until the final shape of the product is completed. The build chamber is evacuated and then filled with inert gases, such as argon, so that an atmosphere with low oxygen content can be maintained during the components building. This technique can produce parts with high accuracy with 
better resolution, and surface quality than the Arcam electron beam machine. More details of the working principle of the SLM machine can be found in references [39-42].

\subsubsection{Process parameters}

There are many different operator defined processing parameters in SLM processes and these vary from machine to machine and need to be adjusted according to many different criteria, for example the alloys being melted will have different material properties such as thermal conductivity and absorptivity, the part being produced could be thin walled or thick sectioned which will affect the resolution required and the final use of the part may be intolerant to porosity or certain microstructural features.

Peng et al. [36] investigated the Direct Laser Fabrication (DLF) of nickel alloy samples using a blown powder system and reported the effect of laser power, beam velocity, powder feed rate and deposition track overlap on individual track geometry and part integrity. They used an orthogonal array experiment to test power, velocity and feed rate at three levels, however, they report their findings as a function of 'Specific Energy' (power/(velocity $\mathrm{x}$ beam diameter) in $\mathrm{J} / \mathrm{mm}^{2}$ ). This misses the point of an orthogonal array which makes it possible to look at the interactions of parameters. Specific energy is reported often on the literature (for example by Kobryn et al. [37]) with regard to the heat input of a laser, the problem with this approach is that it does not account for the effect of different parameter combinations having the same value but notably different effects, this leads to a large degree of scatter in results. Peng et at. [36] showed that the specific energy has a positive effect on track height and width as more material is melted but also that there is a large increase in the remelted depth relative to the track height above the surface as specific energy increases which implies that with increasing power or 
decreasing velocity there is a greater increase in penetration depth than track height for a given powder flow rate. They also showed that reducing specific energy below an optimum range of $100-200 \mathrm{Jmm}^{-2}$ causes a concave top surface of the deposit and conversely above this range the top surface is convex, this is undesirable as the process stability is linked to a flat working surface. These observations do not however take into account the different powder feed rates used across the experiment.

Pinkerton et al. [38] showed that laser power has a more pronounced positive effect on mean layer width and powder flow rate has a larger positive effect on mean layer height after these two primary variables were investigated using a 2-factor, 2-level factorial experiment. They report that final wall height was accurate to within $+/-1 \mathrm{~mm}$ along the wall.

Work has been carried out by Zhang et al. [39] to establish how these control parameters affect the shape of the build; laser power, beam velocity, beam diameter, and powder feed rate were investigated to determine their effect on width and height of a simple line-build. The graphs in figure 2.11 show that increasing power, beam diameter and powder feed rate gives higher, wider tracks, whereas, increasing beam velocity gives narrow tracks which are not as high. The results of this study, while providing good insight into the effects of various processing parameters, do not consider the interactions of the different parameters. This is a fundamental problem with a 'one parameter at a time' approach, another is the number of tests required to gather sufficient information, making the experimentation process very inefficient and costly. 
(a)

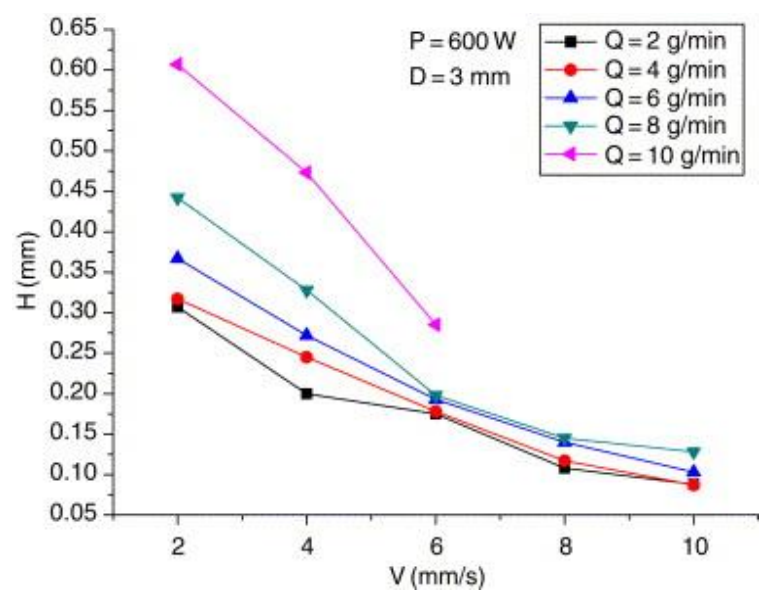

(c),

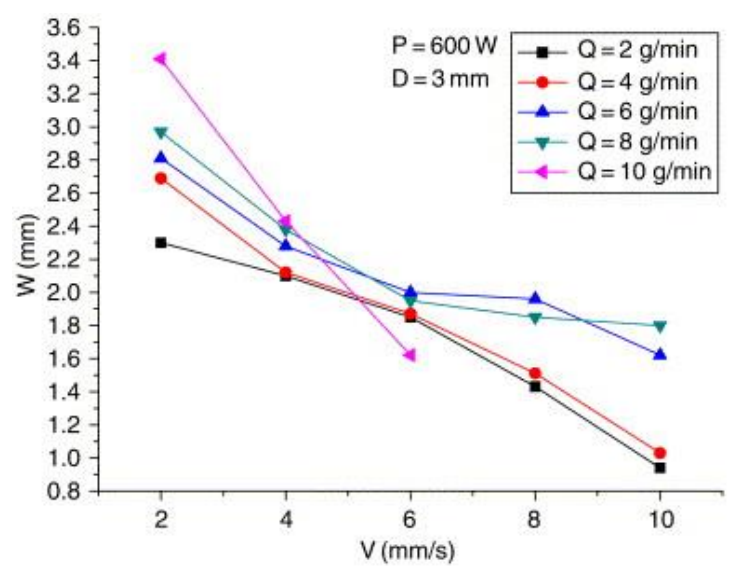

(b)

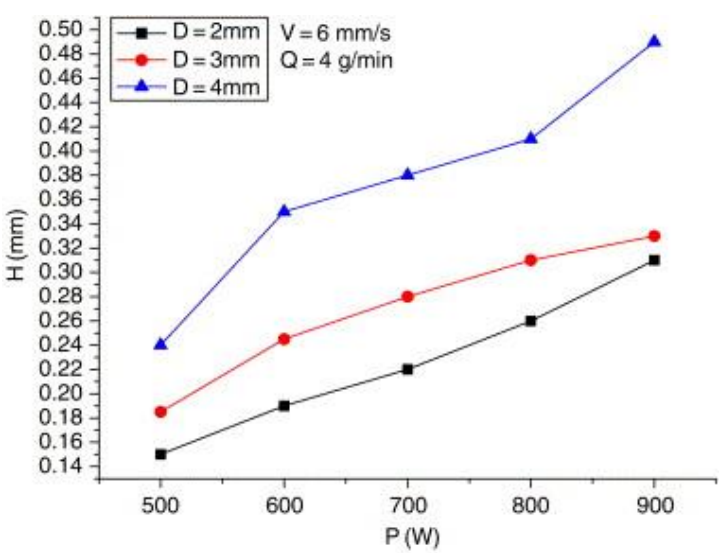

(d)

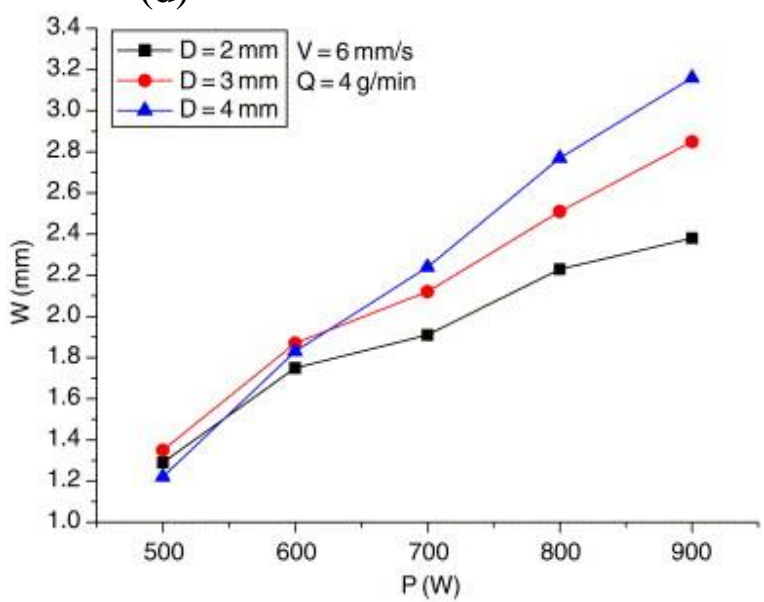

Figure 2. 11: Graphs showing the effect of beam velocity, V, laser power, P, beam diameter, D, and powder feed rate, Q, on deposition track height, (a) and (b), and width, (c) (d). [46].

\subsubsection{Build quality}

Due to the use of gas atomized powder, porosity is a key defect associated with AM. Parts having residual porosity often incorporate the shielding gas during processing. It is easily avoided through control of process variables but does represent limits in processing window where fully dense parts are necessary, there are however potential 
applications for porous material such as in bearings where pores act as reservoirs for lubricating fluid or in biomedical applications where bone- integration with prosthetics can be utilized.

Kobryn et al. [40] reported varying levels of porosity in laser deposited Ti-6AI$4 \mathrm{~V}$, two types of porosity were described; 'lack-of-fusion ' porosity caused by incomplete melting of a layer or poor bonding to adjacent and underlying material, and gas porosity, which is caused by entrapped gas from the delivery system or raw materials. Lack-offusion pores are irregular shapes and often interconnected to form long voids corresponding to inter-track regions whereas gas porosity is spherical and can occur in any area of the deposit. According to the investigation increasing power and velocity resulted in less porosity; this was rationalized since lack-of-fusion pores tend to form when insufficient energy is available to melt the required amount of material so higher powers are capable of melting more material and higher velocity means that less material is delivered to the melt pool in a given time hence there is less material to absorb the incident energy for the laser.

$\mathrm{Wu}$ et al. also reported that low laser powers result in increasing porosity [41], examples of the two types of porosity is shown in Figure 2.12. 


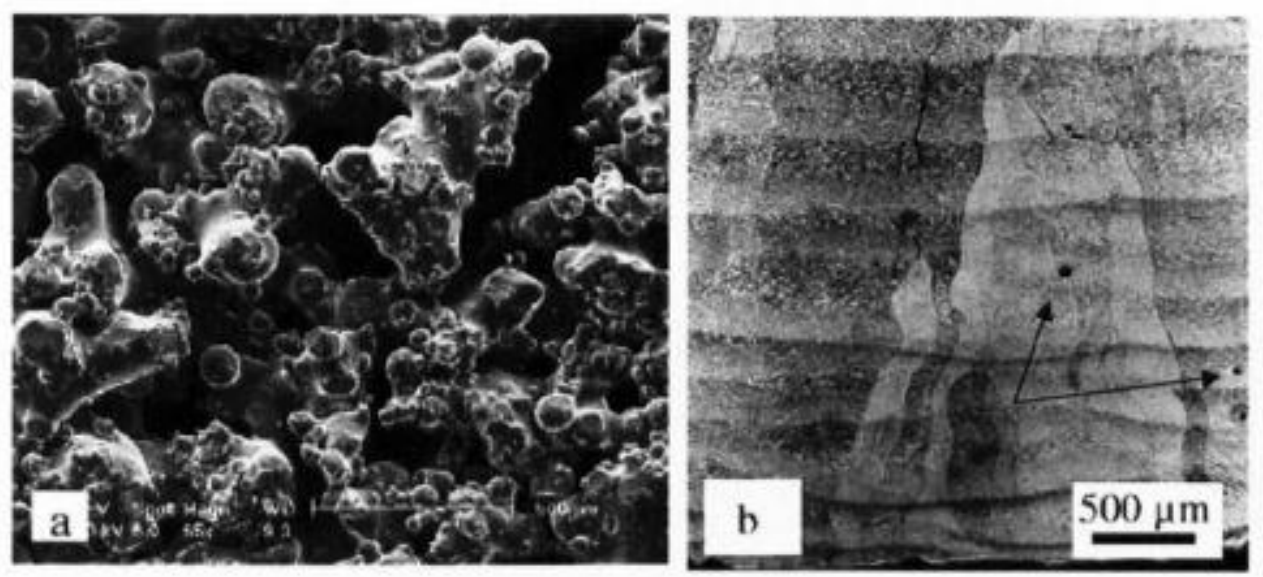

Figure 2. 12: Laser deposited Ti-6-4 (a) lack-of-fusion porosity (b) entrapped gas porosity indicated by arrow. [48].

\subsubsection{Microstructure of laser deposited Inconel 625 alloy}

The microstructure of laser deposited Inconel 625 is significantly different than conventionally processed alloy. Laser deposition is characterized of having rapid cooling cycle which results in very fine columnar dendritic microstructure oriented in the build direction and the formation of non-equilibrium phases. There are numerous published articles on the laser coating of Inconel 625 but very few of them are on selective later melting of Inconel 625.

Dinda et al. [11] investigated on the effect of process parameters on the microstructural evolution of Inconel 625 during direct metal laser deposition. Their investigation on thin walled geometry revealed that the processing parameters strongly affect the geometry, microstructures and hardness of the deposited walls. They were able to produce crack-free walls in which the microstructure mostly consisted of columnar dendrites which grew epitaxially from the substrate as shown in figure 2.13. 

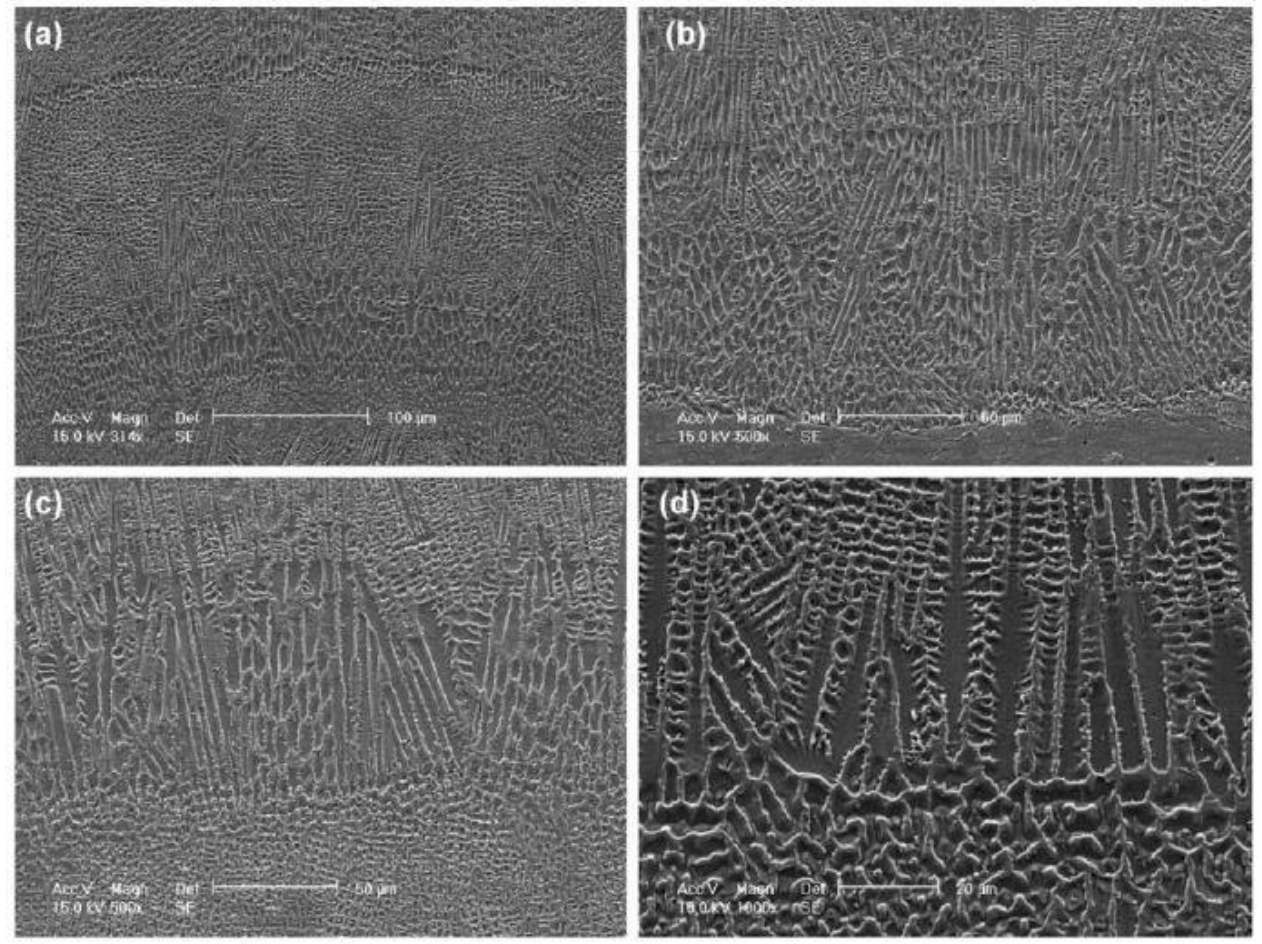

Figure 2. 13: Transverse-section microstructures at different locations of an Inconel 625 powder thin wall sample built using direct laser metal deposition technique [11].

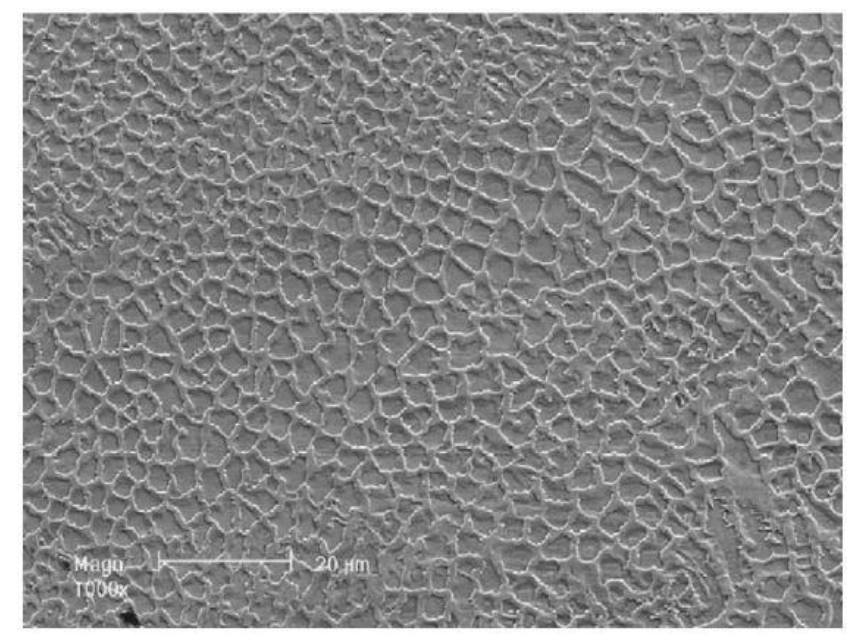

Figure 2. 14: The microstructure of the horizontal section of an Inconel 625 thin wall sample built using direct laser metal deposition technique [11].

The columnar dendritic growth in the upper layer is determined by the microstructure of the previous layer. Partially melted grains in the previous layer acts as 
pre-nuclei for the epitaxial growth of the cellular dendrites in the newly melted layer. A horizontal cross-sectional microstructure in figure 2.14 shows the typical equiaxed/cellulat dendrites. The authors observed the change in the dendrite orientation from vertical to horizontal near the top layer of the wall which they attributed to the change in heat flux direction in this region.

Rombouts et al. [27] investigated on the microstructure of the laser metal deposited Inconel 625 and showed that the structural integrity is largely dependent on microstructure. They observed a very minimal amount of porosity which they identified were due to gas inclusion. A vertical and horizontal cross-sectional micrograph is shown in figure 2.15. Very fine cellular dendritic structure was observed which formed due to rapid solidification.

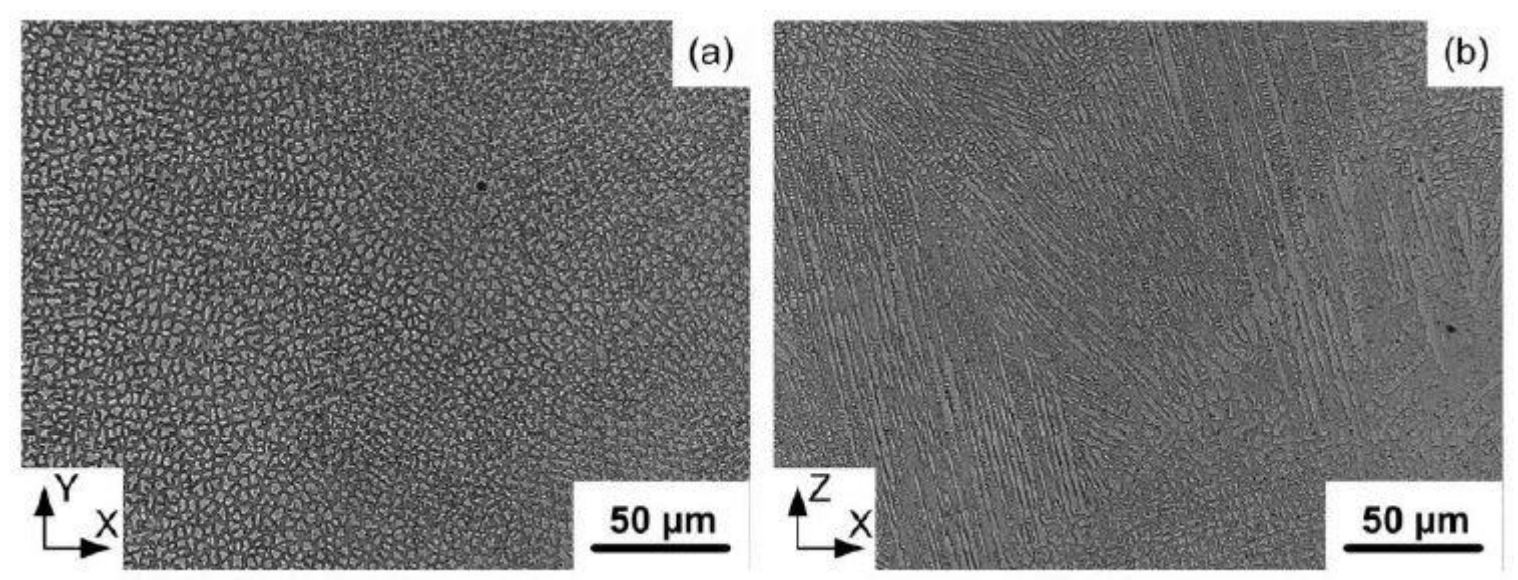

Figure 2. 15: Cross-sections (a) perpendicular and (b) parallel to the build direction in the middle of Inconel 625 sample fabricated by laser metal deposition [27].

Mostly, other works on Inconel 625 powder laser melting focused on corrosion behavior investigations. In all the published works, the interdendritic regions of Inconel 625 coatings are usually occupied by the precipitates which are rich in Mo and Nb. The 
formation of these precipitates is due to the micro-segregation of these elements (of high atomic number) into interdendritic regions during the solidification of the molten alloy.

\subsubsection{Mechanical properties}

Inconel 625 is a solid-solution strengthened nickel-chromium-molybdenum alloy used for its high strength, fabricability (including joining), and corrosion resistance. Service temperatures range from cryogenic to $982^{\circ} \mathrm{C}\left(1800^{\circ} \mathrm{F}\right)$. The alloy is strengthening through the addition of niobium that acts with the molybdenum to stiffen the alloy matrix, and thereby, provide high strength without a precipitation strengthening heat treatment. The alloy resists a wide range of severely corrosive environments and is especially resistant to pitting and crevice corrosion.

Literatures were found containing mechanical property data of additively manufactured Inconel 625. The AM processes included powder bed fusion (using lasers and electron beam energy sources) and directed energy deposition (using a laser energy source). The following is a review of these articles for the properties and conditions of the testing. The data is summarized and compared with conventional Inconel 625 properties. There was no fatigue data presented in the literature for additively manufactured Inconel 625.

Amato et al. presented mechanical properties for both EBM (Arcam) and SLM (EOS M270) of Inconel 625 [4]. The powder size was $22 \mu \mathrm{m}$ for EBM and $20 \mu \mathrm{m}$ for SLM and both were containing less than $0.4 \mathrm{wt} \% \mathrm{Fe}$. Nitrogen purge was used to inert the environment for SLM. EBM data was presented in both as fabricated and HIP condition for $\mathrm{Z}$ oriented bar. For SLM specimens were tested only in the hot isostatic pressure (HIP) condition in $\mathrm{X}, \mathrm{Y}$, and $\mathrm{Z}$ orientations. The HIP treatment was 4 hours at 
$1120^{\circ} \mathrm{C}$ under $100 \mathrm{MPa}$ argon. Authors mentioned that the differences in microstructure constituents were likely due to the differences in processing temperature, where the EBM machine is preheated to $80 \%$ of the melting point, $1068^{\circ} \mathrm{C}$, and the SLM machine is preheated to $90^{\circ} \mathrm{C}$. The SLM process showed higher yield strength (YS) (SLM 0.36GPa, EBM 0.33GPa) and ultimate tensile strength (UTS) (SLM 0.88GPa, EBM 0.77GPa), and lower ductility (SLM 58\%, EBM 69\%) compared to EBM. The tensile properties of SLM material in $\mathrm{X}-\mathrm{Y}$ plane were slightly superior than in the $\mathrm{Z}$ orientation.

Murr et al. [42] produced nickel alloy 625 material using Electron beam melting (EBM) process (ARCAM S12). Individual cylinders, $20 \mathrm{~mm}$ in diameter and $80 \mathrm{~mm}$ in length, were produced and single tensile samples were machined from these cylinders, with the tensile axis in the $\mathrm{z}$ direction. For $\mathrm{Z}$ oriented bar, yield strength of $410 \mathrm{MPa}$ and ultimate tensile strength of $750 \mathrm{MPa}$ was reported. $44 \%$ of elongation was found. Whereas for X-Y orientation, YS of $300 \mathrm{MPa}$, UTS $590 \mathrm{MPa}$ and 53\% elongation was reported. Essential processing conditions (energy, speed, path, preheat, environment, etc.) were not specified in this article; however, additional information is provided in Amato et al. [4] Powder and as-fabricated composition were reported. Notably, there was only $0.4 \mathrm{wt} \% \mathrm{Fe}$ measured in the powder composition. The composition reported for the as-fabricated samples was measured by energy dispersive spectroscopy and does not agree well with the other values. Tensile samples were tested in the as-fabricated and the heat treated condition. The heat treatment was anneal followed by hot isostatic pressure (HIP). Porosity was observed in both the as-fabricated and heat treated. The yield strength of heat treated bar was noted $230 \mathrm{MPa}$ and ultimate tensile strength of $610 \mathrm{MPa}$. $70 \%$ of elongation was found. The measured strength properties in both the as-produced 
and HIP'ed condition were below typical wrought properties, while ductility exceeded wrought minimums.

Yadroitsev, et. al. produced Inconel 625 deposits from which tensile samples were obtained [43]. The SLM equipment was a Phenix PM 100 machine and used gasatomized Inconel 625 powder having a particle size less than $16 \mu \mathrm{m}$. Rectangular parallelepipeds were produced in two orientations to test the $\mathrm{Z}$ and $\mathrm{X}-\mathrm{Y}$ properties of the deposited material. A 'two-zone' scanning method was used to produce each layer, where the first scan fuses the tracks, and the second scan melts the spaces between tracks (without adding additional material). The next layer of powder is applied, the scan direction rotated 90 degrees, and the two-zone method repeated. Tensile samples machined from these blocks were tested at room temperature. $\mathrm{Z}$ sample showed higher YS (800 MPa) compared to X-Y sample (720 MPa) but lower UTS (Z: $1030 \mathrm{MPa}, \mathrm{X}-\mathrm{Y}$ : $1070 \mathrm{MPa}$ ). Elongation were found similar for both orientations (9\%).

A NASA technical report by Betts in 2011 described a Inconel 625 duct that was produced using EOS DMLS Process [44]. Mechanical property testing was conducted, but details of this testing were not provided. Testing was conducted in the $\mathrm{Z}$ and $45^{\circ}$ from Z orientation. The YS (Z: $384 \mathrm{MPa}, \mathrm{Z}-45: 376 \mathrm{MPa})$ was lower than AMS specifications (414 $\mathrm{MPa}$ ) and significantly lower than the EOS reference properties (650 MPa). The fabricated duct was engine-tested seven times (537 seconds) and showed no signs of degradation.

Xue et al. [45] described an laser direct energy deposition (LDED) (Accufusion/National Research Council, Canada) process used to produce Inconel 625 mechanical test samples (geometries not specified). The powder composition is reported, 
but not the iron content. The authors note the laser was modulated with an average power of 20 to $300 \mathrm{~W}$. No indication of heat treatment is provided. Tensile samples were tested in both $\mathrm{X}-\mathrm{Y}$ and $\mathrm{Z}$ orientation. The yield strengths (X-Y: $477 \mathrm{MPa}, \mathrm{Z}$ : $518 \mathrm{MPa})$ are significantly greater than AMS specified value (414 MPa) but UTS value (X-Y: 744 MPa, Z: $797 \mathrm{MPa}$ ) are lower than AMS UTS value (827 MPa).

Roumbouts, et. al. described the mechanical properties of LDED processed nickel alloy 625 for samples built from two different block geometries, testing either the $\mathrm{Z}$ or $\mathrm{X}$ $\mathrm{Y}$ properties [27, 46]. The $\mathrm{Z}$ tensile sample was $10 \times 15 \times 100 \mathrm{~mm}$ (lxwxh), and $\mathrm{X}-\mathrm{Y}$ orientation geometry was $25 \times 100 \times 10 \mathrm{~mm}$. The scan pattern is $0 / 90^{\circ}$ for alternating layers. The tensile yield and ultimate strength are considerably lower and the elongation is larger for the samples built in $\mathrm{Z}$ orientation compared to those built in $\mathrm{X}-\mathrm{Y}$ orientation (Z: YS 656 MPa, UTS 1000 MPa \%Elon. 24; X-Y: YS 480 MPa, UTS 882 MPa \%Elon. 36) . The tensile properties are affected both by the tensile loading orientation relative to the build orientation and the difference in cooling rate for the two build geometries. The former effect is related to the anisotropic microstructure after processing. The impact of build geometry on the other hand results in a coarser microstructure and different phase constitution, including a larger amount of carbides, in the $\mathrm{Z}$ oriented samples due to the lower cooling rate during LDED compared to the X-Y oriented samples.

There are examples of typical mechanical properties produced by SLM and LDED machines available from equipment vendors. EOS reports the typical minimum mechanical properties for SLM (EOS M270) in the as-built and stress-relieved condition [47]. Typical properties are provided in as-built and stress-relieved condition. The stress relief was annealed at $870^{\circ} \mathrm{C}$ for one hour and rapidly cooled. Optomec reports the LDED 
(Optomec LENS) nickel alloy 625 [48]. Data is reported for the $\mathrm{X}-\mathrm{Y}$ and $\mathrm{Z}$ properties in the as-deposited condition. Properties for Optomec LENS L-DED as-deposited nickel alloy 625 exceed AMS 5666 standards for annealed nickel alloy 625 bar. In a review of the LDED process, Dutta et al. [49] reported data for deposited Inconel 625 which along with other literature value are presented in the following table.

Table 2. 6: Mechanical property data from literature.

\begin{tabular}{|c|c|c|c|c|c|c|c|c|c|}
\hline 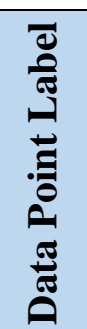 & 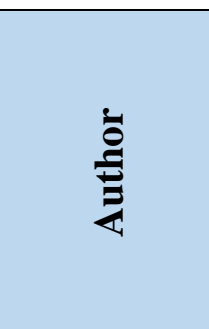 & $\underset{\bar{J}}{\bar{\varpi}}$ & 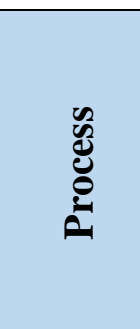 & 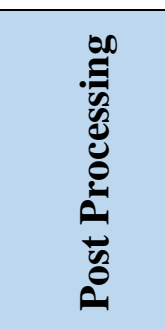 & 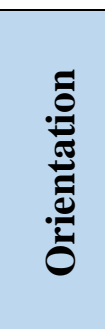 & 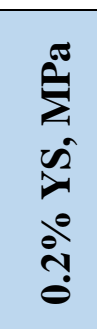 & $\begin{array}{l}\underset{\hat{\sigma}}{\tilde{S}} \\
\hat{S}\end{array}$ & 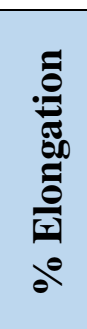 & 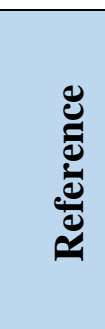 \\
\hline 1 & Xue & 2007 & LDED & $\mathrm{AF}$ & $X-Y$ & 477 & 744 & 48 & 45 \\
\hline 1 & Xue & 2007 & LDED & $\mathrm{AF}$ & $\mathrm{Z}$ & 518 & 797 & 31 & 45 \\
\hline 2 & EOS & 2010 & SLM & $\mathrm{AF}$ & $X-Y$ & 725 & 990 & 35 & 122 \\
\hline 2 & EOS & 2010 & SLM & $\mathrm{AF}$ & $\mathrm{Z}$ & 615 & 900 & 42 & 122 \\
\hline 3 & Betts & 2011 & SLM & $\mathrm{AF}$ & $\mathrm{X}-\mathrm{Y}$ & 384 & 898 & 60 & 44 \\
\hline 3 & Betts & 2011 & SLM & $\mathrm{AF}$ & $\mathrm{Z}$ & 376 & 883 & 57 & 44 \\
\hline 4 & Yadroitsev & 2009 & SLM & $\mathrm{AF}$ & $X-Y$ & 720 & 1070 & 9 & 50 \\
\hline 4 & Yadroitsev & 2009 & SLM & $\mathrm{AF}$ & $\mathrm{Z}$ & 800 & 1030 & 9 & 50 \\
\hline 5 & Optomec & 2012 & LDED & $\mathrm{AF}$ & $X-Y$ & 694 & 1052 & 33 & 48 \\
\hline 5 & Optomec & 2012 & LDED & $\mathrm{AF}$ & $\mathrm{Z}$ & 490 & 829 & 43 & 48 \\
\hline 6 & Murr & 2011 & EBM & $\mathrm{AF}$ & $X-Y$ & 300 & 590 & 53 & 42 \\
\hline 6 & Murr & 2011 & EBM & $\mathrm{AF}$ & $\mathrm{Z}$ & 410 & 750 & 44 & 42 \\
\hline 6 & Murr & 2011 & EBM & $\mathrm{SA}+\mathrm{HIP}$ & $\mathrm{Z}$ & 330 & 770 & 69 & 42 \\
\hline 6 & Murr & 2011 & EBM & $\mathrm{SA}+\mathrm{HIP}$ & $\mathrm{Z}$ & 230 & 610 & 70 & 42 \\
\hline 7 & Rombouts & 2012 & LDED & $\mathrm{AF}$ & $\mathrm{X}-\mathrm{Y}$ & 480 & 882 & 36 & 27,46 \\
\hline 7 & Rombouts & 2012 & LDED & $\mathrm{AF}$ & $\mathrm{Z}$ & 656 & 1000 & 24 & 27,46 \\
\hline 8 & Amato & 2012 & SLM & $\mathrm{SA}+\mathrm{HIP}$ & $X-Y$ & 380 & 900 & 58 & 4 \\
\hline 8 & Amato & 2012 & SLM & $\mathrm{SA}+\mathrm{HIP}$ & $\mathrm{Z}$ & 360 & 880 & 58 & 4 \\
\hline 9 & EOS & 2011 & SLM & SR & $X-Y$ & 720 & 1040 & 35 & 47 \\
\hline 9 & EOS & 2011 & SLM & SR & $\mathrm{Z}$ & 650 & 930 & 44 & 47 \\
\hline 10 & Dutta & 2011 & LDED & - & $\mathrm{Z}$ & 598 & 795 & 14 & 49 \\
\hline 11 & MMPDS & & $\begin{array}{l}\text { AMS } \\
5666\end{array}$ & A & Z & 414 & 827 & 30 & 57 \\
\hline
\end{tabular}




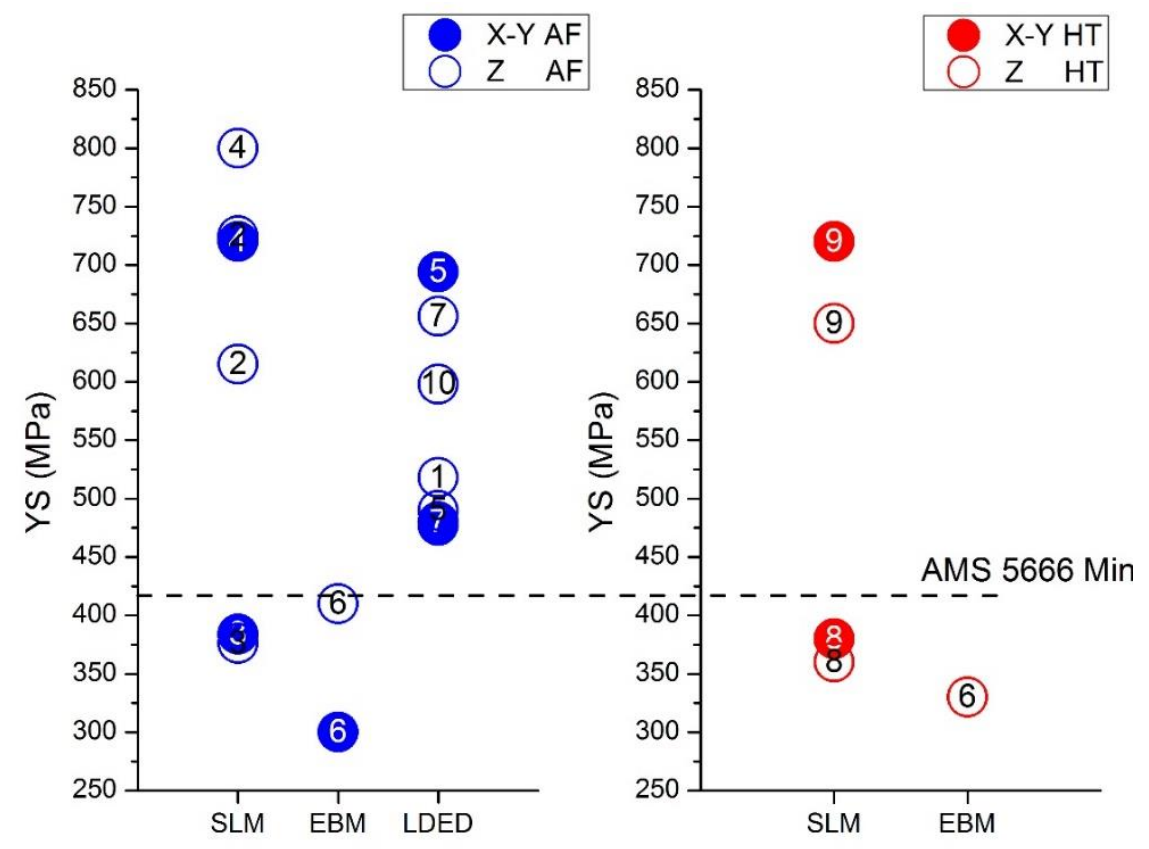

Figure 2. 16: Yield strength $(0.2 \%)$ in as fabricated (AF) and heat treated (HT) condition.

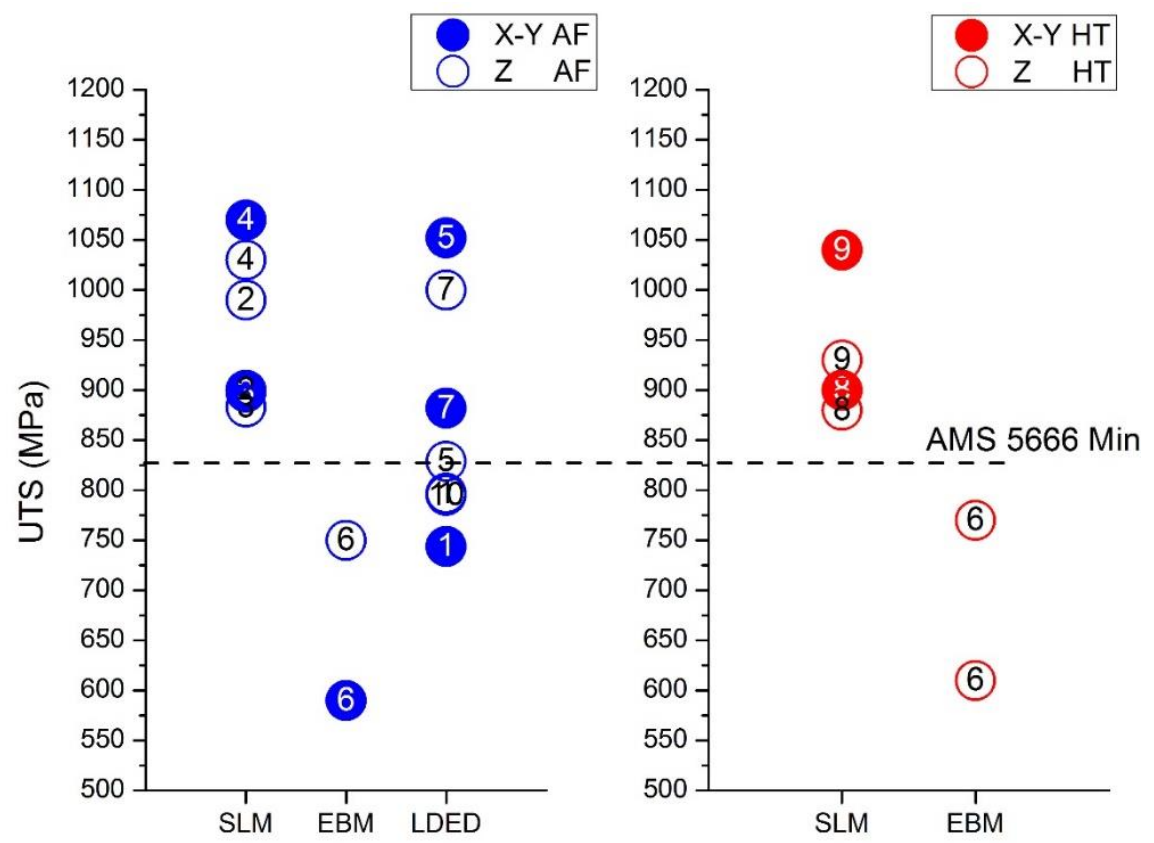

Figure 2. 17: Ultimate tensile strength (UTS) in as fabricated (AF) and heat treated (HT) condition. 


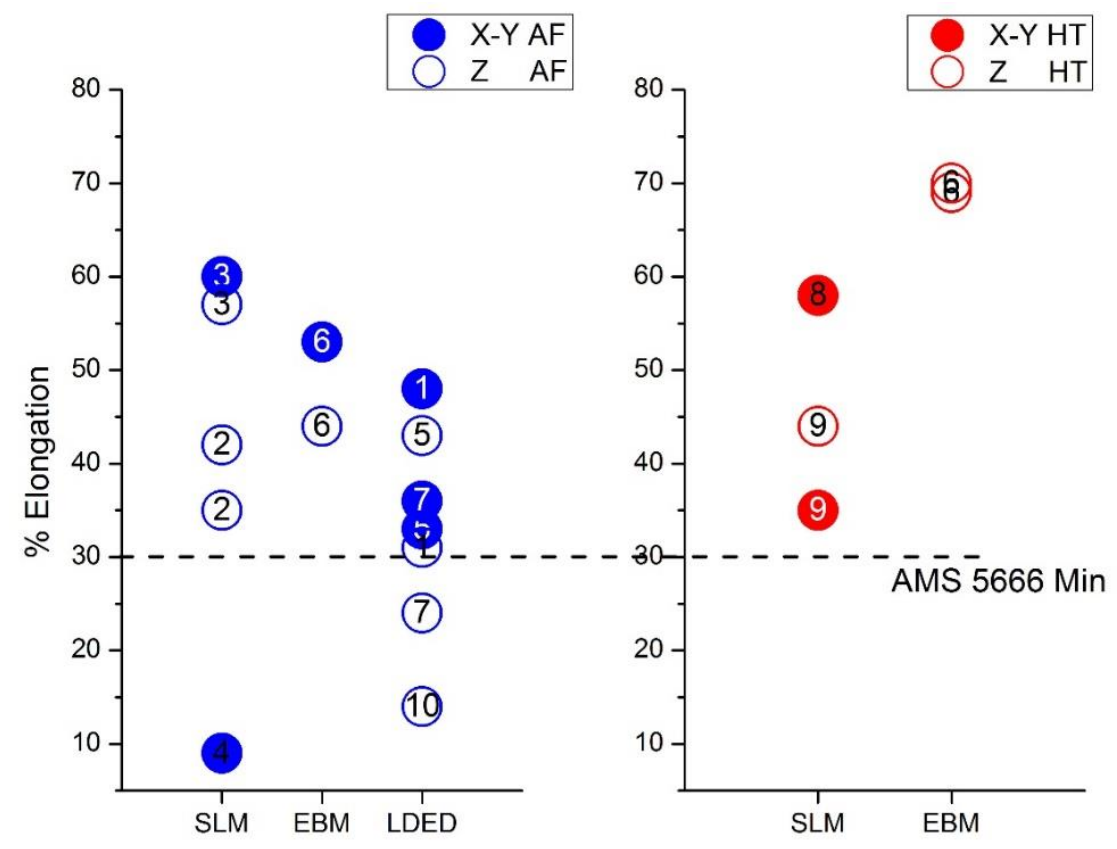

Figure 2. 18: Elongation in as fabricated (AF) and heat treated (HT) condition.

There is significant variation found in the property data of additively manufactured Inconel 625. In general as fabricated strength is significantly higher than heat treated strength and most of the cases data meets AMS 5666 typical minimum value. $\mathrm{X}-\mathrm{Y}$ oriented samples have higher strength than $\mathrm{Z}$ oriented sample but is opposite for elongation. There is very limited amount of heat treated data available which shows that the ductility of the alloy can be improved by heat treatment. 


\section{CHAPTER 3}

\section{OBJECTIVES AND SCOPE}

Based on the problem statement and research objectives stated in Chapter 1 and the work of others, as listed in Chapter 2, the following tasks are identified.

(i) The study begins by identifying optimum process parameters. This is done by conducting a novel single bead experiment where single tracks are built on top of rectangular pads with varying processing parameters. Morphology of the single beads and meltpools are analyzed using optical microscopy (OM) and scanning electron microscopy (SEM). Rectangular test coupons are fabricated with the same processing conditions are analyzed for porosity and hardness.

(ii) The detail microstructural study is conducted and the effect of scan pattern on microstructural evolution of Inconel 625 are investigated. Ideal combination of laser power and scan speed from single bead experiment are used to build samples with varying scan patterns. Microstructural characterization of the samples are carried out using optical microscopy (OM), scanning electron microscopy (SEM), and Transmission electron microscopy (TEM). The morphology of the precipitates are obtained by TEM and their crystallographic structures are derived from Selected Area Diffraction (SAD) patterns. 
(iii) Tensile deformation behavior of Inconel 625 by SLM is then investigated. Solid cylindrical specimens made by SLM is investigated for various scan patterns, build orientations and post-processing. The results are then correlated with corresponding fracture behavior.

(iv) The fatigue behavior of Inconel 625 solid cylindrical parts fabricated by SLM is investigated with respect to build orientation and post-fabrication heat treatment. Fatigue fractography are then analyzed and correlated with processing variation. 


\section{CHAPTER 4}

\section{THE EFFECT OF PROCESSING PARAMETERS ON MICROSTRUCTURES AND PHYSICAL PROPERTIES OF SELECTIVE LASER MELTED SUPERALLOY INCONEL 625}

\subsection{Introduction}

Selective Laser Melting (SLM), a metal based Additive Manufacturing (AM) process which uses a high-intensity laser beam to melt and solidify successive layers of metal powder on top of each other $[50,51]$. SLM offers several advantages compared to conventional production techniques, such as ability to produce complex shape, a high level of flexibility, a near net shape production and a high material use efficiency [52]. Despite the benefits, SLM is a very complicated process where the quality of the parts depends on a large number of processing parameters. Mechanical properties of the parts manufactured by SLM depends on the microstructure of the part which are controlled by the processing parameters. Porous defects and their morphology also influence the properties of SLM parts, can be controlled by the processing parameters [53].

Recent investigations have focused on understanding the effects of processing parameters on the evolution of microstructure and the porosity formation in SLM. The effect of process parameters on structure-property relationships for iron-based powder [54], steel alloys [53, 55], Titanium alloys [56], and Ni-based alloys [57-59] have been 
reported and highlighted that even minor changes in processing parameters can have large effects on the final part properties.

Inconel 625, a nickel-based super alloy is well known for its superior properties such as high tensile, creep and rupture strength, excellent fatigue and good oxidation resistance. However, due to excessive tool wear and low material removal rate, this material is difficult to process by conventional machining methods [58]. Selective laser melting, therefore, becomes a possible option for fabricating complex Inconel 625 parts. In SLM, process parameters are known to have a significant effect on the resulting microstructure and mechanical properties. Therefore it is essential to understand the process-microstructure-properly correlation of the parts.

In SLM, the laser beam melts the powder and solidifies a thin track of material. When the track deposit is repeated with a well-defined overlap, a layer is formed. Layerby-layer iteration leads to part fabrication. Therefore, studying single track deposit is cruesial as it leads to the deeper understanding of the SLM process. This study can also contribute to finding a process window for processing new alloys.

The present study is focused on the fabrication of single track deposits using varying laser power and scan speed. The information was then used to create a process parameter map and finding an optimum process parameter window. In this study, instead of a mild steel base plate (usual substrate in SLM), single tracks were built on rectangular pads of the same material which is less costly and more appropriate for the study. Also, depending on the substrate, thermal history can be different which can change melt pool shape and size. The present study also investigates the effect of laser energy by varying process parameters on porosity, microstructure, and hardness in Inconel 625 cubes. 


\subsection{Experimental Procedure}

\subsubsection{Material specifications}

The material used in the current investigation was gas atomized Inconel 625 powder supplied by EOS GmbH. The morphology of the powder particles was characterized by a Zeiss Supra 35 Scanning Electron Microscope (SEM). Size distribution of the particles was analyzed using a Microtrac S3000 laser-based particle size analyzer. The particles have a spherical shape with a homogeneous size distribution between $15 \mu \mathrm{m}$ and $50 \mu \mathrm{m}$. SEM image in figure 1 shows the gas atomized particles. A high magnification image shows the microdendritic structure of the particles (figure 1 (b)). The chemical composition of the as-built Inconel 625 sample is listed in Table 1.
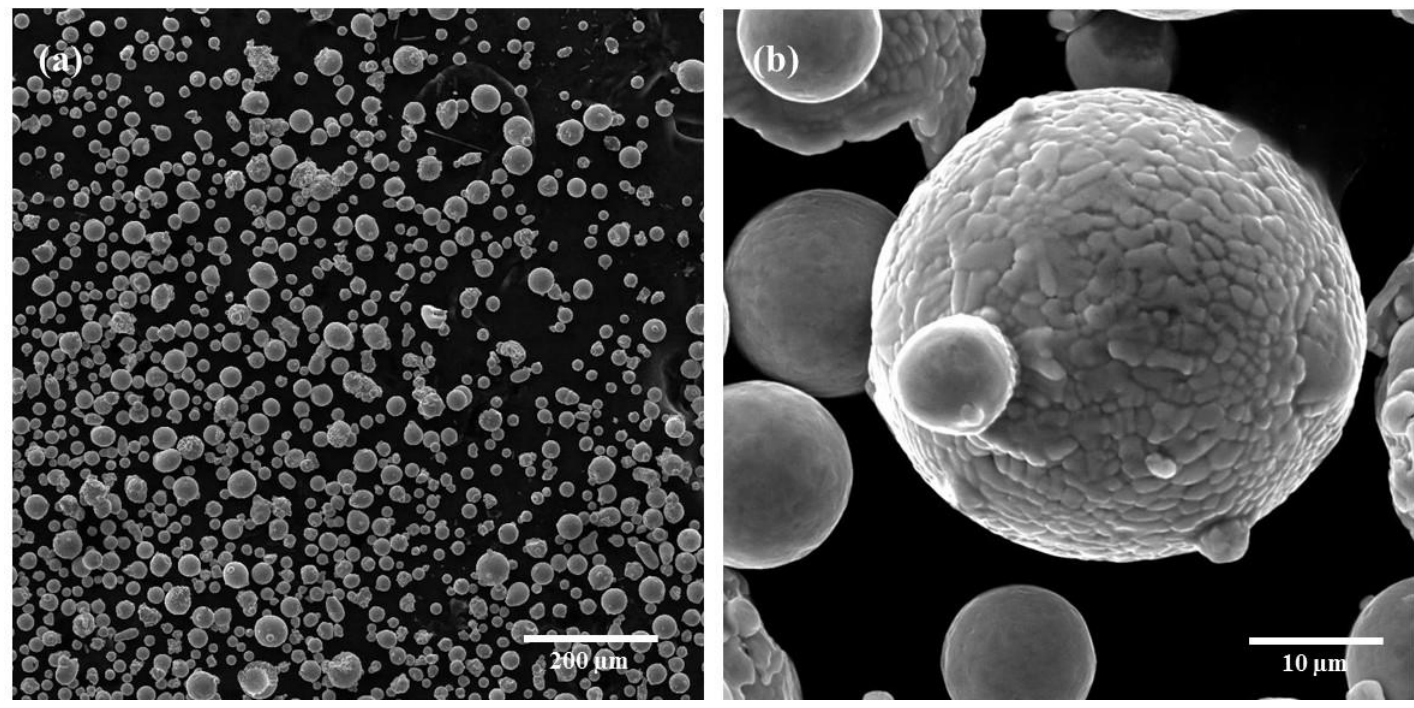

Figure 4. 1: (a) Scanning electron micrograph of Inconel 625 powders (b) High magnification image showing dendritic features 
Table 4. 1: Elemental composition analysis of the Inconel 625 as-built deposit carried out using optical emission spectroscopy.

\begin{tabular}{lll}
\hline Element & As-built IN625 (Wt. \%) & $\begin{array}{l}\text { UNS-N-06625 IN625 } \\
\text { Requirements (Wt. \%) }\end{array}$ \\
\hline Aluminum & 0.31 & 0.40 Maximum \\
Carbon & 0.02 & 0.10 Maximum \\
Columbium & 4.09 & $3.15-4.15$ \\
Chromium & 21.49 & $20.0-23.0$ \\
Iron & 0.68 & 5.0 Maximum \\
Manganese & 0.05 & 0.50 Maximum \\
Molybdenum & 8.34 & $8.0-10.0$ \\
Phosphorus & $<0.005$ & 0.015 Maximum \\
Sulfur & $<0.005$ & 0.015 Maximum \\
Silicon & 0.10 & 0.50 Maximum \\
Titanium & 0.34 & 0.40 Maximum \\
Cobalt & 0.22 & ---- \\
Copper & 0.01 & ---- \\
Tungsten & 0.01 & ---- \\
Vanadium & 0.01 & ---- \\
Nickel & Remainder & Remainder \\
\hline
\end{tabular}

\subsubsection{Processing parameters}

Single track and rectangular coupons were produced using the EOS M270 Direct Metal Laser Sintering (DMLS) system. The EOS M270 uses a Yb-fiber laser with a maximum power of $200 \mathrm{~W}$ and a beam diameter of $100 \mu \mathrm{m}$. For a process with fixed layer thickness and laser optic characteristics, the laser power, scan speed and hatch spacing 
are three influencing energy input factors that determine the melt pool and thus microstructure and physical properties.

Table 4.2 shows the various levels of laser power and scan speed which were used to form single track deposites on substrate pad. A schematic of pad layout with single bead lines are shown in figure 4.2. A single pad contains six single beads of six different speed levels but same power level. For 7 power levels, 7 pads were built. Therefore, a total of 42 single track beads were made on these pads. The single line scans were placed at $5 \mathrm{~mm}$ apart from each other. A picture of the single track deposits made on the pads is shown in figure 4.3. The pads were built using the default parameter sets provided by EOS for Inconel 625. A layer thickness was $20 \mu \mathrm{m}$ for all the SLM builds. The process chamber was purged with Argon gas to avoid oxidation. Operational temperature of the internal chamber was fixed at $80{ }^{\circ} \mathrm{C}$

Table 4. 2: Factors and levels of experimental design for single beads.

\begin{tabular}{|c|c|}
\hline Factor & Level \\
\hline Laser Power $(\mathrm{W})$ & $50,75,100,125,150,175,195$ \\
\hline Scan Speed $(\mathrm{mm} / \mathrm{s})$ & $200,400,600,800,1000,1200$ \\
\hline
\end{tabular}




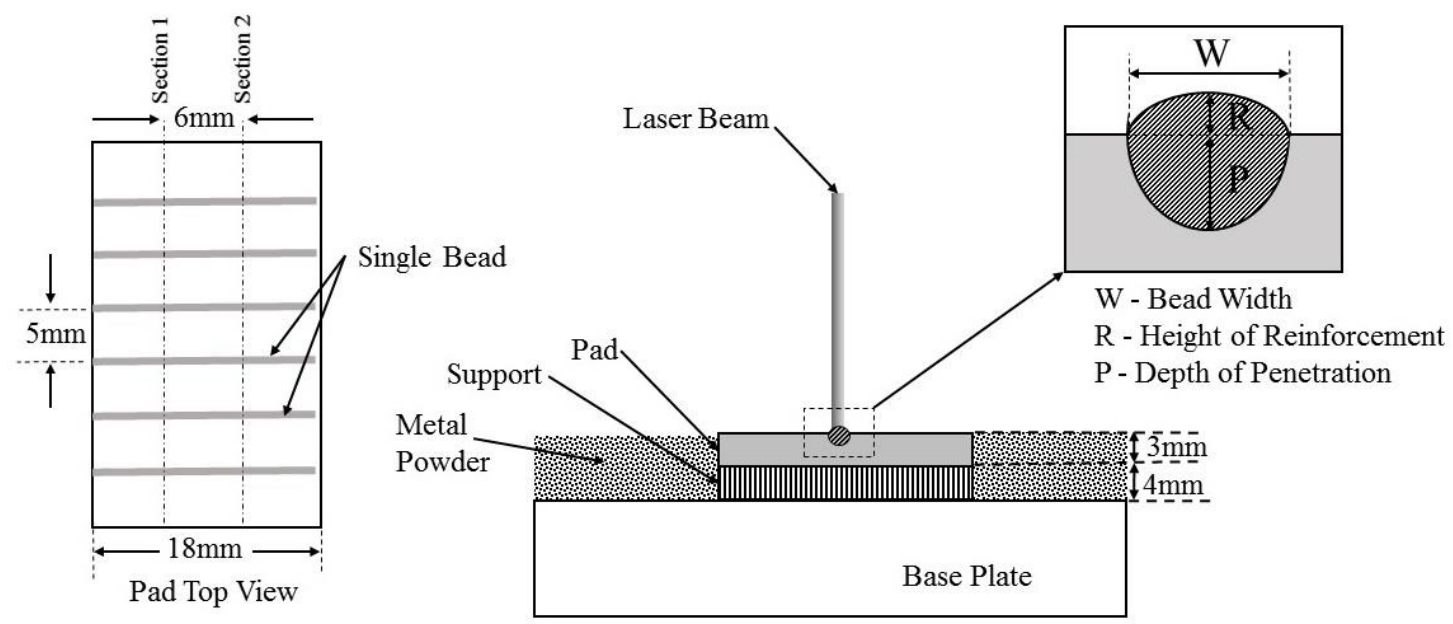

Figure 4. 2: Schematic showing pad layout with horizontal single bead lines and crosssection of laser melted track.

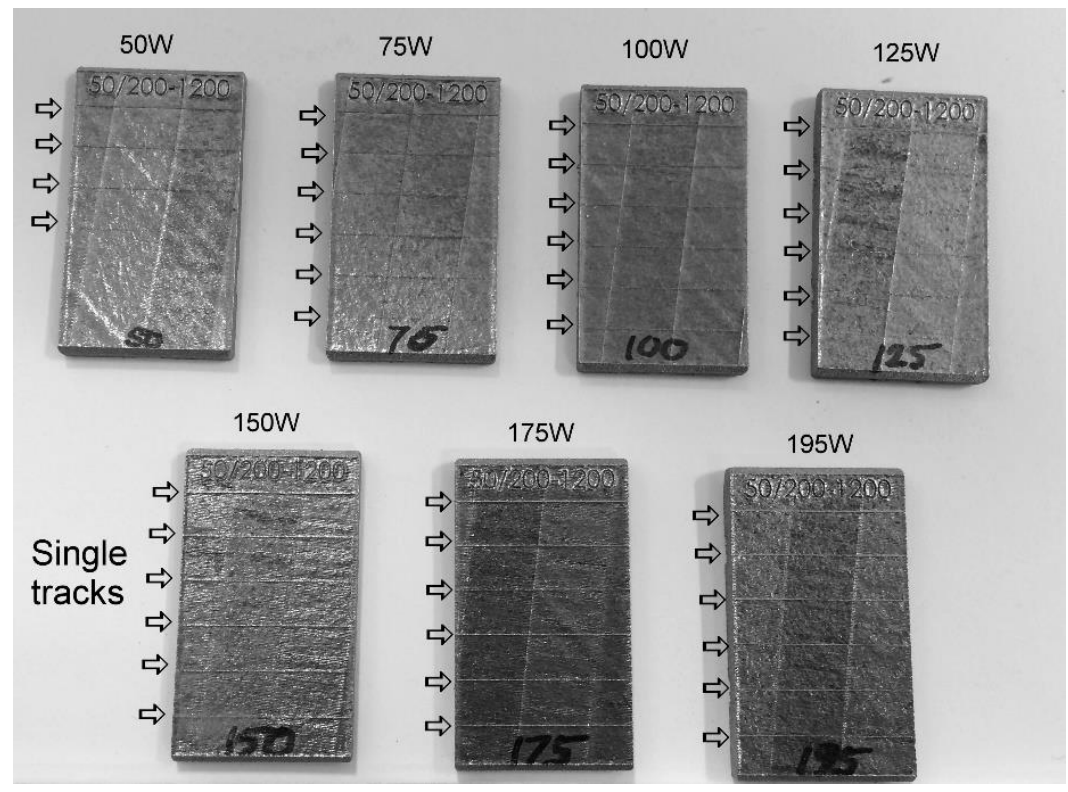

Figure 4. 3: Photograph of the single track deposits made on pad substrate. Arrows indicate single track deposits. 


\subsubsection{Process of building single track on rectangular pad}

In EOS M270 machine, minimum feature can be achieved by using the support structure which is not possible by using direct part. In case of a line support, laser only scan single pass thus the thickness of the line becomes one melt-pool thickness. Utilizing line support structure single bead can be produced.

To ensure a flat surface with respect to scanning surface the rectangular pads were built up from the baseplate as a substrate for the single bead. The outer edge of the pad was supported by a solid support of height $4 \mathrm{~mm}$ and thickness $1.5 \mathrm{~mm}$. The thickness of the pad is $3 \mathrm{~mm}$ on top of the support. The total system forms a rectangular box. The remaining overhanging surface of the pad was supported by conventional block support. Figure 4.4 (a) and (b) shows different views of rectangular pad and solid support.
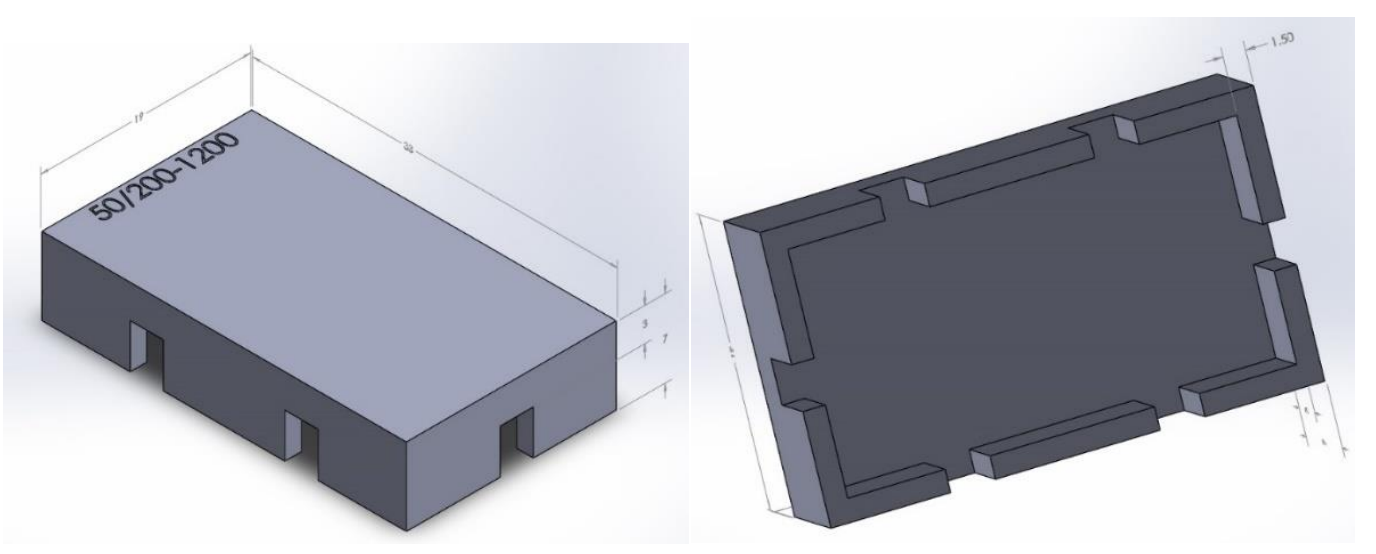

Figure 4. 4: (a) Top surface of the pad with solid support. (b) Bottom surface of the pad showing solid support of thickness $1.5 \mathrm{~mm}$. 
Rectangular thin walls of dimension $15 \mathrm{~mm} \times 0.1 \mathrm{~mm} \times 0.06 \mathrm{~mm}$ were made using Magics software and placed on top of the pad (figure 4.5 (a)). These are the sacrificial parts and only used to make single line support structure beneath the surface of these thin wall. Figure 4.5 (b) shows a line support which was created under the thin wall. Figure 4.5 (c) shows an array of line support. The overhanging surface of the pad were then filled with conventional block support (figure 4.5 (d)).
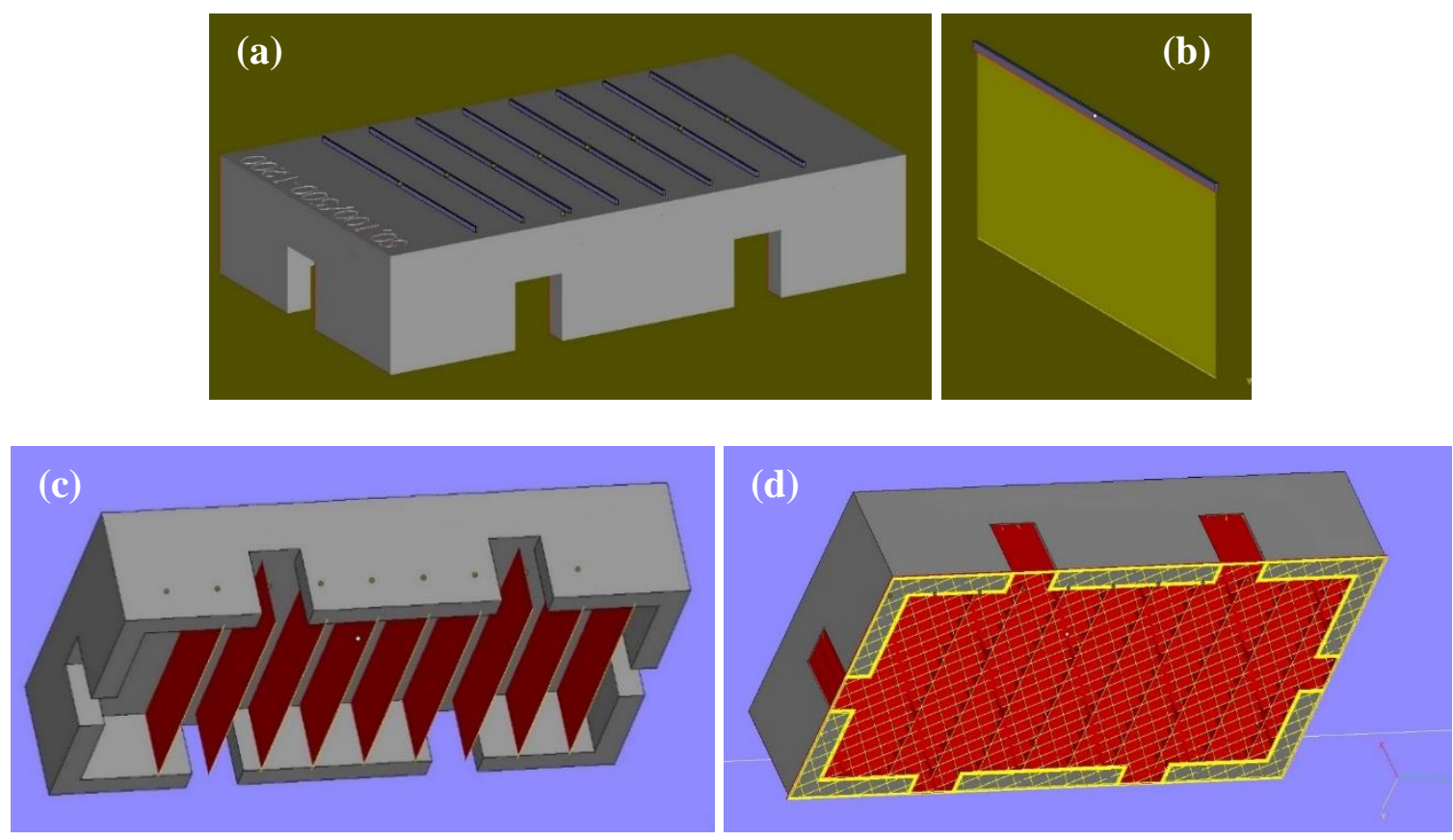

Figure 4. 5: (a) Sacrificial thin walls were placed on top of the pad. (b) A single line support beneath the sacrificial thin walled part. (c) An array of line support beneath the sacrificial part. (d) Conventional block support supports the overhanging region.

Once the line support has been created the thin walls on top of the pad were deleted or put to no exposure parameter. Appropriate parameters (laser power and scan speed) were applied to the line support. Upon laser scanning, the line support produces a thin wall of width one meltpool. Therefore, in each new layer there will be a single track 
for each line support. During the final layer, the pad parameters were set to 'no exposure' thus only single beads were exposed in a single layer of power.

\subsubsection{Microstructural characterization and porosity measurements}

Top surface and cross-section of the pads were prepared for microstructural analysis of single track. Top surfaces of the tracks were examined in as-built condition under SEM to understand laser track morphology. Cross-sections after polishing were etched using Kalling's reagent $\left(\mathrm{CuCl}_{2} 5 \mathrm{gm}\right.$, Ethanol $\left.100 \mathrm{ml}, \mathrm{HCl} 100 \mathrm{ml}\right)$ and examined under an optical microscope.

A $7 \times 6$ test matrix of $10 \times 10 \times 10 \mathrm{~mm}^{3}$ cubes was built using the parameters listed in Table 2. These samples were used in porosity measurements per ASTM E-562. As built top surfaces of the cube samples were examined under SEM for laser track morphology. These samples were then polished and examined under optical microscopy for porosity analysis. Later, the cross-sections of the cube samples were polished and etched using Kalling's reagent for melt pool morphology.

\subsubsection{Hardness measurement}

The hardness values were measured at five locations per cube and obtained using Vickers indenter on a micro-hardness machine (Shimadzu HMV-G) at a load of $500 \mathrm{gf}$ and $15 \mathrm{~s}$ dwell time. 


\subsection{Results and discussion}

\subsubsection{Surface morphology of single track}

Laser energy density strongly influences the surface morphology of the single bead and thus the quality of the SLM part [60]. Energy density, E $\left(\mathrm{J} / \mathrm{mm}^{3}\right)$ in SLM which is a measure of the averaged applied energy per volume of material during the scanning of a layer, can be expressed by the equation (1), where $\mathrm{P}$ is laser power (W), $\mathrm{v}$ is the scan speed $(\mathrm{mm} / \mathrm{s}), \mathrm{h}$ is hatch spacing $(\mathrm{mm})$ and $\mathrm{t}$ is layer thickness $(\mathrm{mm})[34,61]$.

$$
E=\frac{P}{v * h * t}
$$

The combination of laser power and scan speed has a significant influence on meltpool stability of the scan track $[53,55,62]$. Higher laser power and lower scan speed generate higher energy density on the surface. Because of the lower scan speed the interaction time between laser beam and materials becomes longer. The excessive amount of energy absorbed by the materials during this time leads to increased peak surface temperature of the molten pool. Higher temperature gradient results in instability in the solid-liquid surface, hence obtaining a scan track with fluctuating profile and segregation [63]. In addition, due to very high power and slow scanning speed the material might get superheated which may cause evaporation and mass loss of material. On the contrary, lesser energy is absorbed by the materials at lower laser power and higher scan speed. At a given power, when the speed exceeds a critical value, the elongated molten pool becomes more unstable and could split into fragments to attain the equilibrium shape driven by Plateau-Rayleigh instability [64-66]. 
$200 \mathrm{~mm} / \mathrm{s} \quad 400 \mathrm{~mm} / \mathrm{s} \quad 600 \mathrm{~mm} / \mathrm{s} \quad 800 \mathrm{~mm} / \mathrm{s} \quad 1000 \mathrm{~mm} / \mathrm{s} \quad 1200 \mathrm{~mm} / \mathrm{s}$

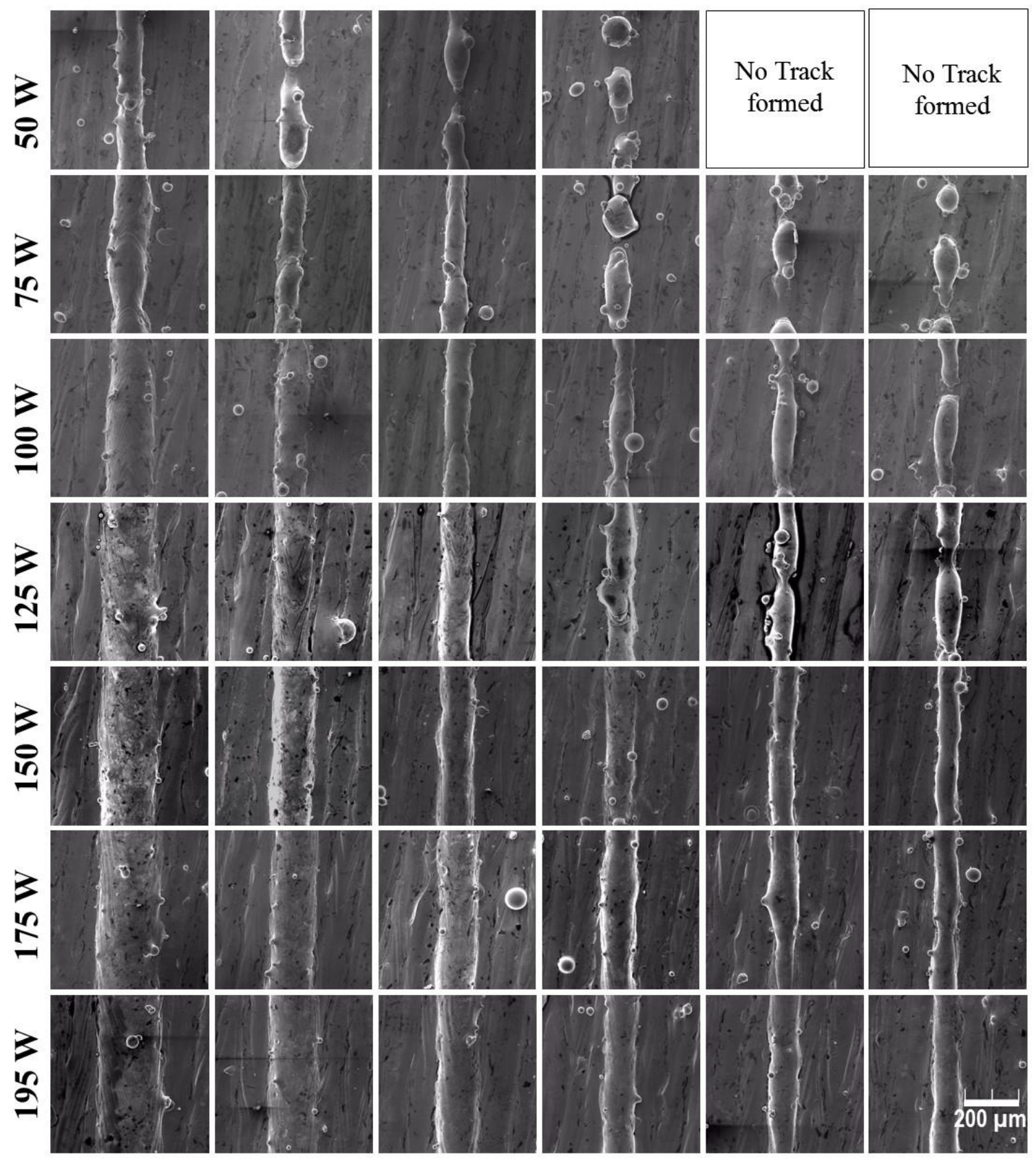

Figure 4. 6: SEM micrographs of the top surface of the single track deposits produced using various process parameters (laser power, scan speed).

Figure 4.6 shows SEM micrographs of the top surface of the single track deposits produced using various process parameters (laser power, scan speed). Under low power 
$(50 \mathrm{~W})$ and low speed $(200 \mathrm{~mm} / \mathrm{s})$ with a moderate energy density $\left(125 \mathrm{~J} / \mathrm{mm}^{3}\right)$, the scan track exhibits a continuous and uniform deposit. As the scan speed increases, the energy density decreases and the deposit become discontinuous due to the balling effect. For 50 W power, the discontinuity begins from $400 \mathrm{~mm} / \mathrm{s}\left(\right.$ E. $63 \mathrm{~J} / \mathrm{mm}^{3}$ ). At the scanning speed of $1000 \mathrm{~mm} / \mathrm{s}$ and $1200 \mathrm{~mm} / \mathrm{s}$ with the power of $50 \mathrm{~W}$, the energy density $\left(20-25 \mathrm{~J} / \mathrm{mm}^{3}\right)$ was too low to form a melted track. On the other hand, under high laser power and low scan speed, the high incident energy causes significant melting of powder resulting in the wider spread of the bead deposit. With an increase in the laser scanning speed, relative heat loss by conduction decreases, and, the absorbed laser energy goes directly into fusing the material. The resulting width of the tracks become comparable to the laser beam diameter [67]. With further increase in scan speed (e.g. speed $>600 \mathrm{~mm} / \mathrm{s}$ for $100 \mathrm{~W}$ and speed $>800 \mathrm{~mm} / \mathrm{s}$ for $125 \mathrm{~W}$ ), the bead surface is observed to have irregular, more rounded shape and bulging upwards, indicating that the surface tension forces of the melt region were dominant due to less melt volume as dwell time of the laser was short $[67,68]$.

\subsubsection{Melt pool characterization}

In SLM, depth of the melt pool is controlled by the applied energy input from the laser. When the laser interacts with the powder particles the skin of the particles absorbed the energy and gets melted. Due to surface tension of the molten material the melted particles then begin to consolidate [69]. The applied energy should be sufficient enough to melt the top layer of the powder as well as some part of the substrate in order to create a good bond between melted layer and the substrate. A good melt pool has a semicircular cross-section where the depth of penetration is about equal to its half-width [70]. Melt 
pools where the depth of penetration is greater than the half width is characterized as keyhole melting. Keyhole is detrimental in this case as it may generate porosity in the lower region of the melt pool. The formation of porosity in the single track deposits is attributed to the collapse of the keyhole. Once the laser beam (heat source) moves farther, the molten metal in the upper part of the keyhole moves downward to fill the keyhole due to gravity and surface tension. During this process, some vapor is entrapped in the lower region of the keyhole, and cannot escape through the melt pool due to rapid solidification of the bead [71].

Figure 4.7 shows the cross-section of single track deposits observed under optical microscopy. The melt pool morphology can be clearly observed from the micrograph. At lower power levels (e.g. $50 \mathrm{~W}$ or $75 \mathrm{~W})$, even with slowest speed $(200 \mathrm{~mm} / \mathrm{s})$, the melt pools were observed to have insufficient penetration depth and balling was prevalent. In this case, the laser was able to melt the powder but did not have sufficient energy to melt the underlying solid material to form a good bond. The melt pool depth was observed to increase significantly for higher power levels (100 to 195W) and lower speeds. Keyhole shape of the melt pool was observed in samples with the power levels $125 \mathrm{~W}$ to $195 \mathrm{~W}$ and scan speed of $200 \mathrm{~mm} / \mathrm{s}$. This parameter range showed porosity in the lower regions of the melt pool (figure 4.8). As the scan speed was increased, the energy density was reduced, which led to lesser volumes of the melted material in the base pad.

Two unusual melt pool profiles were observed for the parameter set 195W$400 \mathrm{~mm} / \mathrm{s}$ and $195 \mathrm{~W}-600 \mathrm{~mm} / \mathrm{s}$ where depth of penetration were less than expected. This may be due to the fluctuation of laser power during scanning at a high power level. The fluctuation is expected to get higher near the maximum power level of the system which 
is $200 \mathrm{~W}$ in this situation. A similar scenario was observed by Gong et al. for selective laser melting of titanium alloy [62]. It was mentioned that the melt pool fluid dynamics at higher energy density could cause instability which may also leads to the inconsistency in melt pools.

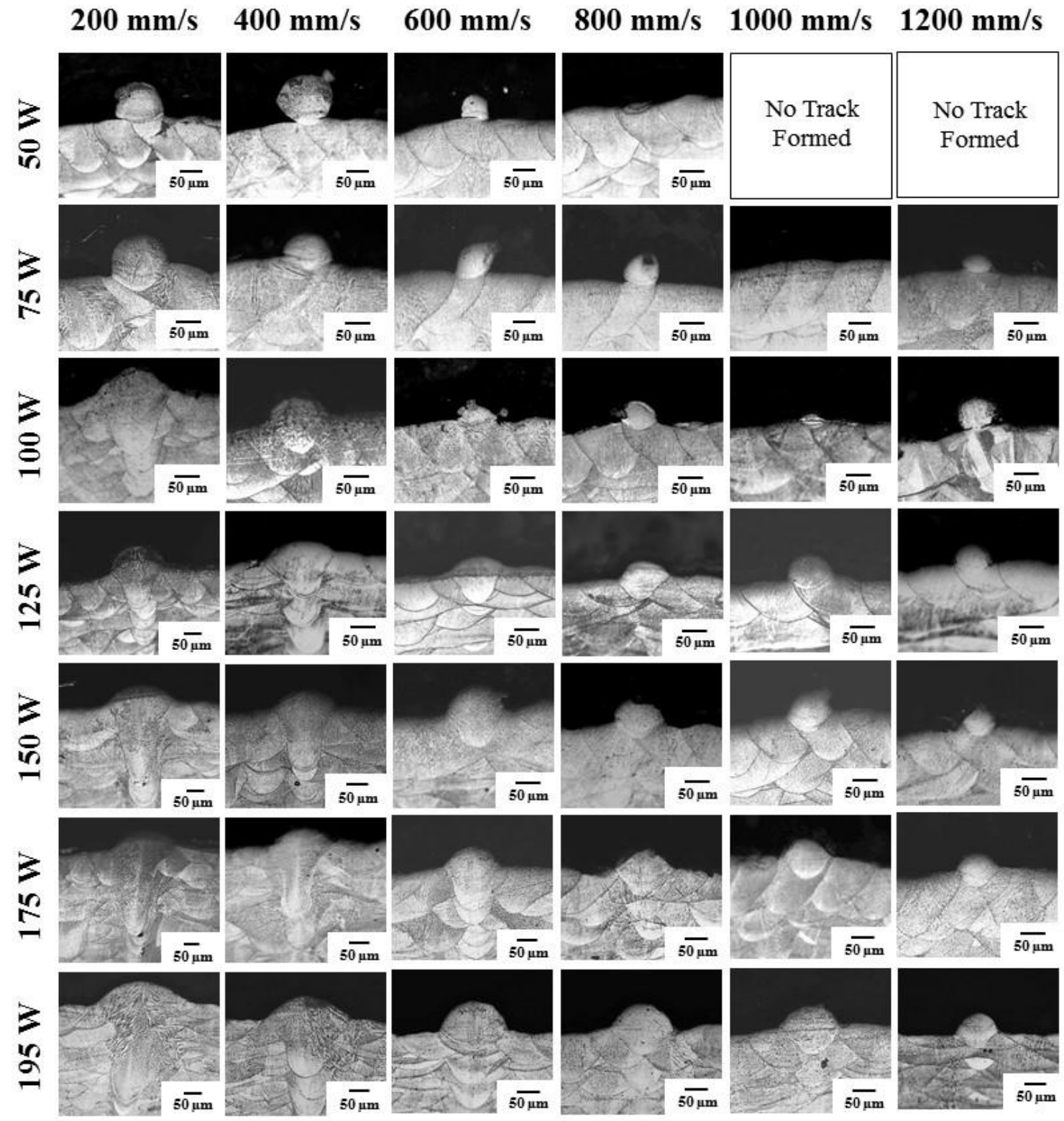

Figure 4. 7: Optical micrographs of the cross-section of the single track deposits produced using various process parameters (laser power, scan speed). 
The semicircular melt pool was observed for power levels $125 \mathrm{~W}$ to $195 \mathrm{~W}$ for medium scan speeds (600 to $1000 \mathrm{~mm} / \mathrm{s}$ ). This shape corresponds to the optimum depth of melt pools. With sufficient overlap and melt pool depth, a process window can be derived. Single track deposit width and depth were measured and the results are plotted in figure 4.9.
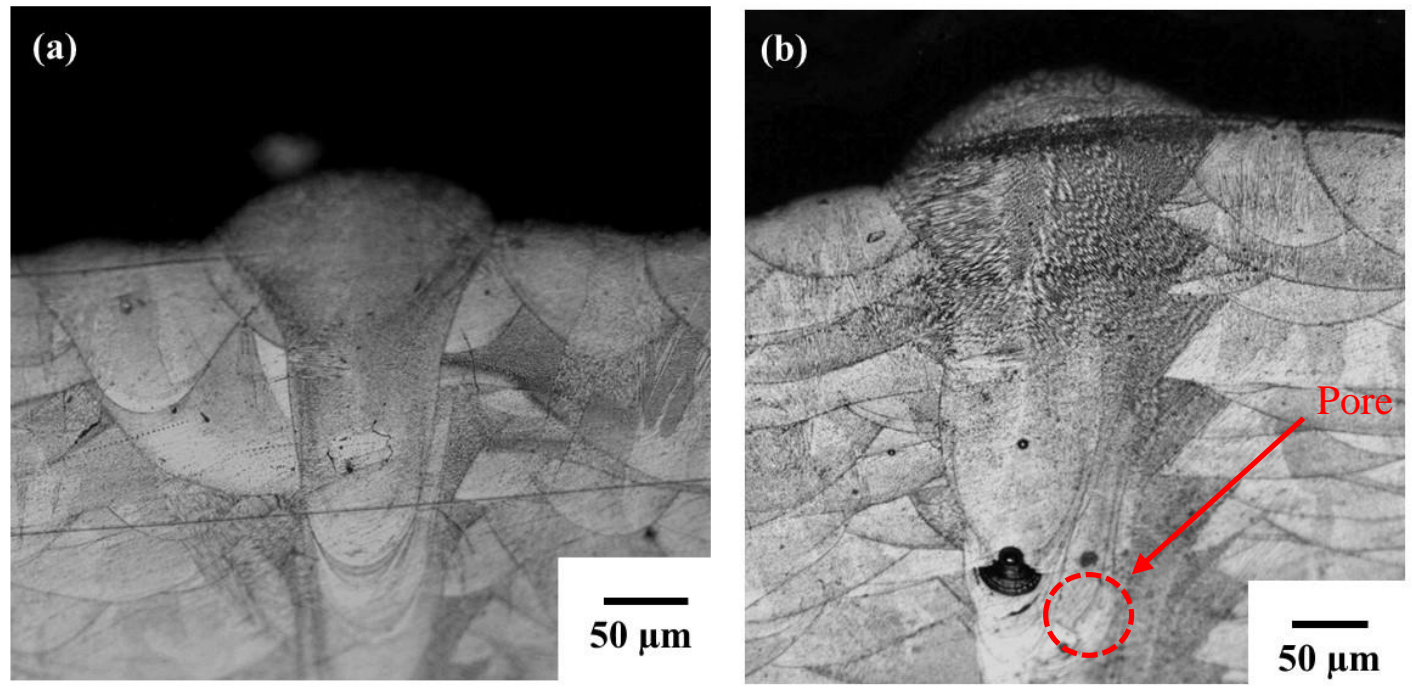

Figure 4. 8: Metallographic cross section of single track deposit showing keyhole melting (a) $150 \mathrm{~W}$ laser power, $200 \mathrm{~mm} / \mathrm{s}$ scan speed, (b) $195 \mathrm{~W}$ laser power, $200 \mathrm{~mm} / \mathrm{s} \mathrm{scan}$ speed. 

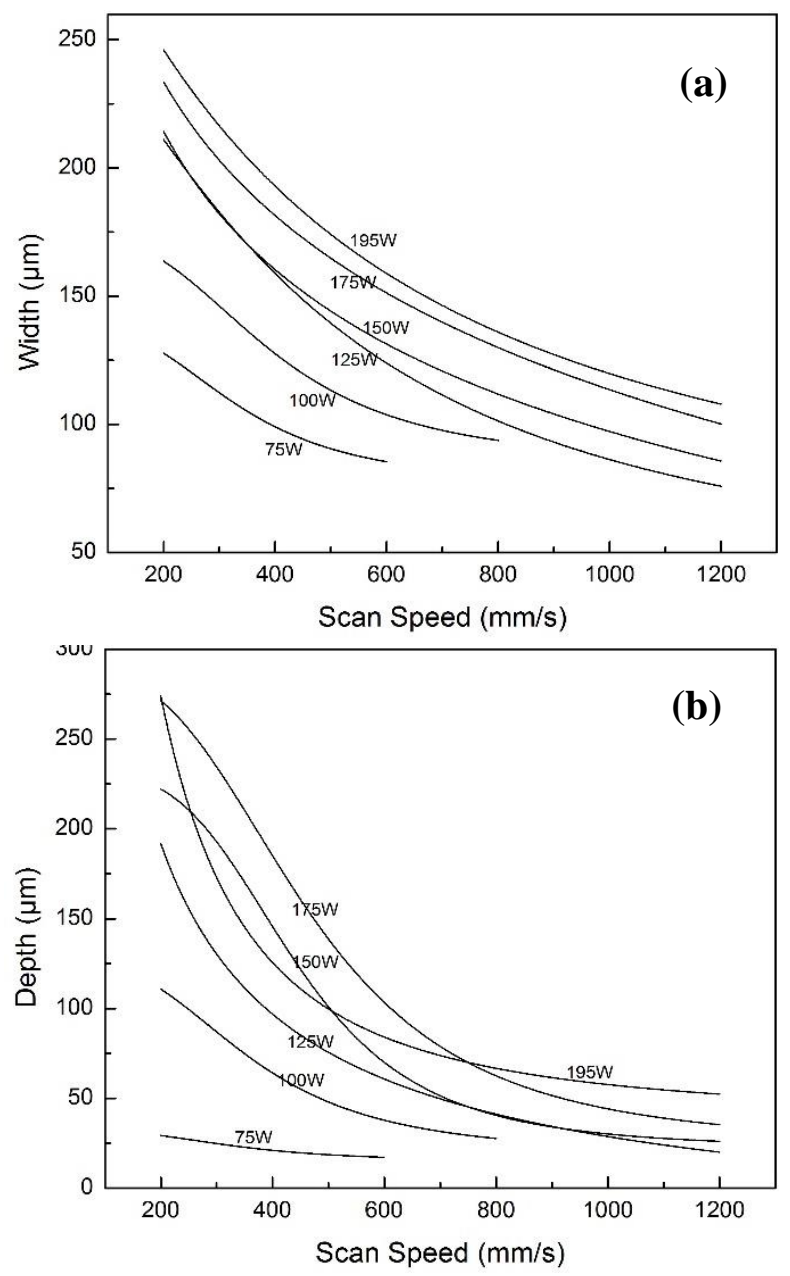

Figure 4. 9: Width and penetration depth of the single beads versus scan speed of laser beam for different power levels.

The relationships between the bead width and laser power to scan speed are plotted in figure 4.9 (a). The results indicate that, for constant power, an increase in speed leads to a decrease in width which is directly associated with the fact that less volume of the powder was melted per unit time. Laser power shows a significant effect on the bead width dimensions. An increase in laser power results in an increase in the width, because of the increase in the energy density. Under low power levels (e.g. 50, 75, $100 \mathrm{~W}$ ), the limited energy density causes insufficient melting or balling. While at higher power level 
(e.g. 125W and above for all speeds) consistent beads were observed. A bead width in between 120 to $160 \mu \mathrm{m}$ was noticed to be suitable for the predefined hatch spacing of $100 \mu \mathrm{m}$ for well-defined overlap.

A similar effect of parameters observed for melt pool depth is presented in figure 4.9 (b). Both laser power and scan speed have a significant effect on depth. When the energy density is high (power $\geq 125 \mathrm{~W}$, speed $\leq 400 \mathrm{~mm} / \mathrm{s}$ ), deeper penetration occurs, penetrating from 5 to 25 layers, and causes a keyhole mode of melting. As the speed increases, energy density decreases, and penetration depth become shallower.

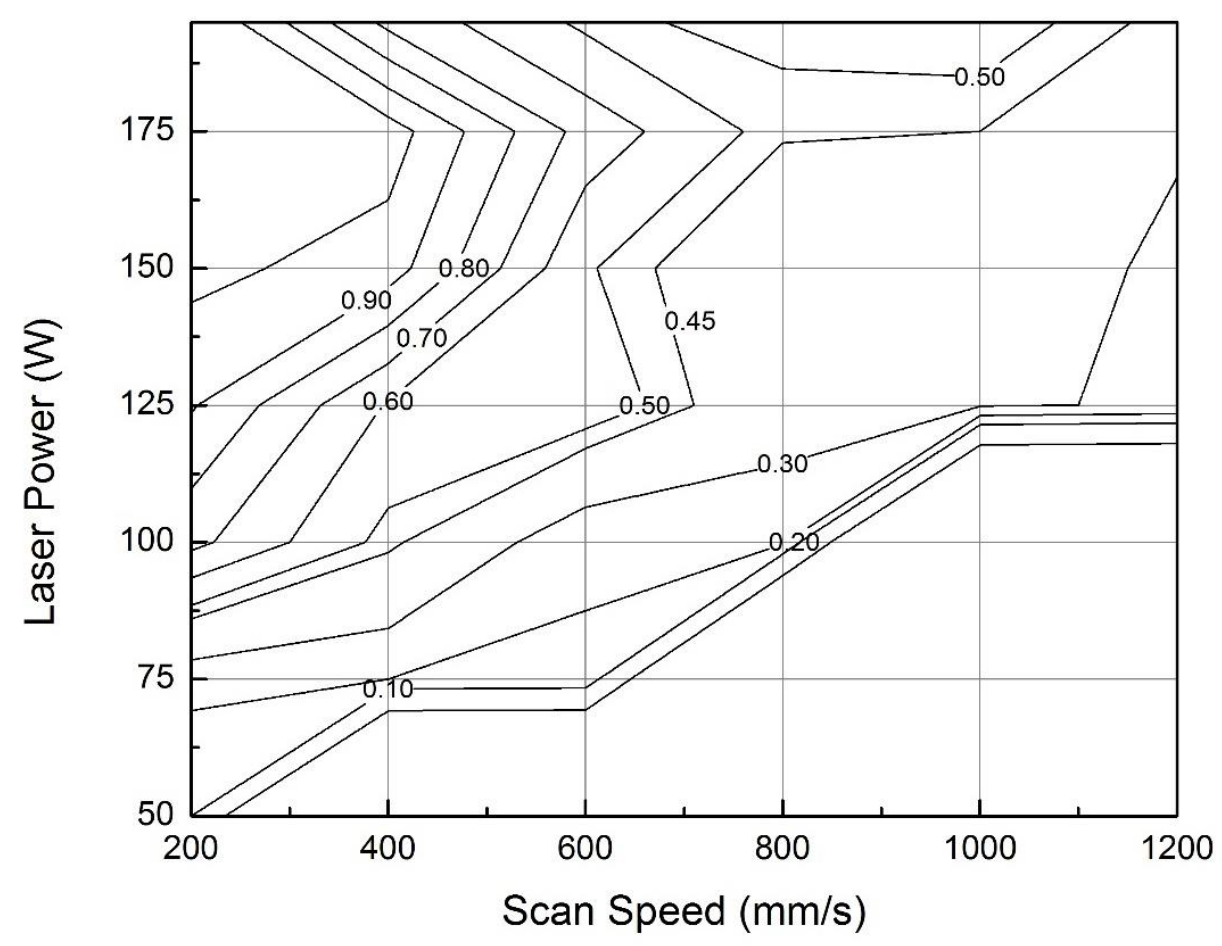

Figure 4. 10: Depth to width ratio as a function of processing parameters (laser power and scan speed)

A process parameter map indicating the effect of laser power and scan speed on the single track depth to width ratio is shown in figure 4.10. This map can help to identify 
optimum sets of parameters that can produce parts with minimum defect. For example, it may be desirable to keep a higher penetration depth to form a good bond with the substrate, however one should avoid forming keyhole melting. Depth to width ratio greater than 0.6 may produce keyhole effect and thus may result in excessive amount of porosities. For the ratios between 0.45 and 0.6 , the depth of penetration spans 2-3 layer thickness, which ensures proper fusion with the substrate and minimum to zero porosity.

\subsubsection{Porosity}

Porosity is a common defect in additive manufactured parts, and can often be minimized by optimizing the processing parameters [53]. Numerous studies have been performed to understand the effect of processing parameters on the porosity of additive manufactured parts [72-75] but very few were performed on Inconel 625. Yadroitsev et al. have analyzed the effect of hatch distance on the porosity of laser melted Inconel 625 parts [76]. Dinda et al. used a direct metal deposition technique to fabricate a series of Inconel 625 samples and showed that parameters can be optimized to obtain defect-free, fully dense parts [11].

Cube samples produced using various process parameters were analyzed for porosity. Figure 4.11 shows the as-polished cross-sections of the as-built cubes along with their processing parameters (laser power and scan speed). Due to excessive balling in the cubes with parameter $100 \mathrm{~W}-200 \mathrm{~mm} / \mathrm{s}$, only $1 \mathrm{~mm}$ of height was achieved with the sample. Other cubes were built successfully. 


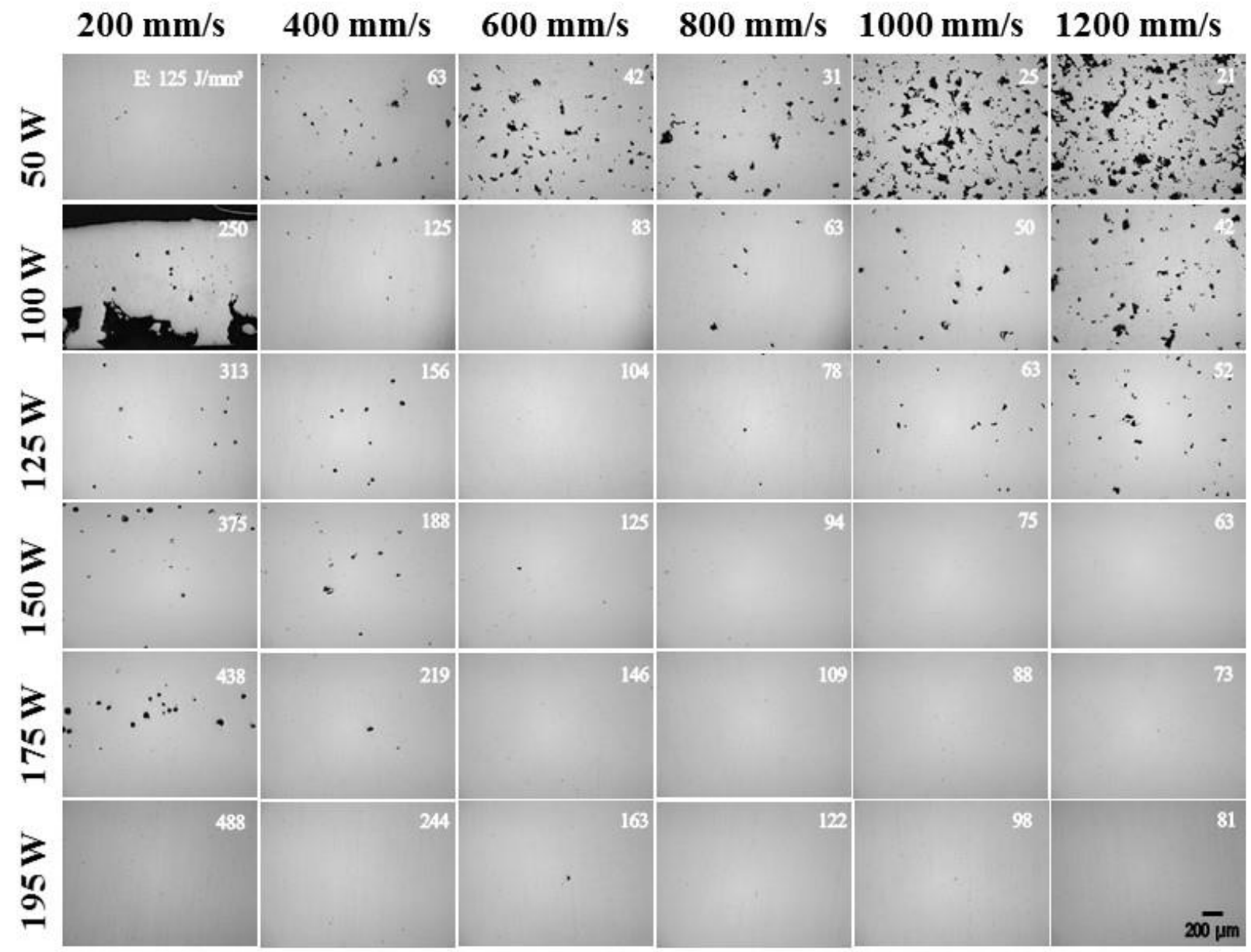

Figure 4. 11: Optical micrographs of the polished cross-section of the cubes produced using various process parameters (laser power, scan speed). The input energy density values are mentioned on top of each micrograph. 


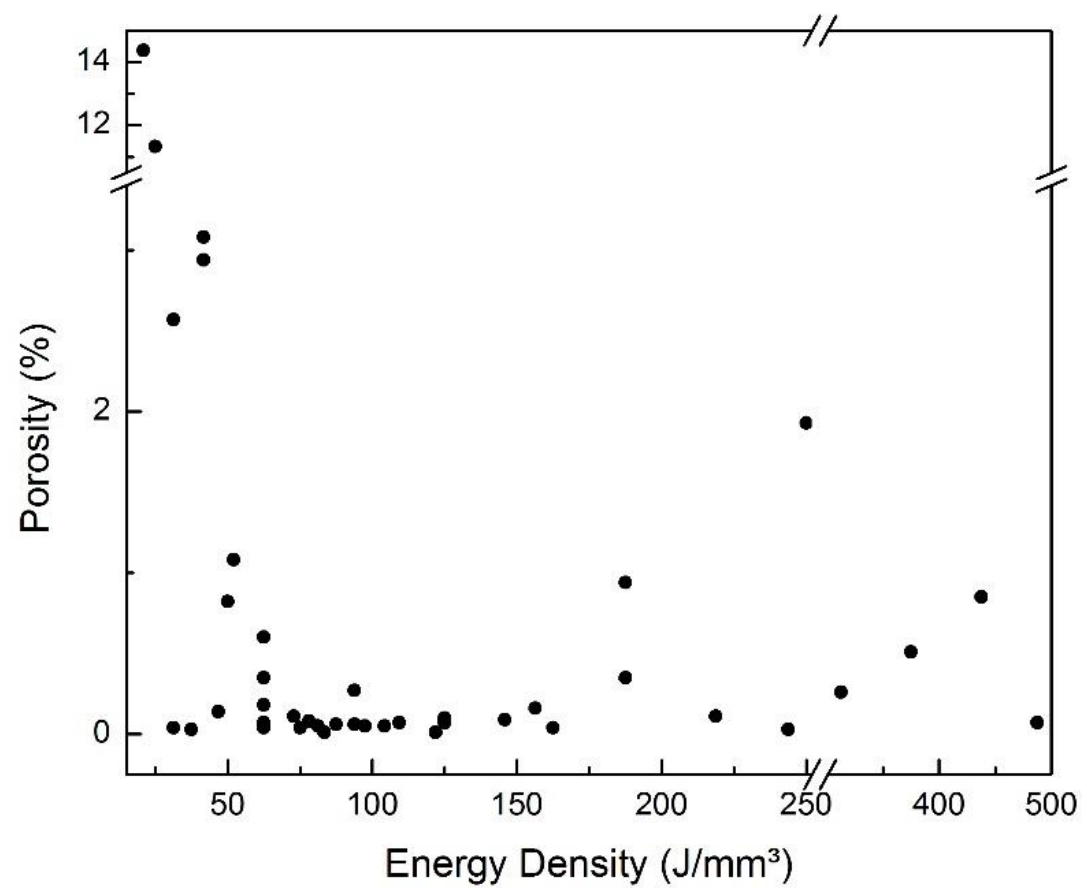

Figure 4. 12: Porosity versus input energy density.

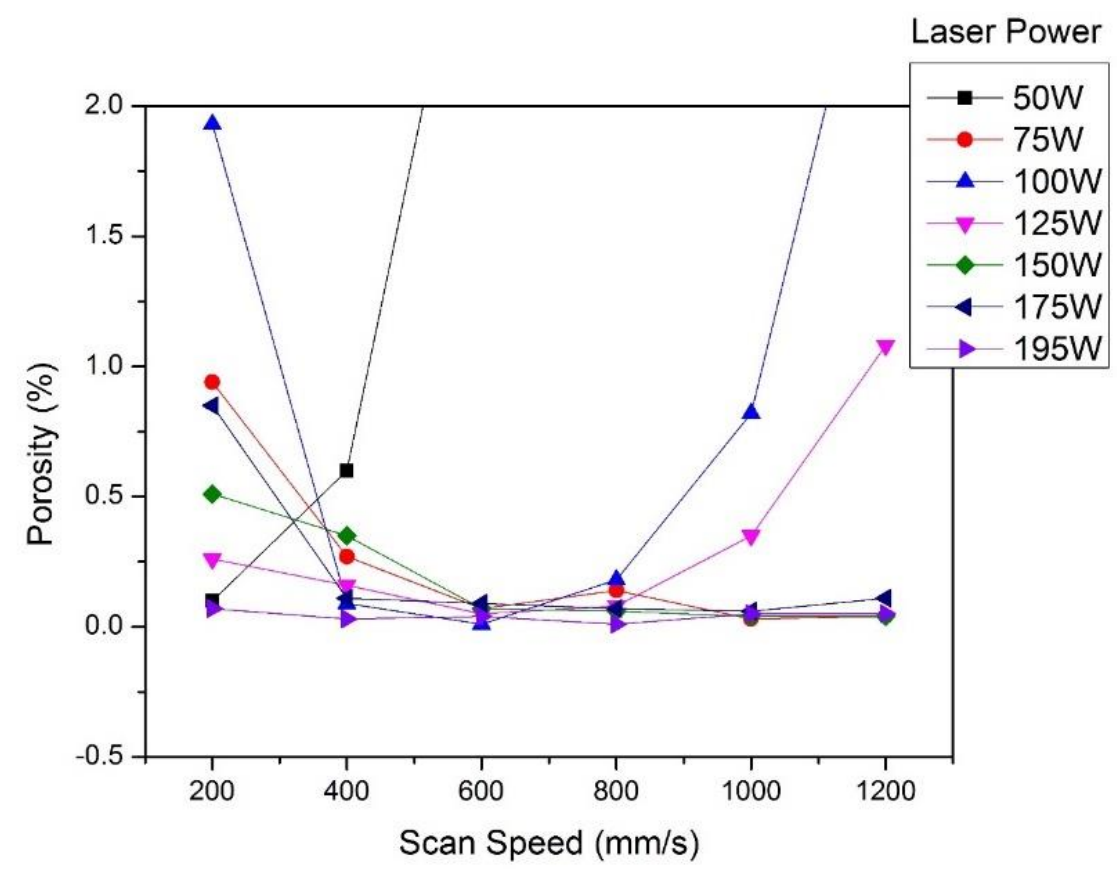

Figure 4. 13: Porosity for various processing parameters (Laser power, scan speed). 
The effect of input energy density on porosity was determined from the cubes and is shown in figure 4.12. It is observed that lower level of energy density $\left(<70 \mathrm{~J} / \mathrm{mm}^{3}\right)$ provides a higher level of porosity and it achieves maximum level (14.5\%) at the lowest energy density $\left(21 \mathrm{~J} / \mathrm{mm}^{3}\right)$. At this level, the pores are broadly dispersed, irregular in shape and interconnected (figure 4.14a). It was also noticed that there exist large cavities of size around $200 \mu \mathrm{m}$ that are filled with loosely held particles (figure $4.14 \mathrm{~b}$, c). It is also clear from the SEM micrograph that the laser tracks are not wide enough to overlap with each other and particles are entrapped in between the tracks. The entrapped particles come from un-melted and partially melted powder particles. This situation arises due to the low energy density that causes insufficient melting and balling.

Increasing energy density from $70 \mathrm{~J} / \mathrm{mm}^{3}$ significantly decreases porosity and at the energy density range of $90-125 \mathrm{~J} / \mathrm{mm}^{3}$ the porosity was found to achieve minimum $(<0.1 \%)$ (Figure $4.15 \mathrm{a}, \mathrm{b})$. When the energy density reaches at a significant level $(>90$ $\mathrm{J} / \mathrm{mm}^{3}$ ) sufficient amount of overlap occur in width and depth that decreases the chance of leaving un-melted particles hence part density increases.

Increasing the energy density further from $125 \mathrm{~J} / \mathrm{mm}^{3}$ results in porosity increase. At this level, the sample shows rounded porosity which is a result of the keyhole effect during the process (Figure $4.15 \mathrm{c}$, d). Low melting elements and contaminants such as oxides or moisture present on the powder particles can become the source of rounded porosity. These contaminants can vaporize due to higher energy density. The vaporized gas then become entrapped and leave behind the pores [77, 78]. Beside gaseous pores, micro shrinkage porosity can also present in melt pools formed with higher energy 
density as larger melt pools are more susceptible to solidification micro shrinkage porosity [53].

Porosity calculated from the cubes is plotted in figure 4.13. It is observed that for low scanning speed $(<600 \mathrm{~mm} / \mathrm{s})$, porosity is higher. This is due to the keyhole effect. On the other hand, for moderate scanning speed (e.g. 600 and $800 \mathrm{~mm} / \mathrm{s}$ ), most of the cube samples show very low porosity. A further increase in scanning speed, porosity increases again. Higher scanning speed $(>800 \mathrm{~mm} / \mathrm{s})$ with laser power less than $150 \mathrm{~W}$ produce insufficient energy that in turn causes shallower and thinner laser tracks and leaves unmelted and partially melted particles.
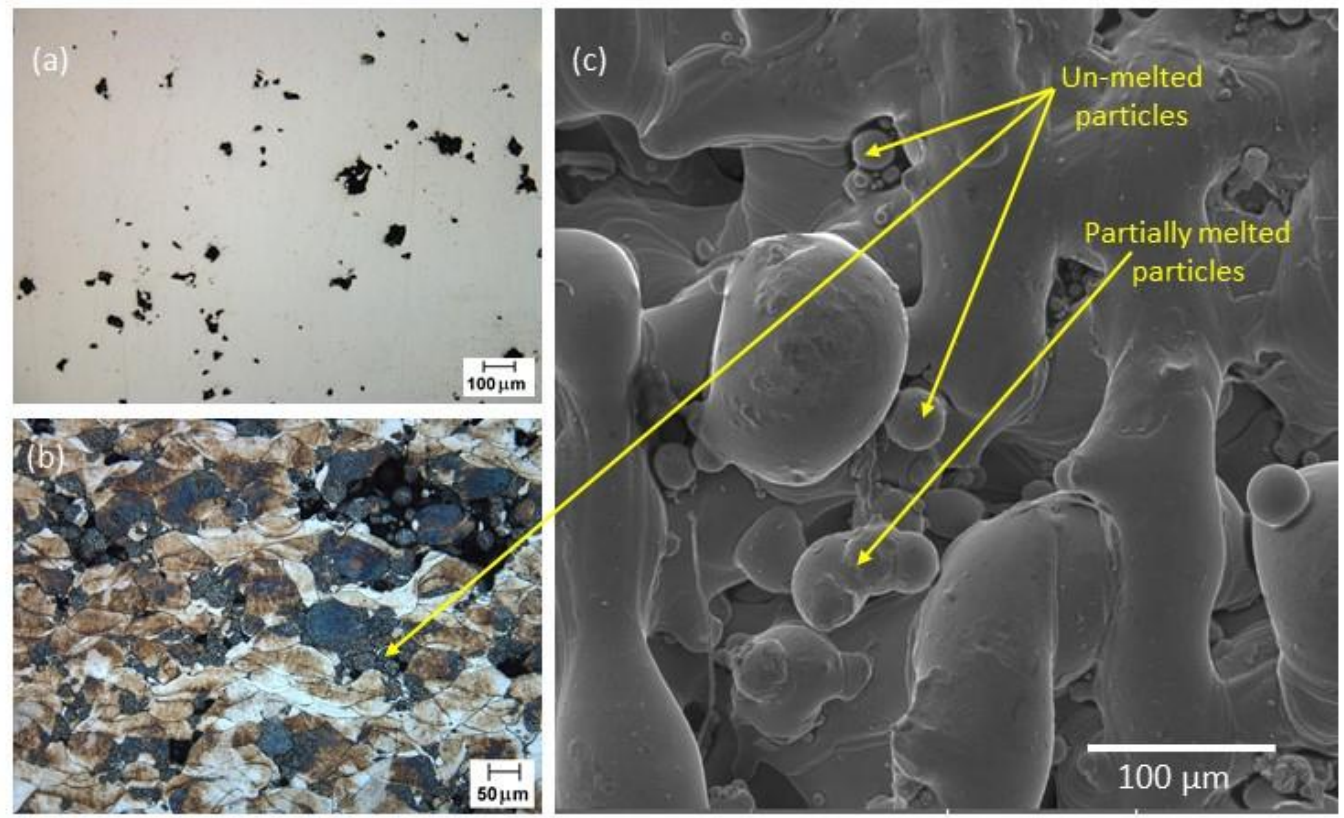

Figure 4. 14: Micrograph showing porosity. Parameter: 50W-800mm/s, E. 31J/mm 3 (a) OM of as polished un-etched cross-section, (b) polished and etched cross-section, (c) SEM of top surface 

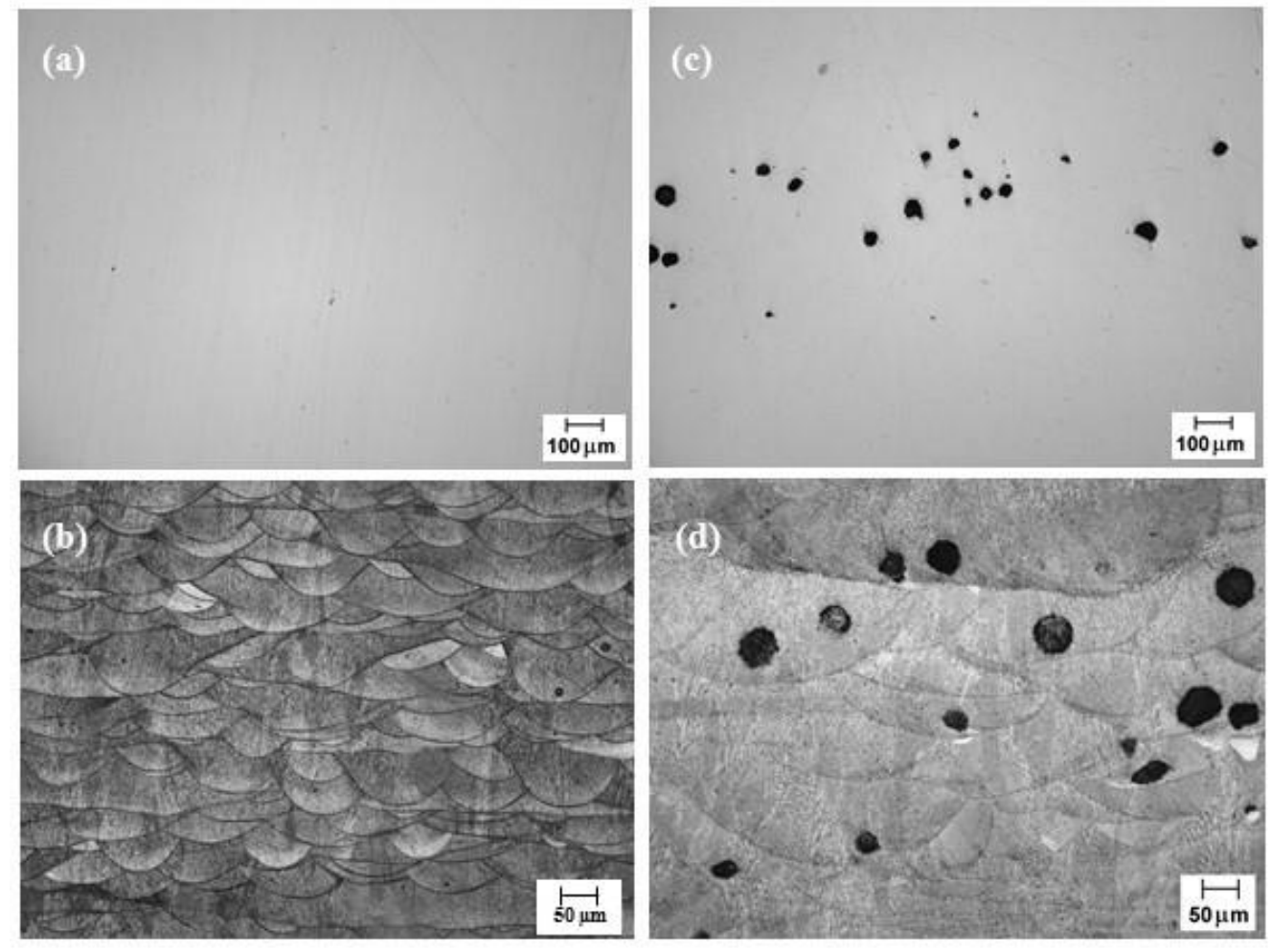

Figure 4. 15: Optical micrographs for porosity; (a \& b) 195W-800mm/s, E. $122 \mathrm{~J} / \mathrm{mm}^{3}$ (a) as polished cross-section, (b) polished and etched cross-section. (c \& d) $175 \mathrm{~W}-200 \mathrm{~mm} / \mathrm{s}$, E. $438 \mathrm{~J} / \mathrm{mm}^{3}$ (c) as polished un-etched cross-section, (d) polished and etched crosssection.

\subsubsection{Hardness}

Microhardness was measured for 42 cube samples and the values are plotted in figure 4.16. The figure shows the hardness values for different energy densities. Hardness is low at low energy but increases with increase of energy density. A higher level of hardness $(325-335 \mathrm{HV})$ was observed for the energy density range of $90-125 \mathrm{~J} / \mathrm{mm}^{3}$. It is because this level of energy density provides parts with minimum porosity. Further increase in energy density display a reduction in material hardness. It is also important to notice the deviation of hardness values at different energy range. Higher deviation was 
observed in both lower $\left(<70 \mathrm{~J} / \mathrm{mm}^{3}\right)$ and higher $\left(>150 \mathrm{~J} / \mathrm{mm}^{3}\right)$ energy level whereas medium $\left(70-150 \mathrm{~J} / \mathrm{mm}^{3}\right)$ energy level shows less deviation. Lower hardness value was observed when indenter interferes with pores (figure 4.17), while higher hardness value was observed when the indenter is applied on the fully dense surface. In both lower and higher energy levels, porosity is higher and distributed uniformly. Therefore, when picked randomly, there is a higher possibility that the indenter can interfere with pores, which yields higher deviations. For medium energy levels, parts have lower porosity, therefore, exhibit less deviation.

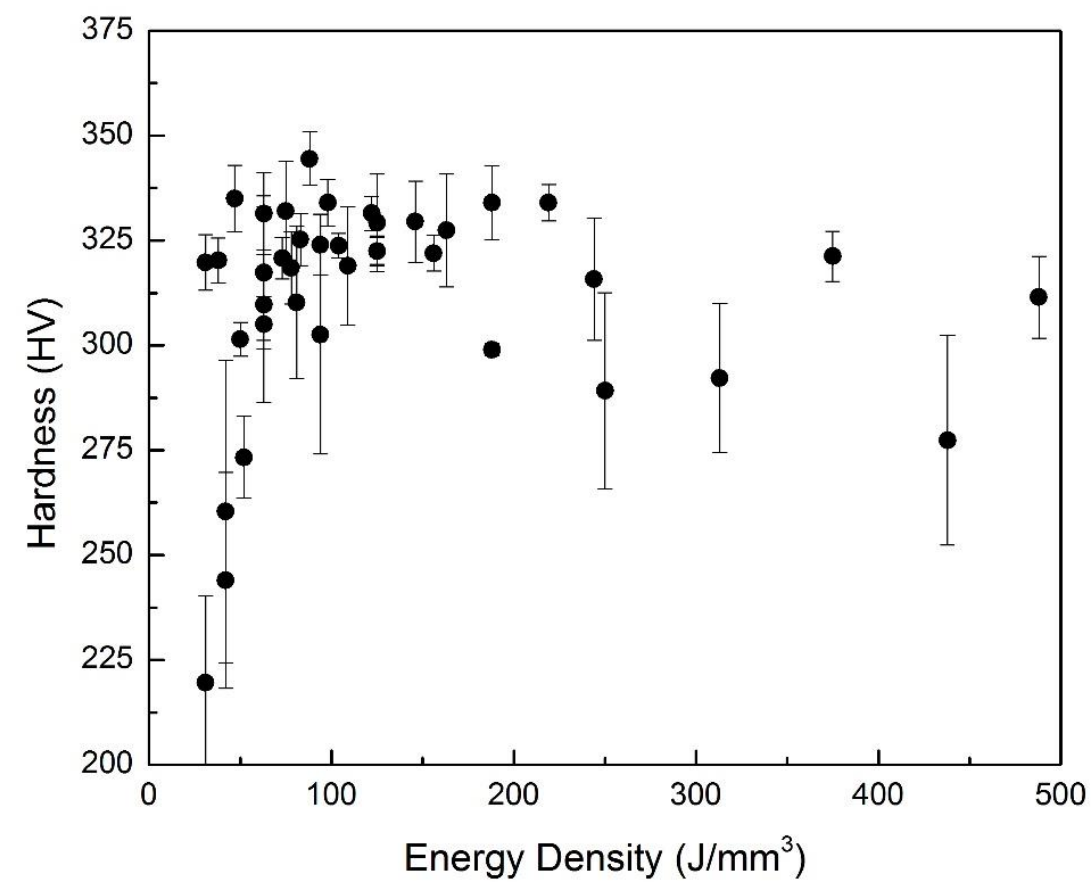

Figure 4. 16: Hardness (HV) vs input energy density $\left(\mathrm{J} / \mathrm{mm}^{3}\right)$ 

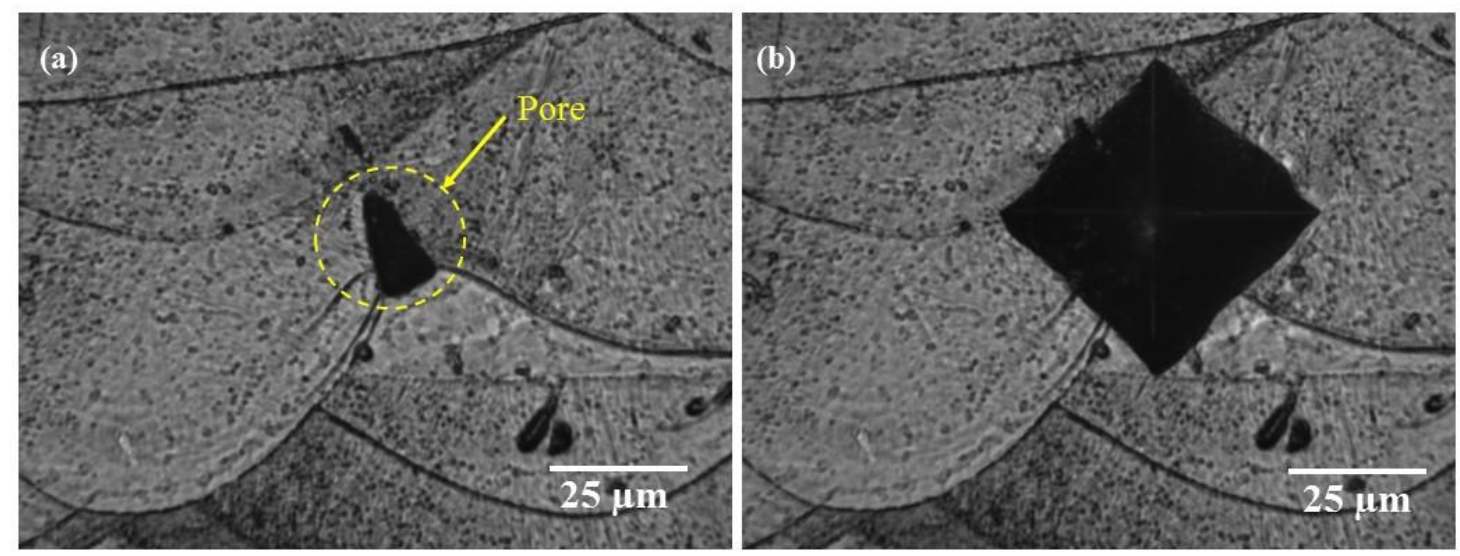

Figure 4. 17: Change in hardness value due to the indenter's interference with porosity (parameter: $195 \mathrm{~W}-1200 \mathrm{~mm} / \mathrm{s}$ ); (a) before indentation, surface with pore, (b) after indentation, less hardness value due to pore (285 HV).

\subsection{Conclusions}

In this work, a novel method was applied to fabricate single track deposit of Inconel 625 on top of rectangular pad using SLM. Multiple combinations of laser power and scan speed were used to fabricate the tracks and their effect on the morphology of the deposits was studied. The single track deposits depict more realistic melt pool morphology compared to a single track on build plate or on a layer of powder as the heating/cooling profile is similar to bulk samples. It was observed that for a constant laser power, as the scan speed increases the width of the track decreases and loses its continuity, eventually resulting in balling. On the other hand, when laser power is increased for a certain scan speed, energy density increases and resulting in wider deposits. Similar to the width, the depth also decreases with an increase of scan speed and increases as the power increases. A process parameter map was constructed using depth 
to width ratio. This map can help to identify optimum sets of parameter that produce parts with minimum defect. Analysis on bulk deposits showed a direct correlation between applied energy density and porosity. It was observed that parameters with both low and high energy density produce a significant amount of porosity. Whereas for medium energy level of $90-125 \mathrm{~J} / \mathrm{mm}^{3}$, porosity was found to be very low $(\leq 0.1 \%)$. Direct correlation between energy density and hardness was found. Hardness was low for both low and high energy densities due to porosity whereas for medium energy levels when the sample was fully dense hardness was found to be very high. 


\section{CHAPTER 5}

\section{EFFECT OF SCAN PATTERN ON THE MICROSTRUCTURAL EVOLUTION OF INCONEL 625 DURING SELECTIVE LASER MELTING}

\subsection{Introduction}

Selective Laser Melting (SLM) is characterized by highly localized high heat input for very short periods of time, which has a profound impact on the microstructure. SLM provides a wide range of advantages over conventional manufacturing techniques, but high temperature gradients and rapid solidification cause high thermal stress build-up and the presence of non-equilibrium phases. Orientation of grains is largely controlled by the heat conduction direction, thus laser scanning strategy becomes a powerful tool for control of grain orientation, and hence the microstructural texture.

This chapter focuses on the analysis of different scan strategies in order to obtain insight into the development of microstructural texture in Inconel 625 during SLM processing. It has been observed that SLM is a complicated process where the evolution of the microstructure depends on a large number of parameters such as laser power, scan speed, layer thickness, and scan strategy [58]. In this research, microstructure evolution during SLM processing of Inconel 625 are analyzed in detail. Different types of scanning strategies are also investigated to understand their effects on the microstructures of Inconel 625 . 


\subsection{Scan patterns in SLM}

SLM machines typically utilize one of 2 basic scan strategies for the interior sections of parts. These strategies are rotating scan pattern and alternating scan pattern.

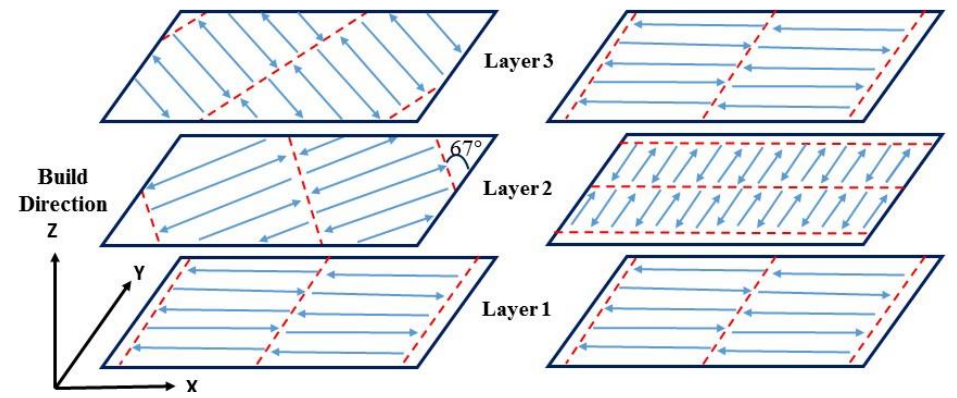

Figure 5. 1: Schematic of a rotating scan pattern (left) and alternating scan pattern (right).

A schematic of these two scan patterns are shown in figure 5.1. When using a rotating pattern, each layer is divided into a series of parallel stripes (red dashed line in figure 5.1) that run across the entire length of the cross-section of any closed contour within a layer. Within each stripe, raster scan vectors are used (blue arrow in figure 5.1). During every new layer, the stripes rotate counterclockwise by $\sim 67^{\circ}$ compared to the previous layer, creating a crosshatch pattern. For alternating pattern, the stripes rotate $90^{\circ}$ instead of $67^{\circ}$ creating a 0-90-0-90 stacking sequence.

\subsection{Experimental detail}

Cube Inconel 625 specimens $(10 \times 10 \times 10 \mathrm{~mm})$ were built in an EOS M270 machine using both rotating and alternating scan patterns. Process parameters used in this experiment are: $195 \mathrm{~W}$ laser power, $800 \mathrm{~mm} / \mathrm{s}$ scan speed, $20 \mu \mathrm{m}$ layer thickness. Horizontal and vertical cross-section of the samples were polished and etched using Kalling's reagent and were examined in an Olympus Optical Microscope (OM) and in a Zeiss Supra 35 Scanning Electron Microscope (SEM). EBSD experiments were 
performed at the nanofab facility at the University of Utah, Salt Lake City. EBSD studies were carried out on the longitudinal (vertical section) of the alternating and rotating scan patterns test coupons. The samples were ground, polished to 1 micron finish, and then final polishing was done using colloidal silica for $4 \mathrm{~h}$. EBSD scans were carried out on the polished surfaces.

For Transmission Electron Microscopy (TEM) sample preparation, the cube samples were sectioned using a low speed saw to a thickness of $0.6 \mathrm{~mm}$ to $0.8 \mathrm{~mm}$. The foils were then polished using $\mathrm{SiC}$ wet emery papers to 100 micron in thickness. The samples were then cut in the form of $3 \mathrm{~mm}$ disc using a disc punch and ultrasonically cleaned. Final polishing was done in an automatic twin-jet electropolisher which uses two jets direct electrolyte flow onto the specimen, which simultaneously thins and polishes both sides. As the specimen is thinned and finally forms a hole at the center of the specimen, light is transmitted to the sensor and indicates the completion of polishing by an alarm. Transmission electron microscopy (TEM) was performed in FEI Tecnai F2 operated at $200 \mathrm{kV}$. Several TEM-based techniques, including diffraction contrast imaging, high-resolution transmission electron microscopy (HRTEM) and selected area electron diffraction (SAED) were used to analyze these samples. In addition, elemental analysis was also carried out using TEM-based energy dispersive X-ray spectroscopy (EDAX Inc). 


\subsection{Result and discussion:}
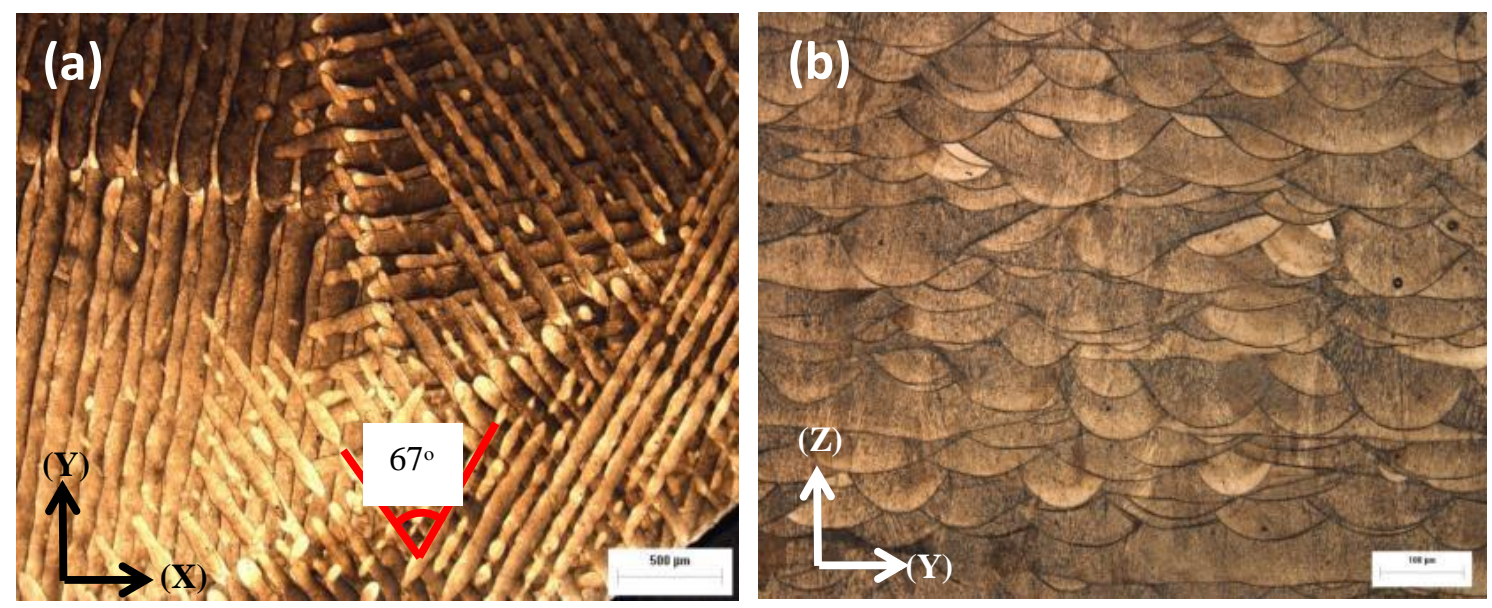

Figure 5. 2: (a) Microstructural evidence of the rotating pattern from a horizontal (XY

plane) cross-section. (b) Melt-pool arrangement as seen from a vertical cross-section (YZ plane) for a rotating pattern.
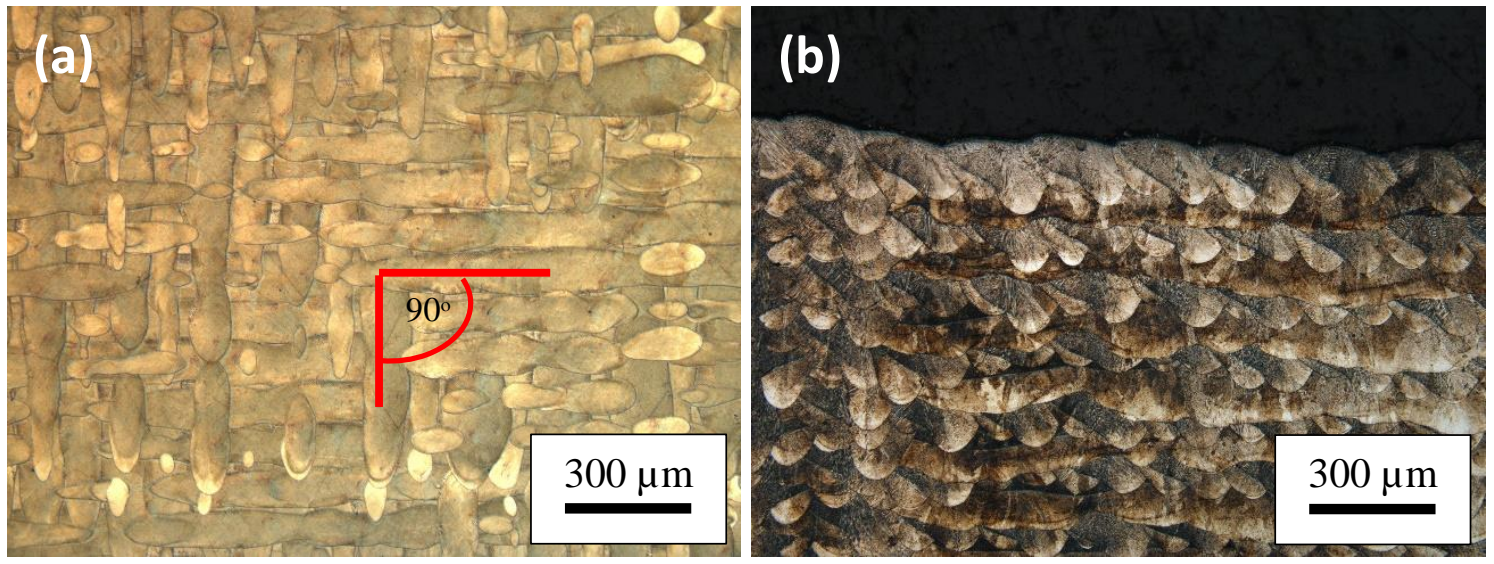

Figure 5. 3: (a) Horizontal cross-section showing laser tracks for the alternating scan

pattern. (b) Melt-pool arrangement in a vertical cross-section using the alternating scan strategy.

Figure 5.2 (a) shows OM of a horizontal cross section of the sample where laser tracks are clearly distinguishable. Multiple layer can be observed in the same image. The angle between laser tracks of consecutive layers was found to be $67^{\circ}$ as illustrated in 
figure 5.2 (a). Two stripes in the same layer, as well as their overlap are visible in the top left corner of figure 5.2 (a). In figure 5.2 (b), the melt-pool arrangement in the vertical cross-section (YZ plane) is shown. It was observed that the shapes of the melt-pools are quite similar (Gaussian) but their sizes are different. This is because scan vectors from different layers are not parallel to each other and not perpendicular to the view plane as well. Thus, different oblique sections of the melt-pools show different sizes. Figure 5.3 shows the etched horizontal and vertical cross section of a sample built using alternating pattern. Stripes rotate $90^{\circ}$ in every new layer and creates an alternating hatch pattern. The melt-pool arrangement is clearly visible in figure 5.3 where the angle between laser tracks of two consecutive layers were $90^{\circ}$.

SLM is characterized by highly localized heat input for a very short period of time leading to a rapid solidification as the melt pool undergoes liquid to solid transformations. This may result in formation of non-equilibrium phases and changes in general microstructural features. Finer cellular dendritic structures evolve due to high cooling rates compared to conventional manufacturing processes $[3,4,32,79-81]$. In addition, cellular/dendritic structures, and thus grain structures, are also controlled by microstructures formed at the boundaries of previously solidified layers (figure 5.4). Although the mechanism of grain growth is highly complex and influenced by many variables, local heat conduction direction plays an important role in determining the orientation of grains.

Temperature gradient is the highest along the midline of the scan track and at the back of the moving melt pool, and decreases radially [82]. Thus grains tend to grow in this direction (figure 5.4). However, due to overlap, major portions of laser tracks and 
their grains remelt during subsequent scanning. Due to the fast cooling conditions, the grains grow epitaxially toward the center of the new melt pool [34, 83, 84]. Based upon these conditions, the orientation of grains is thus highly dependent on the scanning velocity and scanning strategy. Consequently, the scanning strategy can become a powerful tool to control the grain orientation, and hence the microstructural texture [34, $50,85,86]$.
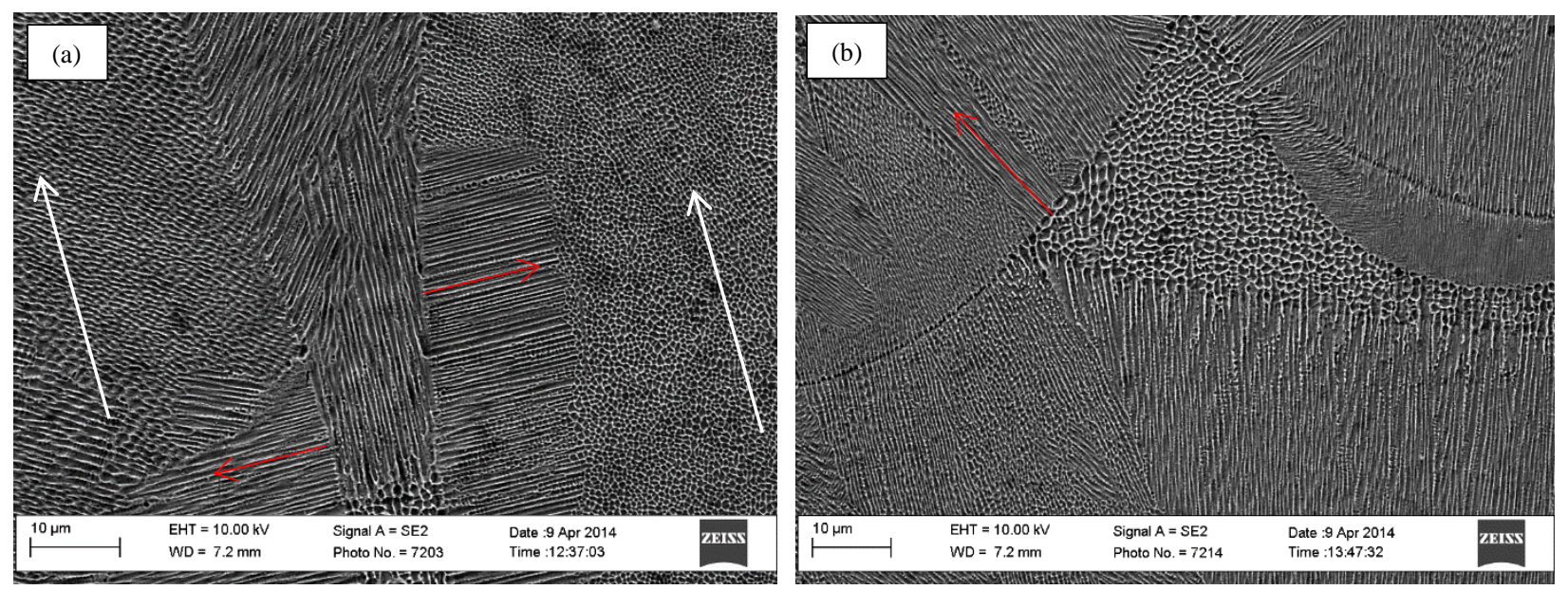

Figure 5. 4: (a) SEM image of a horizontal (XY) section showing cellular/dendritic growth (red arrows) towards the center of the scan track (white arrow), (b) vertical (YZ) section showing radial growth of cellular dendrites. Clear melt-pool boundaries are observed which has an effect on grain size and orientation.

Thijs et al. [34] studied different scan strategies for Ti-6Al-4V and found that grains grow preferentially in the build direction (figure 5.5). They reported that elongated grains are parallel to each other and are tilted at an angle $19^{\circ}$ away from building direction for unidirectional scan patterns, whereas for bidirectional scan patterns grains have a herringbone pattern. For a grid-like pattern, the grains were found to be equiaxed (figure $5.5 \mathrm{~b}$ ). 

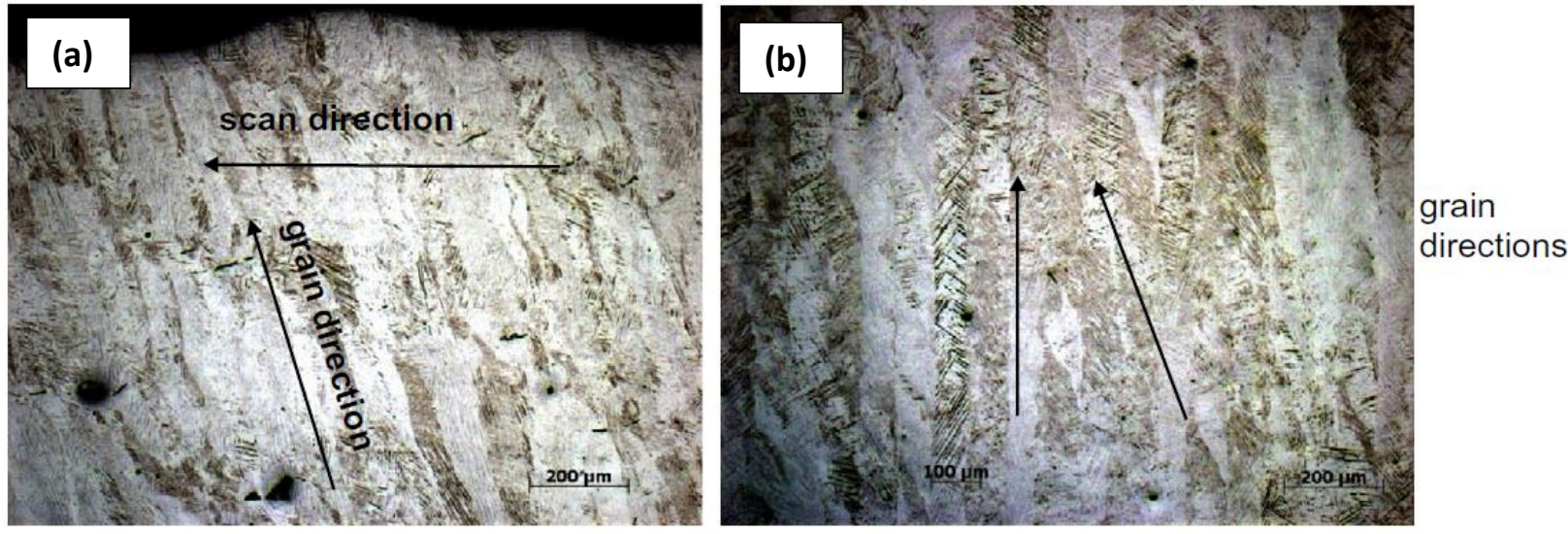

Figure 5. 5: Orientation of elongated grains scanned with: (a) unidirectional scan vectors, and (b) alternating hatch scan vectors. View plane: Side view (YZ plane), Material: Ti-

$$
6 \mathrm{Al}-4 \mathrm{~V}[34]
$$

Similar phenomena were observed for Inconel 625 . For a rotating scan strategy which rotates $67^{\circ}$ for every new layer, more refinement of cellular/dendritic structures occurs due to maximum overlap in the melt, thus creating more equiaxed grains. Figure 5.6 shows optical microscopy of equiaxed grains oriented in the build direction (Z).

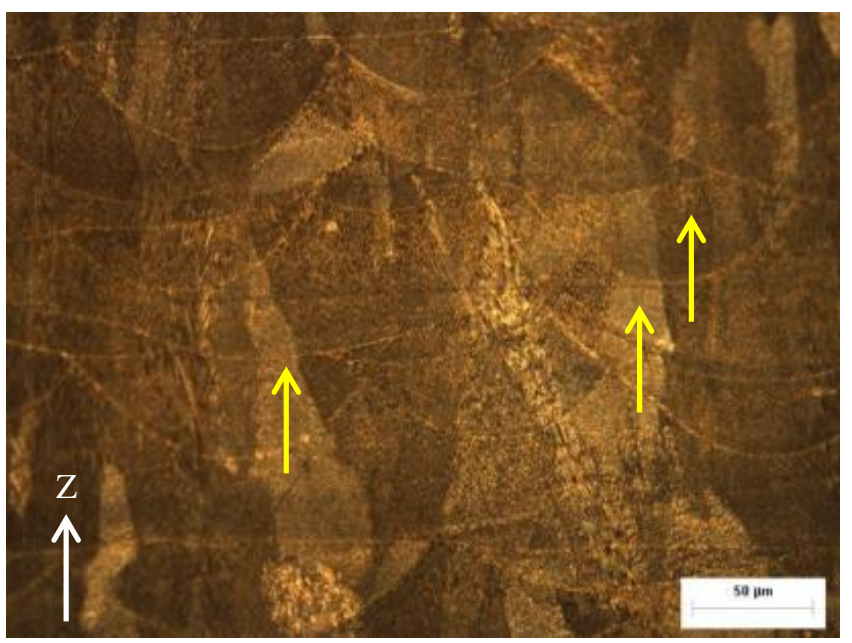

Figure 5. 6: Orientation of elongated equiaxed grains (dark and white regions) formed due to the rotating pattern, which grow preferentially in the build direction $(\mathrm{z})$ indicated by arrows across multiple layers. 
Despite epitaxial solidification, melt pools are still distinguishable due to the appearance of dark bands in optical microscopy (white bands in SEM) (figure 5.7). These dark bands are more noticeable when more energy is applied. The dark contrast which distinguishes these bands arises due to precipitation enhanced in $\mathrm{Nb}$ and Mo which is preferentially etched $[3,4,12,87,88]$. EDS analysis was done for this identification and is shown later in this chapter.
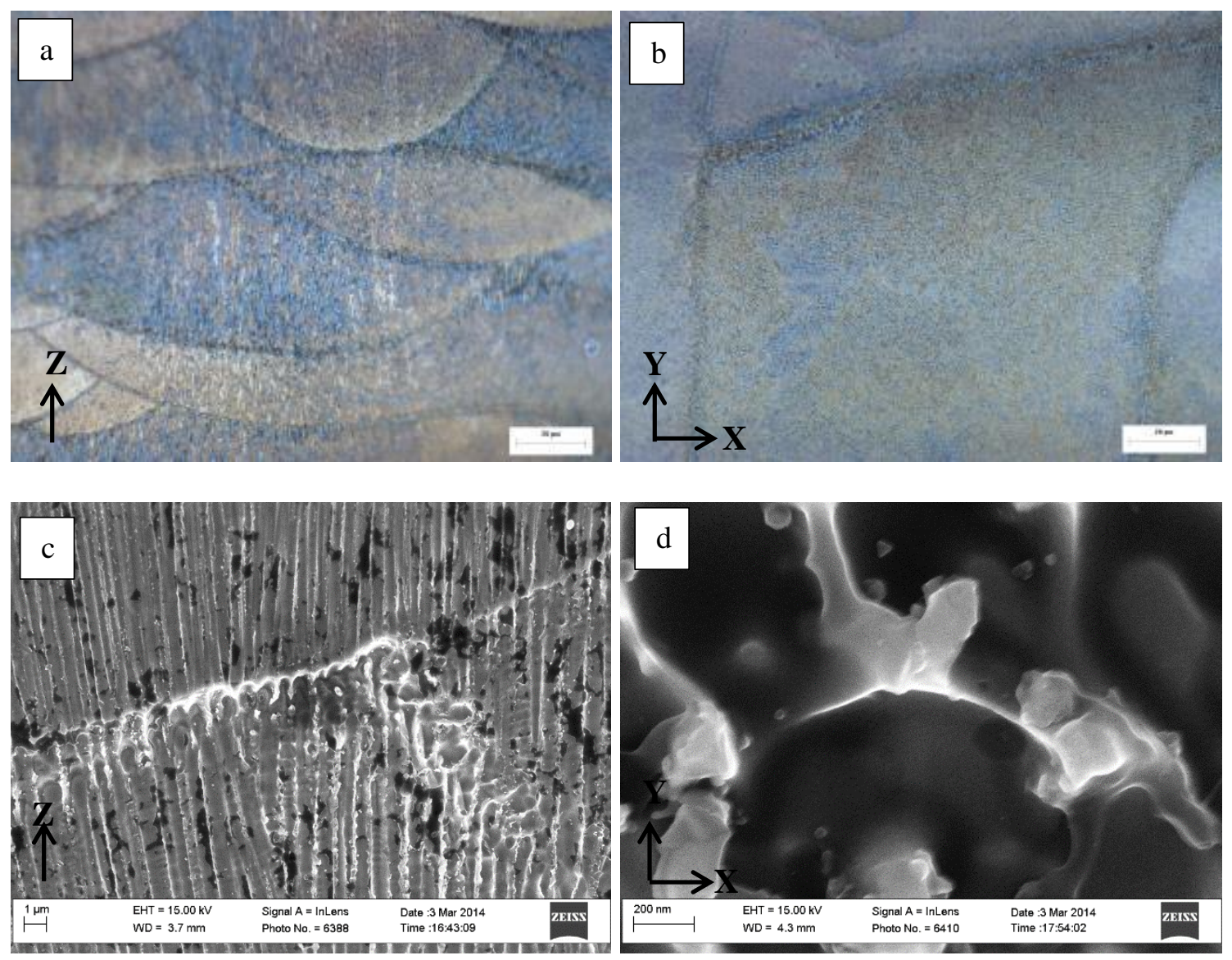

Figure 5. 7: (a) Optical microscopy showing a vertical section of Inconel 625 where melt pools are distinguishable due to the appearance of dark bands. (b) Horizontal section showing dark band region. (c) SEM image showing the same section as 'a' but magnified to illustrate that SEM white regions represent optical microscopy dark bands. (d) High 
magnification SEM image of a horizontal section showing the cross-section of a single dendrite where the white region is formed due to segregation of $\mathrm{Nb}$ and Mo.
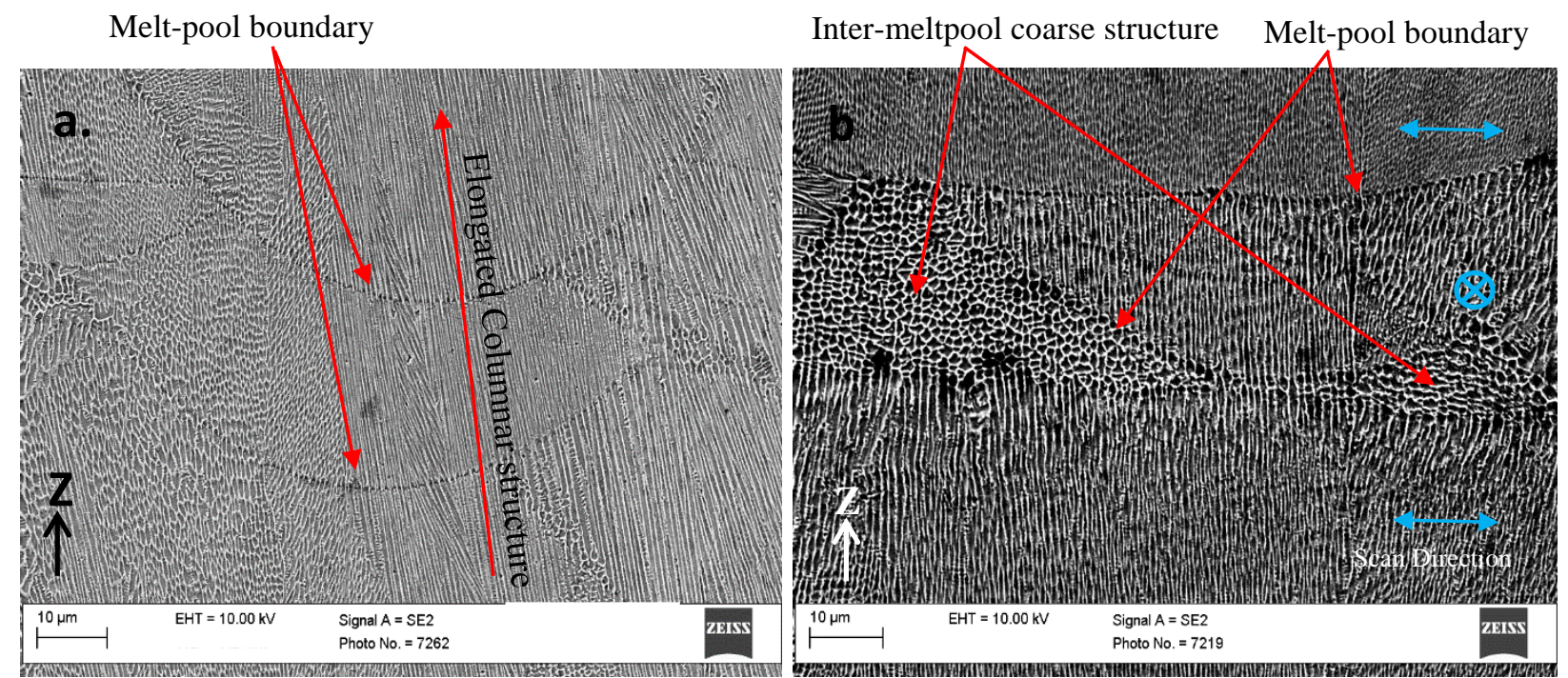

Figure 5. 8: SEM image showing vertical cross-section (YZ plane) of Inconel 625 sample built using (a) Rotating pattern and (b) Alternating pattern. Arrows in the right section in ' $b$ ' show alternating scan directions.

Figure 5.8 (a) shows a typical polished and etched SEM micrograph of the vertical cross-section of an Inconel 625 part built using a rotating pattern. It can be observed from the micrograph that the grains have grown epitaxially and there is grain continuity across multiple melt pools in the build direction. The columnar grains show cellular and dendritic sub-structure. It can also be observed that there is noticeable segregation (bright regions) within the intercellular and inter-dendritic arm spacing. Intercellular spacing is less than $1 \mu \mathrm{m}$ (figure 5.9) which provides excellent strength and hardness that can be achieved both in the as processed and aged conditions. 
Figure 5.8 (b) shows a typical polished and etched SEM micrograph of the vertical cross-section of an Inconel 625 SLM sample using an alternating scan pattern. The microstructural features show epitaxial grain growth from the melt. The grains show columnar morphology with a cellular/dendritic sub-structure. The individual cell/dendrite boundaries are illuminated by segregation of elements during solidification into the inter cell/ dendritic arm spacing. There is also grain continuity across multiple melt pools, which is also common for multipass welds of this alloy. For alternating scan patterns, the elongated columns were found to have shorter length compared to rotated stripe patterns.

Another distinguishable feature is that regions of coarse columnar structure appear in between melt pools in figure 5.8 (b). These regions are less refined. Refinement in columnar structure is done by laser re-melting which is reported by several authors $[32,89]$. Melt-pool depth for this experiment is approximately $60 \mu \mathrm{m}$, which influences three layers. Therefore, overlap and remelting become a common phenomenon in SLM processing. Alternating patterns leaves significant amount of inter-meltpool regions which are not overlapped and less heat affected, thus providing coarse cellular structures and orientation mismatch. For rotated stripe patterns, higher overlap and thus finer cellular structure is found. 

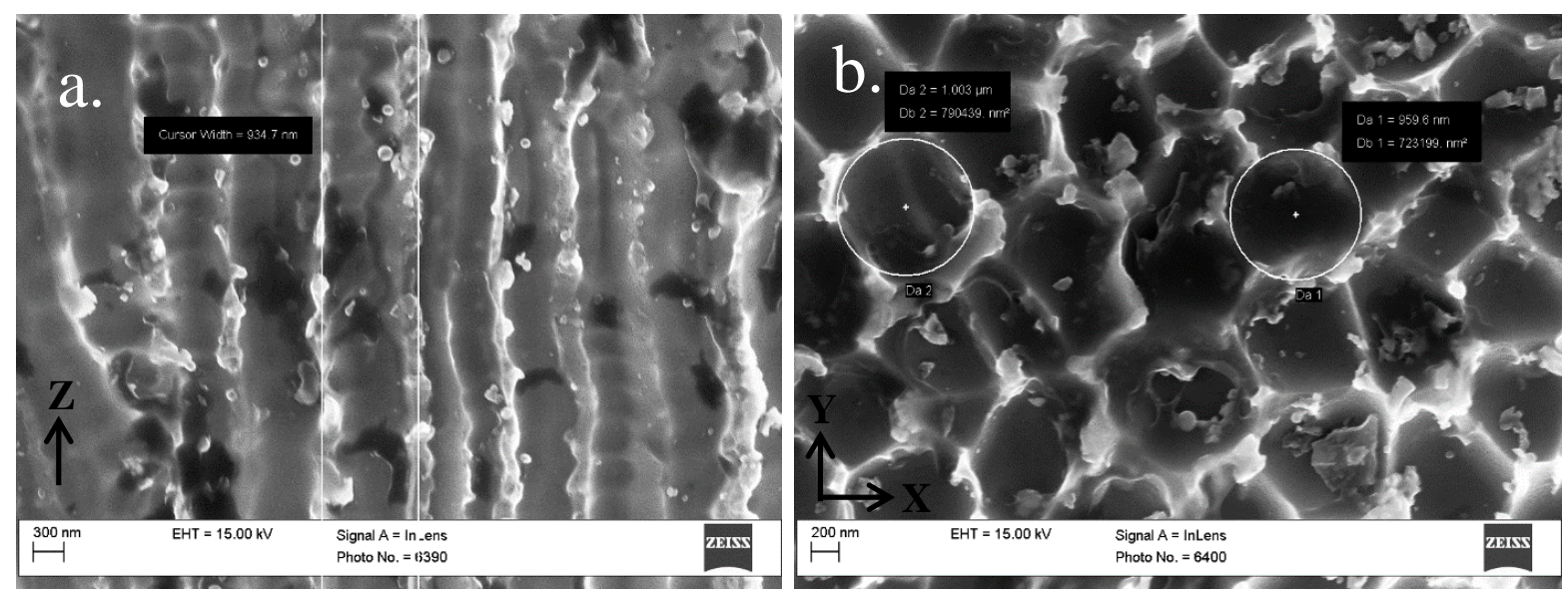

Figure 5. 9: SEM image showing intercellular spacing less than $1 \mu \mathrm{m}$ for a rotated stripe scan pattern in (a) vertical and (b) horizontal sections, which provide excellent strength and hardness.

EBSD studies were carried out on the vertical and horizontal sections of the alternating and rotating scan patterns. Figure 5.10 represents a comparison of Inverse Pole Figure (IPF) map obtained from the vertical cross-section of rotating and alternating scan pattern. The result shows that columnar grains grow in the build direction for both scan pattern, however, for rotating pattern finer grains were observed.
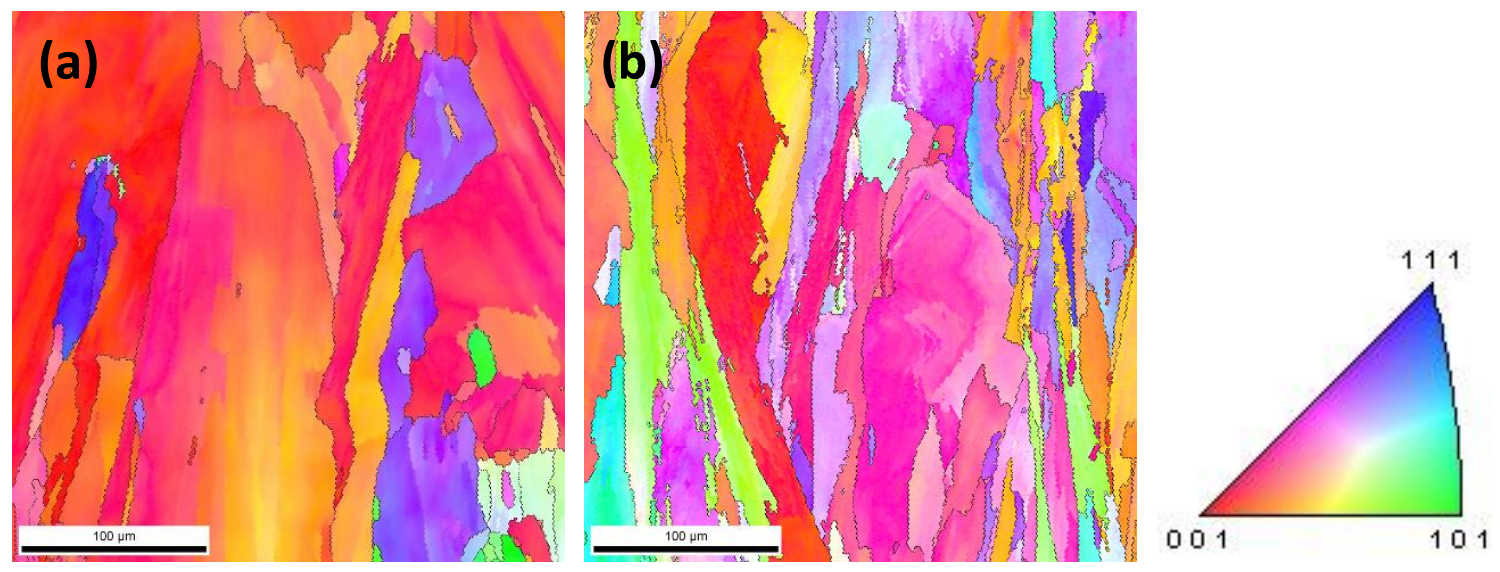

Figure 5. 10: IPF maps of the vertical cross-section of samples built using (a) alternating and (b) rotating scan pattern 
Figure 5.11 shows the IPF map, IPF texture plot, grain boundary map and unique grain color map of the horizontal cross section of the alternating scan pattern sample. It can be observed that grain size and shape are not uniform and they a have very wide range of grain diameters. The IPF texture plot shows the $\{001\}$ orientation of the majority of the grains. The grain boundary misorientation map reveals the fraction of high and low angle boundaries in the region of interest. Most of the grain boundaries were of low angle, $64 \%$, and rest being high angle boundaries. The unique grain color map reveals the individual size and shape of the grains in the horizontal section. In this map each grain is assigned a unique color adjacent to the other grains. The grains are arranged in such a way that the laser scan tracks can also be observed in the microstructure of IPF maps, though not immediately apparent. The dotted lines on the IPF map indicate the laser scan paths during SLM. The width of the scan track was around $100 \mu \mathrm{m}$. 


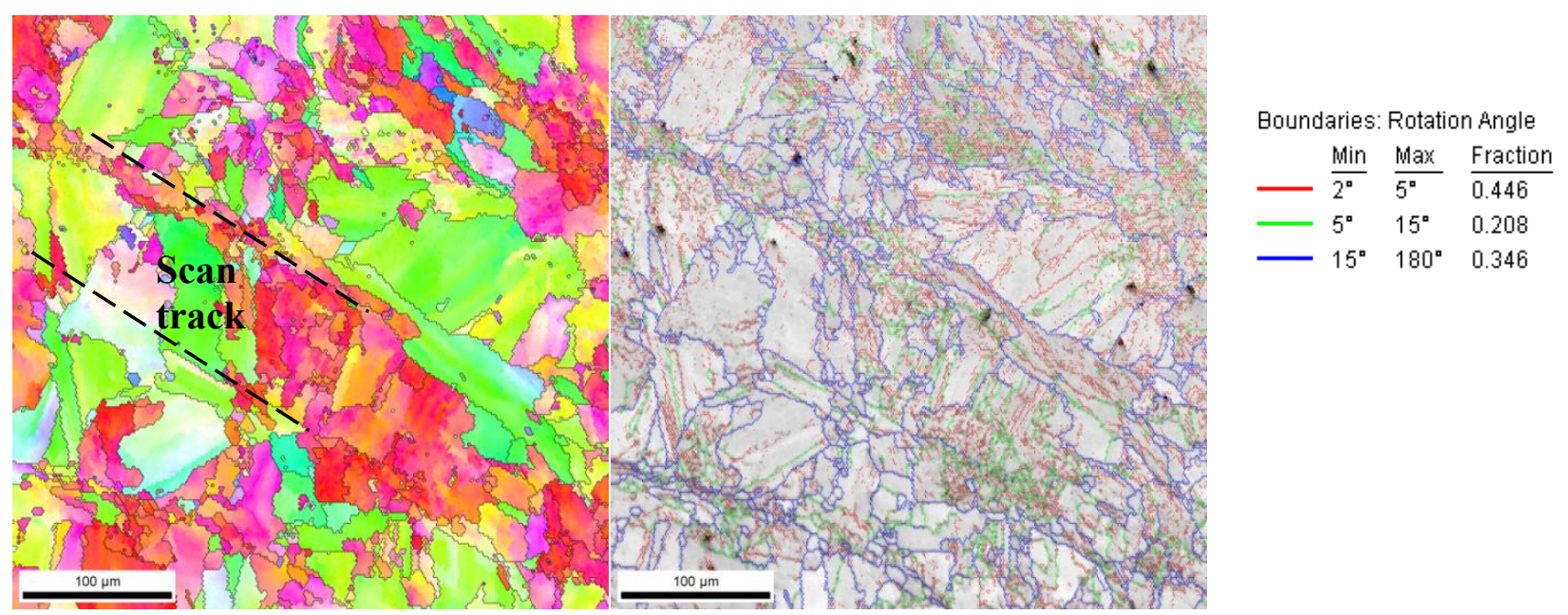

IPF map

[001]

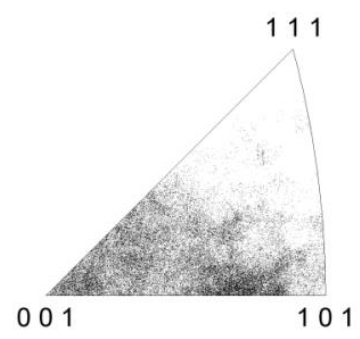

IPF texture plot
Grain boundary misorientation map

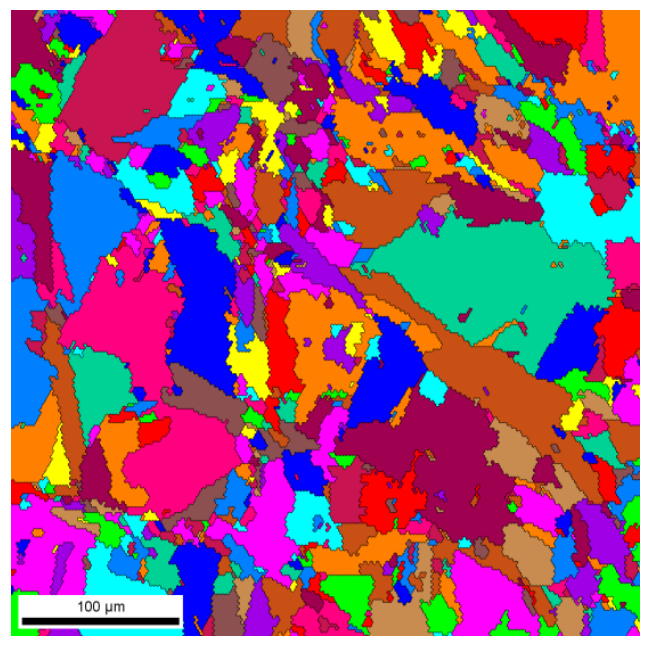

Unique grain color map

Figure 5. 11: EBSD results on the alternating scan pattern horizontal cross section of the SLM processed Inconel 625 sample in an as-fabricated condition. 


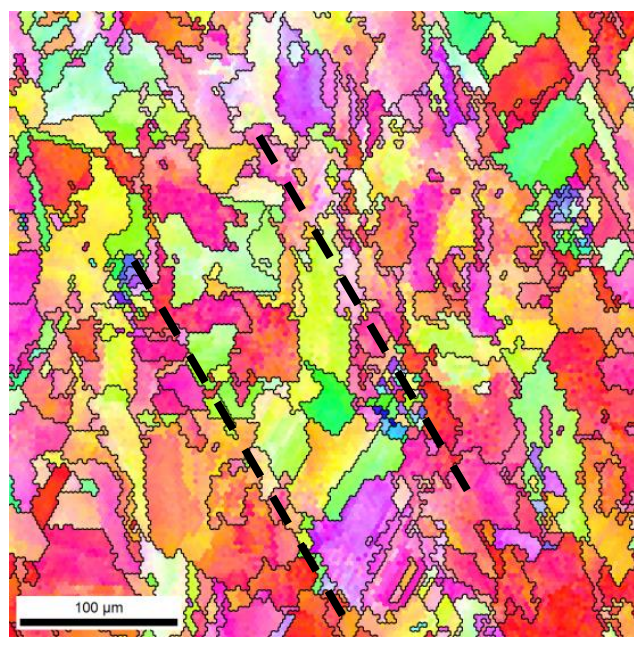

IPF map

[001]

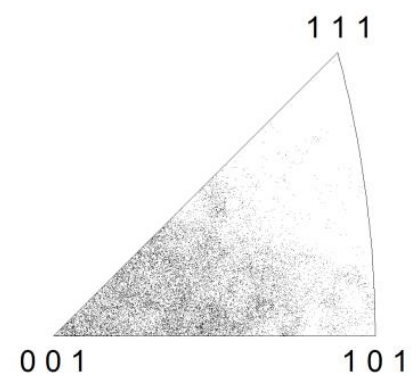

IPF texture plot

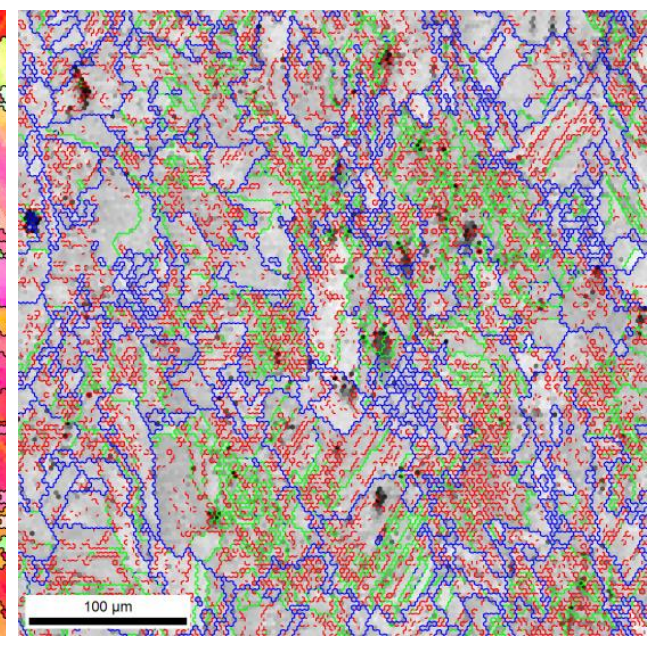

Boundaries: Rotation Angle

$\frac{\text { Min }}{2^{\circ}} \frac{\text { Max }}{5^{\circ}} \frac{\text { Fraction }}{0.454}$

$-5^{\circ} \quad 15^{\circ} \quad 0.217$

Grain boundary misorientation map

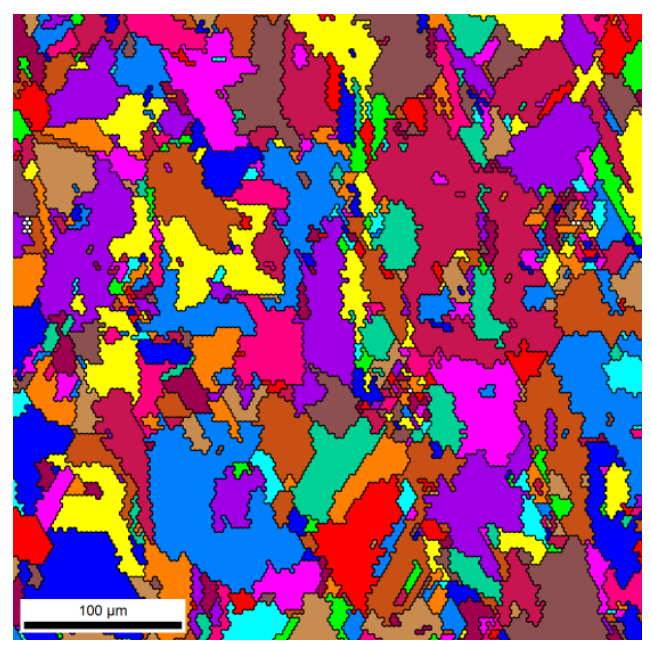

Unique grain color map

Figure 5. 12: EBSD results on the rotating scan pattern horizontal cross section of the SLM processed Inconel 625 sample in an as-fabricated condition.

Figure 5.12 shows the IPF map, IPF texture plot, grain boundary map and unique grain color map of the horizontal cross section of the rotating scan pattern in as built condition. The EBSD results in the case of rotating scan pattern also shows the $\{100\}$ orientation of grains. These results were similar to the observations made in the above case of horizontal cross-section of alternating scan pattern. Comparison of EBSD 
micrograph in horizontal cross-section revealed the finer grain size for rotating scan pattern than alternating. Also, the misorientation for rotating scan pattern is found less compared to alternating scan pattern.

TEM micrograph (low magnification and high magnification) in Figure 5.13 of the Inconel 625 sample shows a large number of fine carbide particles of the order of 50$100 \mathrm{~nm}$. These fine sized carbides were observed primarily in the inter-dendritic arm regions of the matrix. The carbides were observed to collate into longer sized particles. The dendritic arm width was in the range of 0.5 to $1 \mu \mathrm{m}$.

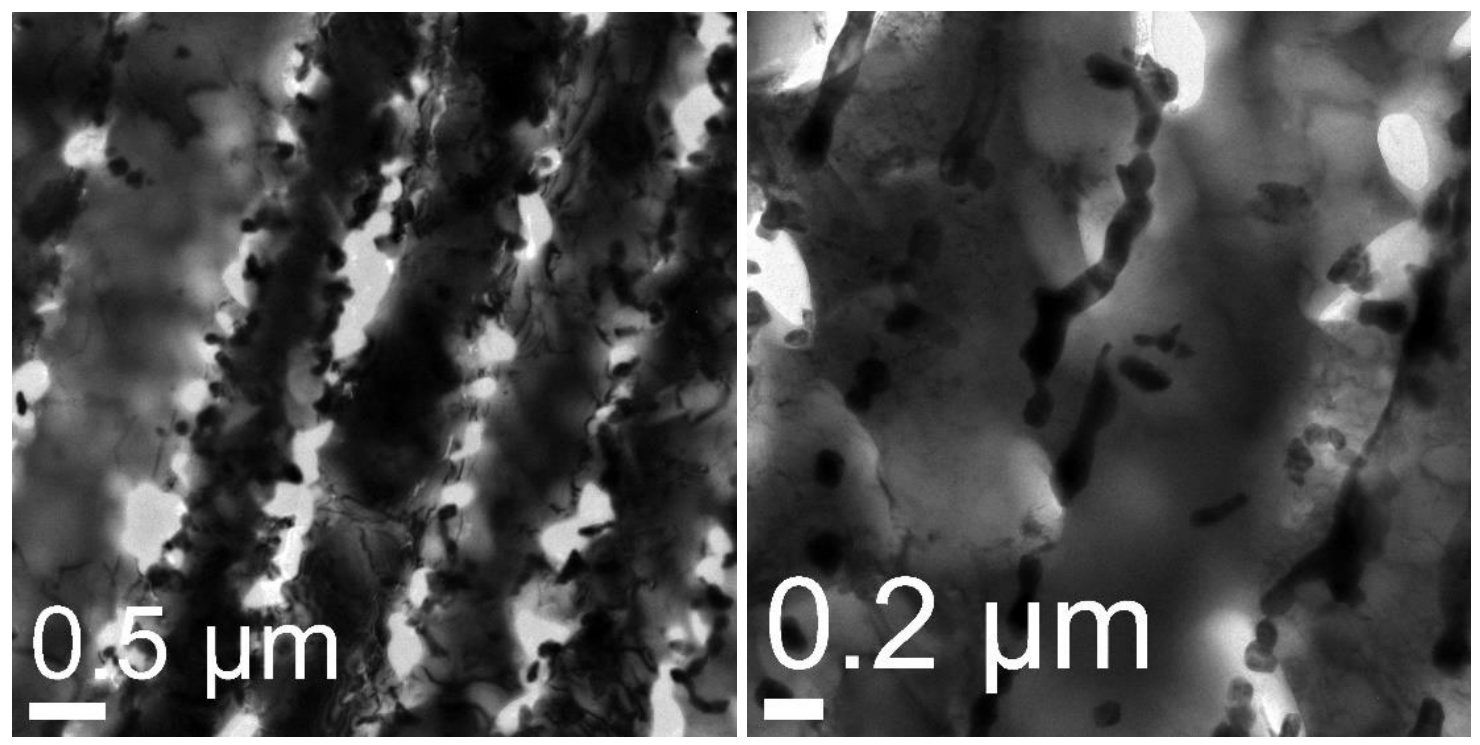

Figure 5. 13: TEM micrograph showing coarse carbide particles precipitated in the interdendritic regions of the SLM built sample. 


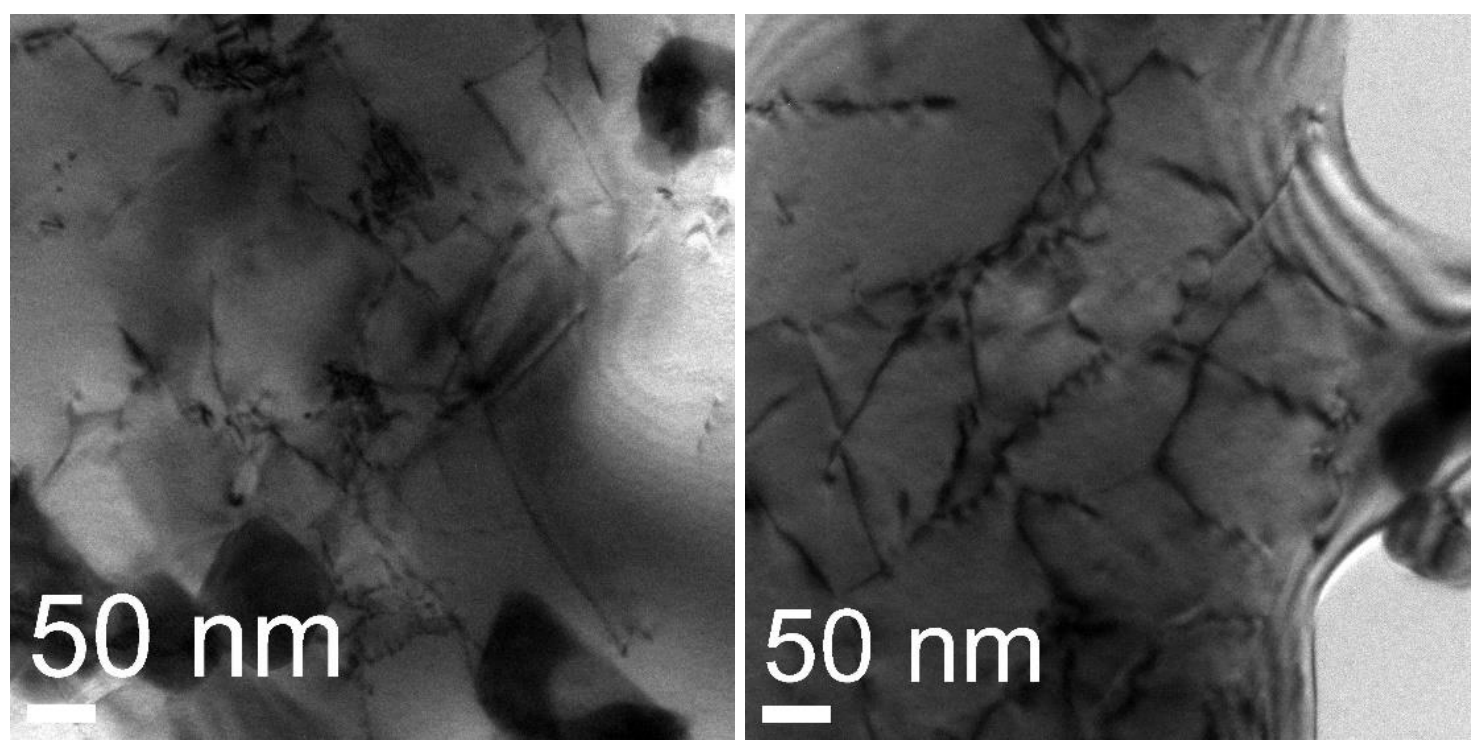

Figure 5. 14: TEM micrograph showing dislocation network in the matrix along with fine carbides.
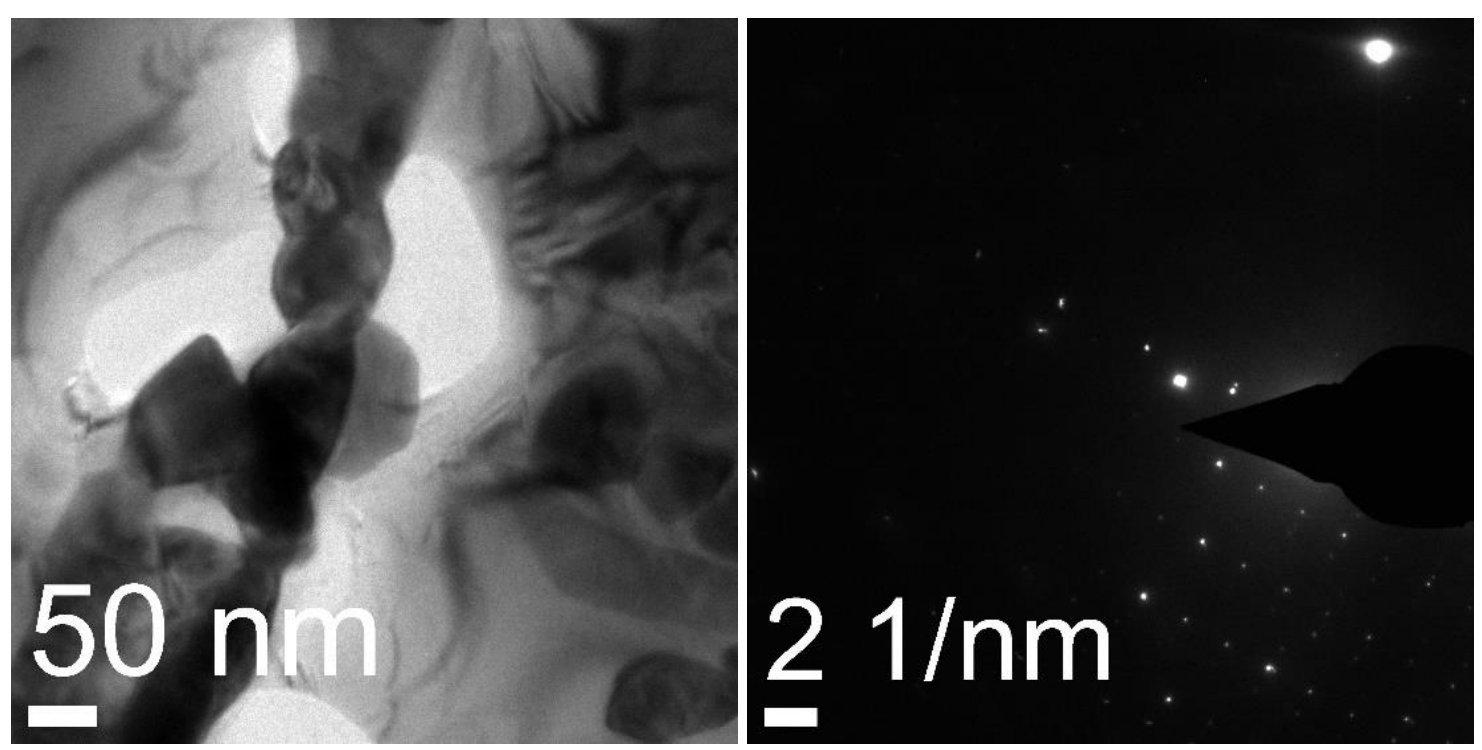

Figure 5. 15: TEM micrograph showing connected network of carbide particles.

Corresponding SAD pattern showing diffraction spots from the carbide particles.

TEM micrograph presented in Figure 5.14 shows matrix with dislocations and carbide particle. There was no evidence of the presence of strengthening precipitates in 
the matrix. Figure 5.15 shows the network of collated carbides and corresponding SAD pattern (carbides).
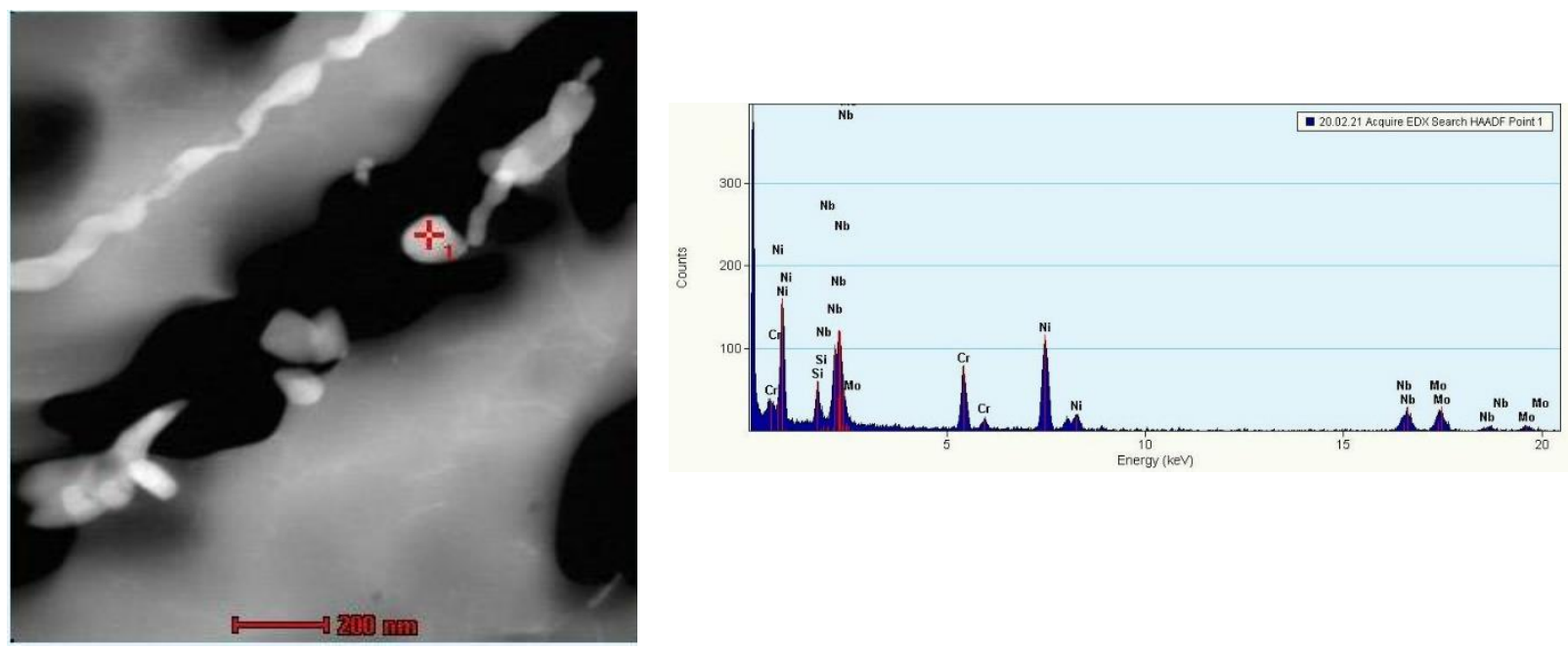

Figure 5. 16: STEM image of the matrix region with carbide particles and corresponding EDS analysis of a typical carbide particle.

Chemical composition analysis of the microstructural constituents was investigated by the method of STEM-EDX (STEM, FEI Tecnai F20, FEGTEM) operating at $200 \mathrm{kV}$ and equipped with an Energy Dispersive X-ray Analyzer. Fig. 5.16 shows the EDS spectrum collected from the carbide particles. The carbides were found to be rich in $\mathrm{Nb}$ and Mo. These particles closely confirm $\mathrm{NbC}$ and $\mathrm{MoC}$. 

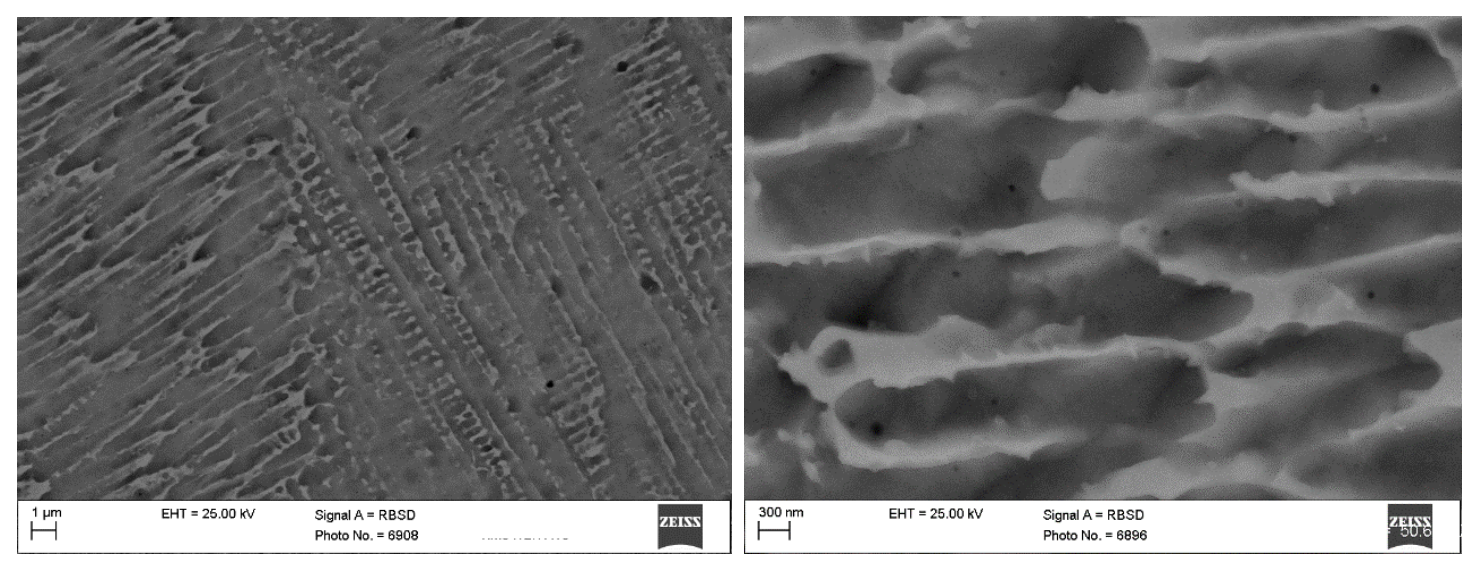

Figure 5. 17: BSE image of a vertical (YZ) cross-section at two different magnifications.

The samples were also observed in the BSE mode in SEM. The BSE imaging mode gives the atomic number contrast of elements in the microstructure under observation. The BSE SEM micrograph of the vertical cross section further confirms the segregation of elements in the inter cell/dendritic arm regions (figure 5.17).

\subsection{Summary}

Two types of scan patterns were analyzed in detail using schematics as well as optical and SEM microscopy for Inconel 625 samples fabricated using selective laser melting. A rotating pattern which uses raster scan vectors and which rotates $67^{\circ}$ for every new layer creates a crosshatch pattern. An alternating pattern, on the other hand, rotates $90^{\circ}$, thus creating 0-90-0-90 alternating building blocks.

In SLM, local thermal gradients inside the melt pool are the most important factor for determining microstructure. The heat conduction direction, based upon scan pattern, plays an important role in determining the orientation of grains. Solidification occurs in a cellular/dendritic fashion with the growth direction preferably oriented towards the center of the melt pool. However, due to overlap, major parts of each solidified track remelts 
and the grains grow epitaxially towards the center of the new, adjacent melt pool. Microstructures of previously solidified layers also control the direction of cellular/dendritic growth.

Noticeable amounts of segregation within the intercellular and interdendritic arms spacing were observed. Intercellular spacing is less than $1 \mu \mathrm{m}$, which contributes to the excellent strength and hardness that can be achieved both in as-processed and aged conditions. These cells are not individual grains but constitute a substructure inside one grain.

Grains grow epitaxially and there is grain continuity across multiple melt pools in the build direction. However, for an alternating pattern, the elongated columns are found to have shorter length compared to a rotated stripe pattern.

Difference in cellular structure were observed in alternating patterns. Intermeltpool regions are less overlapped and less heat affected, thus resulting in coarse cellular structures which may have an affect hardness and strength of SLM built Inconel 625 part. 


\section{CHAPTER 6 \\ TENSILE PROPERTIES OF INCONEL 625 MANUFACTURED BY SELECTIVE LASER MELTING}

\subsection{Introduction}

Inconel 625 is well known for its superior properties such as high tensile and rupture strength, excellent fatigue and oxidation resistance. However, this alloy is difficult and very costly to process by conventional manufacturing process due to excessive tool wear and low material removal rate $[58,90]$. Furthermore, when the design of the part become very complex it become impossible to fabricate the part using the conventional manufacturing techniques. Selective laser melting (SLM) becomes a possible solution for fabricating complex metal part. SLM an additive manufacturing process which uses a high intensity laser to melt metal powder and build a part layer by layer directly from CAD model [50]. Though SLM offers many benefits over conventional manufacturing, such as the ability to produce complex shape, a high level of flexibility, near net shape production and a high material use efficiency, it still has some challenges to overcome [52]. SLM is characterized by highly localized heat input for a very short period of time which produce high thermal stress and the formation of nonequilibrium phases and porosity [57]. The unique microstructure and porosity both have a significant effect on the resulting mechanical property of the parts. In addition to the microstructure, the "stair-case effect" and the "balling effect" are also reported to have 
significant effect on mechanical properties[91]. Although numerous studies have been reported on mechanical properties of SLM processed Titanium [84, 92, 93] and Aluminum alloys [94-96], very few were performed on Inconel 625. Previous studies on the mechanical testing of as-built Inconel 625 parts made by SLM showed the influence of build direction on tensile properties [4]. The tensile strength of Inconel 625 part fabricated by SLM was reported to be higher than the strength of wrought product due to the elongated columnar grains. However, the ductility was lower [43]. In this chapter, the tensile deformation behavior of Inconel 625 are investigated. Solid cylindrical parts made by SLM are investigated for various scan patterns, build orientations and post-processing. The results are then correlated with corresponding fracture behavior.

\subsection{Experimental detail}

Inconel 625 gas atomized powder supplied by EOS GmbH was used in this study. Morphology of the powder was characterized using a Zeiss Supra 35 Scanning Electron Microscopy (SEM). Powder particle size distribution was carried out by a Microtrac S3000 laser-based particle analyzer. The particle was found to exhibit spherical shape with a homogeneous size distribution between $15 \mu \mathrm{m}$ and $50 \mu \mathrm{m}$. However, SEM micrograph revealed some larger particles are having smaller satellite particles attached (figure 6.1). Higher magnification of the SEM shows the typical micro-dendritic structure of particles produced during atomization (figure 6.1 (b)). 

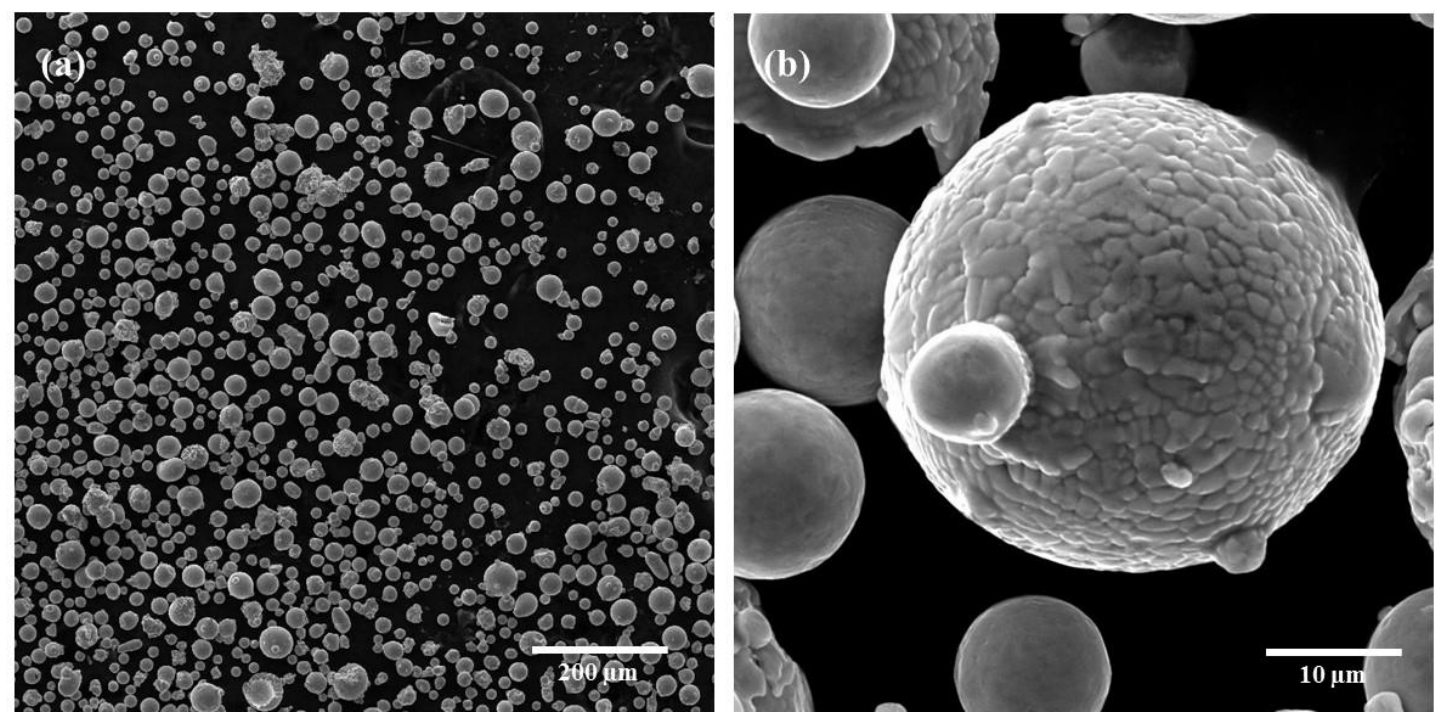

Figure 6. 1: SEM micrographs of Inconel 625 powder particles.

Direct metal laser sintering machine EOS M270 equipped with 200W Nd:YAG fiber laser with a was used to fabricate the test samples. Process parameters used for building the sample are laser power $195 \mathrm{~W}$, scan speed $800 \mathrm{~mm} / \mathrm{s}$, layer thickness $20 \mu \mathrm{m}$ and hatch spacing $100 \mu \mathrm{m}$. Two types of scan patterns, rotating and alternating, were used. The build chamber was maintained at a pressure of 35 mbar above atmosphere with a constant supply of high purity argon. Total 36 cylindrical tensile specimens were fabricated in three different orientations, horizontal $\left(0^{\circ}\right)$, vertical $\left(90^{\circ}\right)$ and inclined $\left(45^{\circ}\right)$. After removing from the support structure, half of the specimens were heat treated at $1038^{\circ} \mathrm{C}$ for 1 hour in an argon-filled furnace for solutionizing followed by water quench. The details of the experimental design are given in table 6.1. The cylindrical samples were then machined in the gauge section to form the dog-bone shaped tensile specimens. The gauge sections of the specimens were then hand polished with 1200-grit sandpaper. 

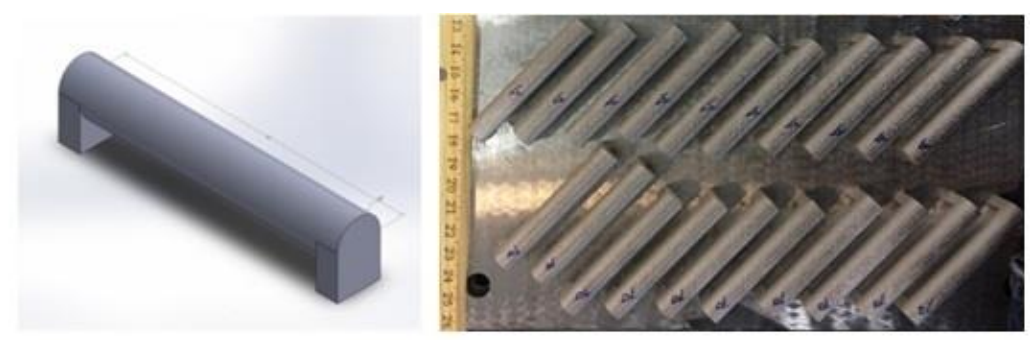

Sample orientation: Horizontal
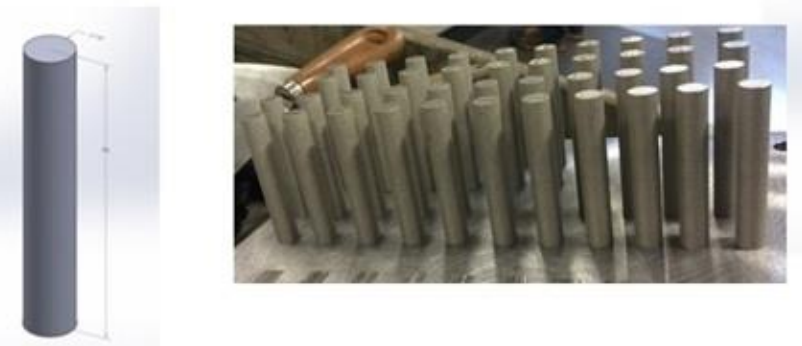

Sample orientation: Vertical
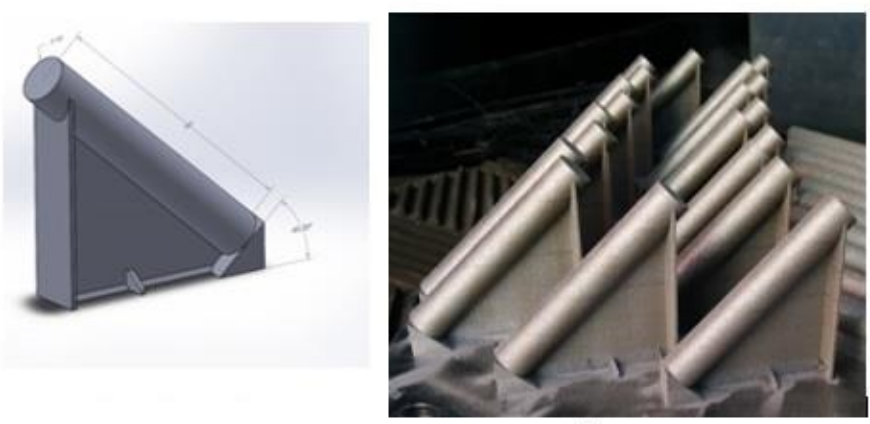

Sample orientation: inclined $45^{\circ}$

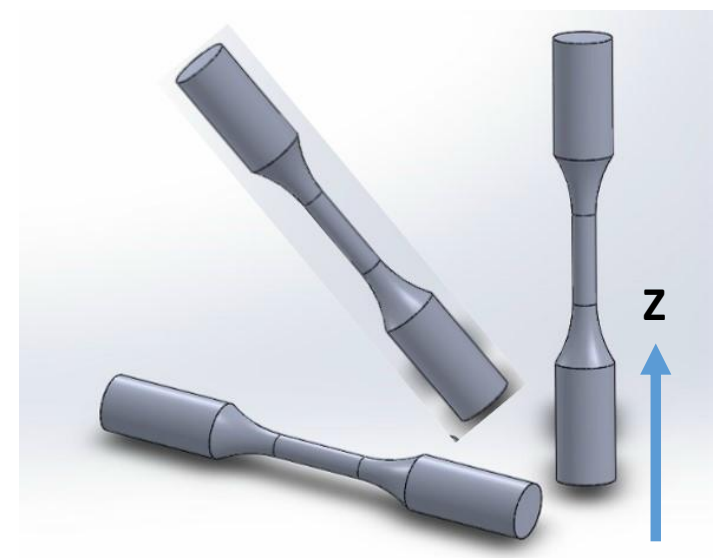

Figure 6. 2: CAD model and samples built for tensile testing in three different orientations. 
Table 6. 1: Build plan for tensile test specimens

\begin{tabular}{|c|c|c|c|}
\hline Scan Pattern & Post Process & $\begin{array}{l}\text { Build } \\
\text { Orientation }\end{array}$ & Replicates \\
\hline \multirow{6}{*}{ Rotating } & \multirow{3}{*}{ As built } & Horizontal & 3 \\
\hline & & $45^{\circ}$ Inclined & 3 \\
\hline & & Vertical & 3 \\
\hline & \multirow{3}{*}{ Heat treated } & Horizontal & 3 \\
\hline & & $45^{\circ}$ Inclined & 3 \\
\hline & & Vertical & 3 \\
\hline \multirow{6}{*}{ Alternating } & \multirow{3}{*}{ As built } & Horizontal & 3 \\
\hline & & $45^{\circ}$ Inclined & 3 \\
\hline & & Vertical & 3 \\
\hline & \multirow{3}{*}{ Heat treated } & Horizontal & 3 \\
\hline & & $45^{\circ}$ Inclined & 3 \\
\hline & & Vertical & 3 \\
\hline
\end{tabular}

Tensile testing was carried out on an Instron 5569A test machine with a $50 \mathrm{kN}$ capacity following ASTM E8M standard. The tensile fracture surfaces were examined using a FEI Nova Nano-scanning electron microscope equipped with an energy dispersive spectroscope (EDS) analysis system. Metallographic samples were prepared from the specimens for optical micrography and SEM using standard metallographic sample preparation methods. The polished samples were etched with Kalling's reagent.

\subsection{Results and discussion}

All of the 36 tensile tested samples (18 as-built and 18 heat treated samples) failed after a considerable amount of necking in the gauge length of the specimens. Representative stress-strain curves are shown in figure 6.3, and Table 6.2 summarizes the obtained results. Section 6.3.1 compares the effect of scan pattern where tensile samples built with rotating and alternating scan pattern in various build orientating are discussed. 
Section 6.3.2 describes the effect of the build orientation and post-processing heat treatment on the tensile behavior of the specimens, respectively, and Section 6.3.3 discusses the fracture characteristics of the samples.

Table 6. 2: Summary of the tensile test result.

\begin{tabular}{|l|l|l|l|l|l|}
\hline $\begin{array}{l}\text { Scan } \\
\text { Pattern }\end{array}$ & Post Process & $\begin{array}{l}\text { Build } \\
\text { Orientation }\end{array}$ & $\begin{array}{l}\text { YS }(\mathrm{MPa}) \\
{[\text { Offset }} \\
0.2 \%]\end{array}$ & $\begin{array}{l}\text { UTS } \\
(\mathrm{MPa})\end{array}$ & $\%$ Elongation \\
\hline Rotating & \multirow{2}{*}{ As built } & Horizontal & $915 \pm 14$ & $1250 \pm 3$ & $40.0 \pm 1.2$ \\
\cline { 3 - 6 } & & $45^{\circ}$ Inclined & $930 \pm 18$ & $1225 \pm 8$ & $38.8 \pm 2.3$ \\
\cline { 3 - 6 } & Vertical & $845 \pm 18$ & $1121 \pm 7$ & $41.0 \pm 0.4$ \\
\cline { 3 - 6 } & \multirow{3}{*}{ Heat treated } & Horizontal & $695 \pm 6$ & $1140 \pm 12$ & $47.7 \pm 0.7$ \\
\cline { 3 - 6 } & & $45^{\circ}$ Inclined & $740 \pm 24$ & $1150 \pm 20$ & $49.8 \pm 1.9$ \\
\cline { 3 - 6 } & Vertical & $615 \pm 42$ & $1030 \pm 1$ & $52.5 \pm 1.1$ \\
\hline \multirow{3}{*}{ Alternating built } & Horizontal & $928 \pm 10$ & $1300 \pm 6$ & $41.2 \pm 3.3$ \\
\cline { 3 - 6 } & & $45^{\circ}$ Inclined & $930 \pm 18$ & $1277 \pm 11$ & $38.5 \pm 1.3$ \\
\cline { 3 - 6 } & Vertical & $825 \pm 5$ & $1100 \pm 2$ & $41.7 \pm 0.6$ \\
\cline { 3 - 6 } & \multirow{3}{*}{ Heat treated } & Horizontal & $719 \pm 6$ & $1192 \pm 6$ & $46.7 \pm 0.4$ \\
\cline { 3 - 6 } & & $45^{\circ}$ Inclined & $710 \pm 19$ & $1150 \pm 37$ & $49.2 \pm 2.9$ \\
\cline { 3 - 6 } & Vertical & $650 \pm 2$ & $1012 \pm 4$ & $51.0 \pm 1.3$ \\
\hline
\end{tabular}
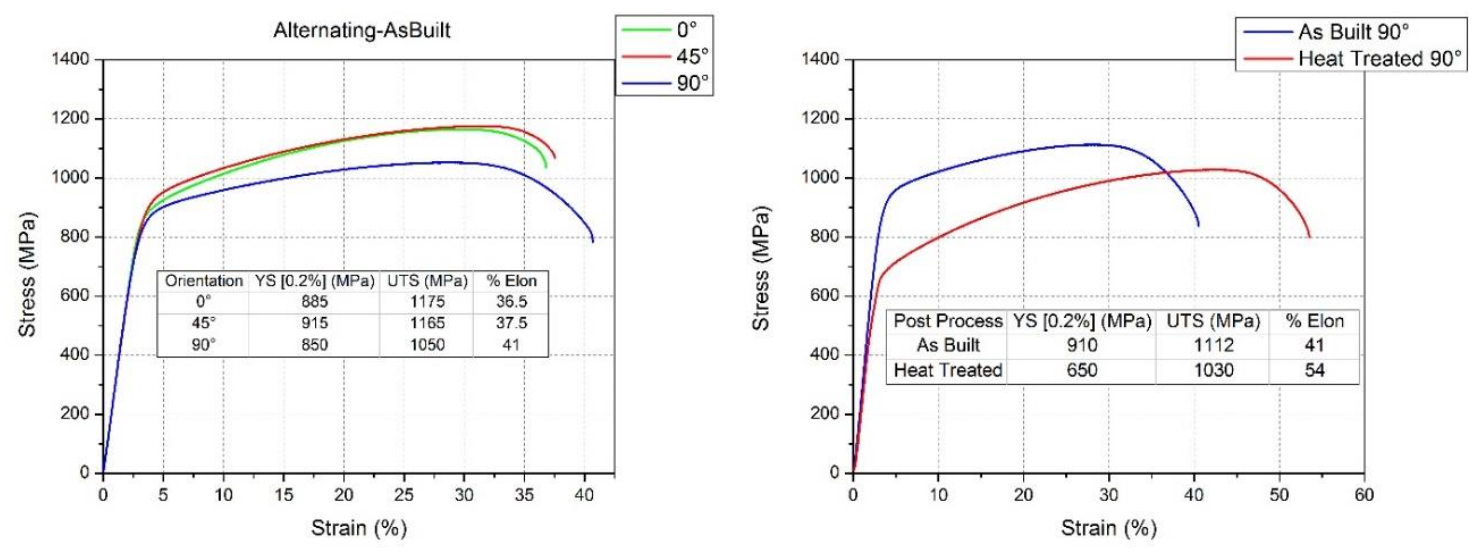

Figure 6. 3: Stress-strain curve showing build orientation effect (left) and post-processing effect (right). 


\subsubsection{Scan patterns}

Inconel 625 samples built using the two types of scan pattern were etched and observed under optical microscope. Figure 6.4 shows a horizontal cross-section of the samples where the laser tracks in multiple layers are clearly distinguishable. The angle between the laser tracks of two consecutive layers were measured to be $67^{\circ}$ for rotating, and $90^{\circ}$ for alternating pattern respectively.
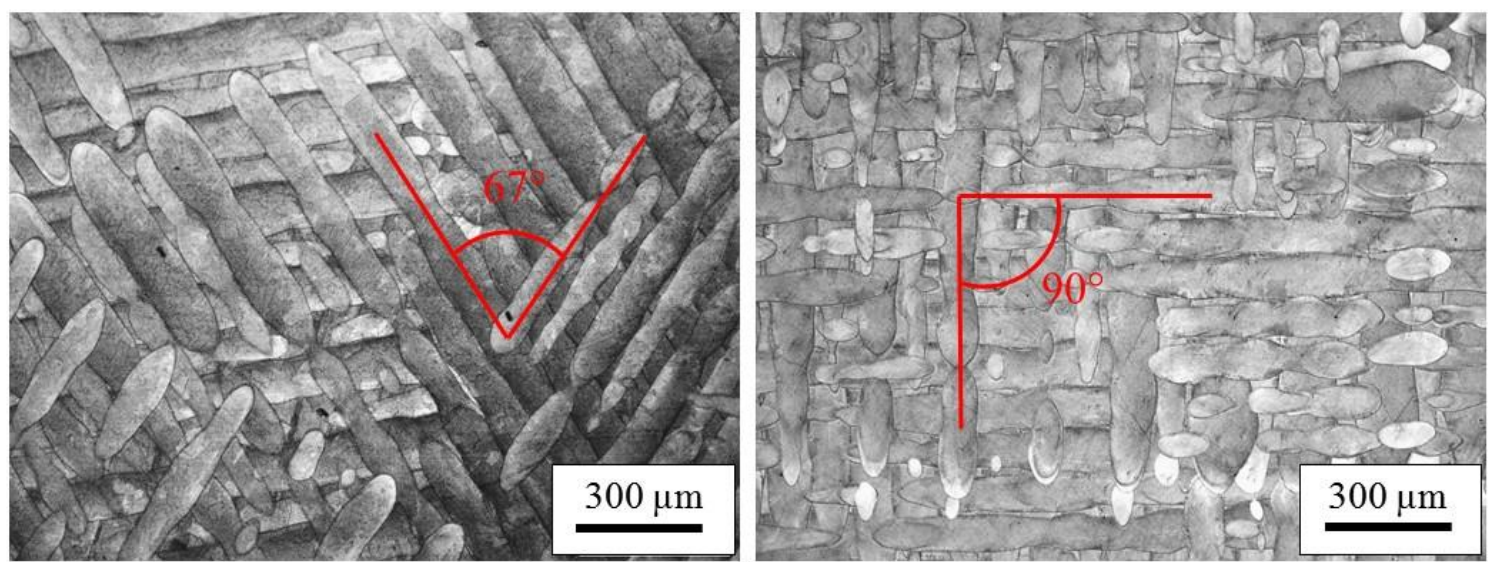

Figure 6. 4: Micrographs showing laser tracks for rotating pattern (left) and alternating pattern (right).

Microstructural change due to scan pattern variation can be observed in figure 6.5. From the vertical cross-section of the samples, the epitaxial growth of the elongated columnar structure can be observed, which continued across multiple melt pools in the build direction. For alternating scan pattern, the columnar structure was shorter in length compared to rotating pattern. Intercellular arm spacing was very fine $(<1 \mu \mathrm{m})$ for both cases which contribute to the excellent tensile strength. Another distinguishable feature is the presence of coarse structure in the inter-melt pool region for alternating scan pattern. This section is not overlapped and thus less refined $[32,97]$. These inter-meltpool region 
undergoes incipient melting and develops a network of undesirable interdendritic phase which may have a negative effect on material strength.

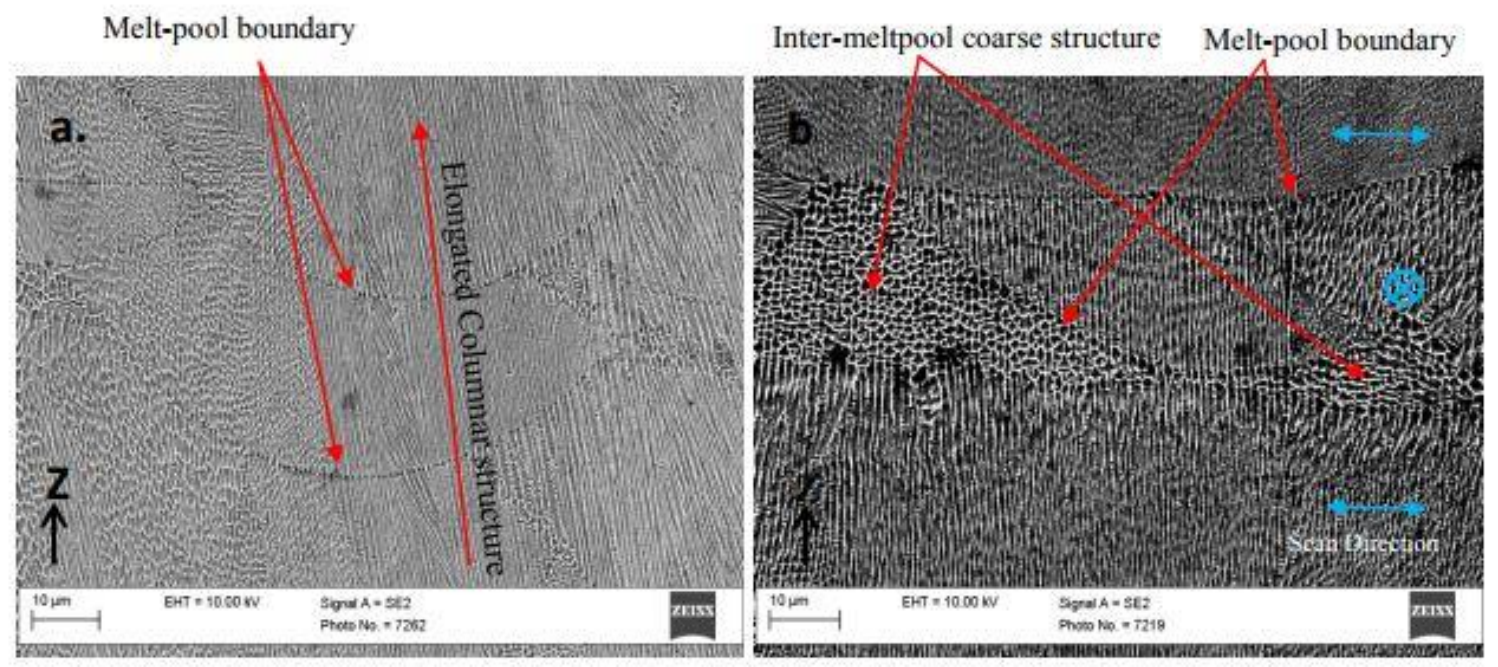

Figure 6. 5: SEM image showing vertical cross-section (YZ plane) of Inconel 625 sample built using (a) rotated stripe pattern and (b) alternating block pattern. Arrows in the right section in ' $b$ ' show alternating scan directions.

Tensile samples built with rotating and alternating patterns were tested and the results are plotted in figure 6.6 and 6.7. Figure 6.6 shows the YS and UTS of heat treated samples fabricated with alternating and rotating scan pattern. Figure 6.7 shows the percent elongation at failure data for alternating and rotating scan pattern both in as built and heat treated condition. Both as-built and heat treated samples were evaluated with respect to scan pattern variation. For as-built condition, the $0.2 \%$ yield strength (YS) and ultimate tensile strength (UTS) were high for all three orientations. This can be attribute to the extremely fine cellular/dendritic structure resulted from the very high cooling rate [98]. Both YS and UTS for all of the samples exceed the typical wrought product minimum values specified in AMS 5666 [99]. However, there is no statistically 
significant difference in strength was found due to scan pattern variation in any of the build direction. The microstructural difference caused by the scan pattern variation may not significant enough to cause any noticeable change in strength in this small crosssectional area. The effect, however, may become significant for larger gauge crosssectional area. The geometrical effect is present in additively manufactured parts which is reported by other authors [100]. It may also possible to find statistical significance for a higher number of sample size by reducing standard deviation. For heat treated samples, although the strength reduced significantly, there was no significant difference due to scan pattern variation. All samples exhibited an elongation at failure greater than typical minimum values reported in AMS 5666 and ASTM F3056 [99, 101]. Similar to the strength data, no significant difference was found due to scan pattern variation in both as built and heat treated condition in any of the three build orientations.

As Built

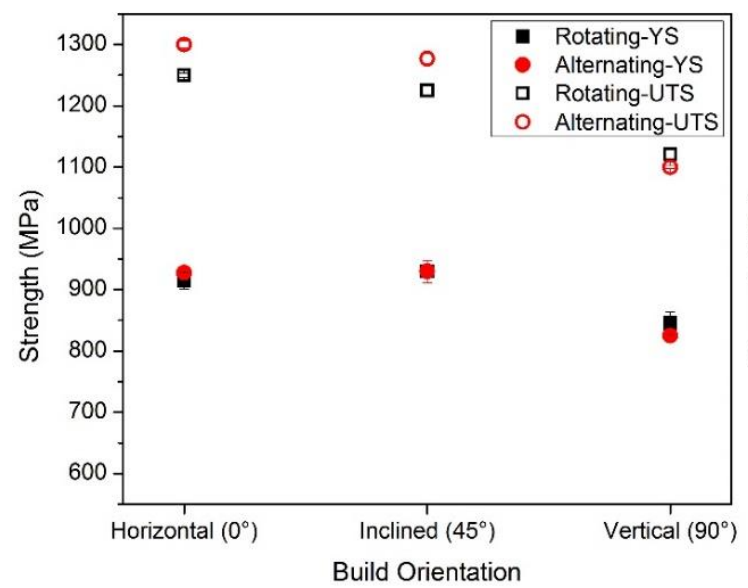

\section{Heat Treated}

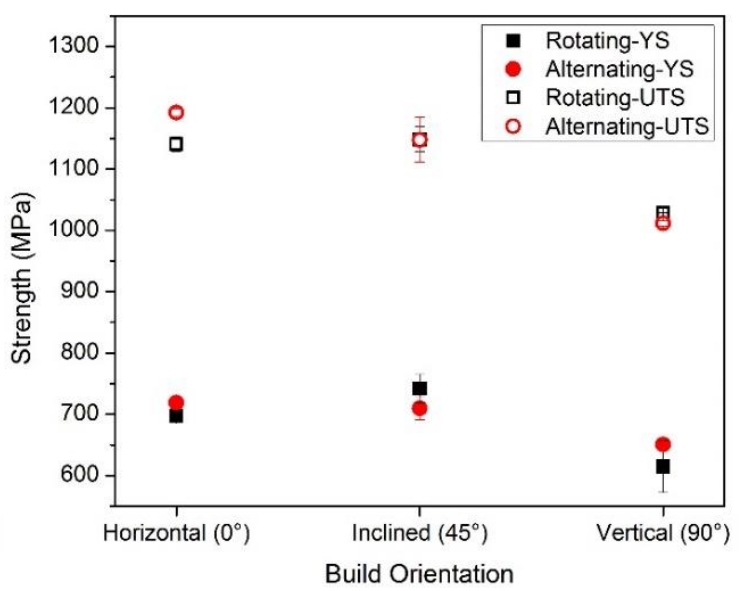

Figure 6. 6: Comparison of the tensile strength of samples fabricated with rotating and alternating scan pattern in different build orientations. The left figure shows results for as-built condition and the right figure for heat treated condition. 


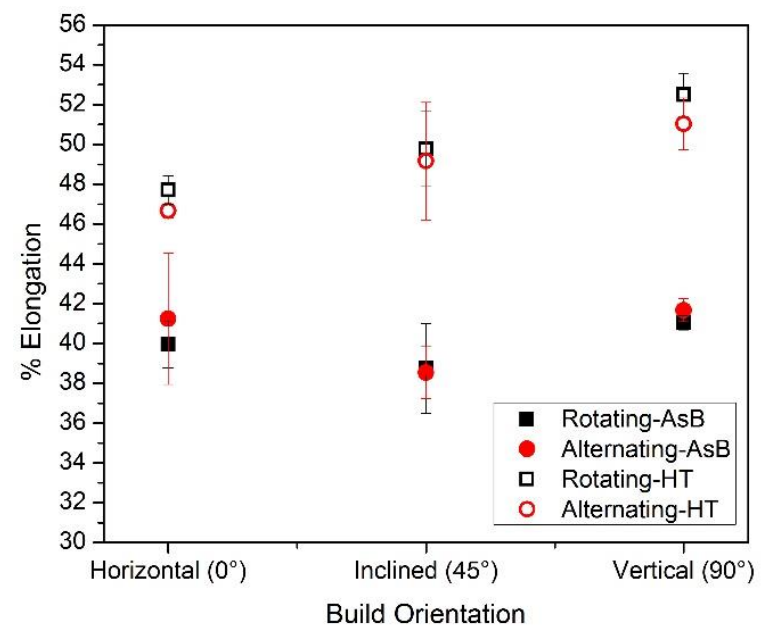

Figure 6. 7: Comparison of elongation of samples fabricated with rotating and alternating scan pattern.

\subsubsection{Build orientation and post-processing}

Anisotropy of tensile property for SLM process has been investigated extensively in recent years. Previous investigations on anisotropic behavior for Titanium and Stainless steel alloys revealed that material tensile property varies depending on build orientation, where vertically built sample showed more ductile property than horizontally build sample [92, 100, 102-104]. Similar behavior was observed in this analysis. Cylindrical tensile samples were built in three orientations: horizontal $\left(0^{\circ}\right)$, inclined $\left(45^{\circ}\right)$ and vertical $\left(90^{\circ}\right)$ and the tensile test results are shown in figure 6.8. The results show a strong evidence of anisotropic tensile behavior in both as-built and heat treated samples. For horizontally $\left(0^{\circ}\right)$ built sample, highest level of yield strength (YS) and ultimate tensile strength (UTS) are observed. The strength reduces as the orientation angle increases. Although the vertical samples exhibit the lowest strength among the three orientations, the YS and UTS were still higher than the typical wrought Inconel 625 minimum values found in AMS 5666 and in ASTM F3056 [99, 101]. Figure 6.8 also 
shows the percentage elongation at failure. Significant differences in ductility were found among samples built in three different orientation for both as built and heat treated conditions. All of the samples exhibited elongation greater than the minimum value found in AMS 5666 and ASTM F3056. Vertical $\left(90^{\circ}\right)$ samples showed the most ductile behavior. After the heat treatment, the ductility increased for all of the samples. The anisotropy still exists after the heat treatment.
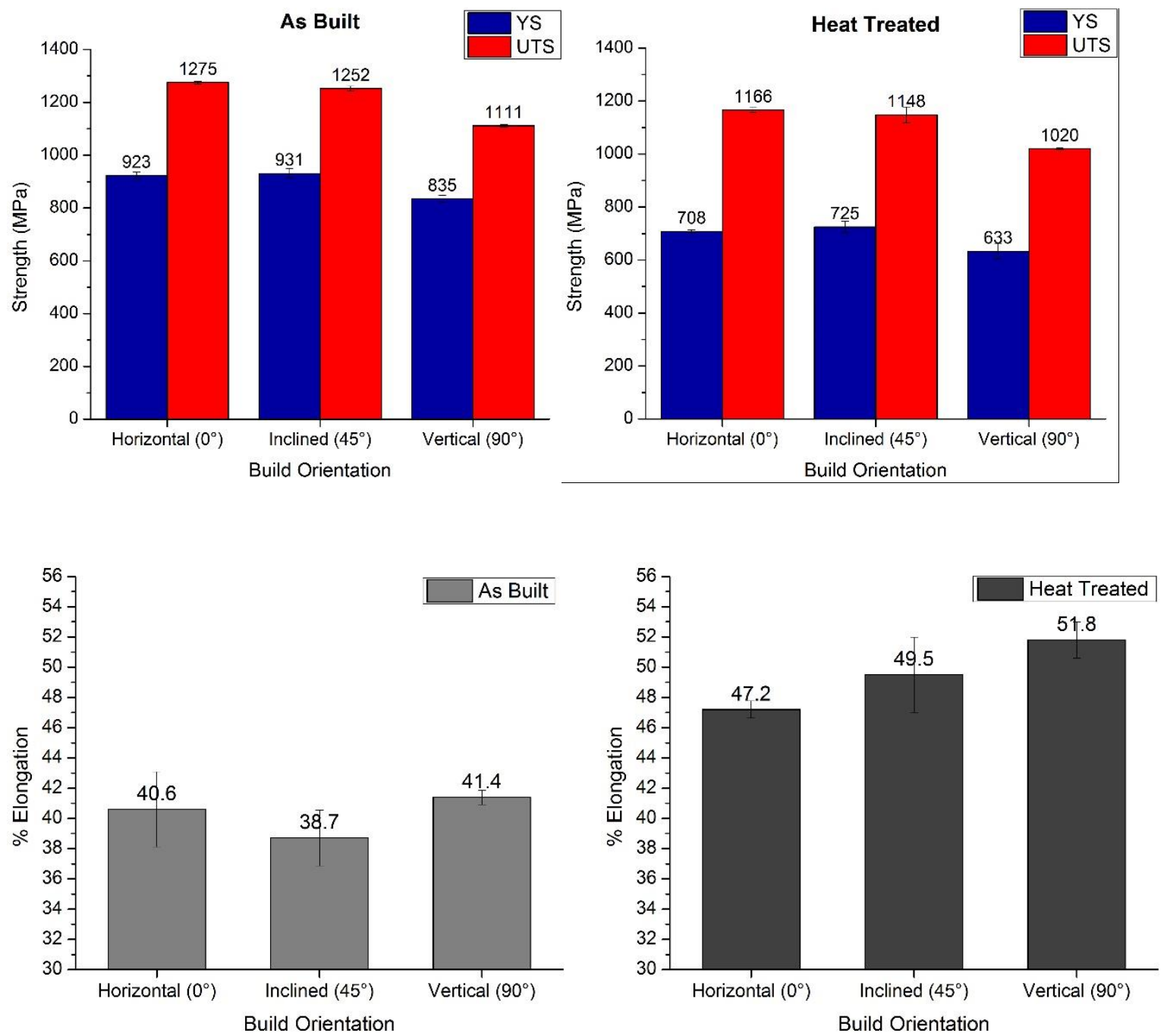

Figure 6. 8: Tensile property of Inconel 625 processed by SLM at different build orientation. 
Many of the researchers attributed the change of mechanical property to the porosity in additively manufactured parts. Two main types of pores exist within the SLM metal parts: gas entrapment pores which are generally rounded in shape and, the lack-offusion pores which are linear and sharp-angled cracks between layers. The gas present in the powder bed may dissolve in the molten pool during the fusion process which may get entrapped because of the high cooling rate and forms the first type of pores. The lack of fusion pores occurs when the molten pool cannot fully encompass the spaces intended to be melted thus leaving a thin flat crack perpendicular to the build direction or between neighboring tracks. This type of pores was reported to have bigger sizes than the gas entrapped pores and more detrimental effect on the tensile properties [100]. In this study, the tensile sample built in vertical orientation has a higher number of layers than the horizontally built sample, thus can be expected to have a higher possibility of developing random lack of fusion pores. The tips of the pores introduce local stress concentrations during the loading and therefore result in early fracture of the parts especially for vertically build part [102]. Both types of porosity can be reduced by carefully selecting the process parameters. Proper laser power, scan speed, and scan pattern can be chosen to have a melt pool to melt at least 2-3 layers of the substrate to avoid the keyhole effect $[57,105]$.

Optimum process parameters for Inconel 625 identified in the earlier work were used to build the test specimen. Samples were checked for porosity using Archimedes method and image processing. The results show that the samples have very low pore volume fraction of less than $0.01 \%$. The pores were mainly formed by gas entrapment and exhibit very fine and round morphologies. Therefore, it could be concluded that the 
underlying reason for anisotropic behavior in this study was mainly due to the anisotropic microstructure of Inconel 625 samples. Figure 6.9 shows a cross-sectional micrograph from EBSD under as-built condition where different grains are shown in different colors. It is observed that the grains are elongated and oriented towards the build direction. It is also noticed that some grains are large enough to traverse multiple melt-pools. The grain boundary and interdendritic arm spacing are reported to have a large amount of segregation with enhanced precipitation of $\mathrm{Nb}$ and Mo. The formation of these precipitates is due to the micro-segregation of these elements (of high atomic number) into interdendritic and grain boundary regions during the solidification of the molten alloy $[3,4,12,57,105]$. It is well documented that there are mainly two types of phases presents in grain boundary: the Laves phase $(\mathrm{Ni}, \mathrm{Cr}, \mathrm{Fe})_{2}(\mathrm{Nb}, \mathrm{Mo}, \mathrm{Ti})$ and carbide particles (MC) $[5,15,26,81,106]$. These phases are less ductile compared to the $\gamma$ matrix and tend to reduce elongation by providing a preferential site for crack initiation and propagation $[16,81,106,107]$.

The build orientation dependency of elongation and strength can be understood by analyzing the relationships between the loading direction and the grain orientation. The fracture characteristics of differently oriented sample is described in figure 6.10. For a horizontally built sample, the grain boundary is perpendicular to the applied load and therefore, subjected to Mode I opening failure. A possible tensile fracture line drawn along the grain boundaries of the microstructure of the horizontal sample indicates that the fracture surface should be less corrugated, and the material should undergo relatively little plastic deformation. On the other hand for the vertically built sample, the grain boundaries are nearly parallel to the loading direction. In this case, a large portion of the 
boundaries are not subjected to Mode I fracture failure. A possible fracture line indicating a more tortuous crack path and therefore, more corrugated fracture surface profiles. As a result, the sample are expeted to exhibit more ductility than horizontal sample. Analysis on fracture tensile surface is discussed in section 6.3.3.

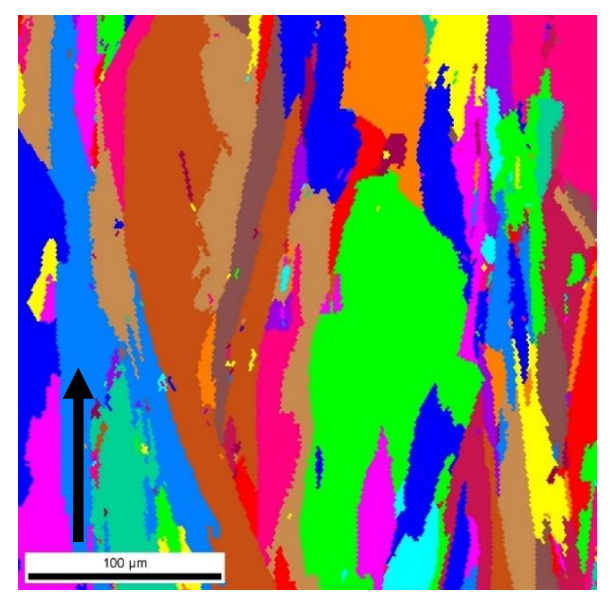

Figure 6. 9: Color grain map of a vertical cross-section of Inconel 625 sample fabricated by SLM process. Arrow indicates the build direction.
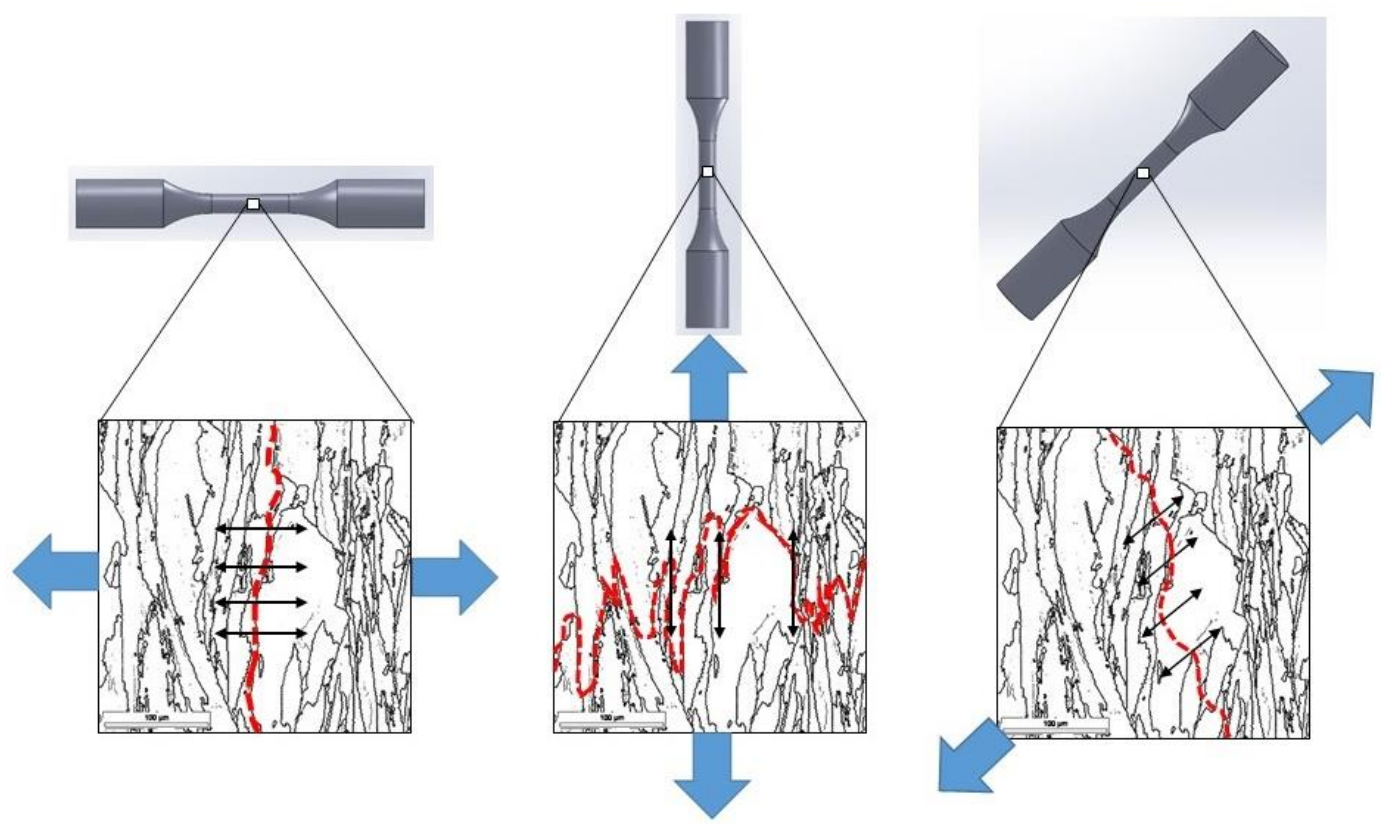

Figure 6. 10: Schematic showing the direction of the tensile load relative to the grain orientation for samples built in three different orientations. 
A comparison of microstructure between as-built and heat treated condition is shown in figure 6.11. In both micrographs, the build direction is vertical. The as-built microstructure in figure 6.11 (a) exhibits elongated cellular dendritic structure in which the melt pool boundaries are clearly observed. After the heat treatment, the microstructure become homogenized, which eliminated the melt-pool boundaries and dendritic structure (figure 6.11 (b)). The microstructure primarily consisted of $\mathrm{NiCr}$ grain structure with intergranular precipitates. The presence of laves particles is reported in the precipitates [4]. During the heat treatment, a large amount of Laves particles dissolved and formed needle-like $\delta\left(\mathrm{Ni}_{3} \mathrm{Nb}\right)$ precipitates at the grain boundary [4]. The presence of $\delta$ precipitates in the grain boundary is beneficial for improving ductility [106]. The recrystallized microstructure retains some original elongated grains oriented in build direction. This is because of the low diffusivity of the large $\mathrm{Nb}$ atom which results in poor dissolution of Laves particle. However, an exposure to a very high temperature can increase the dissolution of Laves particles in this alloy [107].
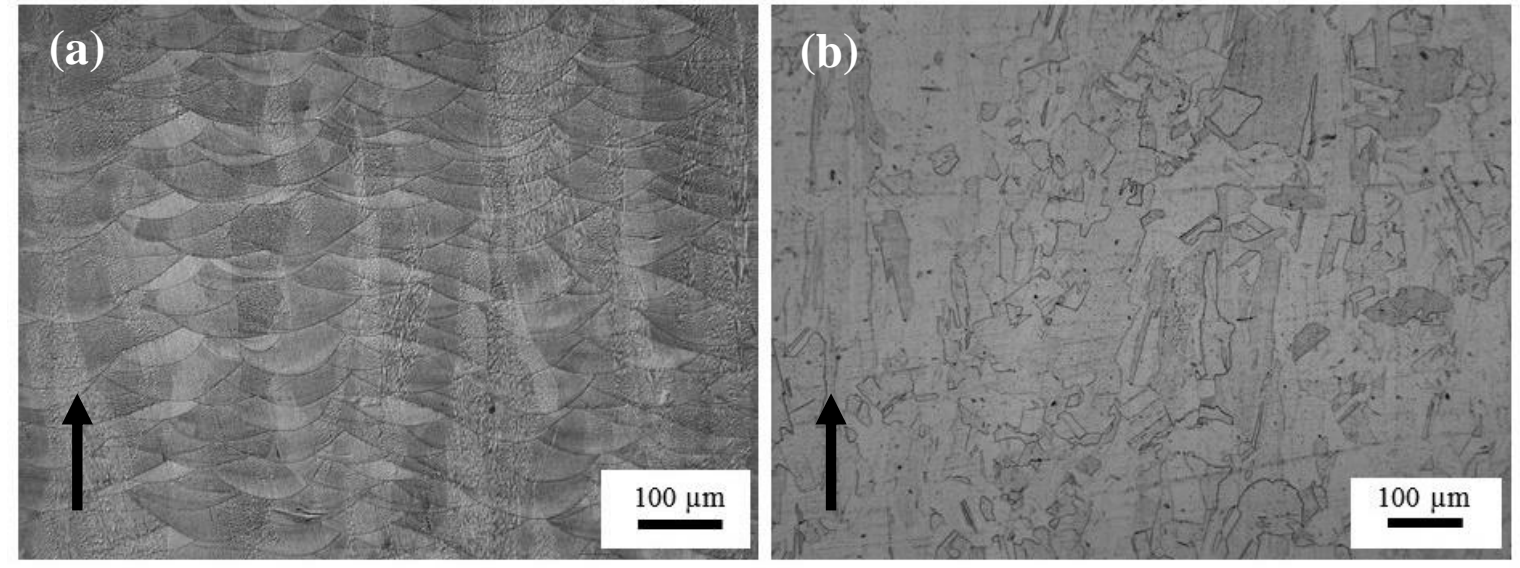

Figure 6. 11: Vertical cross-section of Inconel 625 samples, (a) microstructure in as-built condition, (b) microstructure after heat treatment. The arrow shows the build direction. 
The effect of heat treatment can be clearly distinguished by the tensile test data presented in figure 6.8. It is observed that both YS and UTS reduce significantly after the heat treatment. This is because of the recrystallization of the columnar grains and the change of precipitates. However, the reduced YS and UTS values are still higher than the typical wrought Inconel 625 minimum values found in AMS 5666 and in ASTM F3056 $[99,101]$. Figure 6.8 also shows the comparison in ductility after heat treatment. It is observed that the loss of yield strength due to heat treatment involves an increase of ductility even though the anisotropy is maintained. The anisotropy is mainly due to the elongated grain that still presents after the heat treatment.

\subsubsection{Fractography}

The fracture surfaces of Inconel 625 tensile samples built in three different orientations were analyzed. Both as-built and heat-treated samples were considered. Examination of the fracture surfaces revealed the effect of microstructure on the tensile property of the alloy. Figure 6.12 shows the representative fractograph of an as-built horizontal $\left(0^{\circ}\right)$ sample. It is clear from the overall view of the fractograph that the sample exhibit comparatively flat and smooth fracture surface. Figure 6.12 (b) shows the presence of sharp and smooth cleavage fracture as well as the dimple ductile fracture indicating a mixed mode of ductile and brittle failure mechanism in the horizontally build sample. Microvoid can be seen in figure 6.12 (c). These voids coalesce due to the plastic deformation of the material between them [91]. For Inconel 625 the microvoids initiate from the Laves/matrix interface, and sometimes the Lavis particles can be found inside 
the dimples [106, 107]. Figure 6.12 (d) shows the fine but shallow dimple structure which is an evidence of low ductility of horizontally built parts.

The fractography of the vertically built sample tested in as-built condition is shown in figure 6.13. A rougher surface compared to horizontally built sample was observed, which illustrates the more tortuous fracture line described earlier. A large number of microvoids, as well as some grain boundary cracks, are noticeable in figure 6.13 (b), which indicates the presence of the intergranular fracture mechanism. Some of the voids are found to be on the path of grain boundary crack. These voids likely acted as either crack initiation sites or faciliated crack propagation. A higher magnification of such crack initiator is shown in figure 6.13 (c). Fine dimple structure is observed (figure 6.13 (d)), but unlike the horizontal sample, the dimples are deeper which indicates a more ductile nature of the vertically built sample. 

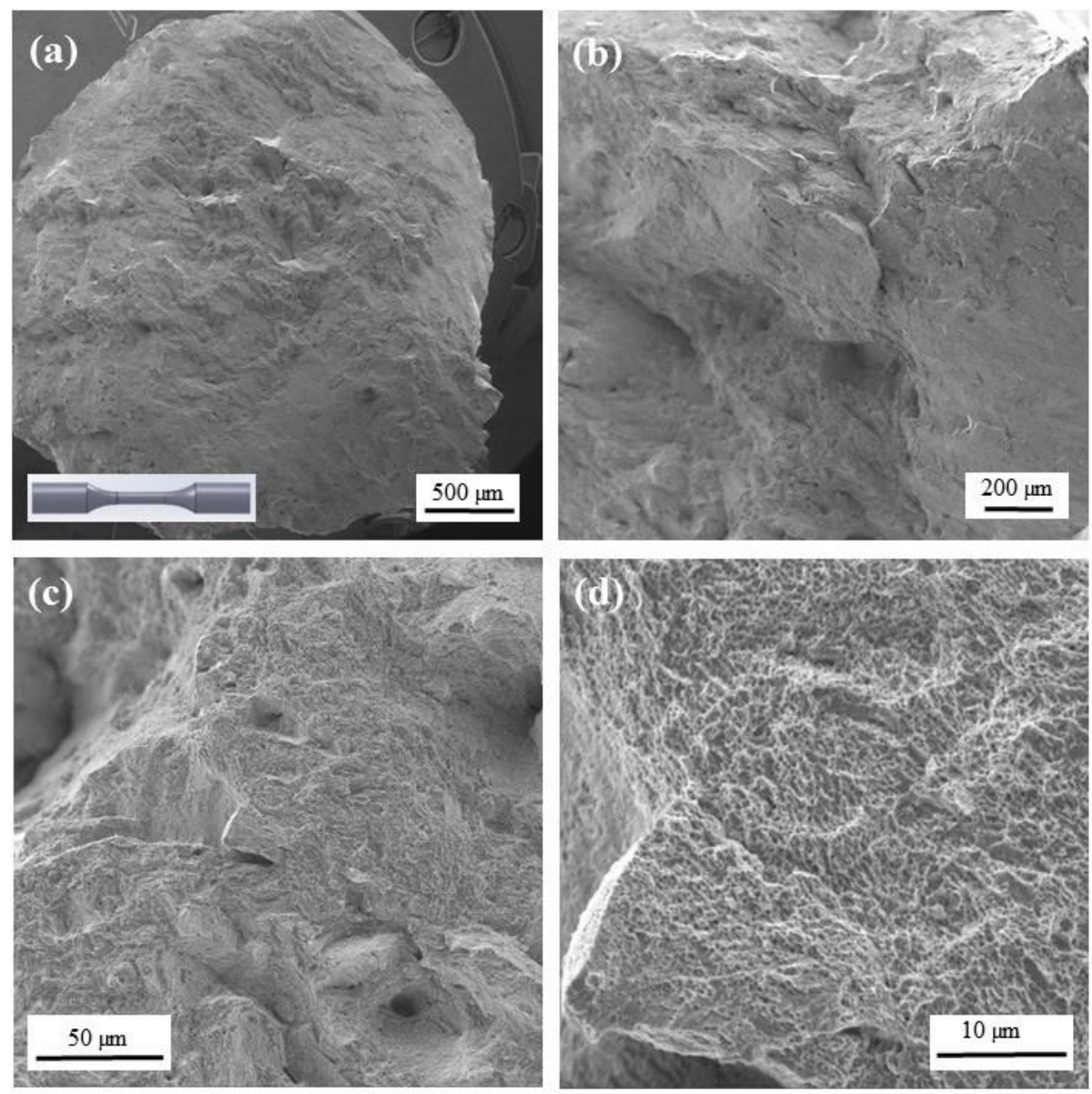

Figure 6. 12: Tensile fracture surface of horizontally $\left(0^{\circ}\right)$ built Inconel 625 sample tested in as-built condition, (a) overall view showing a smooth flat surface, (b) cleavage fracture with a ductile dimple structure, (c) magnified view showing microvoid, (d) fine and shallow dimple structure. 

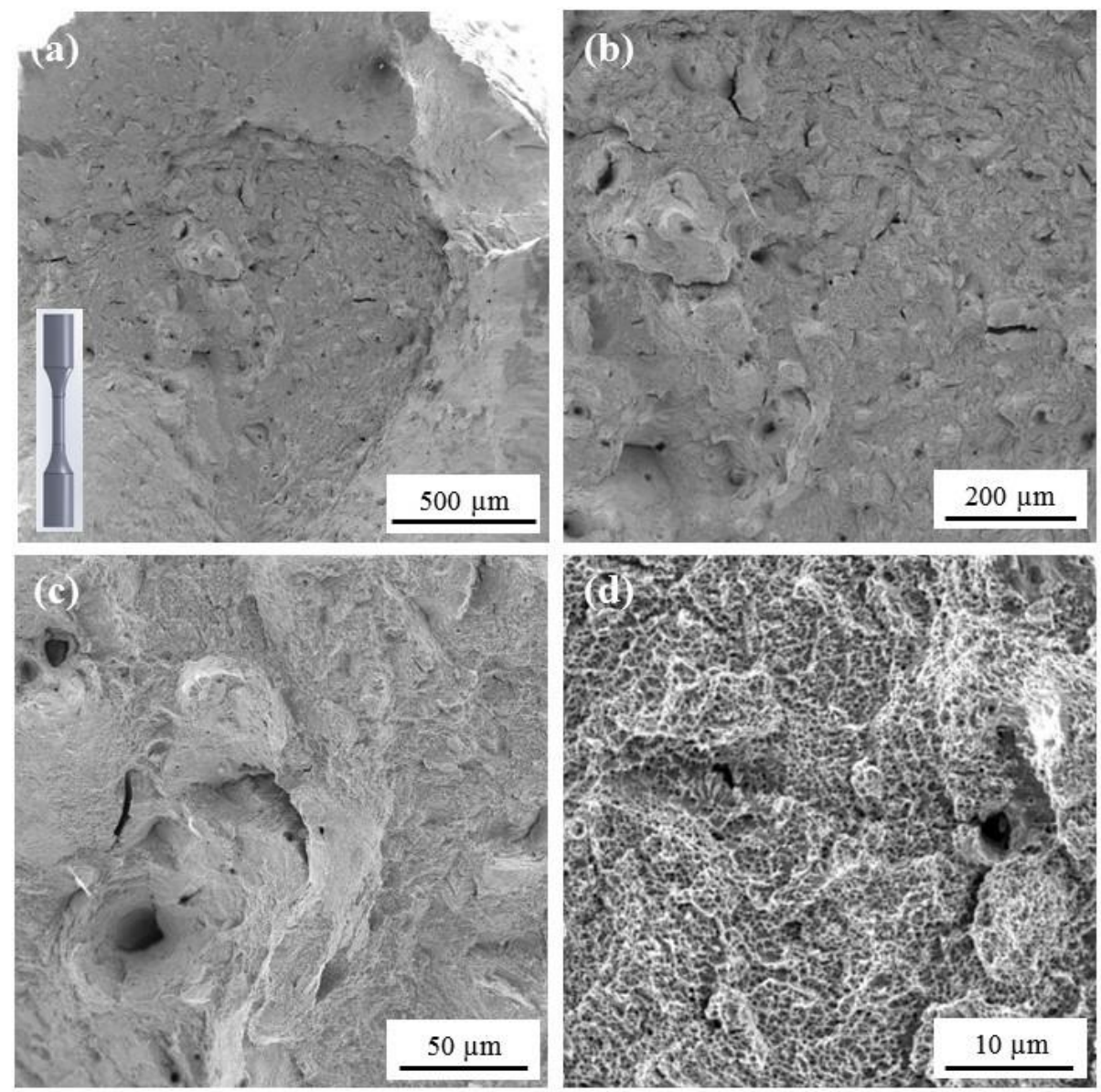

Figure 6. 13: Tensile fracture surface of vertically $\left(90^{\circ}\right)$ built Inconel 625 sample tested in as-built condition, (a) overall view showing a rough surface, (b) a ductile dimple structure with microvoids and grain boundary cracks, (c) magnified view showing microvoid, (d) fine dimple structure with microcracks.

Figure 6.14 and 6.15 show the fractographs of the sample tested after heat treatment. A smooth and flat fracture surface morphology was observed for the horizontal $\left(0^{\circ}\right)$ heat treated sample (figure 6.14 (a), (b)) which is quite similar to the surface observed in as-built condition, except that fewer microvoids were noticed after heat treatment. Grain boundary secondary cracks were noticeable in figure 6.14 (c). The high magnification image also shows very fine dimple structure indicating high ductility of the 
heat treated sample. Fractographs of the heat treated vertical samples are shown in figure 6.15. The sample has a ductile cup-and-cone feature similar to as-built sample. However, the sample is seen to exhibit less rough surface charactierstics as well as less number of voids compared to as-built sample, which is due to the recrystallization of the elongated grain structure that provides higher levels of ductility among the samples.
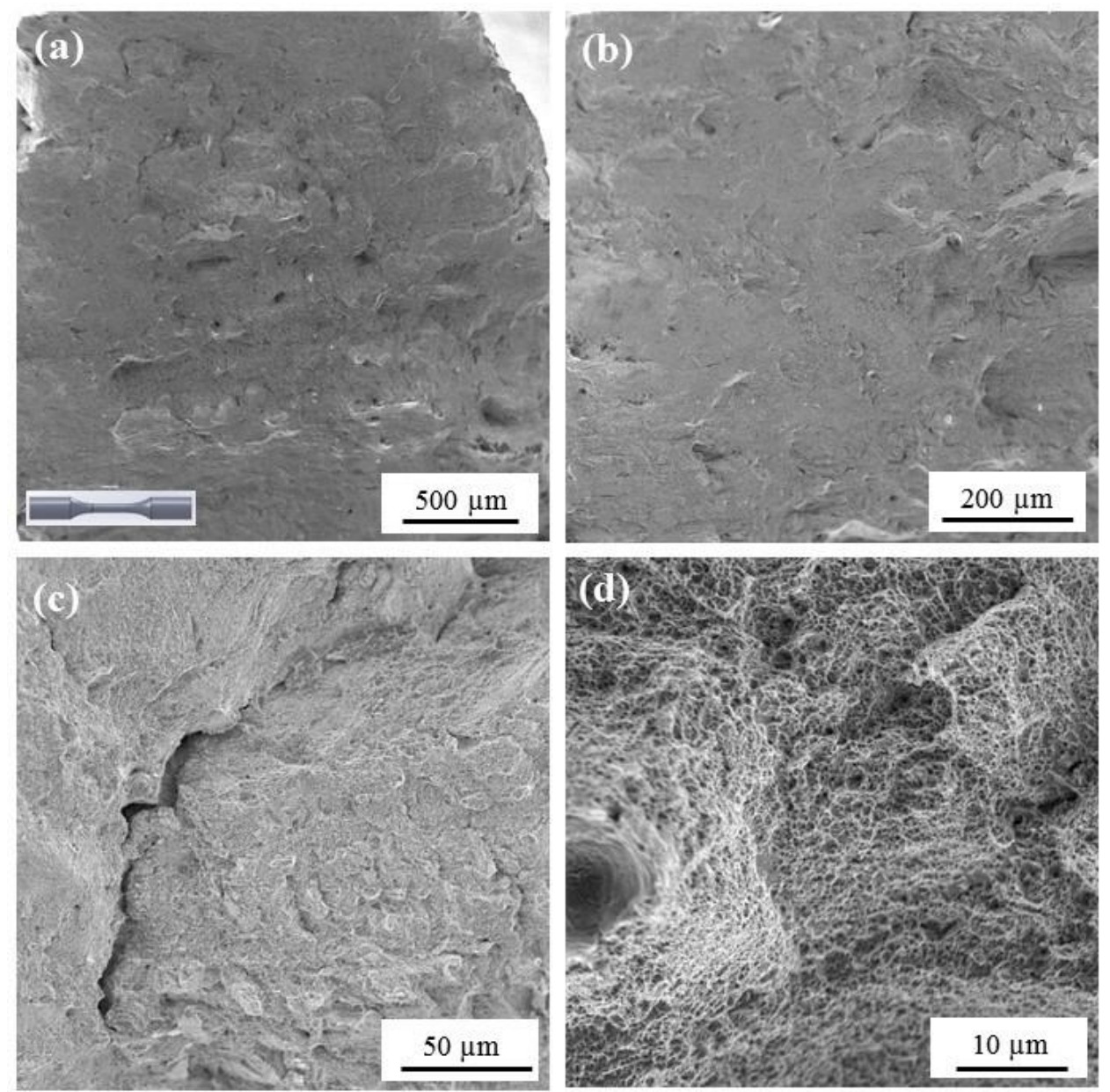

Figure 6. 14: Tensile fracture surface of horizontally $\left(0^{\circ}\right)$ built Inconel 625 sample tested in heat treated condition, (a) overall view showing a smooth flat surface, (b) small number of microvoids can be seen, (c) magnified view showing grain boundary crack, (d) fine and shallow dimple structure. 

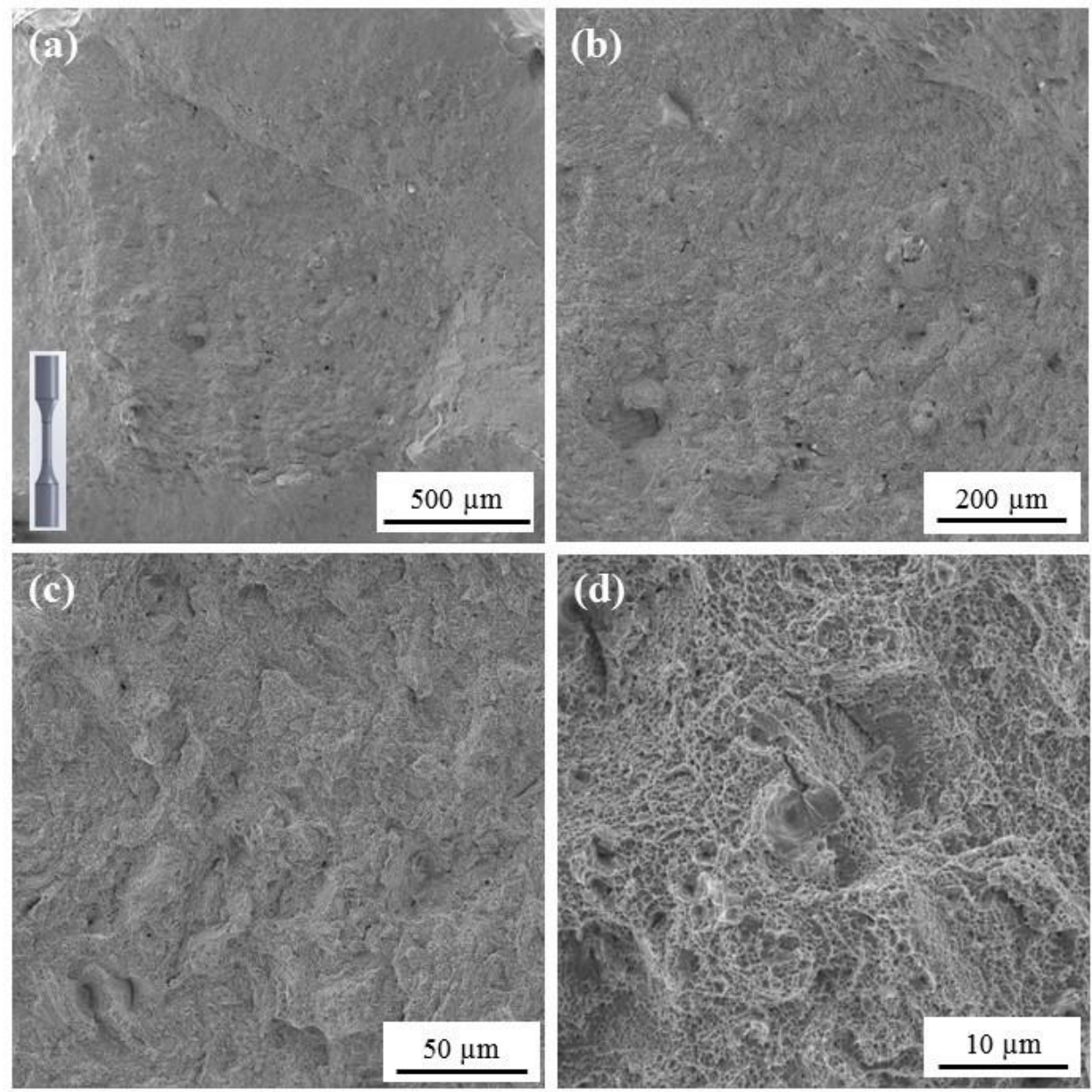

Figure 6. 15: Tensile fracture surface of vertically $\left(90^{\circ}\right)$ built Inconel 625 sample tested in heat treated condition, (a) overall view showing a rough surface, (b) a ductile dimple structure with microvoids, (c) magnified view showing microcracks, (d) fine dimple structure.

Fracture surfaces from samples built in inclined $\left(45^{\circ}\right)$ orientation are shown in figure 6.16. Figure (a), (b) and (c) are from a sample tested in as-built condition and (d), (e) and (f) are from a heat-treated sample. From the image, one distinguishable characteristics is the formation of shear lips which is inclined at an angle to the tensile loading direction (figure 6.16 (a), (d)). Elongated shear dimples were found in the shear lips (figure 6.17). This is due to the inclined orientation of the grain relative to loading 
direction. Both as-built and heat-treated samples have relatively less rough surface and showed less ductility compared to the vertical $\left(90^{\circ}\right)$ sample. Microvoids and grain boundary cracks were seen in the as-built inclined sample (figure 6.16 (b)), which also reduce after the heat treatment (figure 6.16 (e)). In both cases, fine dimple fracture characteristic is present, (figure 6.16 (c) and 6.16 (f)) which indicates good ductility.

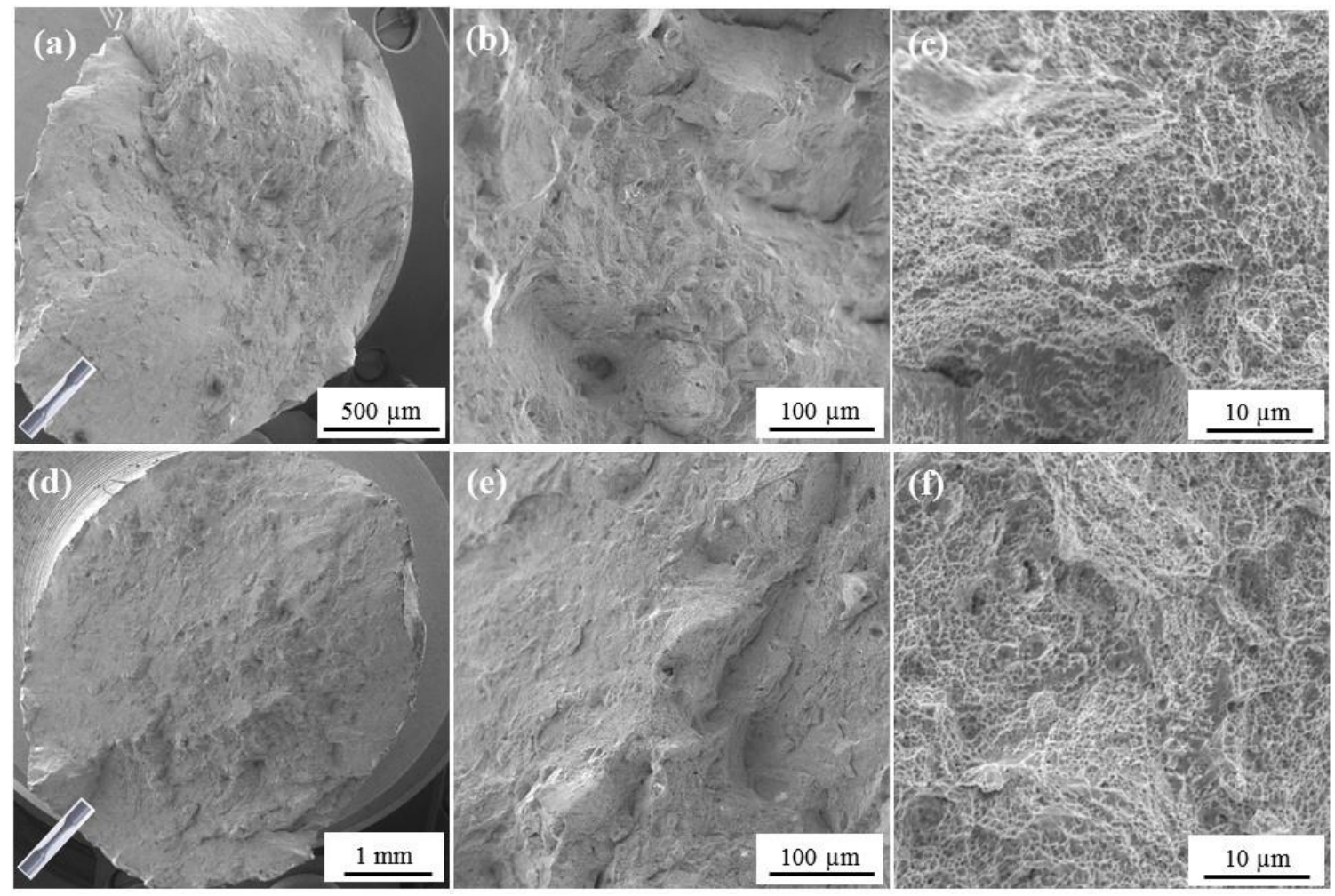

Figure 6. 16:Tensile fracture surface Inconel 625 sample built in inclined $\left(45^{\circ}\right)$ orientation. (a), (b), and (c) are from a sample tested in as-built condition while (d), (e) and (f) are from a heat-treated sample. 


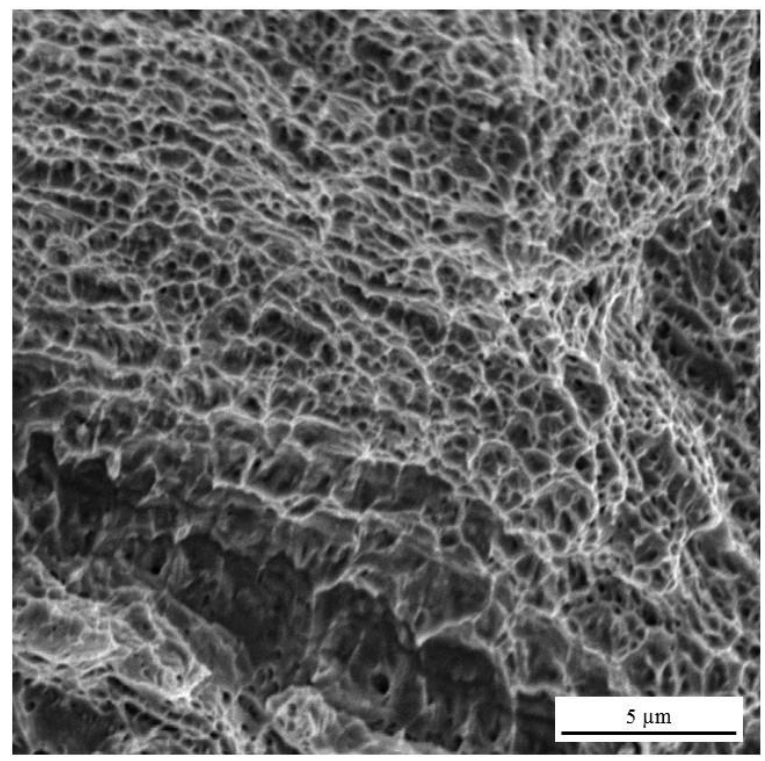

Figure 6. 17: Elongated shear dimples were found in the share lips of as-built inclined tensile sample.

\subsection{Conclusion}

The following conclusions can be drawn from the current study:

1. The tensile properties of SLM built Inconel 625 samples are comparable to or even better than wrought material. Microstructure analysis shows a very fine cellular structure which contributes to the excellent strength. Grains grow epitaxially and there is grain continuity across multiple melt pools in the build direction. For alternating pattern, the elongated columns are found to have shorter length compared to a rotating scan pattern. However, no statistical difference in tensile property was found due to scan pattern difference.

2. The tensile properties are affected by the build orientation. The horizontal build orientation provides better tensile strength than the vertical or inclined tensile specimen.

3. For all three orientations, tensile failure is a mix of ductile and brittle modes. 
4. The ductility of the samples increases and strength decreases after heat treatment due to the recrystallization of the elongated grains. Brittle Lavis phase which acts as microvoid initiator dissolves after heat treatment and forms less brittle $\delta$ phase. 


\section{CHAPTER 7}

\section{FATIGUE BEHAVIOR OF INCONEL 625 MANUFACTURED BY SELECTIVE LASER MELTING}

\subsection{Introduction}

Selective Laser Melting (SLM) is an Additive Manufacturing (AM) process for fabricating metal parts $[50,90]$. SLM is attracting considerable interest because of its ability to produce complex parts directly from CAD model. In this process, a thin layer of metal powders is scanned by a high-intensity laser beam. The scanned area of the powder gets melted and quickly solidifies. The powder is spread on top of the solidified layer and the melting process is repeated. In this way, successive layers of metal powder are melted until the parts are completed. The unmelted metal powder provides support to the parts. However, it is necessary to provide a solid support to attach the part with the rigid base in order to hold the part in place. The solid support also facilitates in dissipating heat thus reduce residual stress and distortion. SLM offers various advantages compared to conventional production techniques, such as the ability to produce complex shape, a high level of flexibility, a near net shape production and a high material use efficiency [52].

Inconel 625, a nickel-based superalloy is well known for its superior properties such as high tensile, creep and rupture strength, excellent fatigue, and good oxidation resistance [81]. However, due to excessive tool wear and low material removal rate, this 
material is difficult to process by conventional machining methods [58]. Selective laser melting, therefore, becomes a possible option for fabricating complex Inconel 625 parts.

Though SLM offers many benefits over conventional manufacturing, it still has some challenges to overcome. SLM is characterized by highly localized heat input for a very short period of time, which has a profound impact on microstructure [57]. The hightemperature gradients and rapid solidification cause high thermal stress build-up and the formation of non-equilibrium phases and porosity [91]. The unique microstructure and porosity both have a significant effect on the resulting mechanical property of the parts. Although superior tensile strength was observed compared to the wrought product, research on the tensile property of Inconel 625 by SLM showed the presence of anisotropy [108]. Horizontally built samples are reported to have higher tensile strength than vertically built samples [76]. The anisotropy is due to the formation of columnar grains and pores [109]. Although a significant amount of research has been done on the microstructure and the tensile property of Inconel 625, there is no study reported on their fatigue characteristics. On the other hand, fatigue data for wrought Inconel 625 is available in the Metallic Materials Properties Development and Standardization Handbook, (MMPDS) [110]. In the current study, the fatigue behavior of Inconel 625 solid cylindrical parts fabricated by SLM is investigated. The experimental result is compared with MMPDS data. The effect of different build orientation and postfabrication heat treatment are studied with corresponding fracture behavior. 
7.2 Material and experimental detail

7.2.1. Material specifications:

The material used in the current study was Inconel 625, a nickel-based superalloy in powder form. Table 1 below shows the chemical composition of the alloy. The morphology of the powder particles was characterized by a Zeiss Supra 35 Scanning Electron Microscope (SEM) and the size distribution was analyzed using a Microtrac S3000 laser-based particle size analyzer. The particles have a spherical shape with a homogeneous size distribution between $15 \mu \mathrm{m}$ and $50 \mu \mathrm{m}$. Figure 1 shows the gas atomized powder particles. A high magnification image shows the microdendritic structure of the particles (figure 1 (b)). Some larger particles are seen to have satellite particle attached to them.

Table 7. 1: Elemental composition analysis of the Inconel 625 as-built deposit carried out using optical emission spectroscopy.

\begin{tabular}{|c|c|c|c|c|c|c|c|c|c|c|c|c|c|c|c|}
\hline $\mathrm{Al}$ & $\mathrm{C}$ & $\mathrm{Nb}$ & $\mathrm{Cr}$ & $\mathrm{Fe}$ & $\mathrm{Mn}$ & $\mathrm{Mo}$ & $\mathrm{P}$ & $\mathrm{S}$ & $\mathrm{Si}$ & $\mathrm{Ti}$ & $\mathrm{Co}$ & $\mathrm{Cu}$ & $\mathrm{W}$ & $\mathrm{V}$ & $\mathrm{Ni}$ \\
\hline $\begin{array}{c}0.31 \\
\%\end{array}$ & 0.02 & 4.09 & 21.49 & 0.68 & 0.05 & 8.34 & $<0.005$ & $<0.005$ & 0.10 & 0.34 & 0.22 & 0.01 & 0.01 & 0.01 & Rest \\
\hline
\end{tabular}
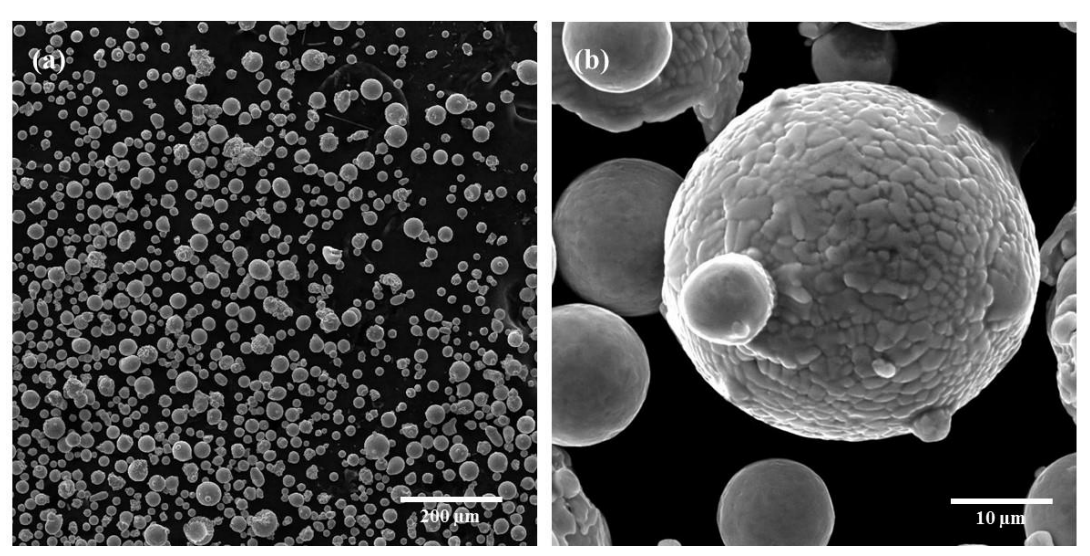

Figure 7. 1: (a) Scanning electron micrograph of Inconel 625 powders (b) High magnification image showing dendritic features. 


\subsubsection{Methods}

An EOS M270 direct metal laser sintering machine equipped with an Nd:YAG fiber laser with a maximum power of $200 \mathrm{~W}$ was used to fabricate the tensile and fatigue samples. Process parameters used for building the sample are laser power $195 \mathrm{~W}$, scan speed $800 \mathrm{~mm} / \mathrm{s}$, layer thickness $20 \mu \mathrm{m}$, beam diameter $100 \mu \mathrm{m}$, and hatch spacing 100 $\mu \mathrm{m}$. The process chamber was purged with Argon gas to avoid oxidation. The operational temperature of the internal chamber was fixed at $80{ }^{\circ} \mathrm{C}$.

\subsubsection{Test conditions}

For tensile, twelve cylindrical samples were fabricated in two different orientation; horizontal (XY) and vertical ( $\mathrm{Z}$ - along build direction). Half of the samples were heat treated at $1038^{\circ} \mathrm{C}$ for 1 hour in an argon-filled furnace for stress relief and water quenched to room temperature. The gauge section of the samples was machined per the drawing is shown in figure 7.2 and polished with 1200-grit sandpaper. Tensile testing was carried out on an Instron $50 \mathrm{kN}$ test machine (model: 5569A) and the tensile specimens were prepared as per ASTM E8M.

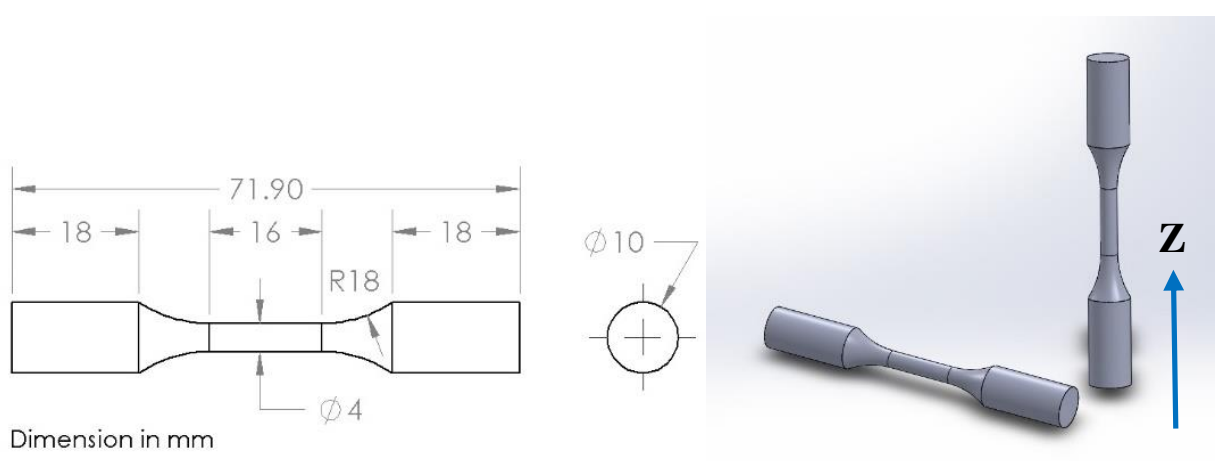

Figure 7. 2: CAD of tensile test sample (unit: $\mathrm{mm}$ ).

For fatigue test, forty cylindrical bars were fabricated in horizontal (XY) and vertical $(Z)$ direction. Similar heat treatment and machining procedure were followed as 
tensile samples. The cylindrical bars were then machined in the gauge section to form the dog-bone shape of the fatigue specimen. The dimension of the fatigue sample is shown in Figure 7.3. Table 7.2 shows the experimental detail. The gauge sections were hand polished with 1200-grit sandpaper. Fatigue tests were conducted on an Instron ElectroPlus E10000 test machine per ASTM E466-07 at room temperature. A sinusoidal load with frequency $40 \mathrm{~Hz}$ was applied where the stress ratio was $\mathrm{R}=-1$ and the maximum stress levels ranged between 350 to $750 \mathrm{MPa}$. Run-out of the fatigue testing was $10^{7}$ cycles.

The fatigue fracture surfaces were examined using a Zeiss Supra 35 scanning electron microscopes equipped with an EDS analysis system. Metallographic samples were prepared from the specimens for optical micrography and SEM using standard metallographic sample preparation methods.

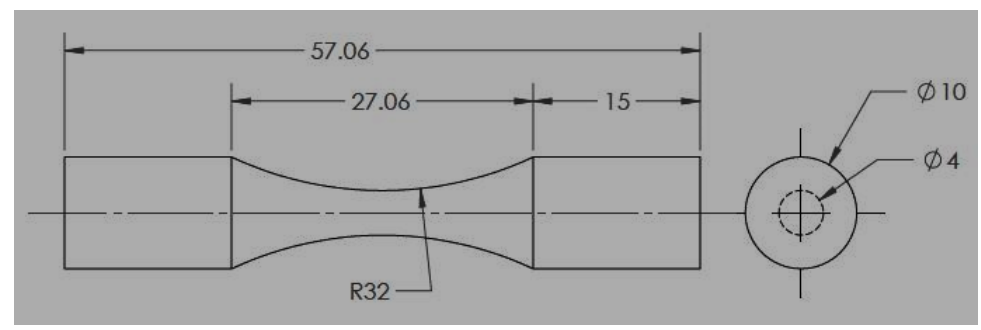

Figure 7. 3: CAD of fatigue test sample (unit: $\mathrm{mm}$ )

Table 7. 2: Build plan for fatigue test specimens

\begin{tabular}{|c|c|c|}
\hline Post processing & Build orientation & Number of specimens \\
\hline \multirow{2}{*}{ As built } & Horizontal $(\mathrm{XY})$ & 10 \\
\cline { 2 - 3 } & Vertical $(\mathrm{Z})$ & 10 \\
\hline \multirow{2}{*}{ Heat treated } & Horizontal $(\mathrm{XY})$ & 10 \\
\cline { 2 - 3 } & Vertical $(\mathrm{Z})$ & 10 \\
\hline
\end{tabular}




\subsection{Results and discussion}

Tensile test results of as-built and heat treated samples built in horizontally (XY) or vertically $(Z)$ are presented in figure 7.4. The result indicates that build orientation and post-build heat treatment both have significant effect on tensile properties. Horizontal sample shows superior yield (YS) and ultimate tensile strength (UTS) compared to vertically built sample. After heat treatment, elongation increases while the YS and UTS value decreases.

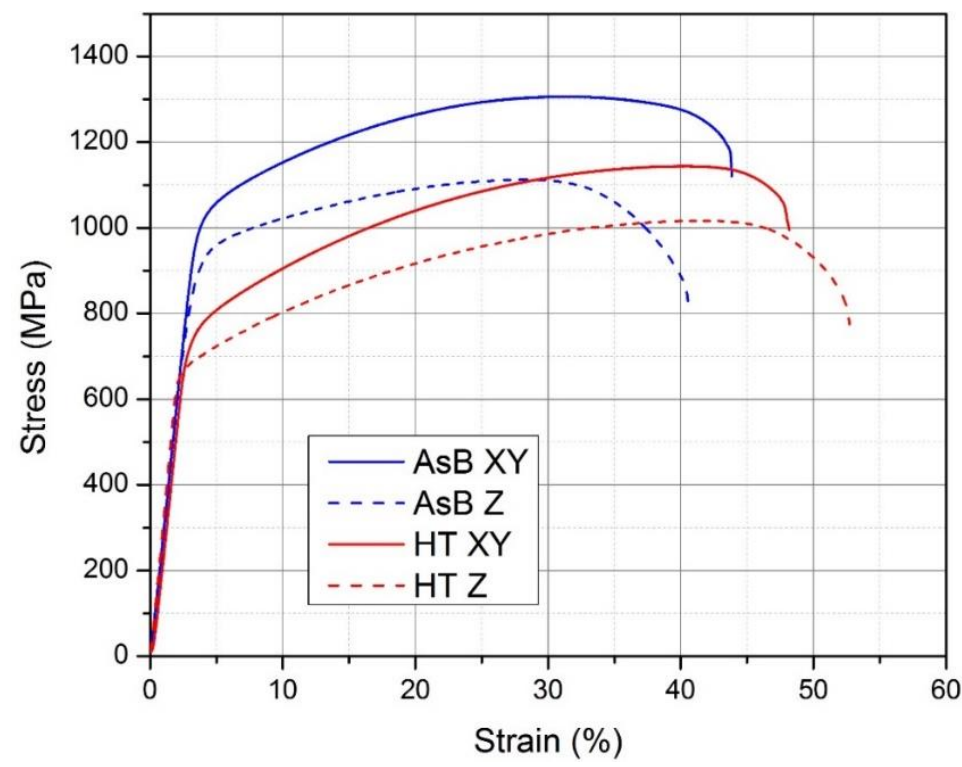

Figure 7. 4: Stress-strain curve of Inconel 625 samples with different orientations and post-processing

Force-controlled high-cycle fatigue data are shown in Figure 7.5. The equivalent stress model (equation 1-2) was used to fit the data. Detail of the fit procedure can be found in MMPDS-02 section 9.6.1.4. Figure 7.5 shows the comparison of fatigue performance between $\mathrm{XY}$ and $\mathrm{Z}$ samples in as-built and heat-treated conditions. The experimental data were also compared with wrought Inconel 625 data available in 
MMPDS 07 [110]. The comparison shows that the majority of the tested data lies above the MMPDS value. The exception are some data from $\mathrm{Z}$ samples, which were tested at a higher stress level more than $550 \mathrm{MPa}$. Comparison between build orientations revealed a strong anisotropic behavior of SLMed Inconel 625. Superior fatigue performance of XY oriented sample was observed compared to the $\mathrm{Z}$ oriented sample in both as-built and heat treated conditions. This behavior is in-line with the tensile properties. In high cycle fatigue, resistance to crack formation and propagation is important. Material with higher yield strength has higher resistance to crack propagation and deformation, and thus provides superior fatigue properties. Higher yield strength of XY build samples therefore increases the fatigue performance over $\mathrm{Z}$ oriented samples.

$$
\begin{array}{ll}
\log N_{f}=A_{1}+A_{2} \log \left(S_{e q}-A_{4}\right) & \text { Equation (1) } \\
S_{e q}=S_{\max }(1-R)^{A_{3}} & \text { Equation (2) }
\end{array}
$$

Where, $\mathrm{N}_{\mathrm{f}}=$ life of the sample, $\mathrm{S}_{\max }=$ Maxium stress, $\mathrm{S}_{\mathrm{eq}}=$ equivalent stress, $\mathrm{R}=$ stress ratio, $\mathrm{A}_{1}, \mathrm{~A}_{2}, \mathrm{~A}_{3}, \mathrm{~A}_{4}=$ constant. 


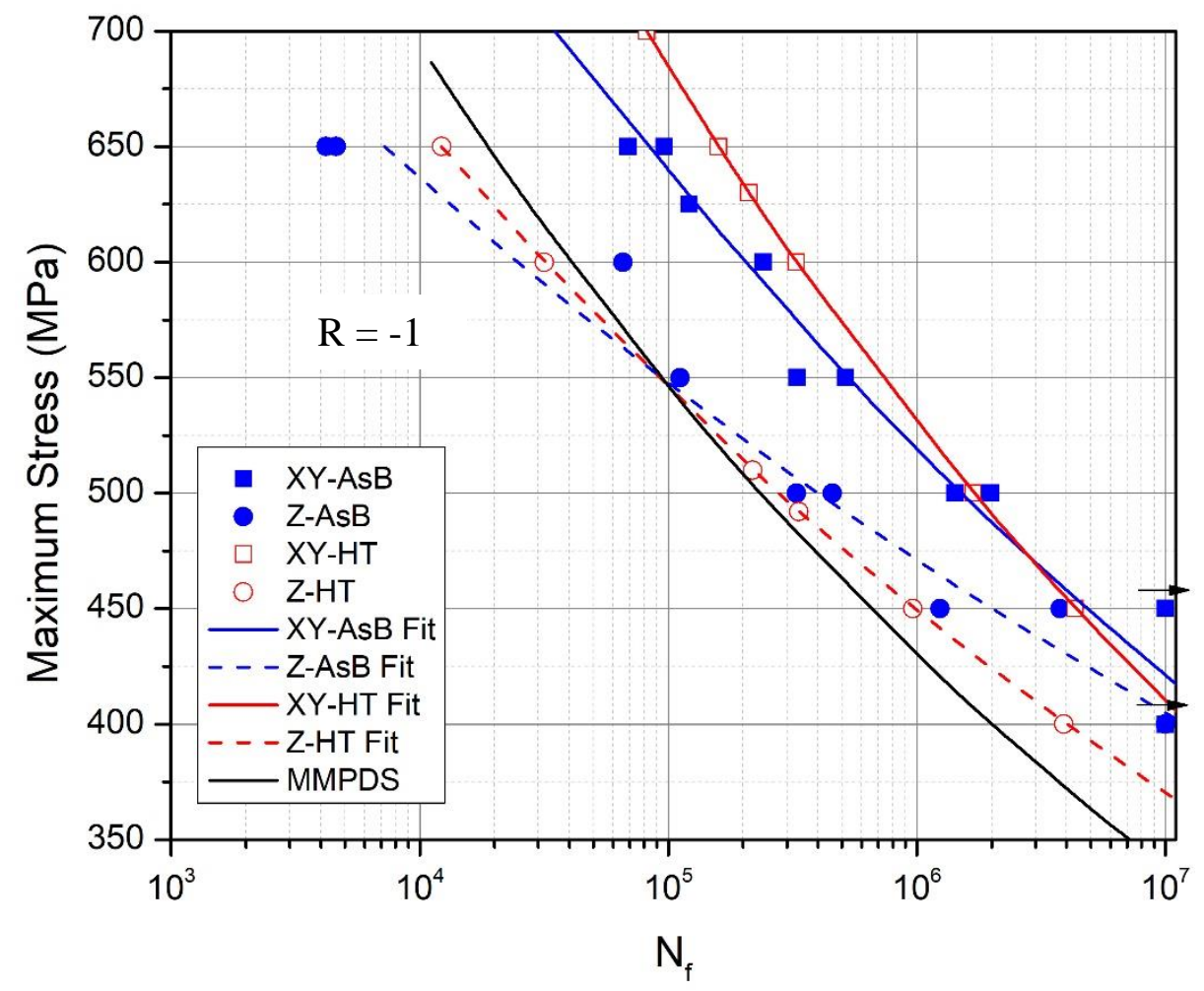

Figure 7. 5: Plot of maximum stress versus cycles to failure for samples with different build orientations and post-processing.

Factors such as level of porosity and orientation of the deposited layers with respect to loading axis play important role in the anisotropic fatigue behavior. Because of the higher number of layers, vertical sample, in general, has a higher chance of generating voids due to lack of fusion and gas entrapment. The number of layers is the most significant factors. It is reported by Wauthle et al. that porosity increases as the angle with the build direction increases. These voids act as a crack initiators and are responsible for premature fatigue failure. Anisotropy in fatigue performance also arises due to the orientation of the deposited layers with respect to the loading direction. The deposited layers in the vertical sample, therefore, the un-melted interlayer porosity is perpendicular to the loading axis. Whereas for a horizontal sample, the loading axis is 
parallel to the interlayer porosity (schematically shown in figure 7.6). Thus the level of stress concentration, for a vertical sample is significantly higher compared to horizontal sample and are more likely to cause crack initiation. Consequently, horizontally built samples exhibit longer fatigue lives under uniaxial fatigue test. Similar phenomena were observed by Yadollahi at el. for additively manufactured 17-4 PH Stainless Steel [111].

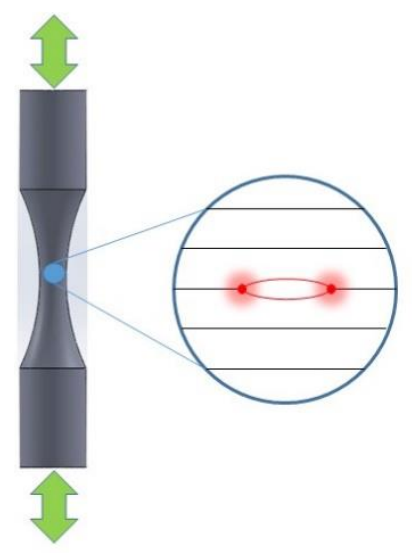

Vertically Built

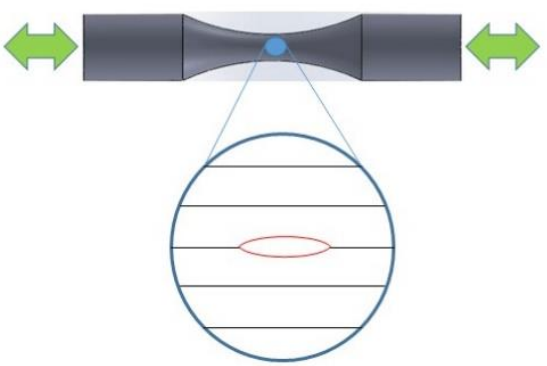

Horizontally Built

Figure 7. 6. Schematics representing the orientation of an un-melted region formed during fabrication of vertical and horizontal specimens with respect to the loading direction and the resultant stress concentrations [111].
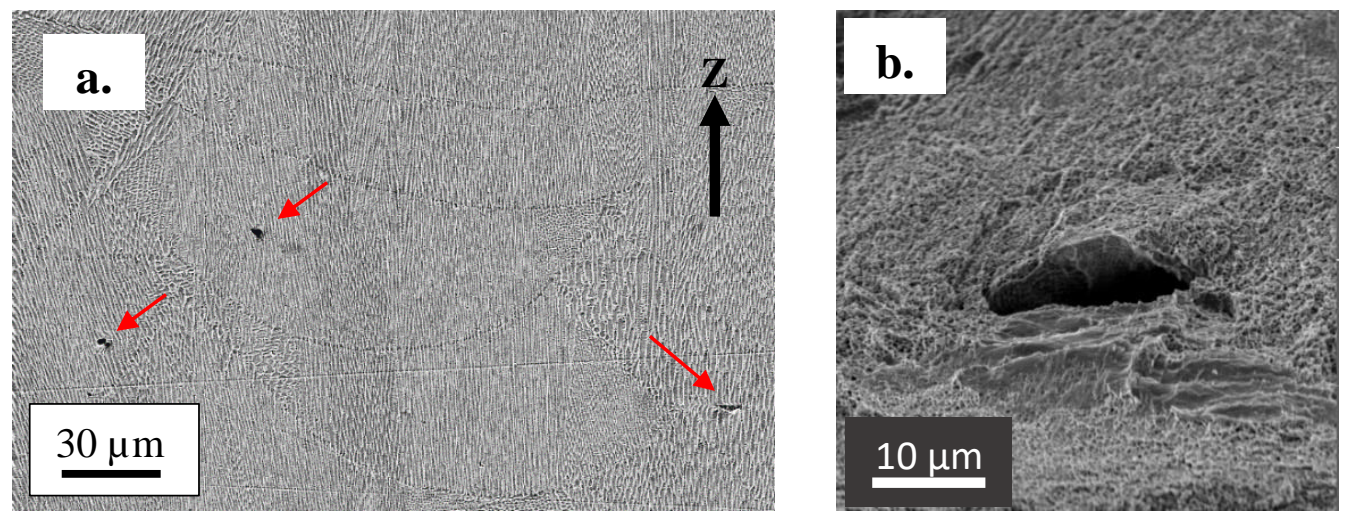

Figure 7. 7: (b) SEM micrograph of a vertically built sample showing sharp angle porosity. (b) Interlayer sharp angle pore in fracture surface. 
A unique characteristic of additively manufactured Inconel 625 is the formation of elongated columnar grains along the build direction which is shown in the EBSD micrograph (figure 7.8). The orientation of the elongated columnar grains affect the crack propagation stage therefore it can be another reason for the anisotropic fatigue behavior of Inconel 625 [16]. The crack propagation mechanism is schematically shown in figure 7.9. For a vertically build sample, the crack growth is perpendicular to the grain growth. In this case, the grain boundary spacing is very small and the crack path is tortuous. On the other hand, for horizontally build sample, the crack growth is parallel to the grain orientation. The crack growth resistance seems to be lower and a smoother crack surface should be observed. According to this mechanism, a fully dense vertical sample without any porosity should have higher fatigue life than a horizontally build sample. However, the test result showed in S-N curve in figure 7.5 is not in accordance with the mechanism. This may be due to the porosity and the defect present in vertically build sample which acted as the primary crack initiator which is shown in figure 7.7 and in the fractography, in figure 7.10. Therefore, the effect of porosity may significantly supersede the effect of columnar grains resulting the lower fatigue life of vertically built samples.
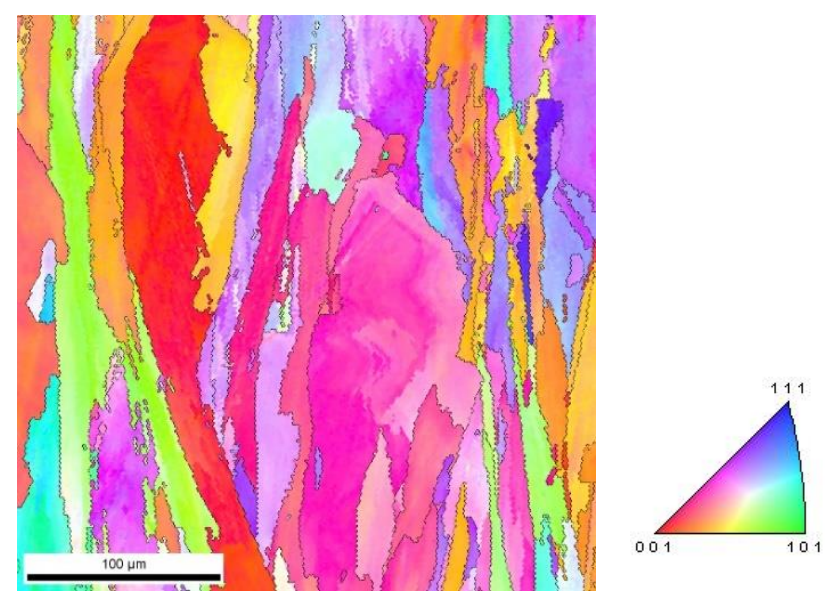

Figure 7. 8: IPF map showing elongated columnar grains. 

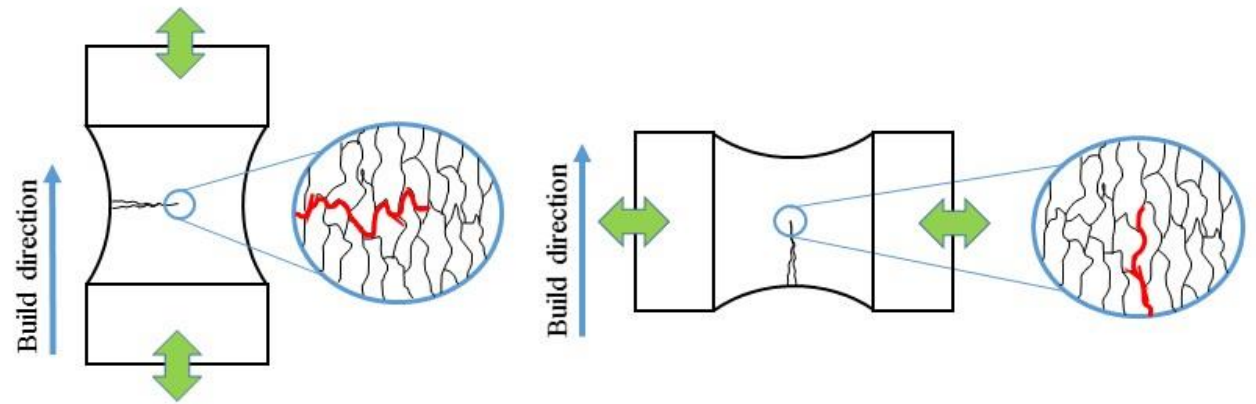

Figure 7. 9: Schematic showing expected crack propagation in vertical and horizontal sample.

It is observed from the $\mathrm{S}-\mathrm{N}$ curve in figure 7.5 that the heat treatment has a significant effect on fatigue life of Inconel 625. The XY samples tested after heat treatment showed improved fatigue lives compared to as-built samples. A better performance due to heat-treatment can be attributed to the change in microstructural features, grain size, and grain orientation which provides higher resistance to crack propagation [12].
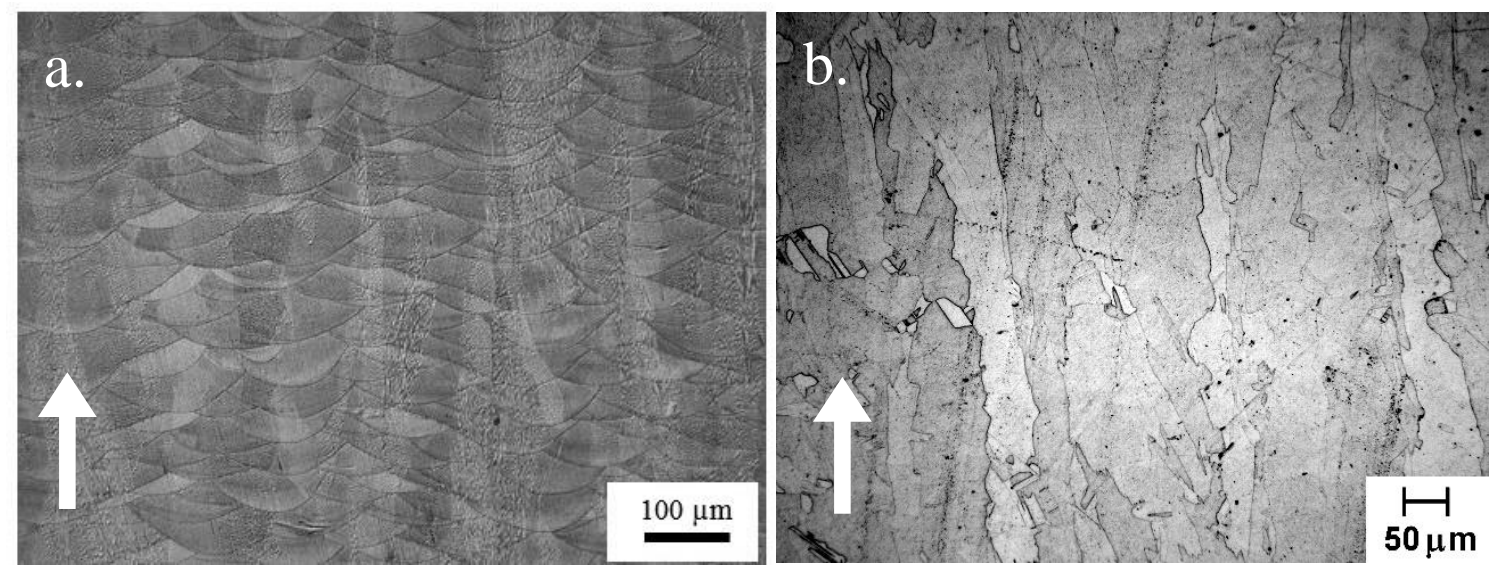

Figure 7. 10: Vertical cross-section of Inconel 625 samples, (a) microstructure in as-built condition, (b) microstructure after heat treatment. The arrow shows the build direction. 
A comparison of microstructure between as-built and heat treated condition is shown in figure 7.10. The as-built microstructure in figure 7.10 (a) exhibits elongated cellular dendritic structure in which the melt pool boundaries are clearly observed. After the heat treatment, the microstructure becomes homogenized eliminating the melt-pool boundaries and dendritic structure (figure $7.10 \mathrm{~b}$ ). The as-built microstructure primarily consisted of $\mathrm{NiCr}$ grain structure with intergranular precipitates (figure 7.11). It is well established that these precipitates contain Laves particles and carbides [15, 18, 26, 27]. During the heat treatment, a large amount of Laves particles dissolved and formed $\delta$ $\left(\mathrm{Ni}_{3} \mathrm{Nb}\right)$ precipitates at the grain boundary. The presence of $\delta$ phase in the grain boundary is beneficial for improving ductility $[4,106]$. The formation of the coarser grains after heat treatment is responsible for improving the fatigue performance $[4,106,112,113]$. In this case, the tip of a crack is oriented towards a large crystallographic grain boundary that acts as a barrier and hinders crack propagation [113]. This is why the XY samples showed improved fatigue lives after heat treatment.

However, fatigue life of $\mathrm{Z}$ samples after heat treatment were found lower compared to as-built samples tested below $500 \mathrm{MPa}$. The samples in this region may contain defects which is responsible for shorter fatigue life. Thus, defect size and shape may play a more dominant role in fatigue life of vertically built samples than heat treatment. 


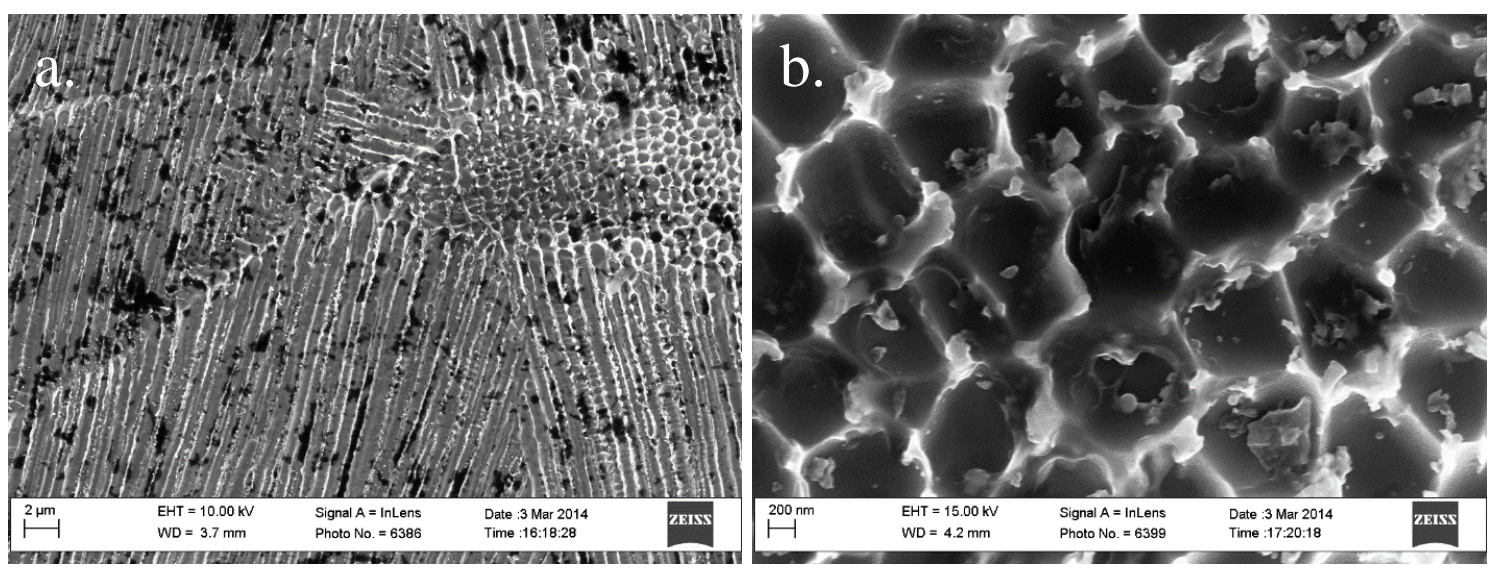

Figure 7. 11: SEM micrographs of as-built sample: (a) vertical cross-section showing fine dendritic structure which provides excellent tensile and fatigue strength. (b) Horizontal cross-section showing dendritic structure and intercellular precipitates.

\subsection{Fractography}

Fracture surfaces of Inconel 625 can be generally divided by appearance into four areas. Figure 7.12 shows the overall appearance of an Inconel 625 fracture surface at different stage levels, with the initiation site marked by an arrow. Area I is a relatively flat surface area at the initial stage. Area II is a distinctively rough area outside the initial flat area marked by dashed lines in figure 8 . Area III is a wide fracture surface with radial stripes along the crack propagation direction, and Area IV is the final stage of failure where dimples were found due to overload. The four areas reflect the different stages during crack initiation and propagation $[114,115]$. 


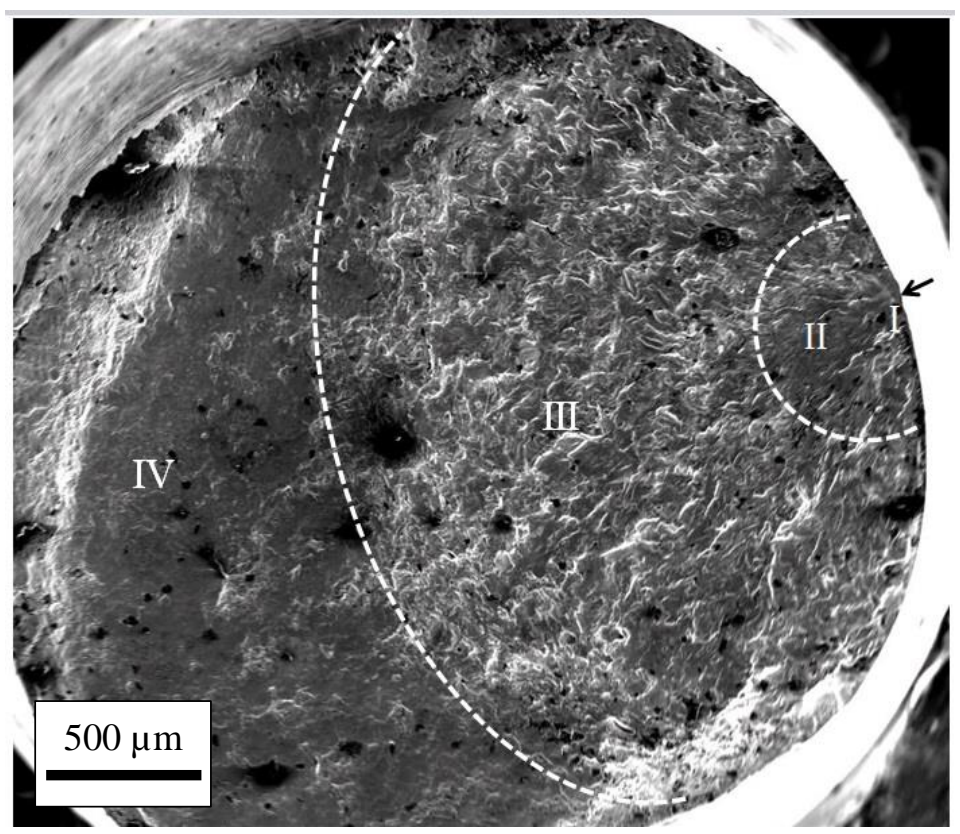

Figure 7. 12: Various areas of Inconel 625 fatigue fracture fabricated by SLM process. As-built XY, max stress $500 \mathrm{MPa}$ failed at $1.98 * 10^{6}$ cycles.

Typically, in high cycle fatigue for Ni-based super alloys, crack initiates from the surface [116]. Microstructural defects such as un-melted particles, inclusions, pores etc. near the surface are the primary crack initiators for additively manufactured parts. These act as a region of stress concentration and localized plastic deformation for fracture [111, 117]. Figure 7.13 shows two cases of $Z$ oriented sample where low fatigue life was observed. In the first case, the fracture was governed by inclusions and un-melted particles (Figure 13.a.) whereas for the second case, fracture initiated due to pores or grooves (Figure 13.b.). 

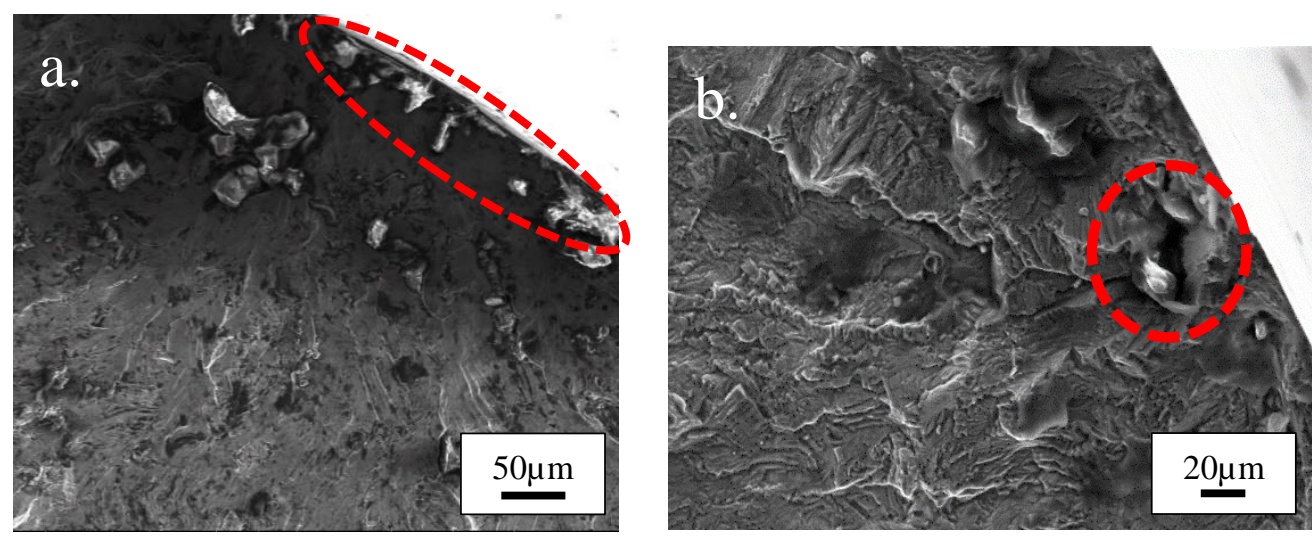

Figure 7. 13: Crack initiation in as-built vertically oriented sample: (a) Low fatigue life due to inclusion and un-melted particles (marked by dashed line), (As-built Z, failed at $4.58 * 10^{5}$ cycles); (b) Low fatigue life due to pore/groove (marked by dashed line),(Asbuilt $\mathrm{Z}$, failed at $6.58 * 10^{4}$ cycles).

In the absence of defects, the crack can still initiate from the surface with the formation of micro-notches and micro-cracks due to the effect of persistent slip band (PSB) $[116,118]$. When grains experience a state of stress/strain dislocation can move on the easy glide plane, resulting in the formation of thin lamellae which is called PSB. The profile of the grain becomes quite irregular, showing an alternation of extrusions and deep intrusion (figure 7.14). After the formation of PSBs, micro-cracks initiate within the fatigued crystal due to micro-stress concentration phenomena occurring either at the deepest intrusions or at the interface between the matrix and PSBs [119]. The cracks can propagate at an angle of approximately $45^{\circ}$ to the applied stress and the surface [117]. A flat facet that can be identified as the narrow initiation zone is observed as well as a large fracture surface. For a sample failed in HCF the surface has wider initiation zone (figure 7.15.b) on the other hand, a narrow initiation zone is observed for a sample with LCF (figure 7.15.a). In both cases the build orientation was horizontal (XY). 

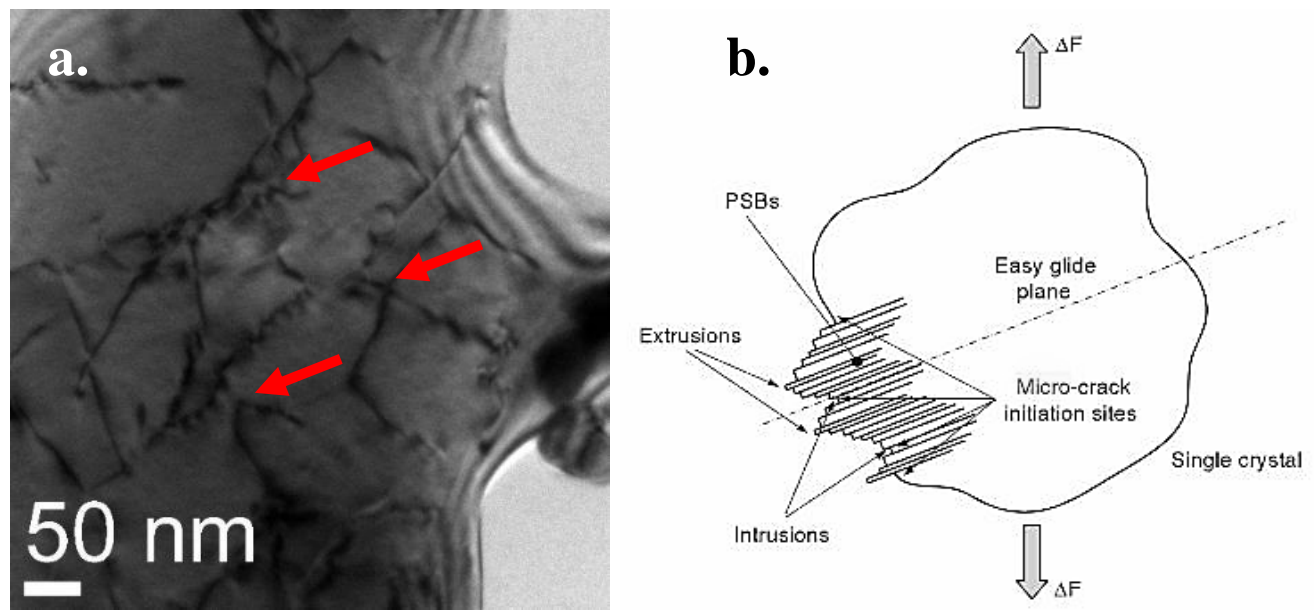

Figure 7. 14: (a) TEM of as-built Inconel 625 showing dislocations. (b) A schematics showing possible micro-crack initiation sites due to PSBs [119].
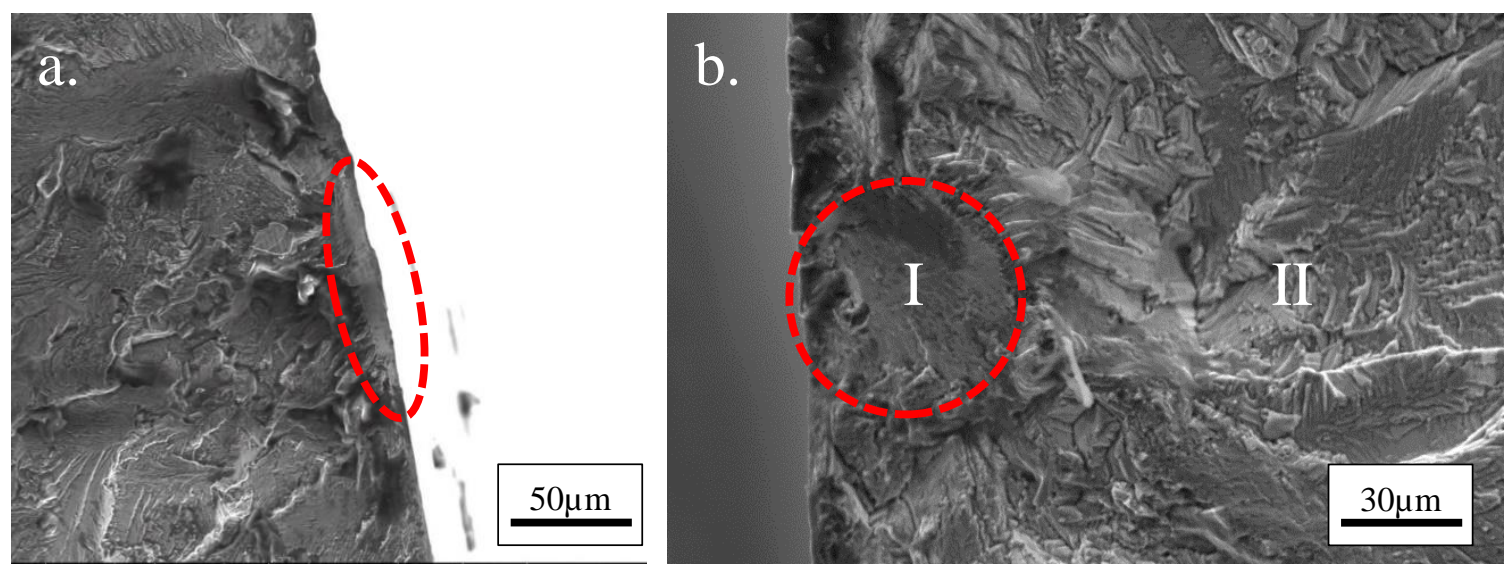

Figure 7. 15: Crack initiation in the as-built horizontal sample (a) Narrow initiation zone (marked by dashed line) (As-built XY, failed at $2.40 * 10^{5}$ cycles); (b) Wide initiation zone (marked by dashed line) (As-built XY, failed at $1.42 * 10^{6}$ cycles).

After the crack initiation in Area I, crack propagation starts at Area II at a right angle to the direction of tensile stress (figure 7.15.b). In this area, a cleavage-like fracture was found (figure 7.16.a). Area III is observed to have a quasi-cleavage fracture with fine striation marks (figure 7.16.b). During the propagation stage, the crack advances by a certain distance with each load cycle leaving a series of striations on the fracture surface. 
The profile of individual striation depends on the material as well as loading conditions $[117,118]$. According to the crack propagation model proposed by C. Laird and G.C. Smith [120], the striations result from the successive opening and closing of the crack flanks. During opening, the crack advances, but during closing, the plastically deformed material at the crack tip is compressed with the formation of upsetting folds which form the striation pattern. The profile varies with the intensity of loading and with the ease of deformation of the material at the crack tip [117]. In the final stage of failure (Area IV), a quasi-cleavage fracture mode was observed where both cleavage and micro-voids were present (figure 7.17.a). Dimple ductile fracture was observed in the high magnification image of this region (figure 7.17.b).
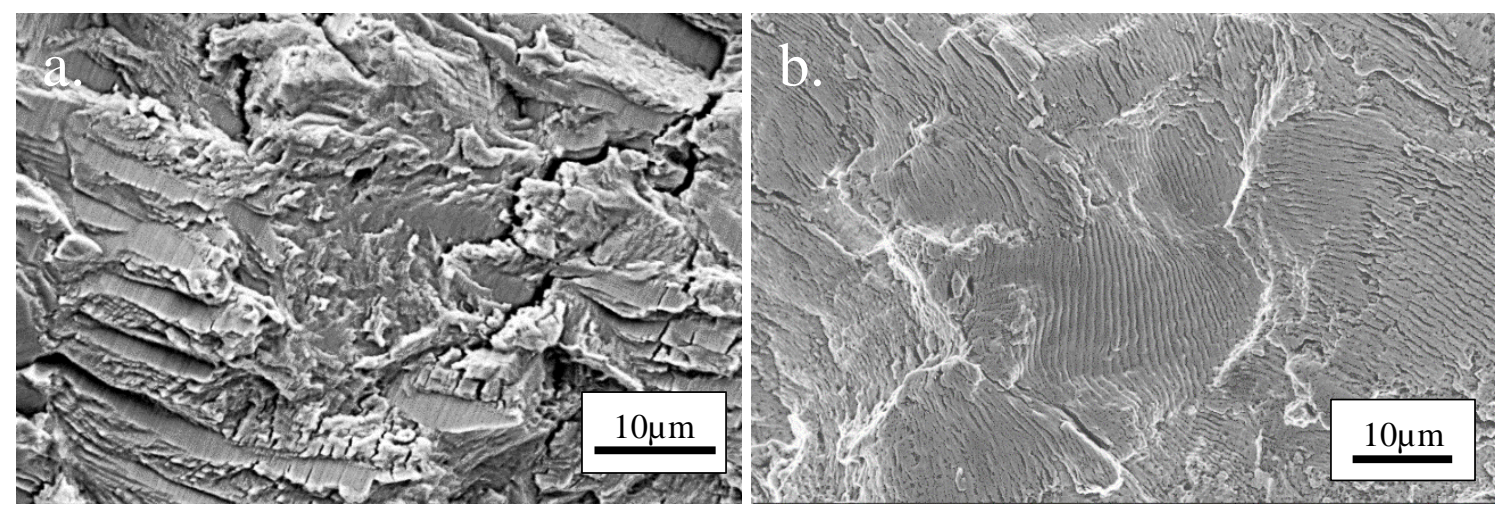

Figure 7. 16: (a) Cleavage-like fracture was observed in Area II at the early stage of crack

propagation. (b) Striation pattern for Hi-cycle failure where fatigue failure propagated in a transcrystalline fashion with distinctive striations ( Propagation Stage). As-built XY, failed at $1.98 * 10^{6}$ cycles). 


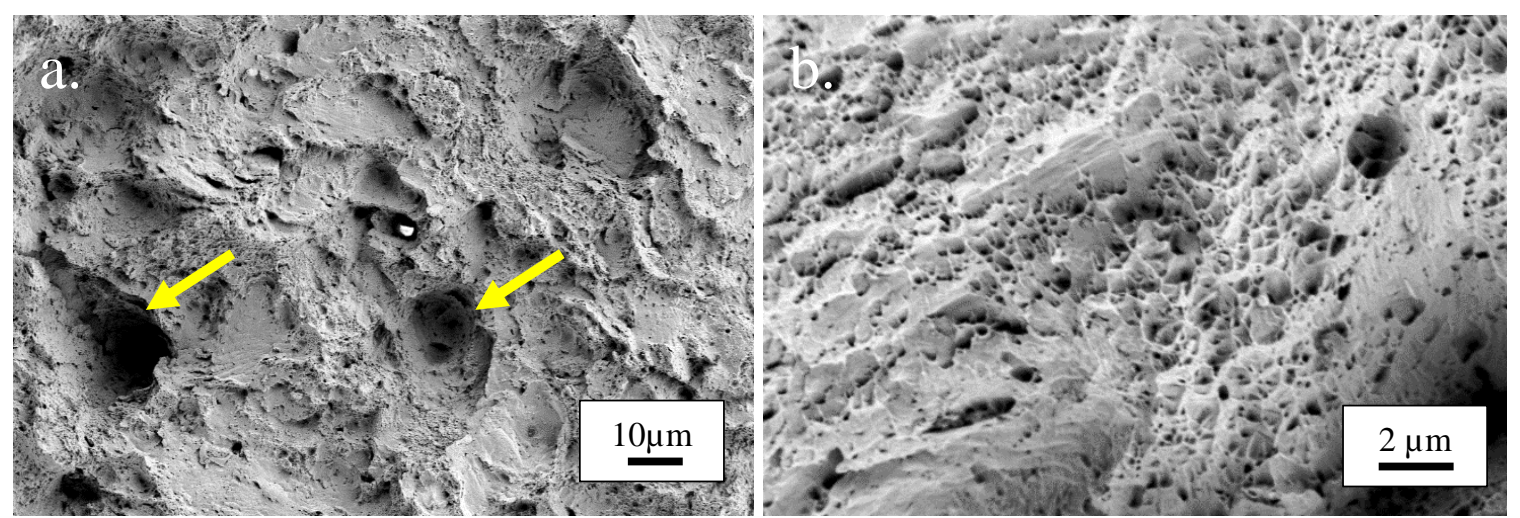

Figure 7. 17: (a) The final stage of fracture showing micro-void coalescence (arrow) and

cleavage areas. (b) Higher magnified image shows dimple ductile fracture of the final fracture area. (As-built XY, failed at $1.42 * 10^{6}$ cycles).

The primary reason for shorter fatigue life of vertically built $(Z)$ sample is the presence of pores and unmelted particles showed in figure 7.13. Pores and unmelted particles act as a site of stress concentration when the load is applied perpendicular to them. The shorter life of $\mathrm{Z}$ sample is indicated by the narrower crack propagation area compared to a wider propagation area in XY sample (figure 7.18). As a result, a smaller ratio of the crack propagation area to final failure area is observed for $\mathrm{Z}$ sample compared to $\mathrm{XY}$ sample. Another noticeable observation is that some $\mathrm{Z}$ samples showed multiple numbers of crack initiation sites which indicates the higher number of impurities presents in $\mathrm{Z}$ sample. Multiple cracks which initiated independently from the surface of the $\mathrm{Z}$ sample are seen to progress and coalesce into a single fracture plane (figure 7.18 (c) \& (d)). 


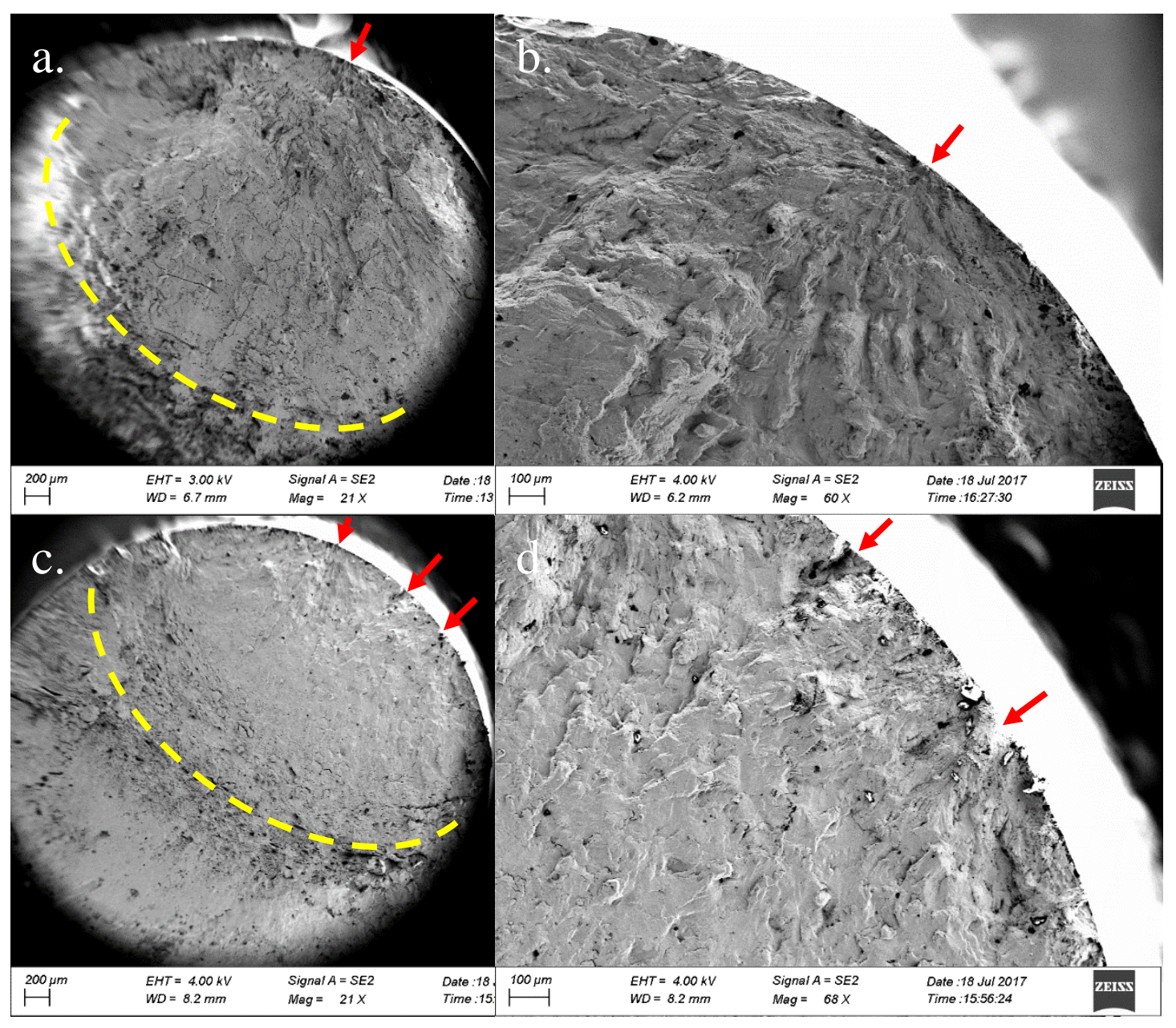

Figure 7. 18: comparison as-built $\mathrm{XY}$ vs as-built $\mathrm{Z}$ (propagation areas are marked by dotted line, crack initiation marked by arrow). (a \& b) As-built XY, failed at $5.17 * 10^{5}$ cycles. (c \& d) As-built Z, failed at $9.22 * 10^{4}$ cycles. Maximum stress $550 \mathrm{MPa}$ in both cases.

Heat treatment does not eliminate porosity of the sample thus has little effect on fatigue property [121]. The slight improvement in fatigue life showed by heat treated sample is due to recrystallization and the removal of unmolten particles. In all of the samples, crack propagation happened primarily in transgranular cleavage fracture mode (figure 7.19). However, the rougher surface due to tortuous crack propagation in heat- 
treated samples indicates the presence of intergranular fracture mode thus the heat-treated surface showed a mixed mode of failure (figure 7.19. b). A comparison of the final fracture surfaces in as-built and heat treated conditions are shown in figure 7.20. In both cases, dimple ductile failure is observed. However, compared to as-built sample, the final fracture surface of the heat treated sample showed more ductile nature of failure as indicated by very fine dimple structure in figure 7.20.b.

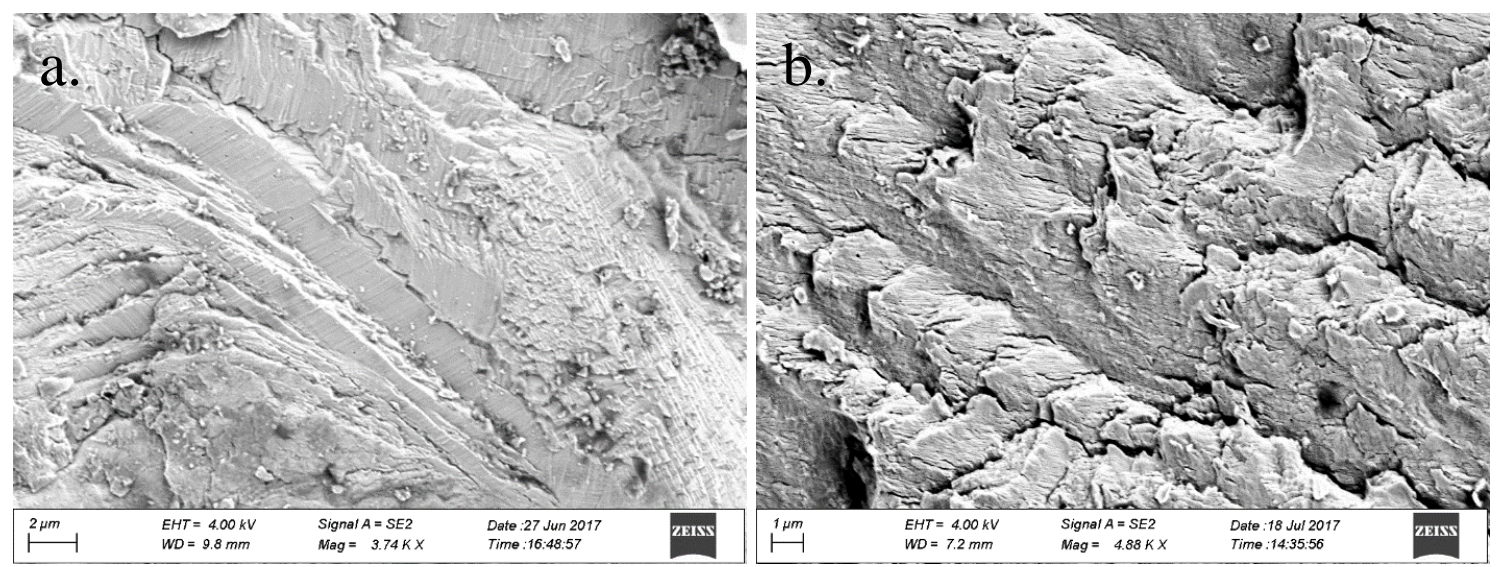

Figure 7. 19: A comparison of fracture surface from as-built and heat treated samples in propagation stage. (a) Transgranular cleavage fracture in as-built sample. (b) Mixed mode of failure in heat treated sample.
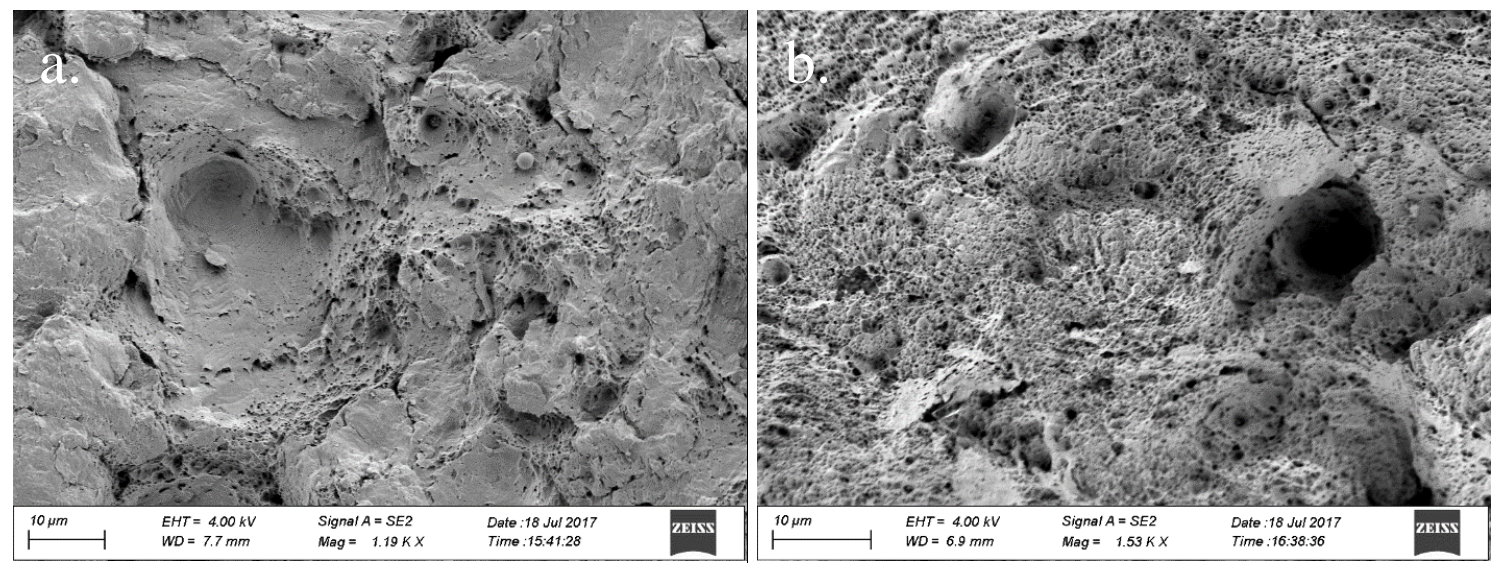

Figure 7. 20: A comparison of fracture surface from as-built and heat treated samples in final failure stage, (a) as-built sample, (b) heat treated sample. 


\subsection{Conclusion}

The primary goal of this study is to investigate the fatigue behavior of Inconel 625 fabricated by selective laser melting. The effect of build orientation and postmanufacturing heat treatment were investigated. The following conclusion can be drawn based on the study:

1. All Inconel 625 samples, regardless of build orientation and heat treatment showed superior fatigue property. Experimental data were compared with the wrought fatigue data presents in MMPDS-07. Except some $\mathrm{Z}$ oriented samples tested at higher stress level (greater than $600 \mathrm{MPa}$ ) all of the samples showed higher fatigue life than wrought Inconel 625.

2. SLM fabricated Inconel 625 samples showed strong anisotropic behavior where horizontally (XY) built samples showed superior fatigue property than vertically (Z) built samples irrespective of post-fabrication heat treatment. The lower fatigue lives of $\mathrm{Z}$ samples is primarily because of the presence of voids and un-melted particles located near the surface of the samples.

3. Heat treatment has a significant effect on fatigue property of Inconel 625. Fatigue life improved after heat treatment except for $\mathrm{Z}$ samples tested at lower stress level less than $500 \mathrm{MPa}$. The formation of coarser grains after heat treatment is responsible for improving the fatigue performance. In this case, the tip of a crack is oriented towards a large crystallographic grain boundary which acts as a barrier and hinders crack propagation. 
4. Fractography showed that for all of the samples crack initiated from the surface. Un-melted particles, inclusions, and pores were observed to be the main reason for crack initiation. A single crack initiation site was observed for XY sample but for $\mathrm{Z}$ sample, cracks initiated from multiple zones and coalesce into a single fracture plane which indicates the higher number of impurities presents in $\mathrm{Z}$ sample.

5. In as-built samples crack propagation happened in transgranular cleavage fracture mode. In heat-treated samples, however, a mixed mode was observed where cracks propagated in both transgranular and intergranular fashion. Final fracture area showed fine dimple ductile nature which is more pronounced in heat-treated samples compared to as-built samples. 


\section{CHAPTER 8}

\section{CONCLUSIONS AND FUTURE WORK}

Beside the main findings of the study which are summarized in the individual chapters, there are some other crucial observations that are summarized below.

Energy density is an important parameter which is often utilized to understand how much energy is transferred from laser beam to the metal powder to form a meltpool. In calculation of the energy density in single track analysis, a $20 \mu \mathrm{m}$ layer thickness was used. In this experiment, a maximum of $488 \mathrm{~J} / \mathrm{mm}^{3}$ energy density was achieved using $195 \mathrm{~W}-800 \mathrm{~mm} / \mathrm{s}$ combination. The same level of energy density could not be achieved in case of a higher layer thickness. Therefore, an exact comparison using energy density may not be possible for a test condition with different layer thickness. However, researchers whose test conditions are different than this study can get valuable insights on meltpool dimensions, type and shape of porosity and other defects from this study.

In the current work, detail microstructure analysis was done on as built condition. Although some research was done on heat treated condition it is not as exhaustive as the as-built condition. A thorough analysis on various heat treatment and the resultant microstructure must be explored for complete understanding.

The aging response of the SLM built Inconel 625 must be investigated. As mentioned in the literature review, aging Inconel 625 for a long period of time can cause 
the formation of other precipitates such as $\gamma$ " which may have significant effect on mechanical properties.

Microstructure analysis showed that elongated columnar grains with very fine dendritic structure grow epitaxially towards the build direction. Although, this fine elongated microstructure provides superior tensile property it causes anisotropy. The anisotropy could slightly be removed by post processing heat treatment through recrystallization of precipitates and eliminating dendritic structure. It could be interesting to investigate the possibility of in-process heat treatment and its effect on SLM part which could reduce anisotropic tensile behavior. The in-process heat treatment could as well reduce thermal stress of the parts.

In fatigue analysis in chapter 7 , it was mentioned that the anisotropy in grain orientation could have an effect on fatigue property and a possible theory was explained. According to the theory vertically built sample should have superior fatigue property than horizontally built sample. However, it was observed that the vertically built samples contain some interlayer porosity and defects which act as a stress concentrator and crack initiator. Further analysis could be done on the microstructural effect and to verify if a defect free vertical sample can provide higher fatigue life than a horizontal sample. It is worth mentioning that characterizing the overall fatigue property of a material is a very complicated and a tedious process. SLM itself is a complicated process which involves a very high number of machine parameters (over 80 settings can be changed on an EOS M270 machine). Fatigue property can differ largely from one machine to another or even one setup to another on the same machine. Therefore, to gain a more in-depth 
understanding and level of confidence in the overall fatigue property of SLM processed Inconel 625 further experiemtns with a higher number of specimen is recommended. 


\section{REFERENCES}

1. Gong, H., Generation and detection of defects in metallic parts fabricated by selective laser melting and electron beam melting and their effects on mechanical properties. 2013.

2. Mueller, B., Additive manufacturing technologies-Rapid prototyping to direct digital manufacturing. Assembly Automation, 2012. 32(2).

3. Amato, K., et al., Microstructures and mechanical behavior of Inconel 718 fabricated by selective laser melting. Acta Materialia, 2012. 60(5): p. 2229-2239.

4. Amato, K., et al., Comparison of microstructures and properties for a Ni-base superalloy (alloy 625) fabricated by electron beam melting. Journal of Materials Science Research, 2012. 1(2): p. 3.

5. Deffley, R.J., Development of processing strategies for the additive layer manufacture of aerospace components in Inconel 718. 2012, University of Sheffield.

6. $\quad$ Reed, R.C., The superalloys: fundamentals and applications. 2008: Cambridge university press.

7. Sims, C.T., The superalloys/2, [High temperature materials for aerospace power] / ed. by Chester T. Sims. A Wiley-Interscience publication. 1987, New York: Wiley. XX, 615 S.

8. Durand-Charre, M., The microstructure of superalloys. 1997, Boca Raton, FL.: CRC Press. xiv, 124 pages.

9. Ahmed, N. and University of Nottingham., Characterisation of different forms of Inconel 625 for determining the effects of microstructural modifications on electrochemical behaviour, in Department of Mechanical, Materials and Manufacturing Engineering. 2008, University of Nottingham: Nottingham. p. 156-192.

10. Inconel 625* Specification. 2016 [cited 2016 01/07/2016]; Available from: http://www.alloywire.com/inconel_alloy_625.html.

11. Dinda, G., A. Dasgupta, and J. Mazumder, Laser aided direct metal deposition of Inconel 625 superalloy: microstructural evolution and thermal stability. Materials Science and Engineering: A, 2009. 509(1): p. 98-104.

12. Paul, C., et al., Investigating laser rapid manufacturing for Inconel-625 components. Optics \& Laser Technology, 2007. 39(4): p. 800-805.

13. Inconel 625-Composition, Properties and Applications of Inconel 625. 2013 [cited 2015 03/09/2015 ]; Available from:

http://www.specialmetals.com/assets/documents/alloys/inconel/inconel-alloy-625.pdf.

14. Kim, H.I., et al. Welding Characteristic Evaluation of GMAW and Laser Cladding for the Gas Turbine 1st Blade. in Key Engineering Materials. 2007. Trans Tech Publ.

15. Cieslak, M., The welding and solidification metallurgy of alloy 625. 1991.

16. Floreen, S., G.E. Fuchs, and W.J. Yang, The metallurgy of alloy 625. Superalloys, 1994. 718(625): p. 13-37.

17. Parimi, L.L., et al., Microstructural and texture development in direct laser fabricated IN718. Materials Characterization, 2014. 89: p. 102-111. 
18. DuPont, J., Solidification of an alloy 625 weld overlay. Metallurgical and Materials Transactions A, 1996. 27(11): p. 3612-3620.

19. Donachie, M.J. and S.J. Donachie, Superalloys a technical guide. 2002, ASM International: Materials Park, OH. p. 1 online resource (x, 439 pages).

20. Kurz, W. and D.J. Fisher, Fundamentals of solidification. Vol. 1. 1986: trans tech publications Aedermannsdorf, Switzerland.

21. Wang, W., P.D. Lee, and M. Mclean, A model of solidification microstructures in nickelbased superalloys: predicting primary dendrite spacing selection. Acta materialia, 2003. 51(10): p. 2971-2987.

22. McLean, M., Directionally solidified materials for high temperature service(Book). London, Metals Society, 1983, 345 p, 1983.

23. David, S. and J. Vitek, Analysis of weld metal solidification and microstructures. 1991, Oak Ridge National Lab., TN (USA).

24. Liu, W. and J. DuPont, Effects of melt-pool geometry on crystal growth and microstructure development in laser surface-melted superalloy single crystals: Mathematical modeling of single-crystal growth in a melt pool (part I). Acta materialia, 2004. 52(16): p. 4833-4847.

25. Porter, D.A., K.E. Easterling, and M. Sherif, Phase Transformations in Metals and Alloys, (Revised Reprint). 2009: CRC press.

26. Dey, G., et al., Microstructural studies on rapidly solidified Inconel 625. Materials Science and Engineering: A, 1989. 119: p. 175-184.

27. Rombouts, M., et al., Laser metal deposition of Inconel 625: Microstructure and mechanical properties. Journal of Laser Applications, 2012. 24(5): p. 052007.

28. Santos, E.C., et al., Rapid manufacturing of metal components by laser forming. International Journal of Machine Tools and Manufacture, 2006. 46(12-13): p. 1459-1468.

29. Zeng, K., Optimization of support structures for selective laser melting. 2015.

30. The ASTM International Committee F42 on Additive Manufacturing Technologies. 2015 [cited 2018 02/08/2018]; Available from: http://www.astm.org/COMMITTEE/F42.htm.

31. Antonysamy, A.A., Microstructure, texture and mechanical property evolution during additive manufacturing of Ti6Al4V alloy for aerospace applications. 2012, The University of Manchester (United Kingdom).

32. Kruth, J.-P., et al. Part and material properties in selective laser melting of metals. in Proceedings of the 16th international symposium on electromachining. 2010.

33. Kruth, J.-P., M.-C. Leu, and T. Nakagawa, Progress in additive manufacturing and rapid prototyping. Cirp Annals, 1998. 47(2): p. 525-540.

34. Thijs, L., et al., A study of the microstructural evolution during selective laser melting of Ti-6Al-4V. Acta materialia, 2010. 58(9): p. 3303-3312.

35. Tsopanos, S., et al., The influence of processing parameters on the mechanical properties of selectively laser melted stainless steel microlattice structures. Journal of Manufacturing Science and Engineering, 2010. 132(4): p. 041011.

36. Peng, L., et al., Direct laser fabrication of nickel alloy samples. International Journal of Machine Tools and Manufacture, 2005. 45(11): p. 1288-1294.

37. Kobryn, P.A. and S. Semiatin, Microstructure and texture evolution during solidification processing of Ti-6Al-4V. Journal of Materials Processing Technology, 2003. 135(2-3): p. 330-339.

38. Pinkerton, A.J., et al., Thermal and microstructural aspects of the laser direct metal deposition of waspaloy. Journal of Laser Applications, 2006. 18(3): p. 216-226.

39. Zhang, K., W. Liu, and X. Shang, Research on the processing experiments of laser metal deposition shaping. Optics \& Laser Technology, 2007. 39(3): p. 549-557. 
40. Kobryn, P., E. Moore, and S. Semiatin, The effect of laser power and traverse speed on microstructure, porosity, and build height in laser-deposited Ti-6Al-4V. Scripta Materialia, 2000. 43(4): p. 299-305.

41. Wu, X., et al., Microstructure and properties of a laser fabricated burn-resistant Ti alloy. Materials \& design, 2004. 25(2): p. 103-109.

42. Murr, L.E., et al., Microstructural architecture, microstructures, and mechanical properties for a nickel-base superalloy fabricated by electron beam melting.

Metallurgical and Materials Transactions A, 2011. 42(11): p. 3491-3508.

43. Yadroitsev, I., et al., Mechanical properties of samples fabricated by selective laser melting. 14èmes Assises Européennes du Prototypage \& Fabrication Rapide, 2009: p. 2425.

44. Betts, E., et al., Using innovative technologies for manufacturing rocket engine hardware. 2011.

45. Xue, L., et al. Investigation of laser consolidation for manufacturing functional net-shape components for potential rocket engine applications. in Proceedings of the 26th International Congress on Applications of Lasers and Electro-Optics. 2007.

46. Rombouts, M., G. Maes, and R. Persoons. Material study of laser cladded Inconel 625. in Proceedings of the 5th International Conference on Advanced Research in Virtual and Rapid Prototyping (Taylor and Francis Group, London, 2011). 2011.

47. EOS GmbH, "Material Data Sheet: EOS NickelAlloy IN625”. 2011.

48. LENS Superalloys Material Data Sheet. 2015, Optomec.

49. Dutta, B., et al., Rapid manufacturing and remanufacturing of DoD components using direct metal deposition. Published in: The AMMTIAC Quarterly, 2011. 6(2): p. 5.

50. Gibson, I., Rosen, D. W., \& Stucker, B., Additive Manufacturing Technologies Rapid Prototyping to Direct Digital Manufacturing. 2009, New York: Springer.

51. Kempen, K., et al., Microstructure and mechanical properties of Selective Laser Melted 18Ni-300 steel. Physics Procedia, 2011. 12: p. 255-263.

52. Thijs, L., et al., Strong morphological and crystallographic texture and resulting yield strength anisotropy in selective laser melted tantalum. Acta Materialia, 2013. 61(12): p. 4657-4668.

53. Cherry, J., et al., Investigation into the effect of process parameters on microstructural and physical properties of $316 \mathrm{~L}$ stainless steel parts by selective laser melting. The International Journal of Advanced Manufacturing Technology, 2015. 76(5-8): p. 869879.

54. Kruth, J.-P., et al., Selective laser melting of iron-based powder. Journal of materials processing technology, 2004. 149(1-3): p. 616-622.

55. Dilip, J., et al., Selective laser melting of HY100 steel: process parameters, microstructure and mechanical properties. Additive Manufacturing, 2017. 13: p. 49-60.

56. Brandl, E., et al., Deposition of Ti-6Al-4V using laser and wire, part I: Microstructural properties of single beads. Surface and Coatings Technology, 2011. 206(6): p. 11201129.

57. Anam, M.A., et al. Effect of scan pattern on the microstructural evolution of Inconel 625 during selective laser melting. in Proceedings of 25th Annual International Solid Freeform Fabrication Symposium. 2014.

58. Anam, M.A., D. Pal, and B. Stucker. Modeling and experimental validation of nickelbased super alloy (Inconel 625) made using selective laser melting. in Solid Freeform Fabrication (SFF) Symposium, University of Texas at Austin, Austin, TX, Aug. 2013.

59. Wang, Z., et al., The microstructure and mechanical properties of deposited-IN718 by selective laser melting. Journal of Alloys and Compounds, 2012. 513: p. 518-523.

60. Yadroitsau, I., Selective laser melting: Direct manufacturing of 3D-objects by selective laser melting of metal powders. 2009: Lambert Academic Publishing. 
61. Song, B., et al., Microstructure and tensile properties of iron parts fabricated by selective laser melting. Optics \& Laser Technology, 2014. 56: p. 451-460.

62. Gong, H., et al. Melt pool characterization for selective laser melting of Ti-6Al-4V prealloyed powder. in Solid freeform fabrication symposium. 2014.

63. Gu, D. and P. Yuan, Thermal evolution behavior and fluid dynamics during laser additive manufacturing of Al-based nanocomposites: Underlying role of reinforcement weight fraction. Journal of Applied Physics, 2015. 118(23): p. 233109.

64. Dai, D. and D. Gu, Effect of metal vaporization behavior on keyhole-mode surface morphology of selective laser melted composites using different protective atmospheres. Applied Surface Science, 2015. 355: p. 310-319.

65. Khairallah, S.A., et al., Laser powder-bed fusion additive manufacturing: Physics of complex melt flow and formation mechanisms of pores, spatter, and denudation zones. Acta Materialia, 2016. 108: p. 36-45.

66. King, W., et al., Overview of modelling and simulation of metal powder bed fusion process at Lawrence Livermore National Laboratory. Materials Science and Technology, 2015. 31(8): p. 957-968.

67. Yadroitsev, I., et al., Single track formation in selective laser melting of metal powders. Journal of Materials Processing Technology, 2010. 210(12): p. 1624-1631.

68. Tolochko, N.K., et al., Balling processes during selective laser treatment of powders. Rapid Prototyping Journal, 2004. 10(2): p. 78-87.

69. King, W.E., et al., Observation of keyhole-mode laser melting in laser powder-bed fusion additive manufacturing. Journal of Materials Processing Technology, 2014. 214(12): p. 2915-2925.

70. Eagar, T. and N. Tsai, Temperature fields produced by traveling distributed heat sources. Welding journal, 1983. 62(12): p. 346-355.

71. Pang, S., W. Chen, and W. Wang, A quantitative model of keyhole instability induced porosity in laser welding of titanium alloy. Metallurgical and Materials Transactions A, 2014. 45(6): p. 2808-2818.

72. Bauereiß, A., T. Scharowsky, and C. Körner, Defect generation and propagation mechanism during additive manufacturing by selective beam melting. Journal of Materials Processing Technology, 2014. 214(11): p. 2522-2528.

73. Frazier, W.E., Metal additive manufacturing: a review. Journal of Materials Engineering and Performance, 2014. 23(6): p. 1917-1928.

74. Gu, D., et al., Laser additive manufacturing of metallic components: materials, processes and mechanisms. International materials reviews, 2012. 57(3): p. 133-164.

75. Li, R., et al., Densification behavior of gas and water atomized 316L stainless steel powder during selective laser melting. Applied surface science, 2010. 256(13): p. 43504356.

76. Yadroitsev, I., et al., Strategy of manufacturing components with designed internal structure by selective laser melting of metallic powder. Applied Surface Science, 2007. 254(4): p. 980-983.

77. Campanelli, S.L., et al., Capabilities and performances of the selective laser melting process, in New Trends in Technologies: Devices, Computer, Communication and Industrial Systems. 2010, InTech.

78. Taha, M., et al., On selective laser melting of ultra high carbon steel: effect of scan speed and post heat treatment. Materialwissenschaft und Werkstofftechnik, 2012. 43(11): p. 913-923.

79. Kelly, S. and S. Kampe, Microstructural evolution in laser-deposited multilayer Ti-6Al$4 V$ builds: Part I. Microstructural characterization. Metallurgical and Materials Transactions A, 2004. 35(6): p. 1861-1867. 
80. Murr, L., et al., Microstructure and mechanical behavior of Ti-6Al-4V produced by rapid-layer manufacturing, for biomedical applications. Journal of the mechanical behavior of biomedical materials, 2009. 2(1): p. 20-32.

81. Shankar, V., K.B.S. Rao, and S. Mannan, Microstructure and mechanical properties of Inconel 625 superalloy. Journal of Nuclear Materials, 2001. 288(2-3): p. 222-232.

82. Alimardani, M., et al., On the delamination and crack formation in a thin wall fabricated using laser solid freeform fabrication process: An experimental-numerical investigation. Optics and Lasers in Engineering, 2009. 47(11): p. 1160-1168.

83. Kruth, J.-P., et al., Assessing and comparing influencing factors of residual stresses in selective laser melting using a novel analysis method. Proceedings of the institution of mechanical engineers, Part B: Journal of Engineering Manufacture, 2012. 226(6): p. 980991.

84. Vrancken, B., et al. Study of the influence of material properties on residual stress in selective laser melting. in Proceedings of the solid freeform fabrication symposium. 2013.

85. Rombouts, M., et al. Roughness after laser melting of iron based powders. in Proc. 2nd Int. Conf. on Advanced Research in Virtual and Rapid Prototyping VRAP, Leiria, Portugal. 2005.

86. Yasa, E. and J.-P. Kruth, Microstructure evolution of selective laser molten $316 \mathrm{~L}$ stainless steel parts with laser re-melting. 2009.

87. Metals Handbook. 10 ed. Vol. 1 \& 2. ASM International.

88. Starr, T.L., et al., Controlling phase composition in selective laser melted stainless steels. Power (W), 2012. 195: p. 195.

89. Kruth, J.-P., Evren Yasa, and Jan Deckers. Experimental investigation of laser surface remelting for the improvement of selective laser melting process. in SFF Symp. 2009. Austin, Texas, USA.

90. Abe, F., et al., The manufacturing of hard tools from metallic powders by selective laser melting. Journal of materials processing technology, 2001. 111(1-3): p. 210-213.

91. Rafi, H.K., T.L. Starr, and B.E. Stucker, A comparison of the tensile, fatigue, and fracture behavior of Ti-6Al-4V and 15-5 PH stainless steel parts made by selective laser melting. The International Journal of Advanced Manufacturing Technology, 2013. 69(58): p. 1299-1309.

92. Rafi, H., et al., Microstructures and mechanical properties of Ti6Al4V parts fabricated by selective laser melting and electron beam melting. Journal of materials engineering and performance, 2013. 22(12): p. 3872-3883.

93. Yadroitsev, I., Krakhmalev, P., \& Yadroitsava, I., Selective laser melting of Ti6Al4V alloy for biomedical applications: Temperature monitoring and microstructural evolution. Journal of Alloys and Compounds, 2014. 15(583): p. 404-409.

94. Brandl, E., Heckenberger, U., Holzinger, V., \& Buchbinder, D, Additive manufactured AlSi10Mg samples using Selective Laser Melting (SLM): Microstructure, high cycle fatigue, and fracture behavior. Materials \& Design, 2012. 34: p. 159-169.

95. Buchbinder, D., Meiners, W., Wissenbach, K., Müller-Lohmeier, K., Brandl, E., \& Skrynecki, N. . Rapid manufacturing of aluminium parts for serial production via selective laser melting (SLM). in International Conference on Rapid Manufacturing. 2008. Loughborough.

96. Kempen, K., Thijs, L., Yasa, E., Badrossamay, M., Verheecke, W., \& Kruth, J. P. Process optimization and microstructural analysis for selective laser melting of AlSilOMg. in Solid Freeform Fabrication Symposium. 2011.

97. Vilaro, T., C. Colin, and J.-D. Bartout, As-fabricated and heat-treated microstructures of the Ti-6Al-4V alloy processed by selective laser melting. Metallurgical and Materials Transactions A, 2011. 42(10): p. 3190-3199. 
98. Buchbinder, D., Schleifenbaum, H. B., Heidrich, S., Meiners, W., \& Bültmann, J., High power selective laser melting (HP SLM) of aluminum parts. . Physics Procedia, 2011. 12: p. 271-278.

99. AMS 5666G, Nickel Alloy, Corrosion and Heat-Resistant, Bars, Forgings, Extrusions, and

Rings, 62Ni - 21.5Cr-9.0Mo - $3.65(\mathrm{Cb}[\mathrm{Nb}]+\mathrm{Ta})$, Annealed. 2013, SAE International.

100. Simonelli, M., Y.Y. Tse, and C. Tuck, Effect of the build orientation on the mechanical properties and fracture modes of SLM Ti-6Al-4V. Materials Science and Engineering: A, 2014. 616: p. 1-11.

101. Standard Terminology for Additive Manufacturing Technologies., in ASTM, F2792 - 12 a. 2012, ASTM.

102. Carroll, B.E., T.A. Palmer, and A.M. Beese, Anisotropic tensile behavior of Ti-6Al-4V components fabricated with directed energy deposition additive manufacturing. Acta Materialia, 2015. 87: p. 309-320.

103. Guan, K., et al., Effects of processing parameters on tensile properties of selective laser melted 304 stainless steel. Materials \& Design, 2013. 50: p. 581-586.

104. Meier, H. and C. Haberland, Experimental studies on selective laser melting of metallic parts. Materialwissenschaft und Werkstofftechnik, 2008. 39(9): p. 665-670.

105. Dilip, J.J.S., Anam, M. A., Pal, D., \& Stucker, B. A short study on the fabrication of single track deposits in SLM and characterization. in Solid freeform fabrication symposium. 2016.

106. Xu, F., et al., Microstructural evolution and mechanical properties of Inconel 625 alloy during pulsed plasma arc deposition process. Journal of Materials Science \& Technology, 2013. 29(5): p. 480-488.

107. Ram, G.J., et al., Microstructure and tensile properties of Inconel 718 pulsed Nd-YAG laser welds. Journal of Materials Processing Technology, 2005. 167(1): p. 73-82.

108. Hack, H., et al., Mechanical properties of additive manufactured nickel alloy 625. Additive Manufacturing, 2017. 14: p. 105-115.

109. Murr, L.E., et al., Fabrication of metal and alloy components by additive manufacturing: examples of 3D materials science. Journal of Materials Research and technology, 2012. 1(1): p. 42-54.

110. Battelle, Metallic Materials Properties Development and Standardization (MMPDS-07). 2012, Battelle.

111. Yadollahi, A., et al., Effects of building orientation and heat treatment on fatigue behavior of selective laser melted 17-4 PH stainless steel. International Journal of Fatigue, 2017. 94: p. 218-235.

112. Kamp, N., et al., Influence of grain structure and slip planarity on fatigue crack growth in low alloying artificially aged $2 x x x$ aluminium alloys. International journal of fatigue, 2007. 29(5): p. 869-878.

113. Riemer, A., et al., On the fatigue crack growth behavior in $316 L$ stainless steel manufactured by selective laser melting. Engineering Fracture Mechanics, 2014. 120: p. $15-25$.

114. Sakai, T., et al., Statistical fatigue properties of SCM435 steel in ultra-long-life regime based on JSMS database on fatigue strength of metallic materials. International journal of fatigue, 2006. 28(11): p. 1486-1492.

115. Sakai, T., Y. Sato, and N. Oguma, Characteristic $S-N$ properties of high-carbonchromium-bearing steel under axial loading in long-life fatigue. Fatigue \& Fracture of Engineering Materials \& Structures, 2002. 25(8-9): p. 765-773. 
116. Ma, X.-f., et al., Fatigue and fracture behavior of nickel-based superalloy Inconel 718 up to the very high cycle regime. Journal of Zhejiang University-Science A, 2010. 11(10): p. 727-737.

117. Engel, L. and H. Klingele, An atlas of metal damage: surface examination by scanning electron microscope. 1981: Prentice-Hall.

118. Kobayashi, K., et al., Grain size effect on high-temperature fatigue properties of alloy718. Materials Letters, 2005. 59(2-3): p. 383-386.

119. Susmel, L., Multiaxial notch fatigue. 2009: Elsevier.

120. Laird, C., The influence of metallurgical structure on the mechanisms of fatigue crack propagation, in Fatigue crack propagation. 1967, ASTM International.

121. Kasperovich, G. and J. Hausmann, Improvement of fatigue resistance and ductility of TiAl6V4 processed by selective laser melting. Journal of Materials Processing Technology, 2015. 220: p. 202-214.

122. EOS GmbH, “Material Data Sheet: EOS NickelAlloy IN625”. 2010. 


\section{CURRICULUM VITA}

Name: $\quad$ Md Ashabul Anam

Address: Department of Industrial Engineering

J.B. Speed School of Engineering

University of Louisville

Louisville, KY 40292

Education: Ph.D., Industrial Engineering

University of Louisville, Louisville, KY

2015-2018

M.S., Industrial Engineering, University of Louisville, Louisville, KY

2012-2014

B.S., Industrial and Production Engineering, Bangladesh University of Engineering and Technology (BUET) Dhaka, Bangladesh

2004-2009

Award: $\quad$ Graduate Research Tuition award from NIST.

Grosscurth Scholarship from University of Louisville (Ph.D. Fellowship)

Society of Manufacturing Engineers (SME) Scholarship Award.

Publications: Anam, M. A., Pal, D., \& Stucker, B. (2013, August). Modeling and experimental validation of nickel-based super alloy (Inconel 625) made using selective laser melting. In Solid Freeform Fabrication (SFF) Symposium, University of Texas at Austin, Austin, TX, Aug (pp. 12-14).

Anam, M. A., Dilip, J. J. S., Pal, D., \& Stucker, B. (2014, August). Effect of scan pattern on the microstructural evolution of Inconel 625 during selective laser melting. In Proceedings of 25th Annual International Solid Freeform Fabrication Symposium.

Yang, L., \& Anam, M. A. (2014). An investigation of standard test part design for additive manufacturing. In Proceeding of the Solid Free Form Fabrication Symposium. 
Dilip, J. J. S., Anam, M. A., Pal, D., \& Stucker, B. (2016). A short study on the fabrication of single track deposits in SLM and characterization. In Solid freeform fabrication symposium. Austin TX, USA Google Scholar. 